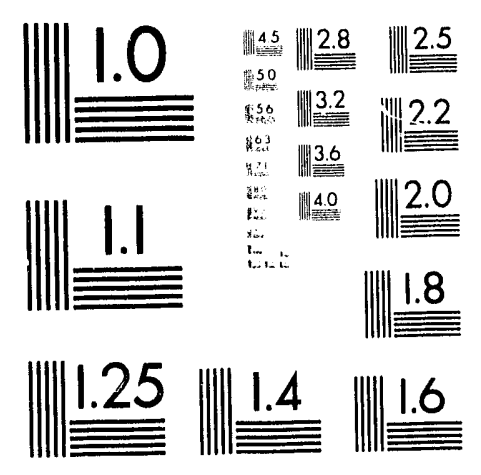



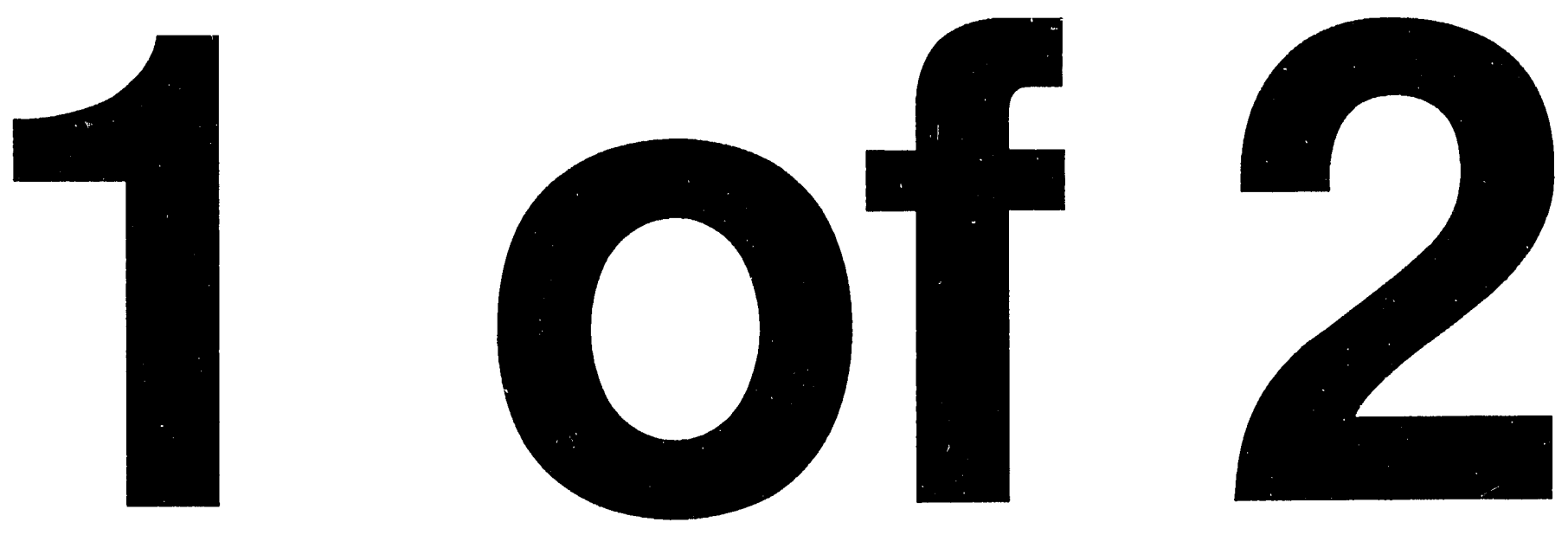
SAND92-2013

Distribution

Unlimited Release

Printed August 1993

Category UC-721

\title{
Uncertainty and Sensitivity Analyses for Gas and Brine Migration at the Waste Isolation Pilot Plant, May 1992
}

\author{
J.C. Helton ${ }^{1}$, J.E. Bean ${ }^{2}$, B.M. Butcher, \\ J.W. Garner ${ }^{3}$, J.D. Schreiber ${ }^{4}$, \\ P.N. Swift ${ }^{5}$, and P. Vaughn ${ }^{3}$
}

\begin{abstract}
Uncertainty and sensitivity analysis techniques based on Latin hypercube sampling, partial correlation analysis, stepwise regression analysis and examination of scatterplots are used in conjunction with the BRAGFLO model to examine two phase flow (i.e., gas and brine) at the Waste Isolation Pilot Plant (WIPP), which is being developed by the U.S. Department of Energy as a disposal facility for transuranic waste. The analyses consider either a single waste panel or the entire repository in conjunction with the following cases: (1) fully consolidated shaft, (2) system of shaft seals with panel seals, and (3) single shaft seal without panel seals. The purpose of this analysis is to develop insights on factors that are potentially important in showing compliance with applicable regulations of the U.S. Environmental Protection Agency (i.e., 40 CFR 191, Subpart B; 40 CFR 268). The primary topics investigated are (1) gas production due to corrosion of steel, (2) gas production due to microbial degradation of cellulosics, (3) gas migration into anhydrite marker beds in the Salado Formation, (4) gas migration through a system of shaft seals to overlying strata, and (5) gas migration through a single shaft seal to overlying strata. Important variables identified in the analyses include initial brine saturation of the waste, stoichiometric terms for corrosion of steel and microbial degradation of cellulosics, gas barrier pressure in the anhydrite marker beds, shaft seal permeability, and panel seal permeability.
\end{abstract}

\footnotetext{
Arizona State University, Tempe, AZ

${ }^{2} \mathrm{New}$ Mexico Engineering Research Institute, Albuquerque, NM

${ }^{3}$ Applied Physics, Inc., Albuquerque, NM

${ }^{4}$ Science Applications International Corporation, Albuquerque, NM

${ }^{5}$ Tech Reps, Inc., Albuquerque, NM
}

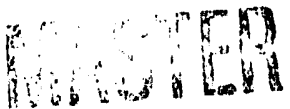

$\Re$ 


\section{ACKNOWLEDGMENTS}

The support provided by D. R. Anderson, B. L. Baker, J. Berglund, W. Beyeler, S. C. Hora, H. J. Iuzzolino, R. P. Rechard, K. K. Rudeen, M. S. Tierney, K. Trauth, and other members of the 1991 performance assessment team for the Waste Isolation Pilot Plant is gratefully acknowledged. Special recognition is extended to $M$. G. Marietta and M. Fewell for their careful prepublication review of this document. The editorial support provided by the staff of Tech Reps, Inc, with special thanks to D. Marchand, F. Puffer, and M. Minahan, is also gratefully appreciated. 


\section{CONTENTS}

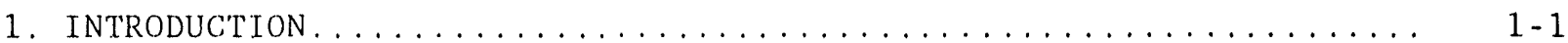

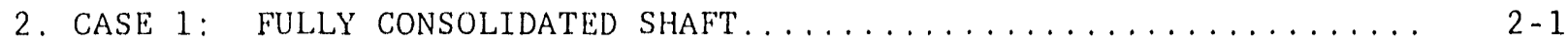

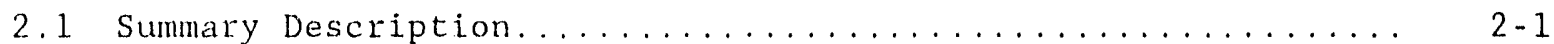

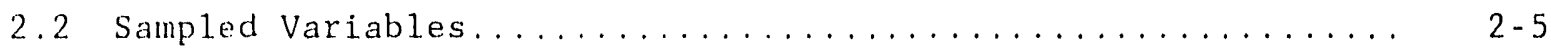

2.3 Uncertainty and Sensitivity Analysis Results............. 2-8

2.3.1 Gas Generation Due to Corrosion............... 2-9

2.3.2 Gas Generation Due to Microbial Degradation......... 2-14

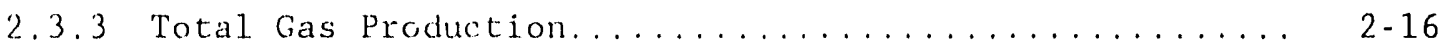

2.3.4 Gas Saturation and Pressure in Waste Pane1......... 2-26

2.3.5 Lateral Gas Migration.................... 2-30

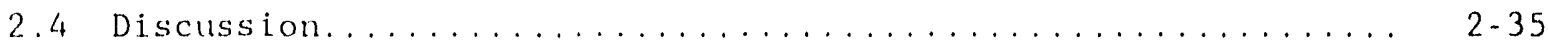

3. CASE 2: PERMEABLE SHAFT WITH PANEL SEALS ................. $3-1$

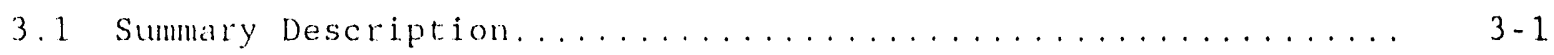

3.2 Sampled Variables.......................... $3-6$

3.3 Uncertainty and Sensitivity Analysis Results............ 3-9

3.3.1 Gas Generation Due to Corrosion................ 3-10

3.3.2 Gas Generation Due to Microbial Degradation.......... 3-14

3.3.3 Total Gas Production..................... 3-16

3.3.4 Gas Saturation and Pressure in waste Panel......... 3-24

3.3 .5 Gas Migration........................ 3-28

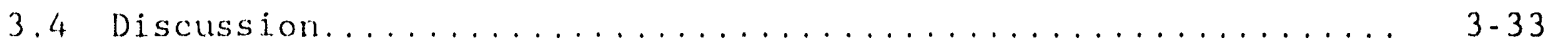

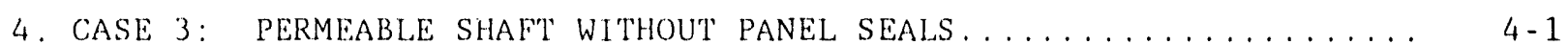

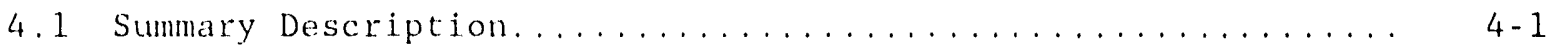

4.2 Sampled variables......................... $4-2$

4.3 Uncertainty and Sensitivity Analysis Results.............. 4-7

4.3.1 Gas Generation Due to Corrosion............... 4-7

4.3.2 Gas Generation Due to Microbial Degradation......... 4-10

4.3 .3 Total Gas Production....................... 4-12

4.3.4 Gas Saturation and Pressure in waste............. 4-20

4.3.5 Gas Movement in Anhydrite Marker Beds............. 4-26

4.3 .6 Gas and Brine flow through shaft Seal............ 4-29

4.4 Discussion. . . . . . . . . . . . . . . . . . . . . . . . . . . . 4 $4-34$

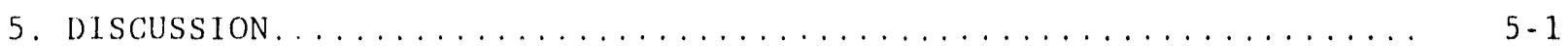

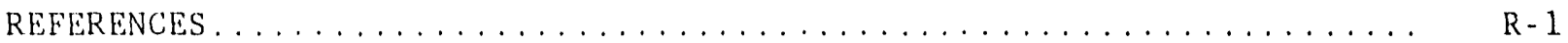


Contents

\section{Figures}

Figure

Page

2-1 Schematic representation of an axisymmetric cylindrical

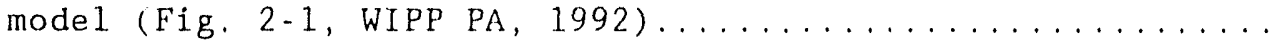

2-2 Gridding scheme employed with BRAGFLO for the cylindrical equivalent panel model used for Case 1 (Fig. 2-2, WIPP PA, 1992)

2-3 Excavated areas in the WIPP repository............... $2-4$

2-4 Uncertainty and sensitivity analysis results for gas generation due to corrosion of steel.......................

2-5 Uncertainty and sensitivity analysis results for gas generation due to microbial degradation of cellulosics under humid and

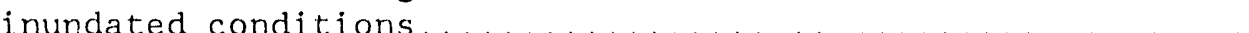

2-6 Uncertainty and sensitivity analysis results for gas generation due to corrosion of steel and microbial degradation of

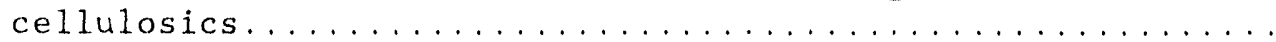

2-7 Scatterplois relating cumulative gas production over 10,000 yr due to corrosicn to STOICCOR (stoichiometric factor for corrosion of steel), BRSAT (initial brine saturation), GRCORI (gas generation rate due to corrosion of steel under inundated conditions) and SALPERM (Salado halite permeability)........

2-8 Uncertainty and sensitivity analysis results for total gas production (i.e., both corrosion of steel and microbial

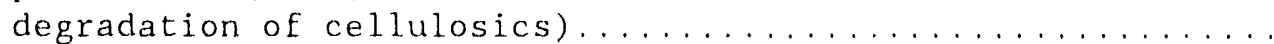

2-9 Uncertainty and sensitivity analysis results for steel and cellulosic inventories in waste panel................

2-10 Scatterplots relating cumulative gas production over $10,000 \mathrm{yr}$ due to both corrosion and microbial degradation to STOICMIC (stoichiometric coefficient for microbial degradation of cellulosics), GRCORI (gas-generation rate due to corrosion of steel under inundated conditions), BRSAT (initial brine saturation) and STOICCOR (stoichiometric factor for corrosion

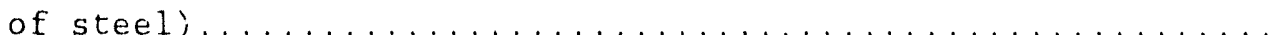

2-11 Uncertainty and sensitivity analysis results for average gas saturation and gas pressure in waste panel.............

2-12 Uncertainty and sensitivity analysis results for total and net

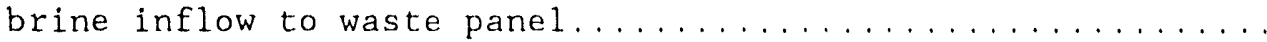


2-13 Uncertainty and sensitivity analysis results for total pore

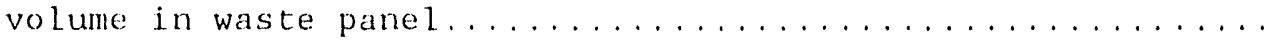

2-14 Uncertainty and sensitivity analysis results for gas pressure in computational cell of disturbed rock zone adjacent to Anhydrite Layers A and B (i.e., Cel1 $(10,5)$ and gas barrier pressure in adjacent computational cell containing undisturbed anhydrite in Anhydrite Layers $A$ and $B(i . e .$, Cell $(11,5)) \ldots \ldots \ldots \ldots$

2-15 Scatterplot for gas pressure in Computational Cell (10,5) versus

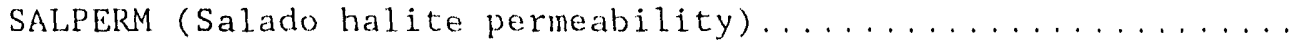

2-16 Uncertainty and sensitivity analysis results for differences between gas barrier pressure in Computational Cel1 $(11,5)$ and gas pressure in Computational Cell $(10,5)$ and the waste panel,

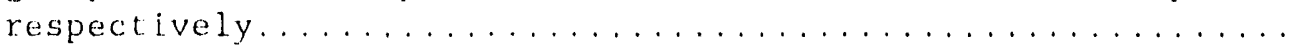

3-1 Gridding scheme employed with BRAGFLo for the two-dimensional vertical cross-section model of the full repository used for

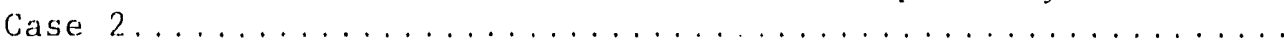

3-2 Uncertainty and sensitivity analysis results for gas generation due to corrosion of steel..................

3-3 Uncertainty and sensitivity analysis results for gas generation due to microbial degradation of cellulosics under humid and inundated conditions...........................

3-4 Uncertainty and sensitivity analysis results for gas generation due to corrosion of steel and microbial degradation of

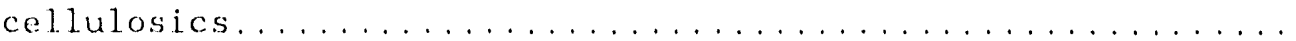

3-5 Scatterplots relating cumulative gas production over 10,000 yr due to corrosion to GRCORI (gas-generation rate due to corrosion of steel under inundated conditions), BRSA'T (initial brine saturation) and STOICCOR (stoichiometric factor for

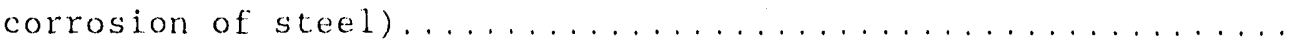

3-6 Uncertainty and sensitivity analysis results for total gas production (i.e., both corrosion of steel and inicrobial

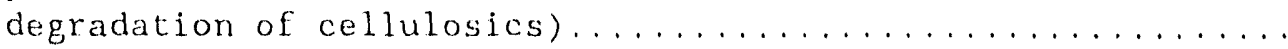

3-7 Uncertainty and sensitivity analysis results for steel and

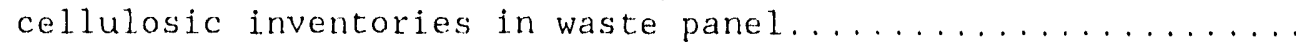

3-8 Uncertainty and sensitivity analysis results for gas saturation in individual waste blocks.......................

3-9 Uncertainty and sensitivity analysis results for gas pressure in individual waste blocks........................

3-10 Uncertainty and sensitivity analysis results for total pore

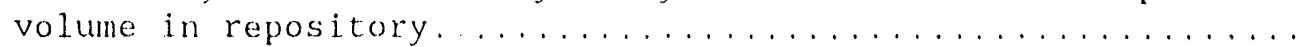


3-11 Uncertainty and sensitivity analysis results for cumulative gas flow out of repository and through shaft to Culebra

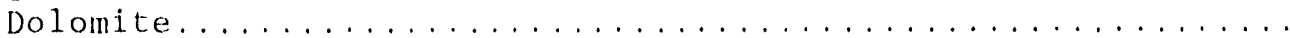

3-12 Scatterplots for cumulative gas flow over 10,000 yr through the shaft to the Culebra Dolomite for the following sampled variables: BRSAT (initial brine saturation), SEALPERM (permeability of seals between waste blocks in repository), SH1PERM (permeability of lower shaft section), SH2PERM (permeability of middle shaft section) and SH3PERM

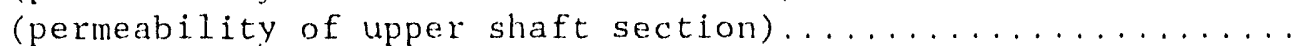

3-13 Scatterplot for cumulative gas flow over 10,000 yr through the shaft to the Culebra Dolomite versus SHlPERM (permeability of lower shaft section). The results in this figure and elsewhere in this section were gunorated with the assumption that the

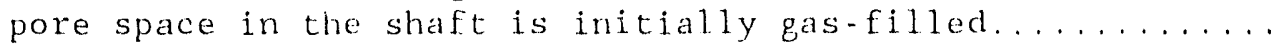

4-1 Gridding scheme employed with BRAGFLO for the two-dimensional vertical cross-section model used for Case 3 . Individual computational cells are identified with an ordered pair $(i, j)$ of integers, where $i$ designates the horizontal coordinate and i designates the vertical coordinate...................

4-2 Uncertainty and sensitivity analysis results for gas generation due to microbial degradation of cellulosics...............

4-3 Uncertainty and sensitivity analysis results for gas generation

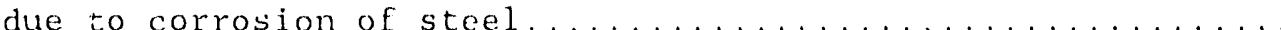

4-4 Uncertainty and sensitivity analysis results for gas generation due to corrosion of steel and microbial degradation of

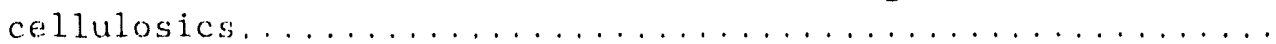

4-5 Uncertainty and sensitivity analysis results for total gas production due to both corrosion of steel and microbial

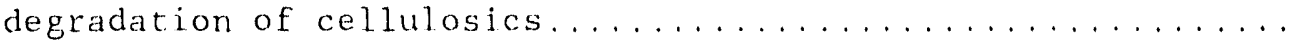

4-6 Uncertainty and sensitivity analysis results for steel and

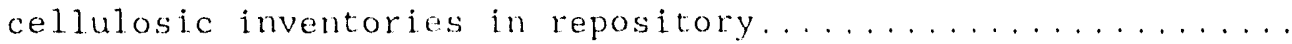

4-7 Uncertainty and sensitivity analysis results for average gas saturation and gas pressure in repository................

4-8 Uncertainty and sensitivity analysis results for total and net brine inflow to repository.....................

4-9 Gas barrier pressures in Computational Celis $(7,6),(7,8)$ and $(7,15)$, gas pressures in Computational Cells $(8,6),(8,8)$ and $(8,15)$, and differences between gas barrier pressure and gas pressure for adjacent computational cells............... 
4-1.0 Partial rank correlation coefficients for gas barrier pressures in Computational Cells $(7,6),(7,8)$ and $(7,15)$, gas pressures in Computational Cells $(8,6),(8,8)$ and $(8,15)$, and differences between gas barrier pressure and gas pressure for adjacent computational cells............................ 4.28

4-11. Uncertainty and sensitivity analysis results for cumulative gas and brine flow through shaft to Culebra.................

4-12 Scatterplots for cumulative gas flow through shaft seal over 10,000 yr with raw and rank-transformed data for the variables BRSAT (initial. brine saturation), SEALPERM (shaft seal. permeability) and TZPOR (scale factor used in definition of transition zone and disturbed rock zone porosity)..........

4-13 Scatterplots for cumulative brine flow through shaft seal over 10,000 yr with raw and rank-transformed data for the variables BRSAT (initial brine saturation), SEALPERM (shaft seal permeability) and TZPOR (scale factor used in definition of transition zone and disturbed rock zone porosity)........... 


\section{Tables}

Table

2-1 Imprecisely Known Variables Used in BRAGFLO in the Estimation of the Behavior of an Undisturbed Waste Panel.............

2-2 Stepwise Regression Analyses with Rank-Transformed Data for Cumulative Gas Production over 10,000 yr Due to Corrosion under llunid and Inundated conditions..................

2-3 Stepwise Regression Models with Rank-Transformed Data for Cumulative Gas Production over 10,000 yr Due to Corrosion

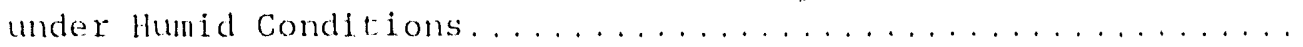

2-4 Stepwise Regression Analyses with Rank-Transformed Data for Cumulat ive Gas Production over 10,000 yr Due to Microbial. Degradation under llumid and Inundated Conditions.............

2-5 Stepwise Regression Analysis with Rank-Transformed Data for. Total Gas production Due to Corrosion and Total Gas Generation Due to Microbial Degradation.......................

2-6 Stepwise Regression Analysis with Rank-Transformed Data for Total Gas Production Over 10,000 yr Due to Both Corrosion and

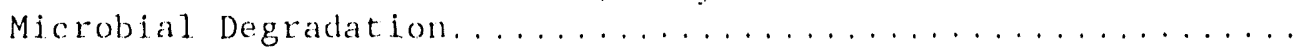

3-1 Imprecisely Known Variables Used in BRAGFLo for Case 2 to Determine the Effects of Seal permeabilities and Gas Generation Parameters on Gas flow through the Repository and up the shaft

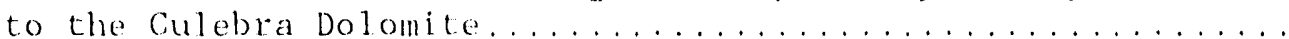

3-2 Stepwise Regression Analyses with Rank-T'ransformed Data for Cumulat ive Gas Production over 10,000 yr Due to Corrosion under Humid and Inundated Conditions. .....................

3-3 Stepwise Regression Analyses with Rank-Transformed Data for Cumblat ive Gas product ion over 10,000 yr Due to Microbial Degradation under Humid and Inundated Conditions.............

3-4 Stepwise Regression Alalysis with Rank-Transformed Data for Total Gas production Due to Corrosion and Total Gas Generation

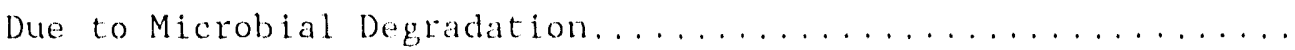

3-5 Stepwise Regression Analysis with Rank-Transformed Data for Total Gas Production Over 10,000 yr Due to Both Corrosion and

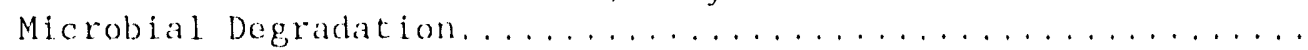

4-1 Imprecisely Known Variables Used in BRAGFlo in the Estimation

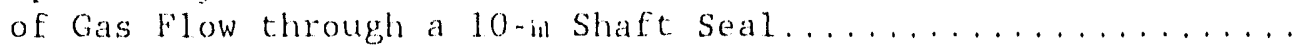


4-2 Stepwise Regression Analyses with Rank-Transformed Data for Cumulative Gas Production over 10,000 yr Due to Corrosion under Humid and Inundated Conditions...................

4-3 Stepwise Regression Analyses with Rank-Transformed Data for Cumulative Gas Production over 10,000 yr Due to Microbial Degradation under Humid and Inundated Conditions............

4-4 Stepwise Regression Analysis with Rank-Transformed Data for Total Gas Production Due to Corrosion over 10,000 yr and Total Gas Generation Due to Microbial Degradation over

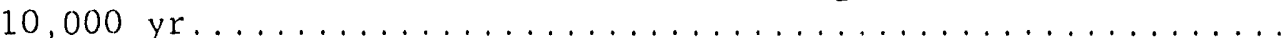

4-5 Stepwise Regression Analysis with Rank-Transformed Data for Total Gas Production Over 10,000 yr Due to Both Corrosion and

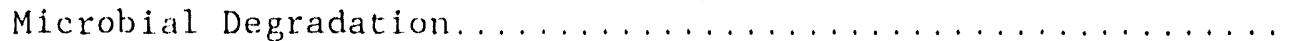

4-6 Stepwise Regression Analyoes with Rank-Transformed Data for Gas Saturation and Gas Pressure in Repository at 10,000 yr.......

4-7 Stepwise Regression Analyses with Rank-Transformed Data for Total and Net Brine Inflow to the Repository over 10,000 yr...

4-8 Stepwise Regression Analyses with Rank-Transformed Data for Cumulative Gas and Brine Flow through Shaft Seal over

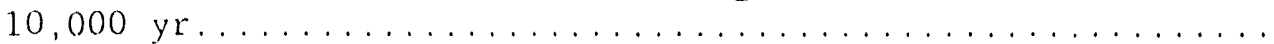

5-1 Important Variables Identified in Uncertainty and Sensitivity Analyses for Gas and Brine Migration................... 


\section{INTRODUCTION}

The Waste Isolation Pilot Plant. (WIPP) in southeastern New Mexico is being developed by the U.S. Department of Energy (DOE) as a research and development facility to demonstrate the safe disposal of defense-generated transuranic waste (U.S. DOE, 1980; U.S. DOE, 1991). The WIPP must comp1y with various environmental regulations of the U.S. Environmental Protection Agency (EPA), including 40 CFR 268.6, Petitions to allow land disposal of a waste prohibited under Subpart $C$ of Part 268 (implementing the Resource Conservation and Recovery Act (RCRA, U.S. EPA, 1986]) and 40 CFR 191, Subpart B, the Environmental Standards for the Management and Disposal of Spent Nuclear Fue1, High-Level and Transuranic Radioactive Wastes (U.S. EPA, 1985). In support of the development of the WIPP and to provide perspective on compliance with various applicable regulations, Sandia National

Laboratories (SNL) is conducting an ongoing performance assessment for the WIPP (Bertram-Howery and Hunter, 1989; Lappin et al., 1989). At present, a performance assessment is carried out each year to summarize what is known about the WIPP and to provide guidance for future work (Marietta et al., 1989; Bertram-Howery et al., 1990; WIPP PA, 1991a).

The 1991 WIPP performance assessment (WIPP PA, 1991a; 1991b; 1991c; Helton et al., 1992) is the first to model the generation of gas in the repository and the potential flow of this gas away from the repository. The primary focus of prior performance assessments for the WIPP has been on compliance with $40 \mathrm{CFR} 191$, Subpart $B$, which primarily involves radionuclide releases due to cuttings removal and transpurt by groundwater. The two phase (i.e., gas and brine) flow calculations performed for the 1991 WIPP performance assessment provide the first opportunity to investigate factors that may influence compliance with 40 CFR 268.6.

To provide perspective on factors influencing compliance with 40 CFR 268, three analysis cases were considered as part of the 1991. WIPP performance assessment:

Case 1: Fully Consolidated Shaft

Case 2: System of Shaft Seals with Panel Seals

Case 3: Single Shaft Seal without Panel Seals.

All three cases examine the undisturbed performance of the WIPP over $10,000 \mathrm{yr}$. Case 1 uses a model configuration identical to that used in the 1991 WIPP performance assessment for scenarios involving human intrusion during exploratory drilling for natural resources, with the significant difference that an intrusion does not occur. Because the Case 1 model configuration was designed to assess flow up a borehole, shafts are, 
depending on preferred terminology, onitted or assumed to be fully consolidated. This assumption forces all significant fluid flow from the repository to occur horizontally through anhydrite layers above and below the waste panels. Cases 2 and 3 contain permeable shafts, with the result that both horizontal and vertical fluid migration is pussible.

For each case, uncertainty and sensitivity analyses are performed to determine the factors affecting gas and brine movement away from the repository. Gas movement provides an indication of the extent to which volatile organic compounds (VOCs) inight be transported away from the repository. Similarly, brine movement provides an indication of the extent to which heavy metals and other contaminants might be transported away from the repository by flowing brine. The uncertainty and sensitivity analyses use techniques based on Latin hypercube sampling, examination of scatterplots, partial correlation analysis and stepwise regression analysjs (Helton et al., 1991; Helton, 1992).

A prior report describes the three analysis cases in detail and provides an overview of the manner in which the BRAGFLO computer program is used to model two-phase flow for these cases (WIPP PA, 1992). Additional information on BRAGLFO is available in Ch. 5 of WIPP PA, 1991b. In addition, WIPP PA, 1992 presents sensitivity analysis results based on the examination of scatierplots and the results associated with individual sample elements. The present report uses more formal procedures based on partial correlation analysis and stepwise regression analysis, although examination of scatterplots will also be used extensively.

As a reminder, there are two types of uncertainty in a performance assessment: stochastic uncertainty and subjective uncertainty (Ch. 3, WIPP PA, 1991a; Helton, 1983). Stochastic uncertainty refers to the fact that many different occurrences have a real possibility of taking place and is incorporated into a performance assessment through the probabilities for individual scenarios. Subjective uncertainty refers to the analysts' lack of knowledge with respect to values for parameters required in the computational implementation of a performance assessinent and is incorporated into a performance assessment by developing distributions for imprecisely known parameters that characterize a degree of belief as to where the appropriate value to use in the analysis is located. The three analysis cases are equivalent to indjvidual scenarios, and there is no consideration of their probability of occurrence. Thus, the results presented in this report do not involve stochastic uncertainty. Rather, the uncertainty and sensitivity analyses are studying the effects of subjective uncertainty. 


\section{CASE 1: FULLY CONSOLIDATED SHAFT}

\subsection{Summary Description*}

Case 1 involves a single waste panel and employs the model configuration used for the undisturbed scenario in the 1991 WIPP performance assessment (Sects. 5.2.3 and 5.2.4, WIPP PA, 1991b). The computational implementation with BRAGFLO is based on an axisymmetric geometry (Fig. 2-1) and uses the gridding scheine shown in Fig, 2-2. The drift and shaft systems are omitted from the model, which is equivalent to the assumption of a sealing system that produces properties identical to undisturbed halite.

The single waste panel considered in Case 1 is represented as a cylinder with the same enclosed volume as the mean volume of the ten wastedisposal panels, including the volume occupied by the halite pillars separating the rooms (Fig. 2-3). Pillars are included in the panel volume to preserve the horizontal cross-sectional area through which brine inflow from the anhydrite interbeds could occur. This results in a cylinder having a radius of approximately $97 \mathrm{~m}$. Porosity of the modeled panel is less than the porosity of the waste and backfill alone due to the presence of the lowporosity halite in the pillars. As discussed later, a correction is also made to approximate the room expansion that might occur from the presence of waste-generated gas. Initial brine saturation is also adjusted for the presence of the pillars, which are fully saturated with brine. These adjustments are discussed in the documentation for the 1991 preliminary comparison with $40 \mathrm{CFR}$ 191, Subpart B (Sect. 3.4.8, WIPP PA, 1991c).

The region modeled with BRAGFLO includes Marker Bed 139 (MB139), which is an anhydrite interbed below the waste-disposal horizon, and Anhydrite Layers $A$ and $B$ above the panel (Fig. 2-2). These units are included in the model because they have higher permeability than the intact halite of the Salado Formation and therefore are preferred pathways for fluid flow. As modeled, Marker Bed 139 is $0.9 \mathrm{~m}$ thick and $2.9 \mathrm{~m}$ below the panel floor. Anhydrite Layers $A$ and $B$ are represented as a single layer $0.21 \mathrm{~m}$ thick, corresponding to the combined thickness of the two units, and are located $5.33 \mathrm{~m}$ above the floor of the panel at the elevation of Anhydrite Layer $B$. The thickness of the waste panel was uncertain and ranged from $2.67 \mathrm{~m}$ to $3.64 \mathrm{~m}$. This variability resulted from uncertainty with respect to waste composition, which in turn controls waste porosity after compaction and thus panel height.

\footnotetext{
*Adapted from Section 2.2 of WIPP PA, 1992.
} 


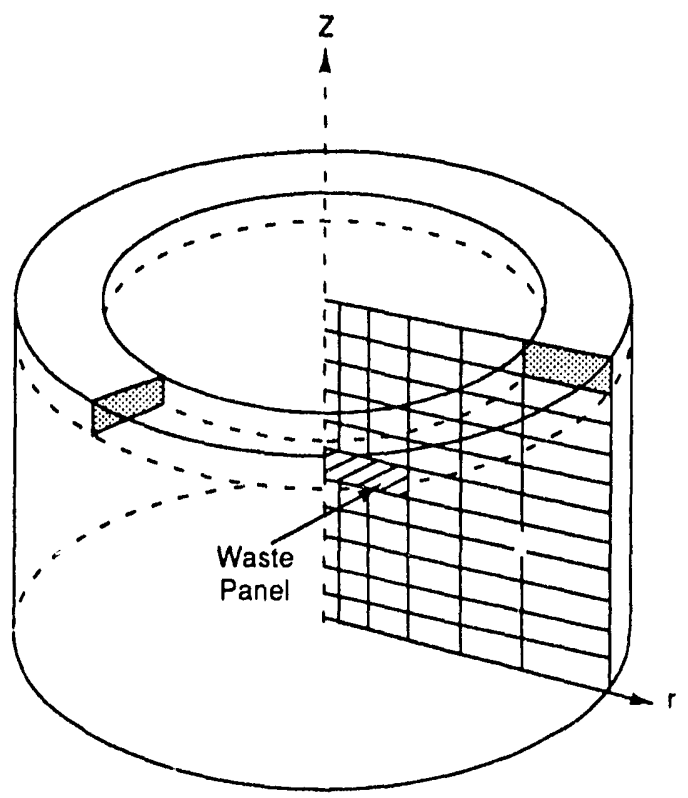

TRI.6342.1476.0

Figure 2-1. Schematic representation of an axisymmetric cylindrical model (Fig. 2-1, WIPP PA, 1992). 


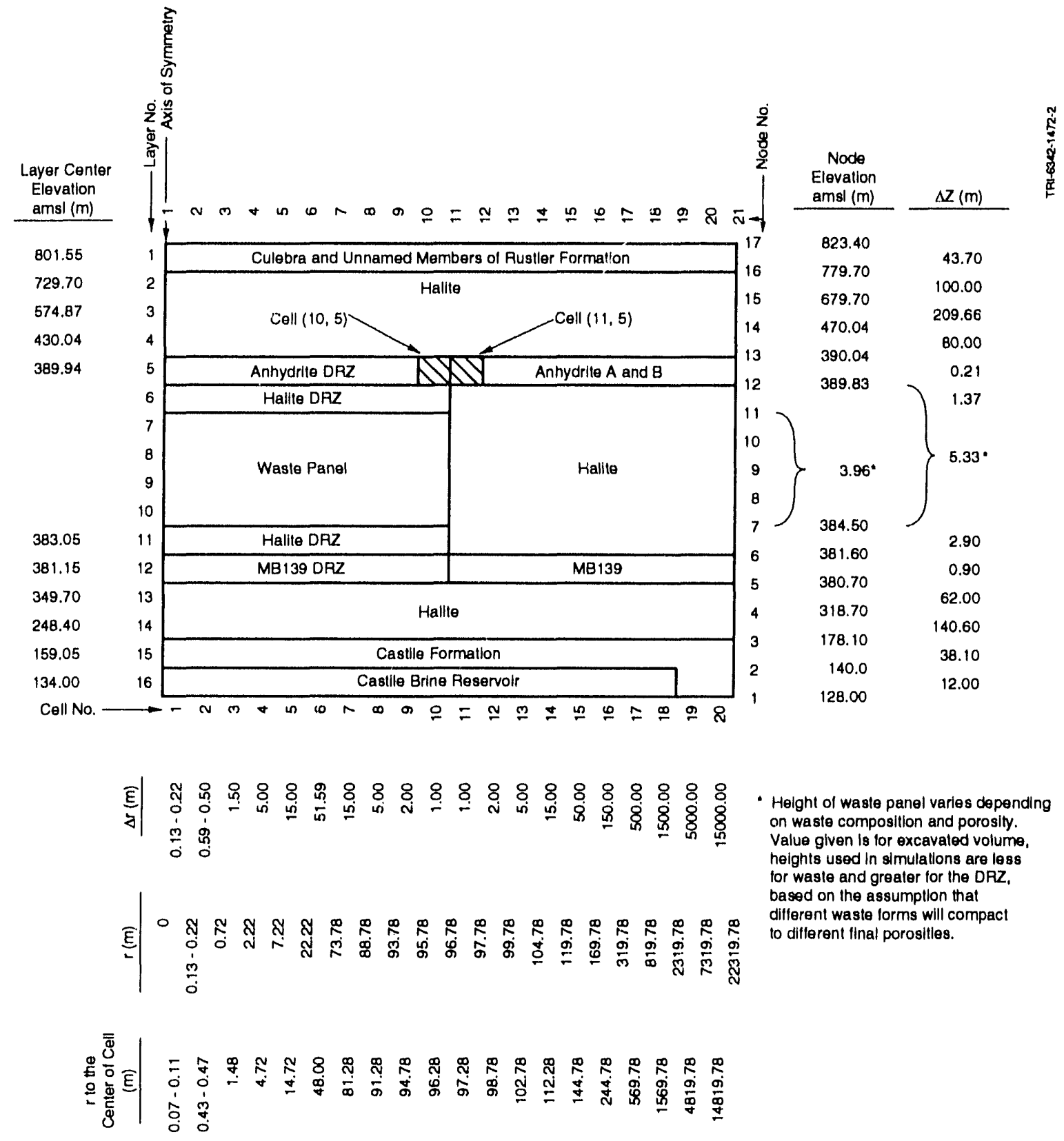

Figure 2-2. Gridding scheme employed with BRAGFLO for the cylindrical equivalent panel model used for Case 1 (Fig. 2-2, WIPP PA, 1992). Individual computational cells are identified with an ordered pair $(i, j)$ of integers, where $i$ designates the horizontal coordinate and $j$ designates the vertical coordinate. 


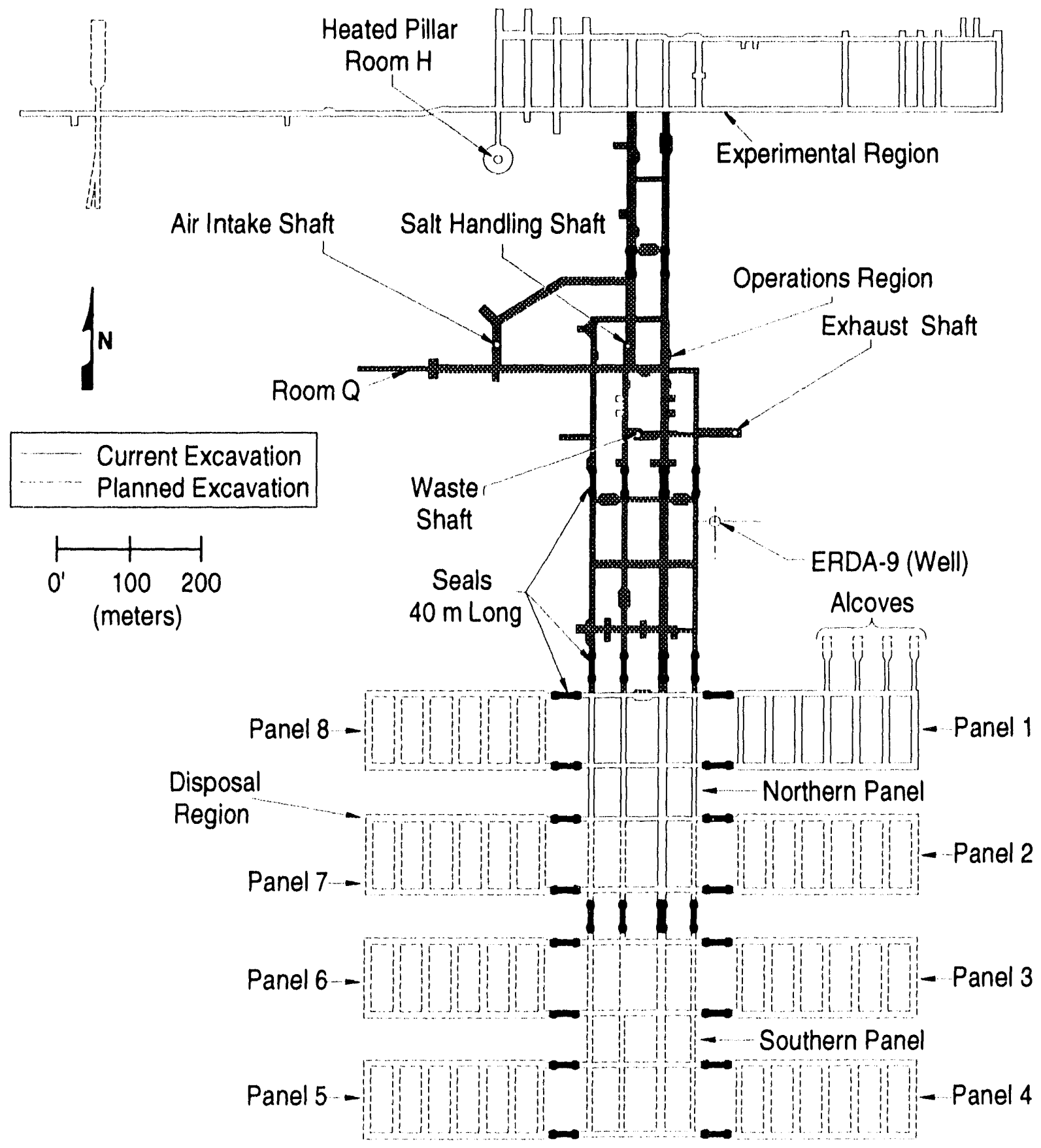

TRI- $6334-206-5$

Figure 2-3. Excavated areas in the WIPP repository. 
The disturbed rock zone (DRZ) surrounding the excavation is assumed to extend upward to the top of Anhydrite Layers $A$ and $B$ and clownward to the base of Marker Bed 139. The lateral extent of the disturbed rock zone within the halite is not included in this model because the principal flow paths of interest are through the disturbed rock zone vertically to the anhydrite layers.

The modeled region extends laterally for a radius of approximately 22 $\mathrm{km}$. This distance is a compromise value; a more-distant boundary might result in greater computational accuracy, but uncertainty in the geologic system being modeled increases away from the repository (Powers et al., 1978). The model extends upward to the Culebra Dolomite Member of the Rustler Formation and downward to the Castile Formation. These units are included because they represent potential sinks and sources, respectively, for brine flow in the system. For simplicity, the lower unnamed member of the Rustler Formation is combined with the Culebra Dolomite, and the two are modeled as a single unit with properties representative of the Culebra Dolomite. No flow in the direction normal to the horizontal boundary is assumed below the repository in the Castile Formation and above the repository in the Culebra Dolomite. Within the Culebra, the vertical farfield boundary is defined at a constant pressure, reflecting the Culebra's high transmissivity relative to adjacent layers and role as a sink for fluid flow.

\subsection{Sampled Variables}

The 14 imprecisely-known variables 1 isted in Table $2-1$ were used as input to BRAGFLO for the Case 1 uncertainty and sensitivity analyses. As discussed in the Introduction, the distributions indicated in Table 2-1 for the individual variables are characterizing subjective uncertainty. The Case 1 calculations used a Latin hypercube sample (Mckay et al., 1979; Iman and Shortencarier, 1984) of size 60 from the 14 variables in Table $2-1$. Further, the restrictive pairing technique developed by Iman and Conover (Iman and Conover, 1982; Iman and Davenport, 1982) was used to ensure that the correlations between uncorrelated variables were close to zero and that correlated variables had correlations close to their specified values. The resultant sample is listed in Table 3.1-2 of WIPP PA, 1992.**

**The 1991 performance assessment for the WIPP used a Latin hypercube sample of size 60 from 45 imprecisely known variables (Table B-2, WIPP PA, 1991b; Table 3-1. Helton et al., 1992). The BRAGFLO calculations for Case 1 are the BRAGFLO calculations performed for undisturbed panel behavior in the 1991 WIPP performance assessment. Further, the indicated variable values in Table 3.1-6 of WIPP PA, 1992 are the values obtained in this original sample of size 60 for the 14 variables in Table 2-1. 
Chapter 2. Case 1: Fully Consolidated Shaft

Table 2-1. Imprecisely Known Variables Used in BRAGFLO In the Estimation of the Behavior of an Undisturbed Waste Panel.

Variable

BRSAT

GRCORH

GRCORI

GRMICH

GRMICl

MBPERM

\section{Definition}

Initial liquid (brine) saturation of waste (dimensionless). Range: 0 to $2.76 \times 10^{-1}$. Median: $1.38 \times 10^{-1}$. Distribution: Uniform. Additional information: Section 3.4.9, WIPP PA, 1991c. Varlable 1 in Latin hypercube sample is unlformily distributed on interval $[0,1]$ and used to select value for BRSAT by preprocessor to BRAGFLO.

Scale factor used in definition of gas generation rate for corrosion of steel under humid conditions (dimensionless). Actual gas generation rate is GRCORH • GRCORI. Range: 0 to $5 \times 10^{-1}$. Median: $1 \times 10^{-1}$. Distribution: Piecewise uniform. Additional information: Memo from Brush, July 8, 1991, contalned in Appendix A, WIPP PA, 1991c; Section 3.3.8, WIPP PA, 1991c. Variable 3 in Latin hypercube sample.

Gas generation rate for corrosion of steel under inundated conditions $\left(\mathrm{mol} / \mathrm{m}^{2}\right.$ surface area steel.s). Range: 0 to $1.3 \times 10^{-8} \mathrm{~mol} / \mathrm{m}^{2} \mathrm{~s}$. Medlan: $6.3 \times 10^{-9} \mathrm{~mol} / \mathrm{m}^{2} \mathrm{~s}$. Distribution: Piecewise uniform. Additional information: Same as GRCORH. Variable 4 in Latin hypercube sample.

Scale factor used in definition of gas generation rate due to microbial degradation of cellulosics under humid conditions (dimensionless). Actual gas generation rate is GRMICH.GRMICI. Range: 0 to $2 \times 10^{-1}$. Median: $1 \times 10^{-1}$. Distribution: Piecewise uniform. Additional information: Same as GRCORH. Variable 5 in Latin hypercube sample.

Gas generation rate due to microbial degradation of cellulosics under inundated conditions (mol $/ \mathrm{kg}$ cellulosics $\cdot \mathrm{s}$ ). Range: 0 to $1.6 \times 10^{-8} \mathrm{~mol} / \mathrm{kg} \mathrm{s}$. Median: $3.2 \times 10^{-9} \mathrm{~mol} / \mathrm{kg} \mathrm{s}$. Distribution: Plecewise uniform. Additional information: Same as GRCORH. Varlable 6 in Latin hypercube sample.

Permeability ( $k$ ) in anhydrite marker beds in Salado Formation under undisturbed conditions $\left(\mathrm{m}^{2}\right)$. Range: $8.5 \times 10^{-21}$ to $1.8 \times 10^{-18} \mathrm{~m}^{2}$. Median: $7.8 \times 10^{-20} \mathrm{~m}^{2}$. Distribution: Plecewise uniform with a 0.8 rank correlation with SALPERM. Additional Information: Memo from Beauheim, June 14, 1991, contained in Appendix A, WIPP PA, 1991c; Section 2.4.5, WIPP PA, 1991c. Variable 12 in Latin hypercube sample.

Porosity $(\phi)$ in anhydrite marker beds in Salado Formation under undisturbed conditions (dimensionless). Range: $1 \times 10^{-3}$ to $3 \times 10^{-2}$. Median: $1 \times 10^{-2}$. Distribution: Plecewise uniform. Additional information: Section 2.4.7, WIPP PA, 1991c. Varlable 13 in Latin hypercube sample. 
Table 2-1. Imprecisely Known Variables Used in BRAGFLO in the Estimation of the Behavior of an Undisturbed Waste Panel (concluded).

Variable

MBPRES

MBTHPRES

SALPERM

STOICCOR

STOICMIC

VMETAL

WWOOD
Definition

Pressure $(p)$ in anhydrite Marker Bed 139 under undisturbed conditions (Pa). Pressures at other elevations in the Salado Formation were varled hydrostatically relative to the sampled value for MBPriES. Range: $8.21 \times 10^{6}$ to $1.48 \times 10^{7} \mathrm{~Pa}$. Median: $1.28 \times 10^{7} \mathrm{~Pa}$. Distribution: Piecewise uniform. Additional information: Memos from Beauheim, June 14,1991, and Howarth, June 12, 1991, contained in Appendix A, WIPP PA, 1991C; Section 2.4.6, WIPP PA, 1991c. Variable 11 In Latin hypercube sample.

Threshold displacement pressure $\left(\mathrm{p}_{t}\right)$ in anhydrite marker beds in Salado Formation $(\mathrm{Pa})$. Range: $3 \times 10^{3}$ to $3 \times 10^{7} \mathrm{~Pa}$. Median: $3 \times 10^{5} \mathrm{~Pa}$. Distribution: Lognormal Additional information: Davies, 1991; memo from Davies, June 2, 1991, contained in Appendix A, WIPP PA, 1991c; Section 2.4.1. WIPP PA, 1991c. Variable 14 in Latin hypercube sample is normally distributed on $[0,1]$ and used to select value for MBTHPRES by preprocessor to BRAGFLO; the actual value used for threshold displacement pressure, $p_{t}$ in BRAGFLO is $\log p_{t} \cdot \log \left(5.6 \times 10^{-7}\right) \cdot 0.346 \log$ $($ MBPERM $)+(4 \cdot$ MBTHPRES-2)

Permeability $(k)$ in halite component of Salado Formation $\left(\mathrm{m}^{2}\right)$. Range: $2.0 \times 10^{-22}$ to $1.4 \times 10^{-19} \mathrm{~m}^{2}$. Median: $5.7 \times 10^{-21} \mathrm{~m}^{2}$. Distribution: Piecewise uniform. Additional information: Memo from Beauheim, June 14, 1991, contained in Appendix A, WIPP PA, 1991c; Section 2.3.5, WIPP PA, 1991c. Variable 10 in Latin hypercute sample.

Stoichiometric factor for corrosion of steel (dimensionless). Defines proportion of two different chemical reactions that take place during the corrosiuin process. Range: 0 to 1. Median: $5 \times 10^{-1}$. Distribution: Uniform. Additional information: Brush and Anderson in Lappin et al., 1989, p. A-6; Section 3.3.8, WIPP PA, 1991c. Variable 2 in Latin hypercube sample.

Stoichiometric coefficient for microblal degradation of cellulosics $(\mathrm{mol}$ gas $/ \mathrm{mol}$ $\mathrm{CH}_{2} \mathrm{O}$ ). Range: 0 to $1.67 \mathrm{~mol} / \mathrm{mol}$. Median: $8.35 \times 10^{-1} \mathrm{~mol} / \mathrm{mol}$. Distribution: Uniform. Additional information: Brush and Anderson in Lappin et al., 1989, p. A-10; Section 3.3.9. WIPP PA, 1991c. Variable 9 in Latin hypercube sample.

Fraction of total waste volume that is occupled by IDB (Integrated Data Base) metals and glass waste category (dimensionless). Range: $2.76 \times 10^{-1}$ to $4.76 \times 10^{-1}$. Median: $3.76 \times 10^{-1}$. Distribution: Normal. Additional information: Section 3.4.1, WIPP PA, 1991c. Variable 7 in Latin hypercube sample.

Fraction of total waste volume that is occupled by IDB combustible waste category (dimensionless). Range: $2.84 \times 10^{-1}$ to $4.84 \times 10^{-1}$. Median: $3.84 \times 10^{-1}$.

Distribution: Normal. Additional Information: Section 3.4.1, WIPP PA, $1991 \mathrm{c}$. Variable 8 in Latin hypercube sample. 
The version of BRAGFLO used in the 1991 WIPP performance assessment did not include a model for the competing effects of creep closure of a waste panel and the resistance to and possible reversal of this process due to waste generated gas. As a compromise, the pore volume in a waste panel was initially set to the volume necessary to contain all the waste-generated gas that could be produced from the initial inventory of steel and cellulosics at 1 ithostatic pressure (i.e., $14.9 \mathrm{MPa}$ ). As a result, initial pore volume was a function of STOICCOR (stoichiometric factor for corrosion of steel), STOICMIC (stoichiometric coefficient for inicrobial degradation of cellulosics), VMETAL (fraction of total waste volume occupled by IDB metals and glass waste category) and VWOOD (fraction of total waste volume occupied by IDB combustible waste category). This procedure resulted in a pore volume that was approximately equal to the pore volume of an uncompacted waste panel (i.e., at the time of repository closure) but was approximately five times the estimated pore volume of a waste panel for compaction at lithostatic pressuif with no gas-related resistance. Additional discussion is provided in Section 3.4.8 of WIPP PA, 1991c.

One BRAGFLO calculation was performed for earh of the 60 sample elements generated from the variables listed in Table 2-1. Thus, a total of 60 BRAGFLO calculations are available for analysis. The remainder of this chapter is devoted to an exploration of the resultant mapping from BRAGFLO input to BRAGFLO predictions.

In addition to the 14 sampled variables 1 isted in Table $2-1$, the calculations for Case 1 also required values for a number of additional variables that were fixed at their best-estimate values. These variables and their values are listed in Tables 3.1-1a and 3.1-1b of WIPP PA, 1992. Further, additional discussion of the BRAGFLo input for Case 1 is available in Section 3.1 of WIPP PA, 1992.

\subsection{Uncertainty and Sensitivity Analysis Results}

Given that gas migration into the marker beds (i.e., anhydrite layers) in the Salado Formation is the outcome of greatest interest for Case 1, a natural starting point is an exploration of gas generation. Gas generation has two sources: corrosion of steel and microbial degradation of cellulosics. Further, each of these gas-generating processes can take place under either inundated or humid conditions. Results relating to gas generation are presented in Sections 2.3.1, 2.3.2 and 2.3.3. Then, gas saturation and gas pressure in a waste panel are investigated in Section 2.3.4. Finally, lateral gas migration in the anhydrite marker beds is investigated in Section 2.3.5. 


\subsubsection{Gas Generation Due to Corrosion}

A summary of the results for gas generation due to corrosion is given in Figure 2-4. The two upper frames in Figure 2-4 show cumulative gas generation as a function of time due to corrosion under humid conditions (upper left frame) and corrosion under inundated conditions (upper right frame). Each curve in the upper two frames results from a single Latin hypercube sample element (i.e., each frame has 60 curves, one for each sample element). Overall, the range of gas production under humid conditions is similar to the range of gas production under inundated conditions, although the largest gas production curves occur for inundated conditions.

Formal sensitivity analysis techniques based on partial rank correlation (Helton et a1., 1991; Helton, 1992) can be used to investigate the variation in cumulative gas production shown in the upper two frames of Ffgure 2-4. Specifically, the lower two frames in Figure 2-4 show timedependent plots of partial rank correlation coefficients between cumulative gas production and individual variables from Table 2-1. These coefficients were calculated on the basis of vertical slices through the cumulative gas production curves. Figure 2.4 and other similar figures in this presentation show the partial rank correlation curves for all sampled variables that had a partial rank correlation coefficient whose absolute value exceeded 0.5 for the particular dependent variable under consideration and were generated with the PCCSRC program (Iman et a1,, 1985). As a reminder, a positive rank correlation coefficient indicates that two variables tend to increase and decrease together, and a regative rank correlation coefficient indicates that, as one variable increases, the other tends to decrease.

As shown by the partial correlation results in the lower left frame of Figure 2-4, cumulative gas production due to corrosion under hunid conditions tends to increase as GRCORH (scale factor used in definition of gas-generation rate for corrosion of steel under humid conditions) and GRCORI (gas-generation rate for corrosion of steel under inundated conditions) increase. The positive effects for GRCORH and GRCORI result because the actual gas-generation rate due to corrosion under humid conditions is defined by GRCORH•GRCORI. Thus, increasing each of these variables increases the rate at which gas is generated under humid conditions. 
Cumulative Gas Production Due to Corrosion of Steel
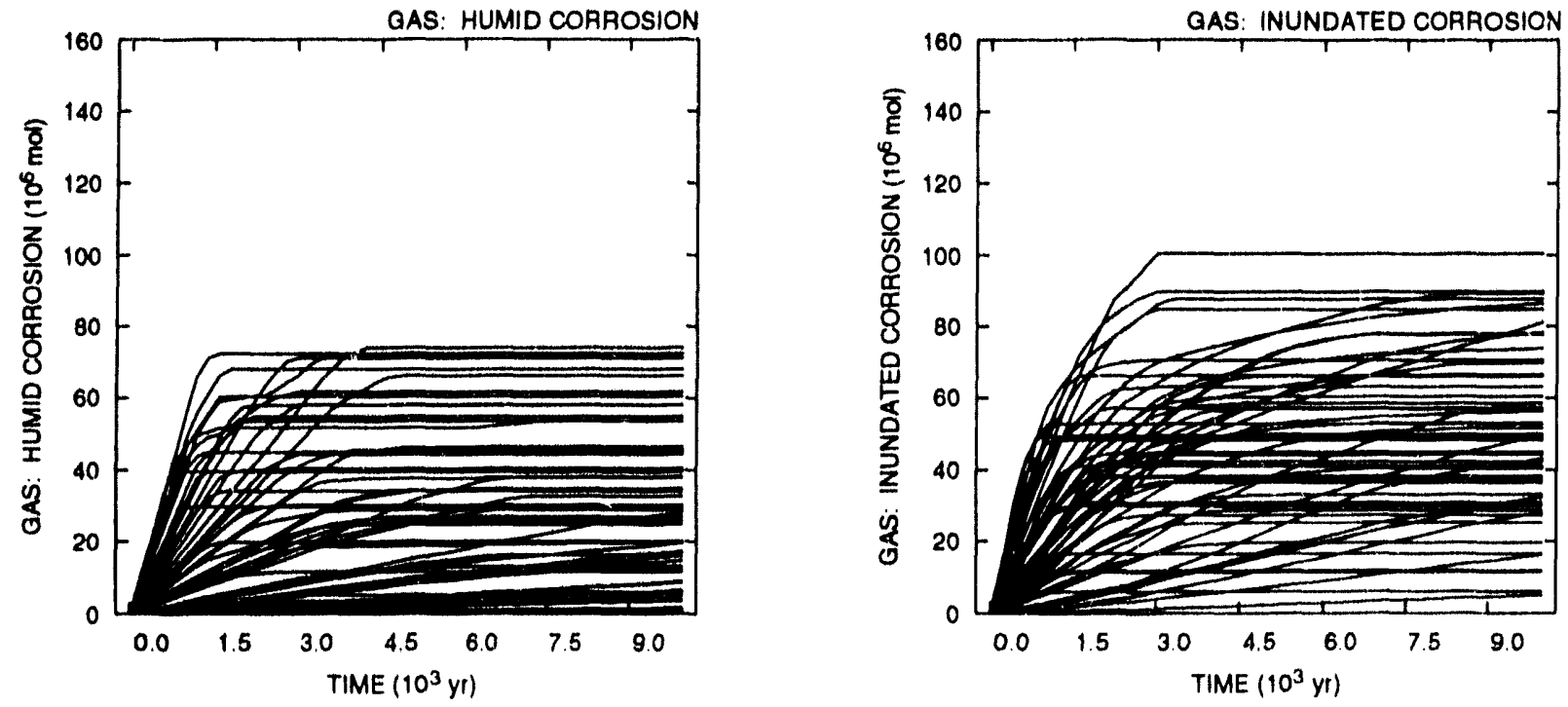

HT. $032 \cdot 10230$

IA1).032.10240

Partial Rank Correlation Coefficients for Cumulative Gas Production Due to Corrosion of Steel
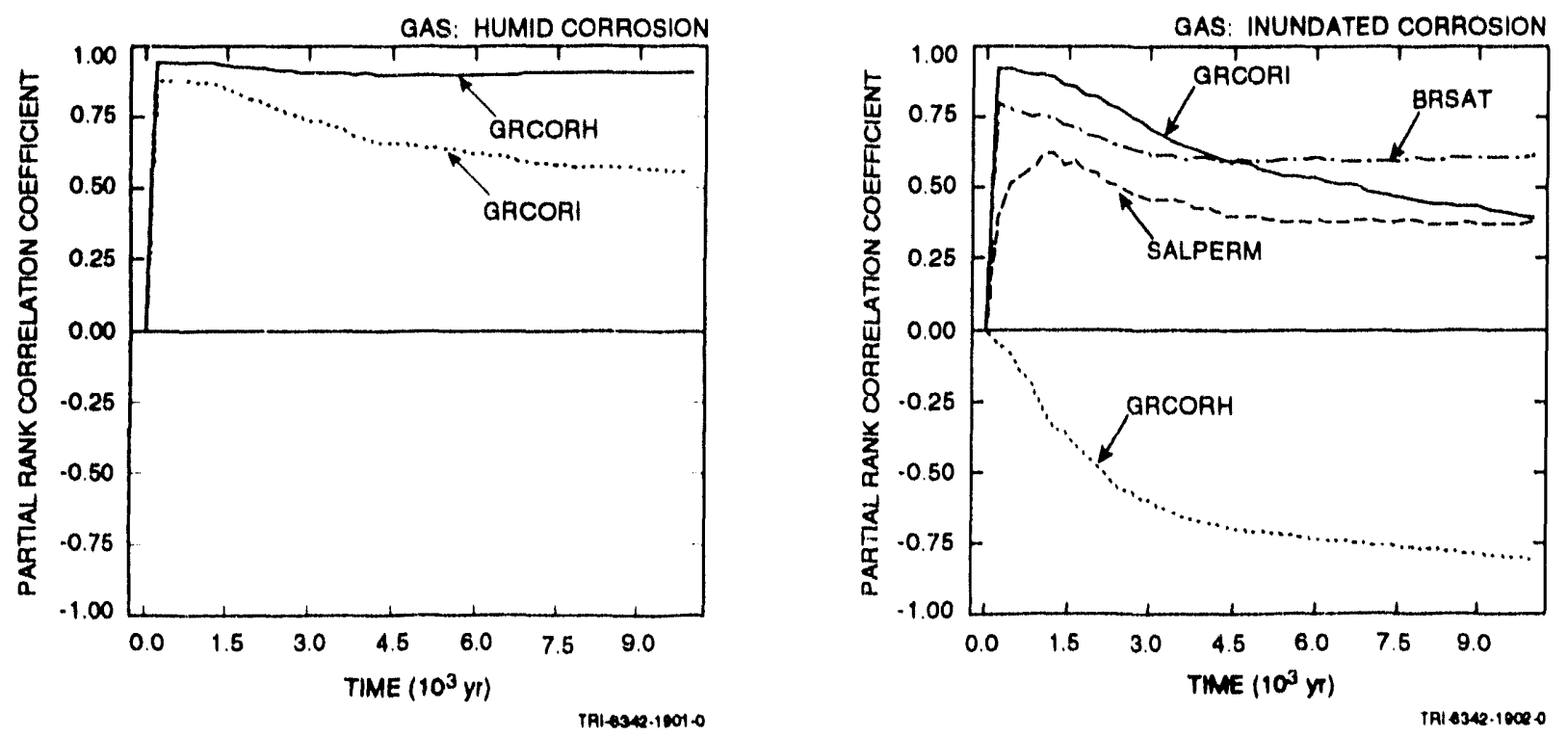

Figure 2.4. Uncertainty and sensitivity analysis results for gas generation due to corrosion of steel. 
As shown by the partial correlation results in the lower right frame of Figure 2-4, cumulative gas production due to corrosion under inundated conditions tends to increase as GRCORI (gas-generation rate for corrosion of steel under inundated conditions), BRSAT (initial brine saturation of waste) and SALPERM (Salado halite permeability) increase and tends to decrease as GRCORH (scale factor used in definition of gas-generation rate for corrosion of steel under humf conditions) increases. The positive effects for GRCORI, BRSAT and SALPERM result because increasing GRCORI increases the rate at which gas is generated by corrosion under inundated conditions and increasing BRSAT and SALPERM increases the amount of steel that w111 be consumed by corrosion under inundated conditions. The lmportance of CRCORI decreases with time because, although GRCORl determines the rate at which gas is generated, it does not determine the total amount of gas that is generated. The negative effect for GRCORH results because the increased consumption of steel and brine by corrosion under humid conditions reduces the amount of gas that can be produced by the corrosion of steel under inundated condit lons.

Stepwise regression analysis (Helton et al., 1991; Helton, 1992) can also be used to analyze the cumulative gas production results shown in Figure 2-4. As an example, the two regression analyses shown 1 n table $2-2$ are for cumulative gas production over 10,000 yr due to corrosion under humid and inundated conditions, respectively. Thus, these two regression analyses are for the gas production values appearing above $10,000 \mathrm{yr}$ in the two upper frames of Figure 2.4 .

These analyses and other simflar analyses in this report were performed with the STEPWISE program (Iman ot al, 1980). A variable was required to be significant at the 0.02 a-level to enter a regression mos 1 and to renain significant at the $0.05 \alpha-10 v e l$ to be retained in a regression model (Draper and Smith, 1981). A considorable amount of discretion was used in the selection of the stopplng polnts for the individual regression analyses and took into account behavlor of $R^{2}$-values, a-values, the PRESS criterion (A1ten, 1971), scaterplots, and the entry of apparently spurious vartables into the regression model. The analyses were tried with both raw (i.e., untransformed) data and rank-transformed (Iman and 'jonover, 1979) data. The regression analyses with rank-transformed variables iypically ylelded regression models with higher $R^{2}$ values and more reasonoble vartable selections than the regression analyses with raw data. Therefore, all the regression analyses presented in this report were performed with ranktransformed data.

The regression analysis in Table $2-2$ for gas production under humld conditions indicates positive effects (i.e., positive regression coefficients) for circoRH (scale factor used in definition of gas-generation 
Table 2-2. Stepwise Regression Analyses with Rank-Transformed Data for Cumulative Gas Production over 10,000 yr Due to Corrosion under Humid and Inundated Conditions.

\begin{tabular}{|c|c|c|c|c|c|c|c|}
\hline \multicolumn{4}{|c|}{$\begin{array}{c}\text { Total Gas Production over } 10,000 \mathrm{yr} \\
\text { (Humid Corrosion) }\end{array}$} & \multicolumn{4}{|c|}{$\begin{array}{l}\text { Total Gas Productlon over } 10,000 \mathrm{yr} \\
\text { (Inundated Corrosion) }\end{array}$} \\
\hline Stepa & Variableb & SRCC & $R^{2 d}$ & Stepa & Varlableb & SRCC & $\mathrm{R}^{2 \mathrm{~d}}$ \\
\hline $\begin{array}{l}1 \\
2 \\
3 \\
4\end{array}$ & $\begin{array}{l}\text { GRCORH } \\
\text { GRCORI } \\
\text { SALPERM } \\
\text { BRSAT }\end{array}$ & $\begin{array}{r}0.81 \\
0.27 \\
-0.21 \\
-0.18\end{array}$ & $\begin{array}{l}0.70 \\
0.76 \\
0.80 \\
0.83\end{array}$ & $\begin{array}{l}1 \\
2 \\
3 \\
4\end{array}$ & $\begin{array}{l}\text { GRCORH } \\
\text { BRSAT } \\
\text { SALPERM } \\
\text { GRCORI }\end{array}$ & $\begin{array}{r}-0.66 \\
0.37 \\
0.31 \\
0.21\end{array}$ & $\begin{array}{l}0.40 \\
0.52 \\
0.63 \\
0.67\end{array}$ \\
\hline \multicolumn{8}{|c|}{$\begin{array}{l}\text { a Steps in stepwise regression analysis } \\
\text { b Variables listed in order of selection in regression analysis } \\
\text { c Standardized regression coefficients in final regression model } \\
\text { d Cumulative } \mathrm{R}^{2} \text { value with entry of each variable into regression model }\end{array}$} \\
\hline
\end{tabular}

rate for corrosion of steel under humid conditfons) and ciRCORI (gasgeneration rate for corrosion of steel under inundated conditions) and negative effects (1.e., negative regression coefficients) for SALPERM (Salado halite permeability) and BRSAT (Initial brine saturation of waste). As indicated earlier, the positive effects for GRCORII and GRCORI result because the gas-generation rate for the corrosion of steel under hunid conditions is GRCORH-GRCOR1. The negative effects for SALPERM and BRSAT result from increasing the anount of steel corroded under inundated conditions and thus decreasing the amount of steel avallable for corrosion under huid conditions. The scale factor GRCORll is the most important. variable and accounts for $708\left(1.0, R^{2}=0.70\right)$ of the varfability in gas generation due to corrosion under humid conditions. Further, CRCORI, SALPERM and BRSAT collectively account for an additional 13 of the variability $($ i.e., $83 z-70 \%=13 \%)$.

The regression analysis in Table $2-2$ for gas production under Inundated conditions indicates positive effects for BRSAT (initial brine saturation of waste), SALPERM (Salado halite permeability) and GRCORI (gasgeneration rate for corrosion of steel under inundated conditions) and a negative effect for GRCORH (scale factor used in definition of gasgeneration rate for corrosion of steel under humid conditions). These effects result because increasing BRSAT and SALPERM increases the amount of steel exposed to corrosion under inundated conditions, increasing GRCORI increases the gas-generation rate under inundated conditions, and increasing GRCORH decreases the anount of steel avallable for corrosion under inundated conditions. The scale factor GRCORH is the most important variable and accounts for 40 of the varlability in gas generation due to 
corrosion under inundated conditions. Further, BRSAT, SALPERM and GRCORI collectively account for an additional 278 of the variability.

The varlables (RCORI (gas-generation rate for corrosion of steel under inundated conditions) and GRCORH (scale factor used in definition of gasgeneration rate for corrosion of steel under humid condlions) are used in the product GRCORH-GRCORI to define the gas-generation rate for the corrosion of steel under humid conditions. As a result, GRCORH・GRCORI is a natural candidate variable for inclusion in a stepwise regression analysis for gas production due to corrosion under humid conditions. As shown in Table 2-3, this inclusion results in CRCORH-GRCORI being the first variable selected in a stepwise regression analysis for total gas production over 10,000 yr due to corrosion under humid conditions, with 778 of the variability being accounted for. For comparison, the regression results summarized in Table 2-2 Indicate that GRCORH by itself can account for 70 o of the variability and that GRCORH and GRCORI together can account for $76 \%$ of the variability. As the stepwise regression analysis presented in Table 2-3 continues, GRCORI is picked in the third regression model (1.e., at step 3). However, unllke the results shown in Table 2-2. for gas generation under humid conditions, GRCORI now has a negative rather than a positive regression coefficient; also, the regression coefficient for

Table 2-3. Stepwise Regression Models with Rank-Transformed Data for Cumulative Gas Production over 10,000 yr Due to Corrosion under Humid Conditions. Four regression models were constructed; standardized regression coefflcients and $R^{2}$ values are given for each of these models.

$\begin{array}{lcccc}\text { Variablea } & \begin{array}{c}\text { Model 1: } \\ \text { SRCb }\end{array} & \begin{array}{c}\text { Model 2: } \\ \text { SRC }\end{array} & \begin{array}{c}\text { Model 3: } \\ \text { SRC }\end{array} & \begin{array}{c}\text { Model 4: } \\ \text { SRC }\end{array} \\ \text { GRCORH.GRCORI } & 0.87 & 0.89 & 1.02 & 1.01 \\ \text { SALPERM } & -. & -0.25 & -0.25 & -0.25 \\ \text { GRCORI } & -. & -. & -0.23 & -0.23 \\ \text { BRSAT } & -. & -. & -. & -0.14 \\ \text { R }^{2} \text { Value } & 0.77 & 0.83 & 0.86 & 0.88\end{array}$

a Variables selected in regression models.

bStandardized regression coefficlents for variables in model. Model i designates the ith model constructed in the stepwise regression analysis for $i=1,2,3,4$ (l.e., the model constructed at step i). $c_{R}^{2}$ value for regression model. 
GRCORH -GRCORI Jumps from 0.89 to 1.02. This behavior results from the fact that GRCORH.GRCORI and GRCORI are correlated and hence are being, played-off against each other in the regression analysis obtained at the third step of the stepwise regression analysis presented in Table 2-3. The final rugression models presented in Tables $2-2$ and $2-3$ involve the same underlying variables (1.e., GRCORH, GRCORI, SALPERM, BRSAT) and can account for 838 and 888 , respectively, of the gas production under humid conditions. Thus, inclusion of GRCORH•GRCORI in the analysis results in a regression model that can account for somewhat more of the variability in gas production; at the same time, the interpretation of the analysis is inade more difficult by the resultant instability in the regression coefflclents for GRCORH.GRCORI and GRCORI (i.e., the regression coefficlent for each variable depends on whether or not the other variable is in the regression mode1).

\subsubsection{Gas Generation Due to Microbial Degradation}

A sumnary of the analysis results for gas generation due to microbial degradation is given in Figure 2-5. The upper two frames in figure 2-5 show cumulative gas generation due to microblal degradation under humid and inundated conditions, respectively. As comparison with the corresponding plots in Figure 2.4 shows, gas generation due to microbial degradation is approximately $50 z$ or less of the gas generation due to corrosion. The range of cumulative gas generation shown in Figure 2.5 is slightly larger for inundated than for humid conditions.

The lower two frames in figure $2-5$ present sensitivity analysis results based on partial rank correlation coefficients as in Figure 2-4. For cumulative gas production under humid conditions, increasing each of STOICMIC (stoichiometric coefficient for microbial degradation of cellulosics), GRMICH (scale factor used in definition of gas-generation rate due to microbial degradation of cellulosics under hunid conditions) and GRMICI (gas-generation rate due to microbial degradation of cellulosics under inundated conditions) increases gas production and increasing BRSAT (initial brine saturation) decreases gas production. Increasing STOICMIC increases the amount of gas produced per unit of cellulose consumed while increasing GRMICH and GRMICI increases the rate GRMIC.GRMIC of inicrobial degradation. Increasing BRSAT decreases the amount of gas produced under humid conditions by increasing the anount of cellulosics that will be consumed under inundated conditions. The importance of GRMICI decreases over time as the inventory is depleted. For cumulative gas production under inundated conditions, increasing each of STOICMIC, BRSAT, GRMICI and SALPERM (Salado halite permeability) increases gas production. The positive effects for BRSAT and SALPERM result from increasing the amount of cellulosics that will be consuned under inundated conditions. 
Cumulative Gas Production Due to Microbial Degradation of Cellulosics
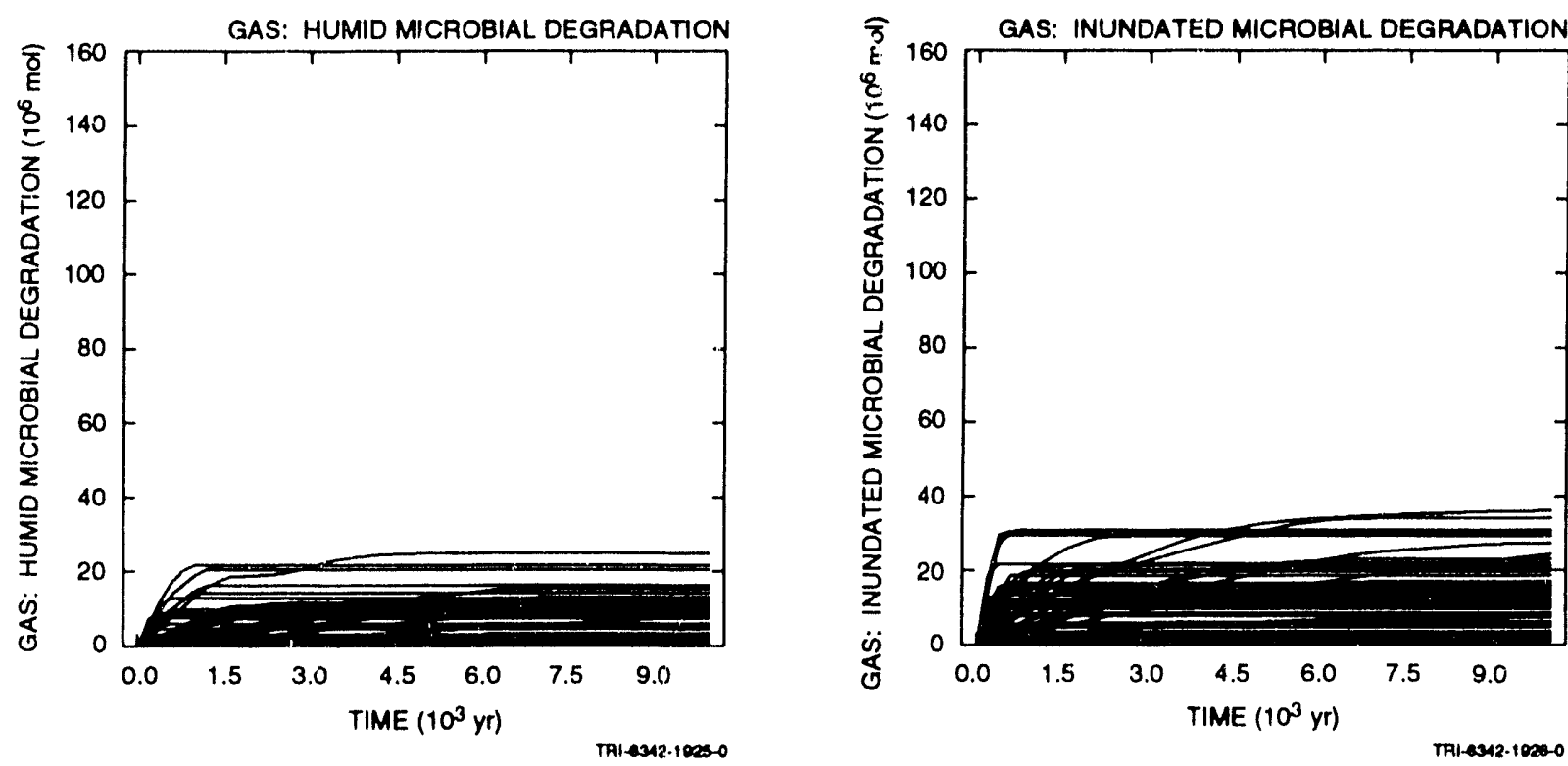

TRI-

Partial Rank Correlation Cnefficients for Cumulative Gas Production Due to Microbial Degradation of Cellulosics
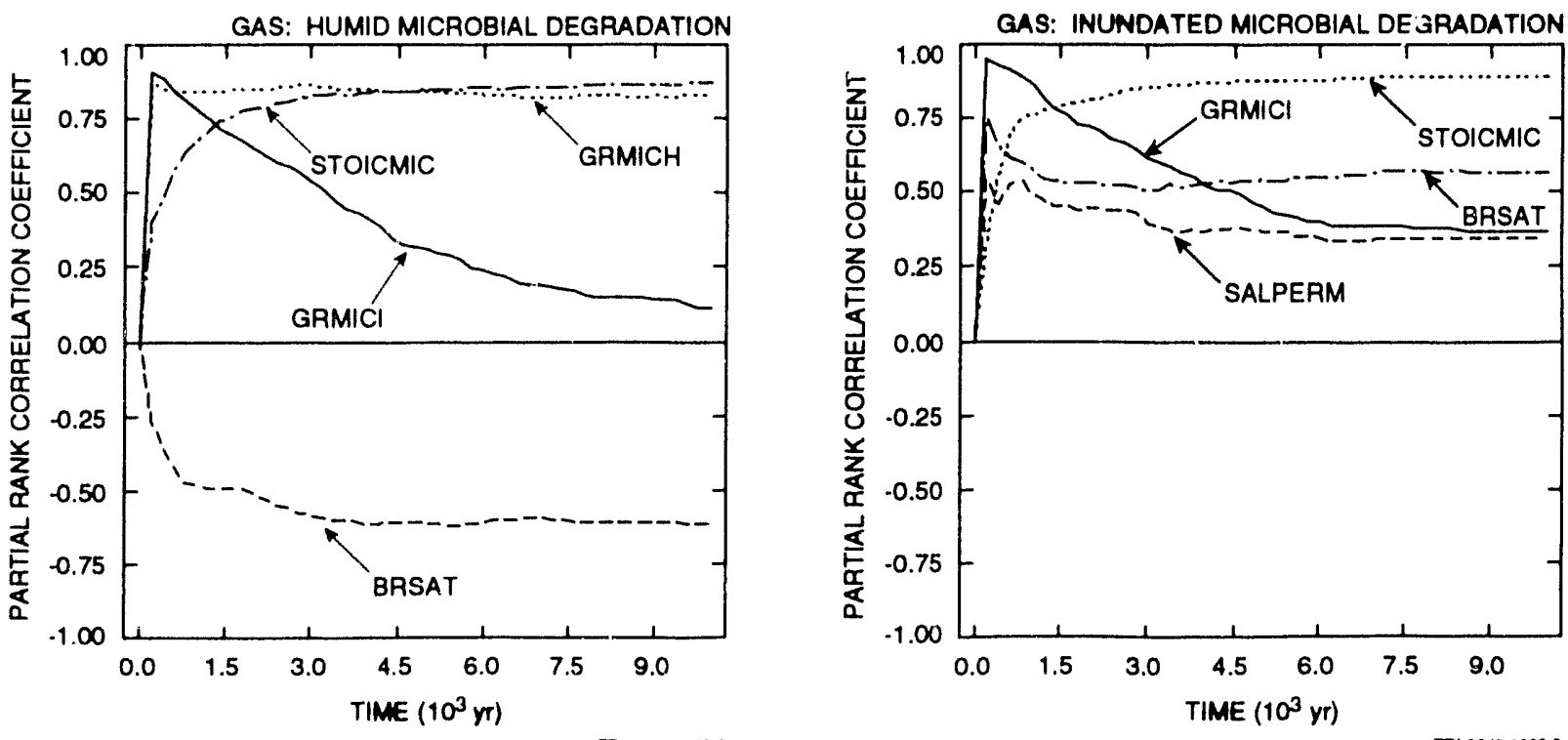

Figure 2-5. Uncertainty and sensitivity analysis results for gas generation due to microbial degradation of cellulosics under humid and inundated conditions . 
The two regression analyses in Table 2-4 are for cumulative gas production over 10,000 yr due to microbial degrada ion under humid and inundated conditions, respectively. Thus, these tw regression analyses are for the gas-production values appearing above $10,000 \mathrm{yr}$ in the two upper frames of Figure 2-5. For gas production under humid conditions, the variables STOICMIC (stoichiometric coefficient for microbial degradation of cellulosics), GRMICH (scale factor used in definition of gas-generation rate due to microbial degradation of cellulosics under humid conditions) and BRSAT (initial brine saturation) can account for 818 of the observed variability in gas production, with gas production tending to increase with increasing values for STOICMIC and GRMICH and tending to decrease with increasing values for BRSAT. For gas production under inundated conditions, the variables STOICMIC and BRSAT can account for 718 of the observed variability in gas production, with gas production tending to increase as earh of these variables increases. When the three additional variables SALPERM (Salado halite permeability), GRMICI and VWDOD (fraction of total waste volume that is occupied by IDB combustible waste category) are added to the regression model, 81 of the variability in gas production can be accounted for, with gas production again tending to increase as each of these variables increases. The positive effects for SALPERM and VWOOD result because increasing SALPERM increases the amount of brine flowing into a waste panel and thus increases the amount of gas generation that will take place under inundated conditions and increasing VWOOD increases the amount of cellulosics available for microbial degradation.

\subsubsection{Totai Gas Production}

The upper two frames in Figure 2-6 show total gas production due to corrosion and microbial degradation and were obtained by combining the corresponding results in Figures $2-4$ and 2-5 for gas production under humid and inundated conditions. Typically, low gas production under humid conditions is associated with higher gas production under inundated conditions and vice versa. As a result, the gas-production curves in Figure 2-6 tend to lie farther above the abscissa than many of the individual curves in Figures $2-4$ and $2-5$. Overall, the gas production due to corrosion tends to be at least twice the gas production due to microbial degradation. Gas production due to microbial degradation has more curves close to zero than gas production due to corrosion because STOICMIC (stoichiometric coefficient for microbial degradation of cellulosics) was assigned a range of possible values that extends to zero, which results in no gas generation due to microbial degradation.

The lower two frames in Figure 2-6 present sensitivity analys is results based on partial rank correlation coefficients as in Figure 2-4. For cumulative gas production due to corrosion, increasing each of GRCORI 
Table 2-4. Stepwise Regression Analyses with Rank-Transformed Data for Cumulative Gas Production over 10,000 yr Due to Microbial Degradation under Humid and Inundated Conditions.

Total Gas Production over $10,000 \mathrm{yr}$ (Humid Degradation)

\begin{tabular}{clrr}
\hline Stepa $^{\mathrm{a}}$ & Variable $^{\mathrm{b}}$ & SRCC & $\mathrm{R}^{2 \mathrm{~d}}$ \\
& & & \\
1 & STOICMIC & 0.66 & 0.43 \\
2 & GRMICH & 0.55 & 0.73 \\
3 & BRSAT & -0.29 & 0.81
\end{tabular}

Total Gas Production over $10,000 \mathrm{yr}$ (Inundated Degradation)

\begin{tabular}{clll}
\hline Step & Variable & SRCC & R $^{2 d}$ \\
& & & \\
1 & STOICMIC & 0.79 & 0.65 \\
2 & BRSAT & 0.27 & 0.71 \\
3 & SALPERM & 0.22 & 0.76 \\
4 & GRMICI & 0.16 & 0.79 \\
5 & VWOOD & 0.15 & 0.81
\end{tabular}

a Steps in stepwise regression analysis

b Variables listed in order of selection in regression analysis

c Standardized regression coefficlents in final regression model

d Cumulative $R^{2}$ value with entry of each variable into regression model

(gas-generation rate for corrosion of steel under inundated conditions), GRCORH (scale factor used in definition of gas-generation rate for corrosion of steel under humid conditions) and BRSAT (initial brine saturation) tends to increase gas production and increasing STOICCOR (stoichiometric factor for corrosion of steel) tends to decrease gas production. Increasing GRCORI, GRCORH and BRSAT tends to increase the rate of gas production and hence cumulative gas production, with this effect becoming less important at later times due to exhaustion of either steel or brine in the waste panel. The negative effect for STOICCOR results because increasing STOICCOR increases the proportion of low-gas-producing reactions in the corrosion process. For cumulative gas production due to microbial degradation, GRMICI (gas-generation rate due to microbial degradation of cellulosics under inundated conditions) and BRSAT (initial brine saturation) have positive effects at early times and then decrease in importance. In contrast, STOICMIC (stoichiometric coefficient for microbial degradation of cellulosics) has an increasingly important positive effect with time and ultimately dominates the variability in cumulative gas production.

The two regression analyses in Table 2-5 are for cumulative gas production over $10,000 \mathrm{yr}$ due to corrosion and microbial degradation, respectively. Thus, these two regression analyses are for the gas production values appearing above $10,000 \mathrm{yr}$ in the two upper frames of Figure 2-6. The regression analysis for gas production due to corrosion selected the variables STOICCOR (stoichiometric factor for corrosion of 

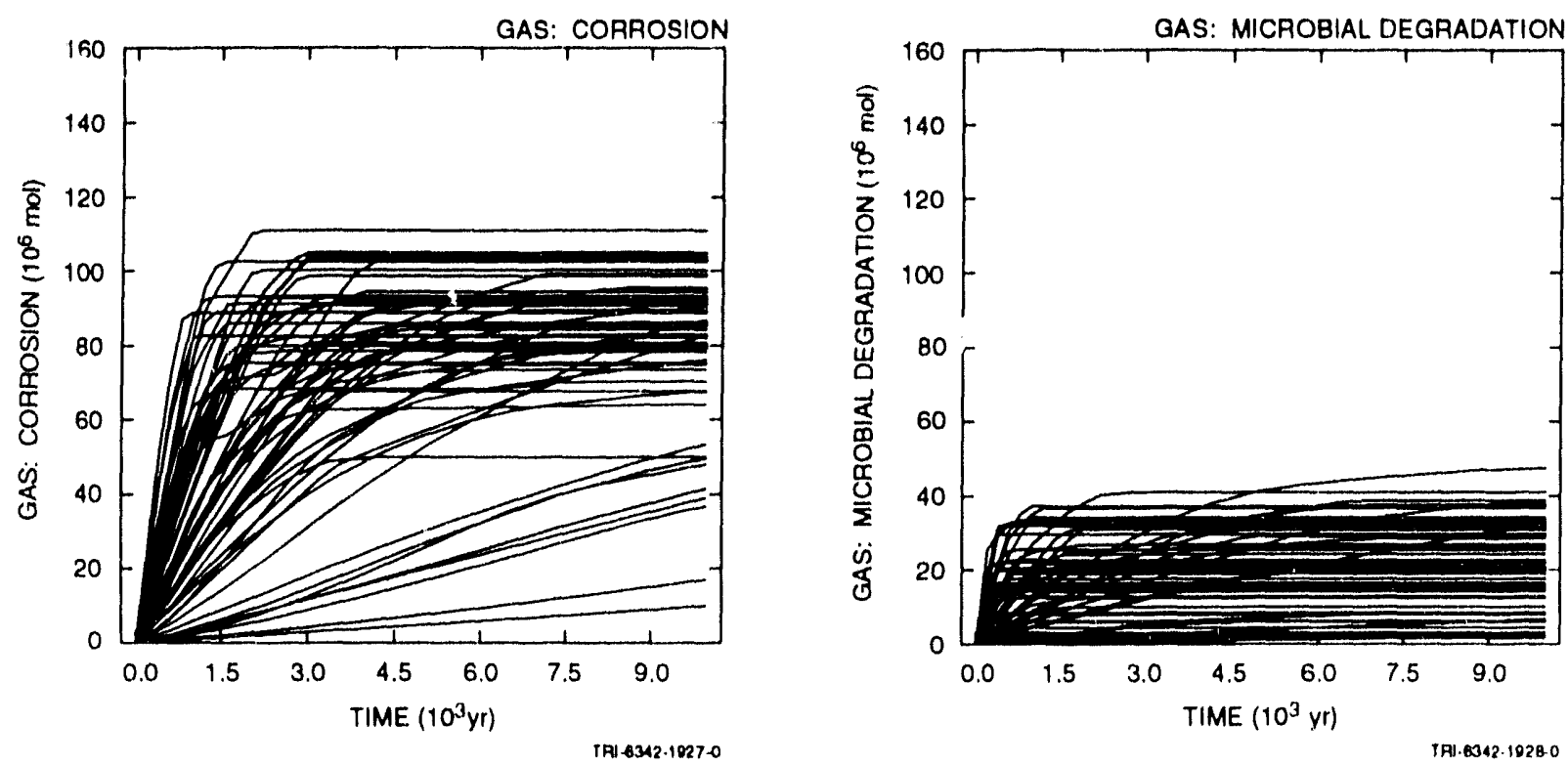

Partial Rank Correlation Coefficients for Cumulative Gas Production
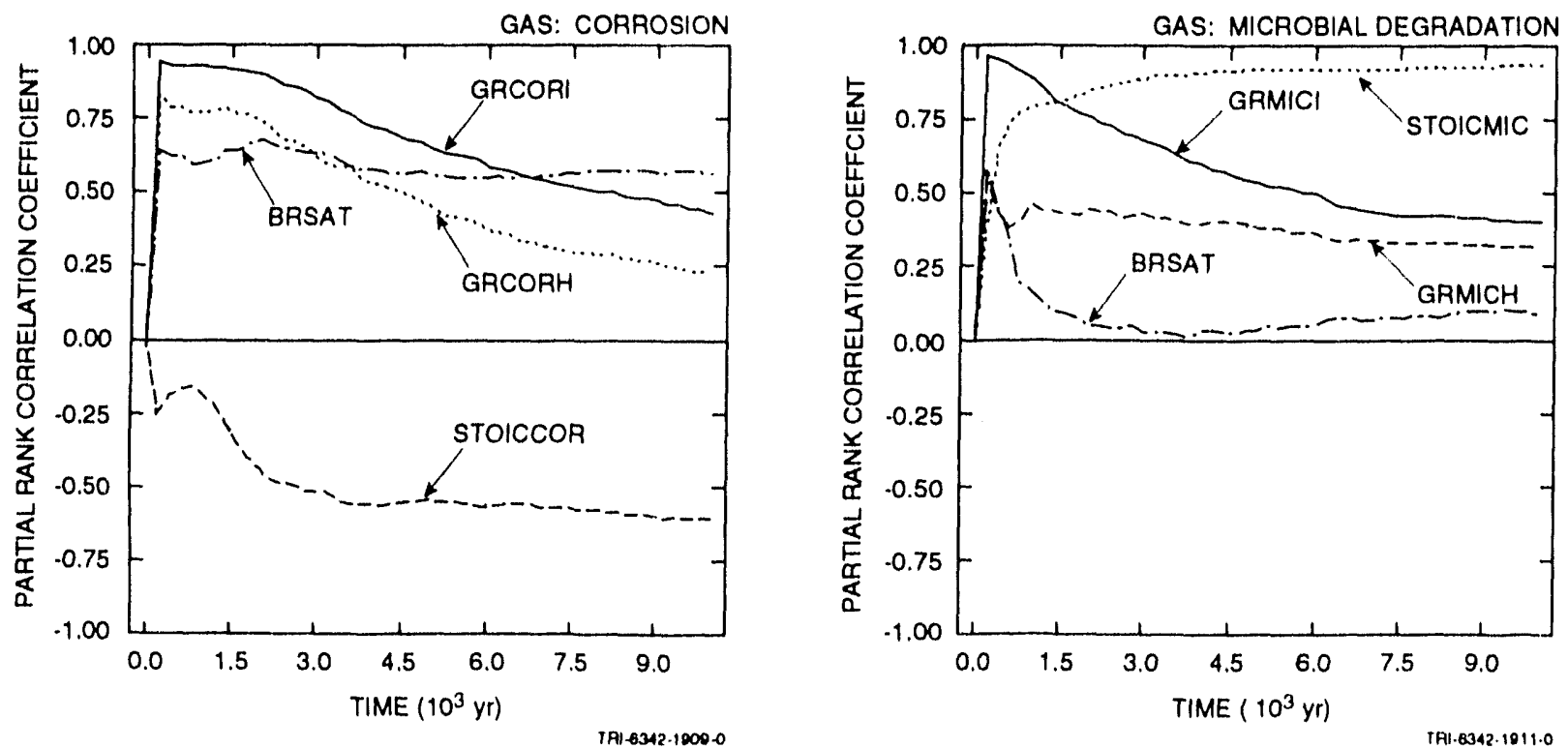

Figure 2-6. Uncertainty and sensitivity analysis results for gas generation due to corrosion of steel and microbial degradation of cellulosics. 
Table 2-5. Stepwise Regression Analysis with Rank-Transformed Data for Total Gas Production Due to Corrosion and Total Gas Generation Due to Microbial Degradation.

\begin{tabular}{clrl} 
Total Gas Production over & $\begin{array}{c}\text { 10,000 yr } \\
\text { (Corrosion) }\end{array}$ & & \\
\hline Stepa & Varlableb & SRCC & $\mathrm{R}^{2 \mathrm{~d}}$ \\
& & & \\
1 & STOICCOR & -0.48 & 0.21 \\
2 & BRSAT & 0.43 & 0.38 \\
3 & GRCORI & 0.31 & 0.48 \\
4 & VMETAL & 0.24 & 0.53 \\
5 & MBPRES & 0.21 & 0.58
\end{tabular}

Total Gas Production over 10,000 yr (Microblal Degradation)

\begin{tabular}{clll}
\hline Stepa & Variableb & SRCC & R2d $^{2 d}$ \\
& STOICMIC & 0.89 & 0.79 \\
2 & VWOOD & 0.17 & 0.82 \\
3 & GRMICI & 0.14 & 0.84
\end{tabular}

\section{a Steps in stepwise regression analysis \\ b Varlables listed in order of selection in regression analysis \\ c Standardized regression coefficients in final regression model \\ d Cumulative $R^{2}$ value with entry of each variable into regresslon model}

sted), BRSAT (initial brine saturation), GRCOR] (gas-generation rate for corrosion of steel under intudated conditlonss), VMETAL, (fraction of total waste volume that is occupied by IDB metals and glass waste category) and MBPRES (pressure in Marker Bed 139 under und sturbed conditions), with STOlCCOR having a negative effoce on gas production and BRSA'T, CRCORI, VMETAL and MBRPlis having positive effects on gas production. However, the resolution in the regression model is low, with all five vartables account ing for only 38 of the variability in gass production due to corrosion. This low resolution probably results from notse introduced into the analysis by samplo elements in which the corrosion process stops in individual computational calls before 10,000 yr due to the depletion of brine.

To provide additional insight, Figure 2.7 presents selected scatterplots displaying the relationships between individual sampled variables and total gas production over 10,000 yr due to corrosion. As exallination of the upper two frames shows, gas production tends to decrease as STOICCOR (stoichiometric factor for corrosion of steel) increases and tends to increase as BRSAT (initial brine saturation) increases. However, there is a large amount of variability around these trends. These patterns are consistent with the signs of the regression coefficients and low $R^{2}$. values in Table 2-5. Tho scatterplots for STOICCOR and BRSAT are particularly diffuse due to the almost random appearance of gas-production values of less than $6 \times 10^{7} \mathrm{~m}^{3}$ over their ranges. As examination of the scatterplot for GRCORl (gas-generation rate for corrosion of steel under inundated conditions) in the lower left frame of figure $2-7$ shows, these 
small gas production values tend to be assoclated with small values of GRCORI. Total gas production increases almost linearly with GRCORI unt 1 a value of $2 \times 10^{-9} \mathrm{~mol} / \mathrm{m}^{2} \mathrm{~s}$ is reached, after which there appears to be no relationship between GRCORI and total gas production. The scatterplot for SALPERM (Salado halite permeability) in the lower right frame of Figure 2.7 shows an interesting pattern, with there belng wide variablitity in the total gas production associated with values of SALPERM less than $1.5 \mathrm{x}$ 10-20 $\mathrm{m}^{2}$ and a substantially reduced amount of variability for values of SALPERM greater than $1.5 \times 10^{-20} \mathrm{~m}^{2}$. The superposition of the effects of GRCORI and SALPERM on the effects of STOICCOR and BRSAT results in a pattern of relationships that cannot be easlly captured by a simple regression model.

The regression analysis in Table 2.5 for gas production due to Inicrobial degradation is considerably more successful in accounting for the observed variability in gas production than is the corresponding regression analysis for gas production due to corrosion. In particular, stolcmic (stoichiometric coefficient for microbial degradation of cellulosics) was found to account for 798 of the observed variability and small additional effects were indicated for VWOOD (fraction of total waste volume occupied by IDB combustible waste category) and GRMICl (gas-generation rate due to microbial degradation of cellulosics under inundated conditions). The regression model with STOICMIC, VWOOD and CiRMICI was able to account for 848 of the variability in gas production due to microbial degradation of cellulosics.

The cumblative gas production due to corrosion and to microbial degradation can be combined to produce total gas production, as shown in the upper frame of Figure 2-8. Most samplo elements result in a total gas production over 10,000 ye between $5 \times 10^{7}$ mol and $1.2 \times 10^{8}$ mol. Also, most sample elements show a period of rapid gas production in the first few thousand years, with considerably reduced rates of gas production at later times. As exanination of the two upper frames in figure $2-9$ shows, the inventory of steel and cellulosies is often exhausted or significantly depleted after the first few thousand years.

The lower frame in Figure $2-8$ presents sensitivity analysis results based on partial rank correlation coefficients. At early times, total gas production is dominated by GRCORI (gas-generation rate for corrosion of steel under inundated conditions), CRCORH (scale factor used in definition of gas-generation rate for corrosion of steel under humid conditions), GRMICI (gas-generation rate for microbial degradation of cellulusics under 

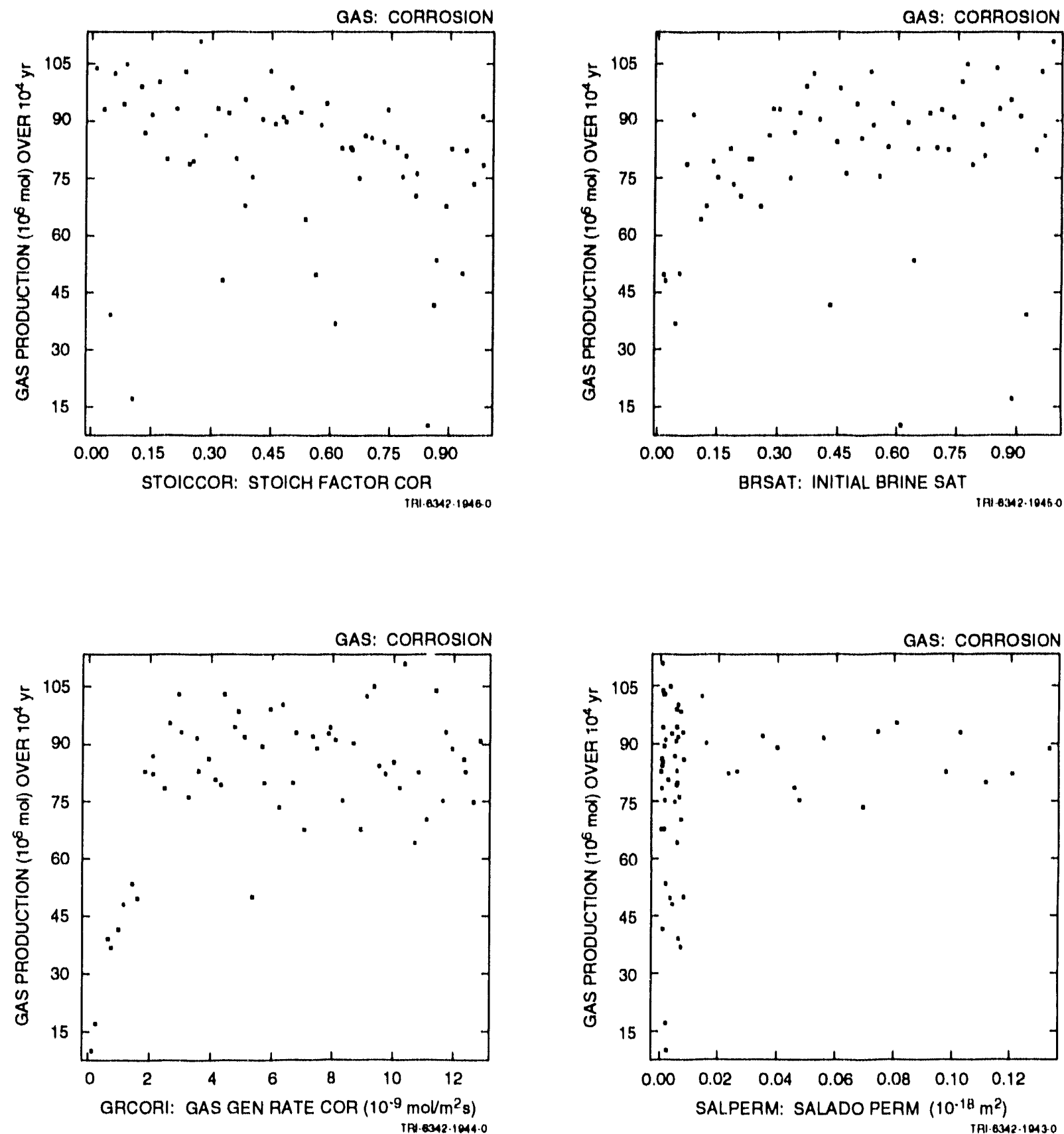

Figure 2-7. Scatterplots relating cumulative gas production over 10,000 yr due to corrosion to STOICCOR (stoichiometric factor for corrosion of steel), BRSAT (initial brine saturation), GRCORI (gas generation rate due to corrosion of steel under inundated conditions) and SALPERM (Salado halite permeability). 
Cumulative Gas Production

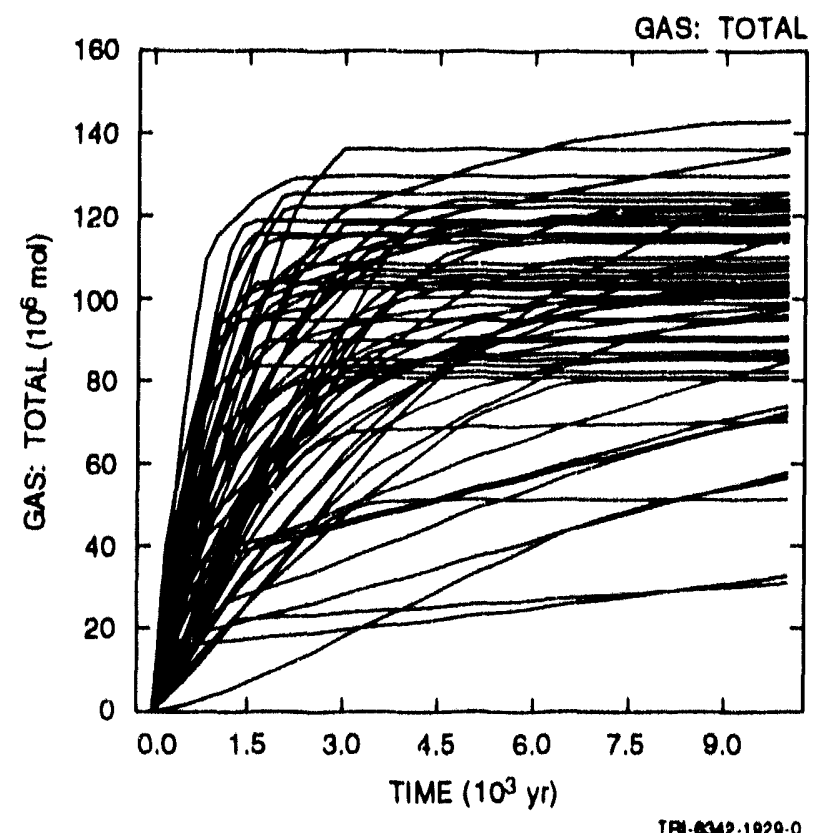

Partial Rank Correlation Coefficients for Cumulative Gas Production

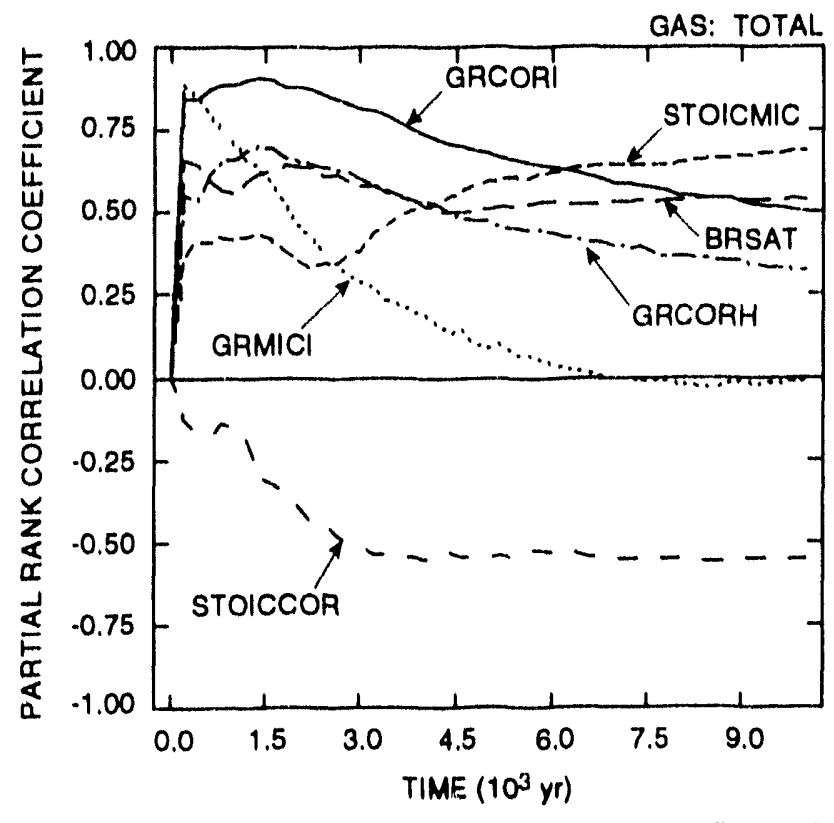

[म1 674219120

Figure 2-8. Uncertainty and sensitivity analysis results for total gas production (i.e., both corrosion of steel and microbial. degradation of cellulosics). 
Steel and Cellulostc Inventorles
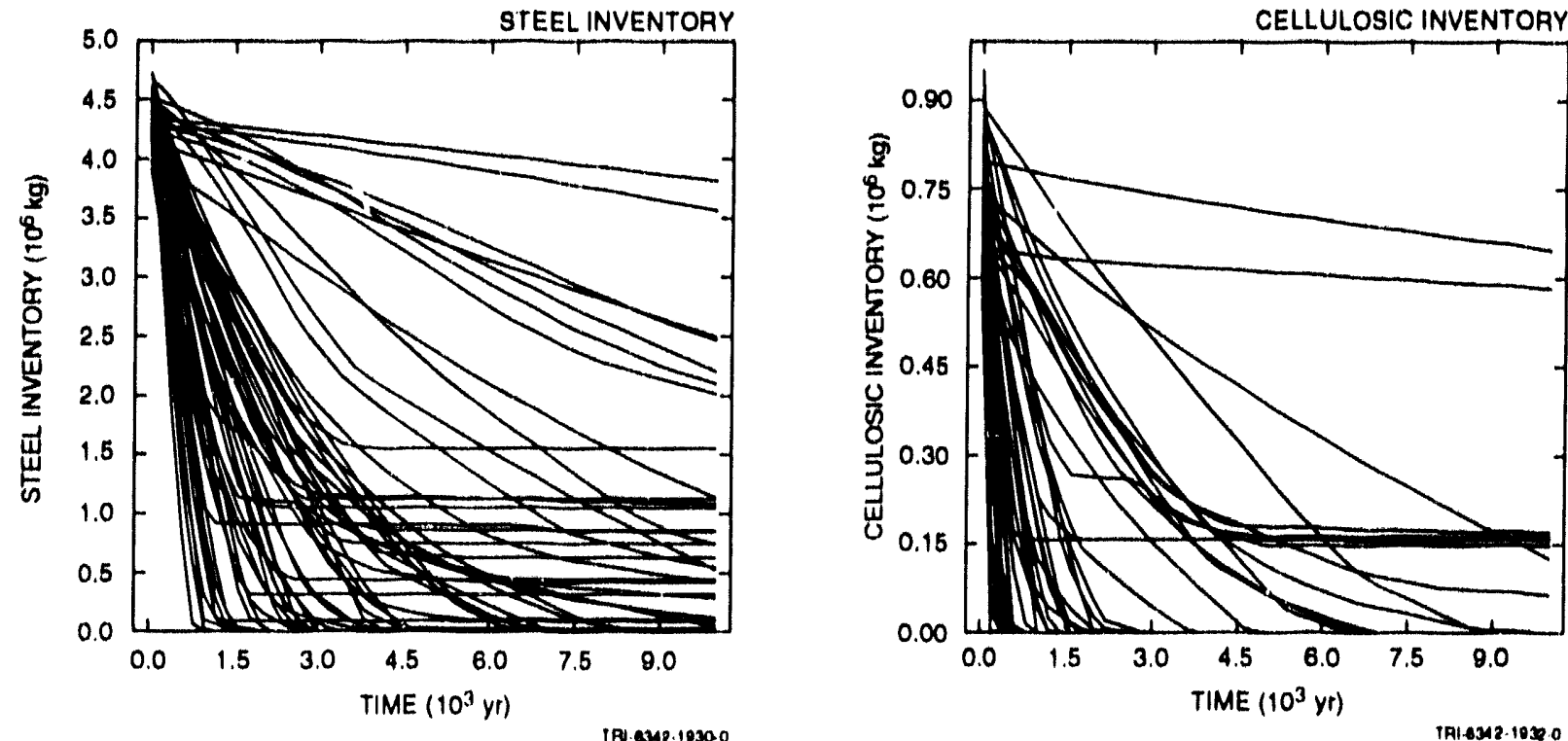

Partial Rank Correlation Coefflcients for Steel and Cellulosic Inventories
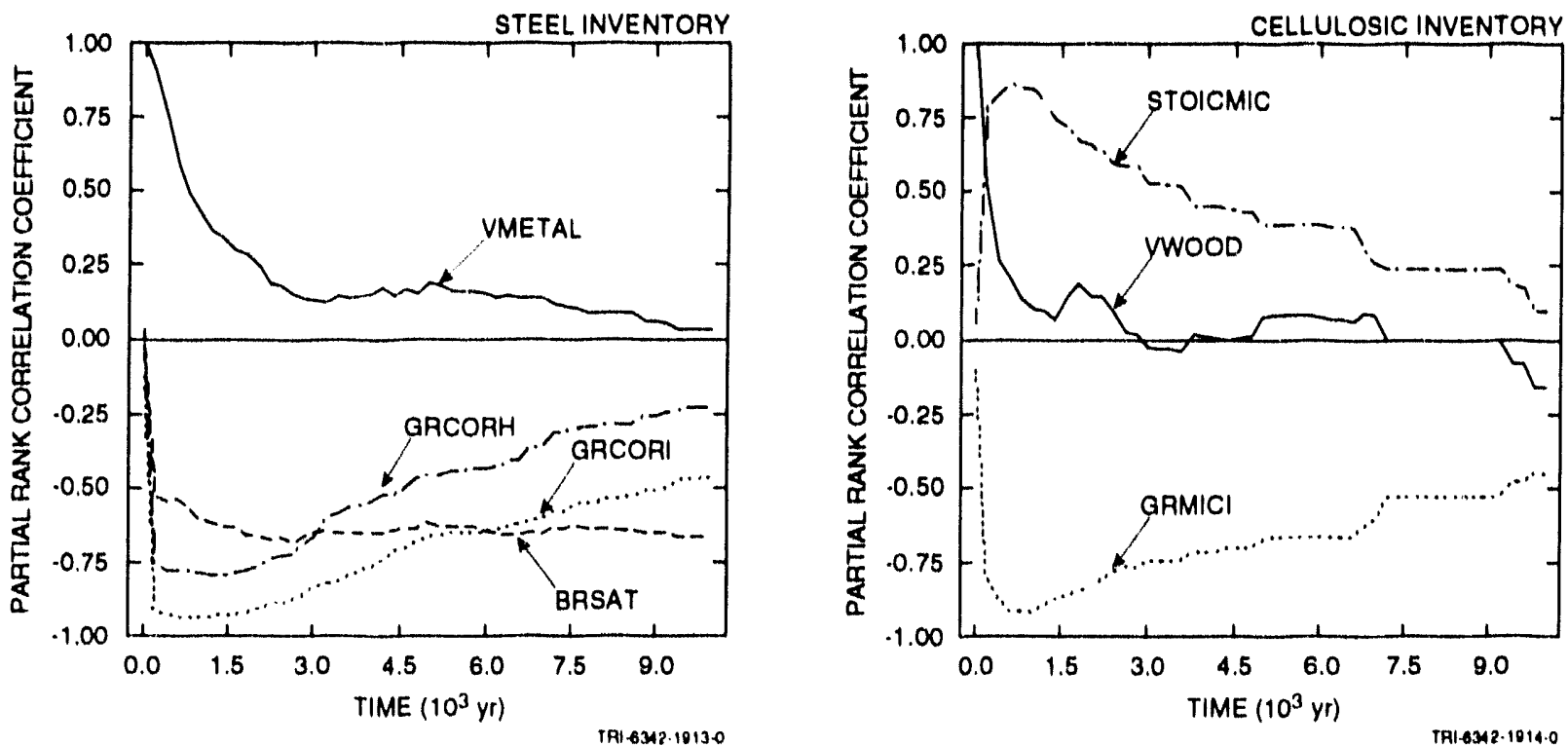

Figure 2.9. Uncertalnty and sensitivity analysis results for steel and cellulosic inventories in waste panel. 
Inundated conditions) and BRSAT (initial brine saturation), with total gas generation tending to increase as each of these variables increases. As time Increases, GRMICI, GRCORH and GRCORI become less lmportant. In contrast, STOICMIC (stolchlometric coefficlent for inicroblal degradation of collulosics) and STOICCOR (stolchiometric factor for corrosion of steel) are unimportant at early times but are the domlnant variables influencing gas production at later times, with gas production tending to increase as STOICMIC increases and tending, to decrease as STOICCOR increases.

The regression analysis in Table 2.6 is for cumulative gas production over $10,000 \mathrm{yr}$ due to both corrosion and microblal degradation. The first. varlable selected in the analysis is STOICMIC (stolchlometric coefficlent for microblal degradation of cellulosics), which has a positive regression coefficlent and can account for 278 of the varlabllity in total gas production. The indicated effect for STolCMIC is conslstent with its dominant influence on gas generation due to inferoblal degradation as Indicated in Flgure 2.6 and Table 2.5. The next varlable selected in the regression analysis is STOICCOR (stolchlometrle factor for corrosion of steel), with gas production toncing to decrease as STOlcor increases. The selection of STOICMIC and STOICCOR as the flrst two varlables in the stepwlse regression analysis is consistent with the effects indicated for then in the partial correlation analysis In Figure 2-8 for total gas production. After STOICMIC and STOICCOR, the regression analysis selects GRCORI (gas-generation rate for corrosion of steel under inundated conditions) and BRSAT (Initial brine saturation). The positive regression coefflcients for GRCORI and BRSAT and the negative regression coefficient for STOICCOR are consistent with the effocts of these varlables on gas generation due to corrosion already seen In Figures 2-6 and 2-7 and Table 2.2. Collectively, STOICMlC, S'TOICCOR, BRSAl and GRCORI can account for 598 of the varlability in total gas production over 10,000 yr. As shown by the scatterplots in Flgure 2-10, no single varlable identifled in the regression analysis in Table 2-6 (1.e., STOICMIC, STOLCCOR, BRSAT and GRCORI) plays a dominant role in the determination of cumulative gas production over $10,000 \mathrm{yr}$ due to both corrosion and mlcroblal degradation.

As previously indicated, the upper two frames in Figure 2.9 show the time-dependent steel and cellulosic inventorles assoclated with the individual sample elements. The lower two frames present sensitivity analyses based on partial rank correlation coefficlents. The steel inventory is initially dominated by VMLTAL (fraction of total waste volume occupled by IDB inetals and glass category), with the lmportance of this varlable decreasing with time. The variables GRCORI (gas-generation rate for corrosion of steel under Inundated conditions), GRCORH (scale factor 

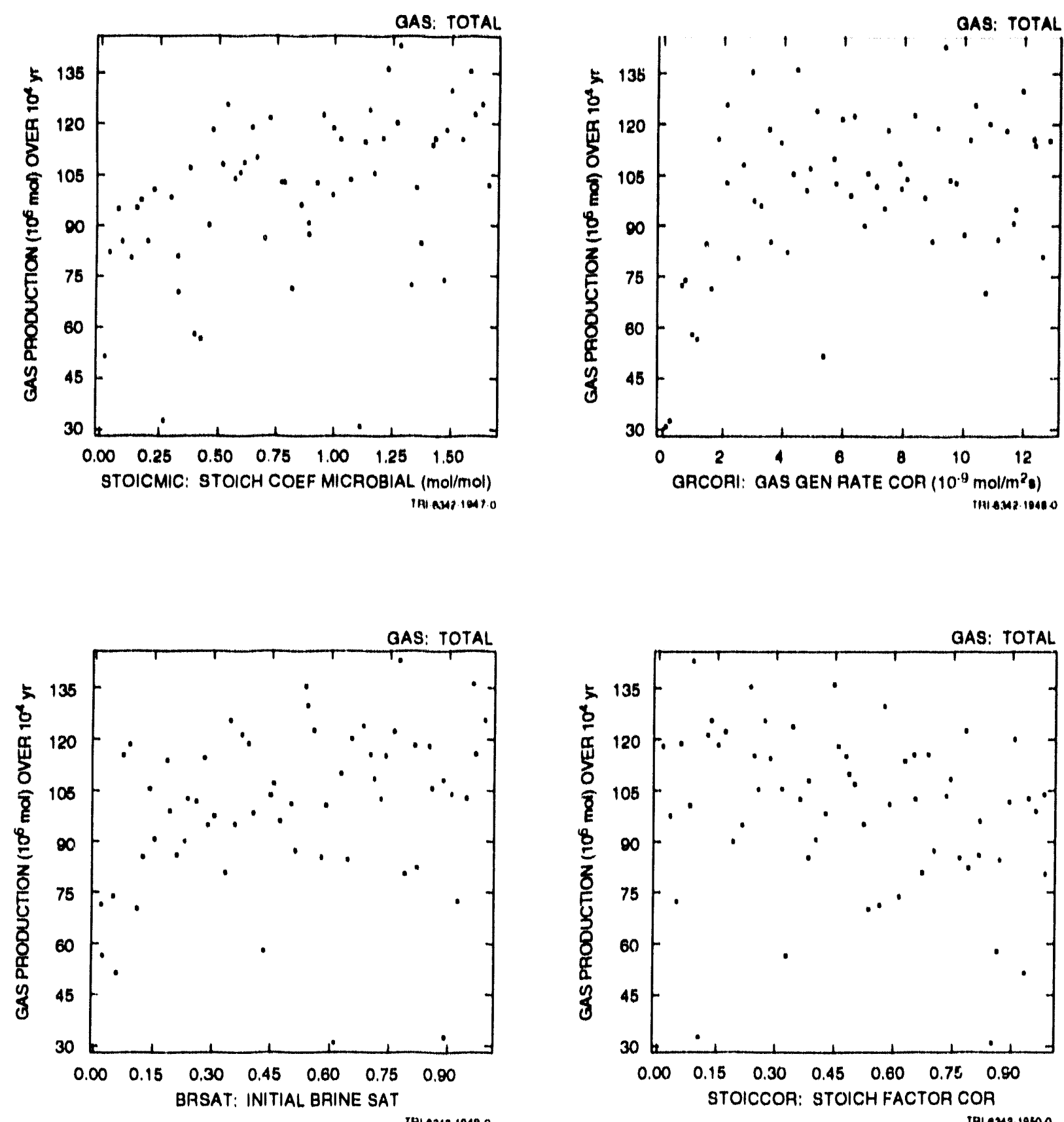

Figure 2-10. Scatterplots relating cumulative gas production over 10,000 yr due to both corrosion and intcroblal degradation to STOICMIC (stolchlometric coefficlent for microbial degradation of cellulosics), GRCORI (gas-generation rate due to corrosion of steel under inundated conditions), BRSAT (Initlal brine saturation) and STOICCOR (stoichlometric factor for corrosion of steel). 
Table 2-6. Stepwise Regression Analysis with Rank-Transtormed Data for Total Gas Production Over 10,000 yr Due to Both Corrosion and Microbial Degradation.

Total Gas Production over 10,000 yr

(Corrosion and Blodegradation)

\begin{tabular}{clrr}
\hline Step $^{a}$ & Variableb & SRCC & $R^{2 d}$ \\
& & & \\
1 & STOICMIC & 0.51 & 0.27 \\
2 & STOICCOR & -0.35 & 0.38 \\
3 & BRSAT & 0.34 & 0.49 \\
4 & GRCORI & 0.33 & 0.59
\end{tabular}

\footnotetext{
a Steps in stepwise regression analysis

b Varlables listed in order of selection in regression analysis

c Standardized regression coetticlents in final regresslon model

d Cumulative $R^{2}$ value with entry of each varlable Into regression model
}

used In defluttion of gas-generat fon rate for corrosion of steel under hunfd condlefons) and BRSAT (fult fal brine saturat foll) have negat Ivo effects on the stoel luventory. As wlth VMlitAl, the Importance of ciRCOR

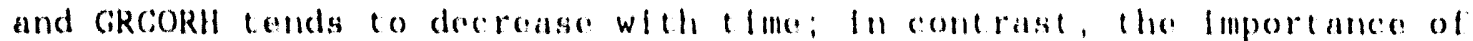

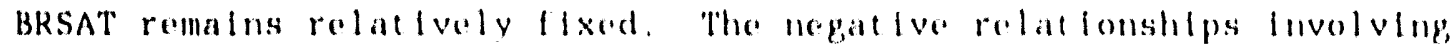
(IRCOR], GRCORH and BRSAT resule from the fr offects in fucrostug the rate

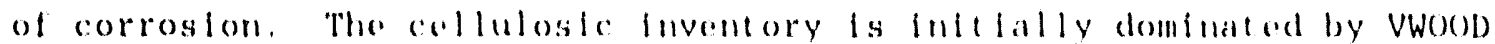
(fraction of total waste volume that is occupiced by lDb combustible waste category), with the importance of thls vartable decreaslug, rapldly whth time. The varlable CRMlcl (gas-generatlon rate due to mlerobtal degradation of cellulosics under fnundated condltons) shows a strong, negative effect on cellulosic Inventory due to los affect in Increasfing the rate at whlch cellulosics are consumed. The positive effect fndicated for Stolcmic (stolchlometrfe cooffictent for microblal degraditfon of cellulostcs) probably results because increased values for STOlcMlc lead to increased rates of gas goneration, whlch fin turn load to humld conditions and thus lower rates of mferoblal degradation of ecllulostess.

\subsubsection{Gas Saturation and Pressure In Waste Panel}

Time-dependent values for average gas saturation in the waste (i.e., averaged over entire waste pancl) and gias pressure in the waste atre presented in the two upper frames of figure?-11. As shown fil the upper left frame, gas saturat ton often decreases in the flest one thousand years and then steadlly focreasos to an asymptote. This hehavfor happens because 

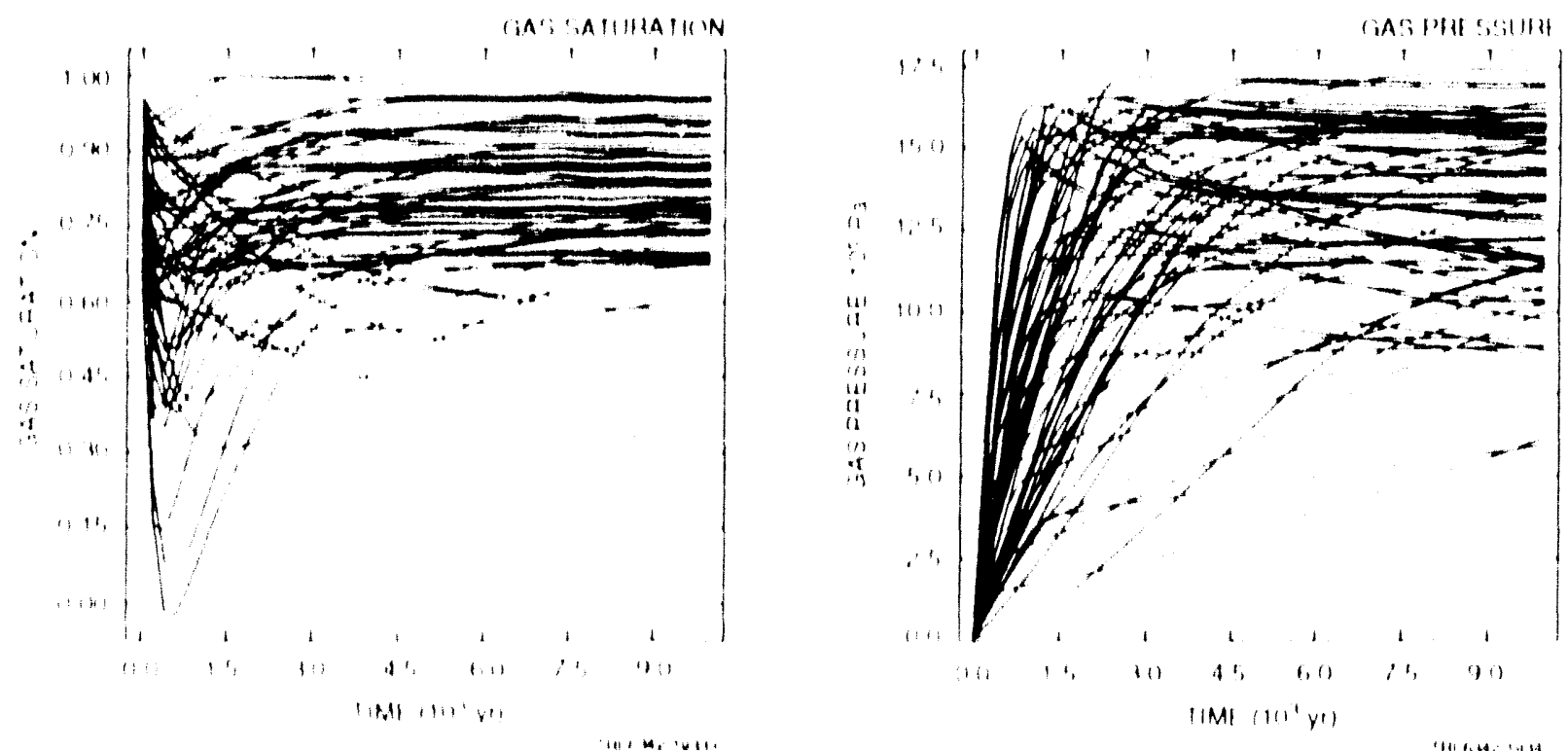

$1,1: 1,1 ! 1,1$

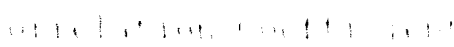

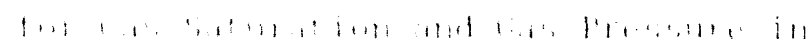
$\therefore, 1,1,1,1$
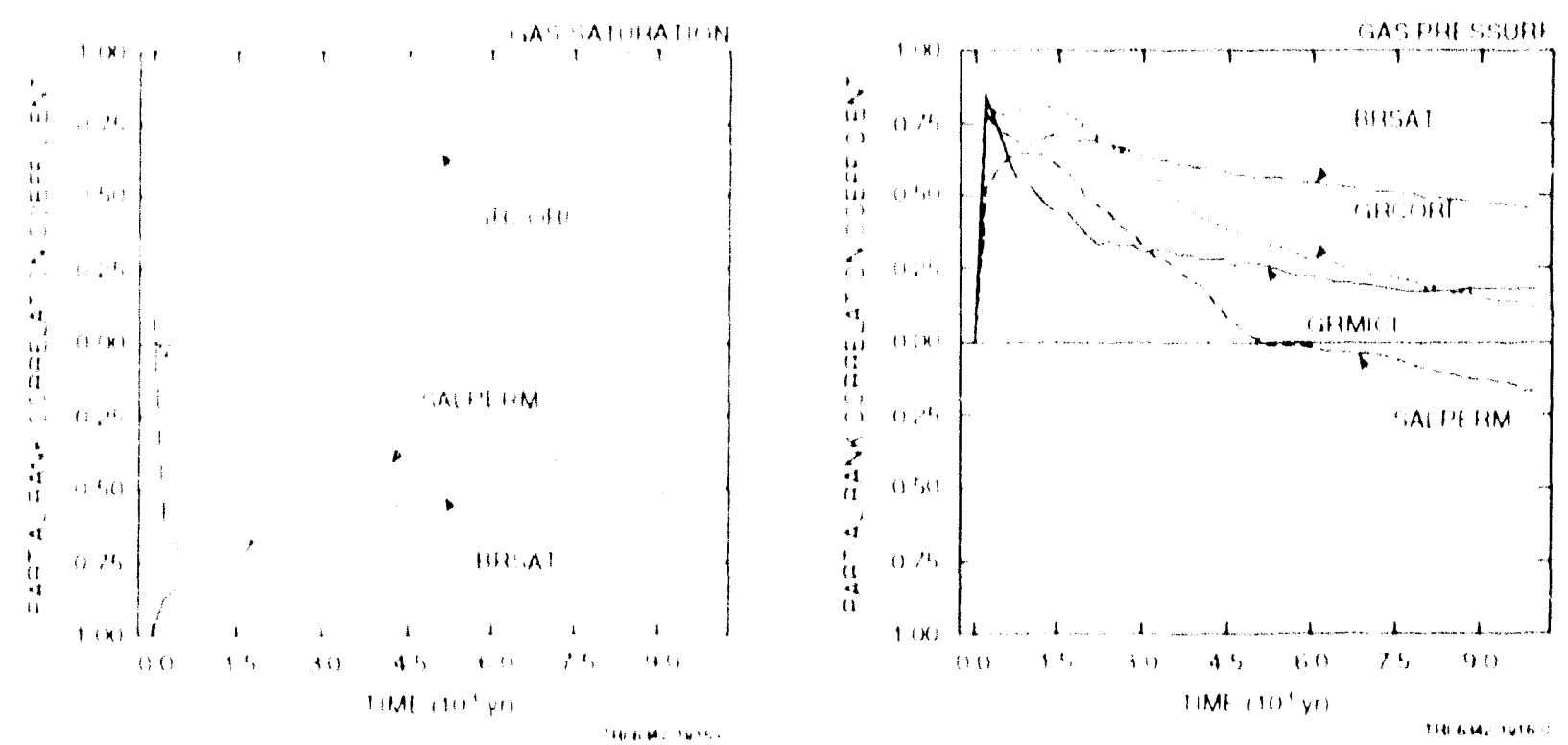

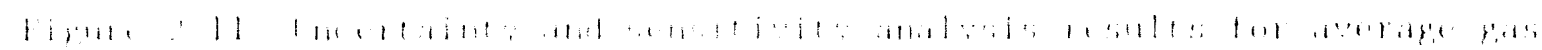

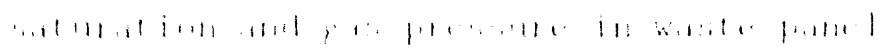


brine inftially flows into the waste panel and reduces the fraction of the pore space occupled by gas; then, as gas pressure increases, brine is forced out of the waste panel and gas saturation increases. This pattern of behavior can be seen in the two upper frames of Flgure 2-12, which show total brine flow into the repository and net brine flow into the repository. In addition, brine is consumed during the corrosion of steel, with most of this consumption taking place during the first 3000 yr (Figure 2-9). As the partial rank correlation coefficlents for gas saturation in the lower left frame of Figure 2-11 show, Increasing GRCORI (gas-generation rate for corrosion of steel under inundated conditions) tends to increase gas saturation and increasing each of BRSAT (initial brine saturation) and SALPERM (Salado halite permeabllity) tends to decrease gas saturation, with these effects resulting because increasing GRCORI increasts the amount of gas in the panel and Increasing each of BRSAT and SALPERM increases the amount of brine in the panel. The dominant effect of BRSAT and SALPERM on net brine flow into the waste panel is indicated by the partial correlation coefficients shown in the lower right frame of Figure 2-12.

As shown in the upper right frame of Figure 2-11, time-dependent gas pressure in the waste panel displays three patterns of behavior: (1) a strictly monotonic increase in pressure, (2) a monotonic increase in pressure until an asymptote is reached, and (3) a monotonic increase in pressure unt 11 a maximum is reached and then a monotonic decrease in pressure. The largest gas pressures are approxlmately 2 MPa above the 1 ithostatic pressure of $14.8 \mathrm{MPa}$. The partial rank correlation coefficients for gas pressure in the lower right frame of Figure 2-11 indicate that GRCOR1 (gas-generation rate for corrosion of steel under inundated conditions), GRMICI (gas-generation rate due to mfcrobial degradation of cellulosics under inundated conditions), BRSAT (initial brine saturation of waste) and SALPERM (Salado halite permeability) have positive effects on gas pressure at early times. However, the importance of these variables decreases with time, and no single varlable appears to have a large effect: on the gas pressure at 10,000 yr. A stepwise regression analysis with rank-transformed data for gas pressure at 10,000 yr selected the variables BRSA'T and MBPRES (pressure in Markor Bed 139 under undisturbed conditions) with an $R^{2}$ value of 0.30 . This poor performance probably results from different variables being important in each of the three patterns of time-dependent gas pressure indicated at the beginning of this paragraph. Examination of scatterplots did not reveal a strong relationship between gas pressure at $10,000 \mathrm{yr}$ and any of the sampled variables.

As previously indicated, the 1991 WIPP preliminary performance assessinent did not directly model closure of the waste panels. However, possible interaction of gas generation and panel closure was incorporated 
Total and Net Brine Inflow to Waste Panel
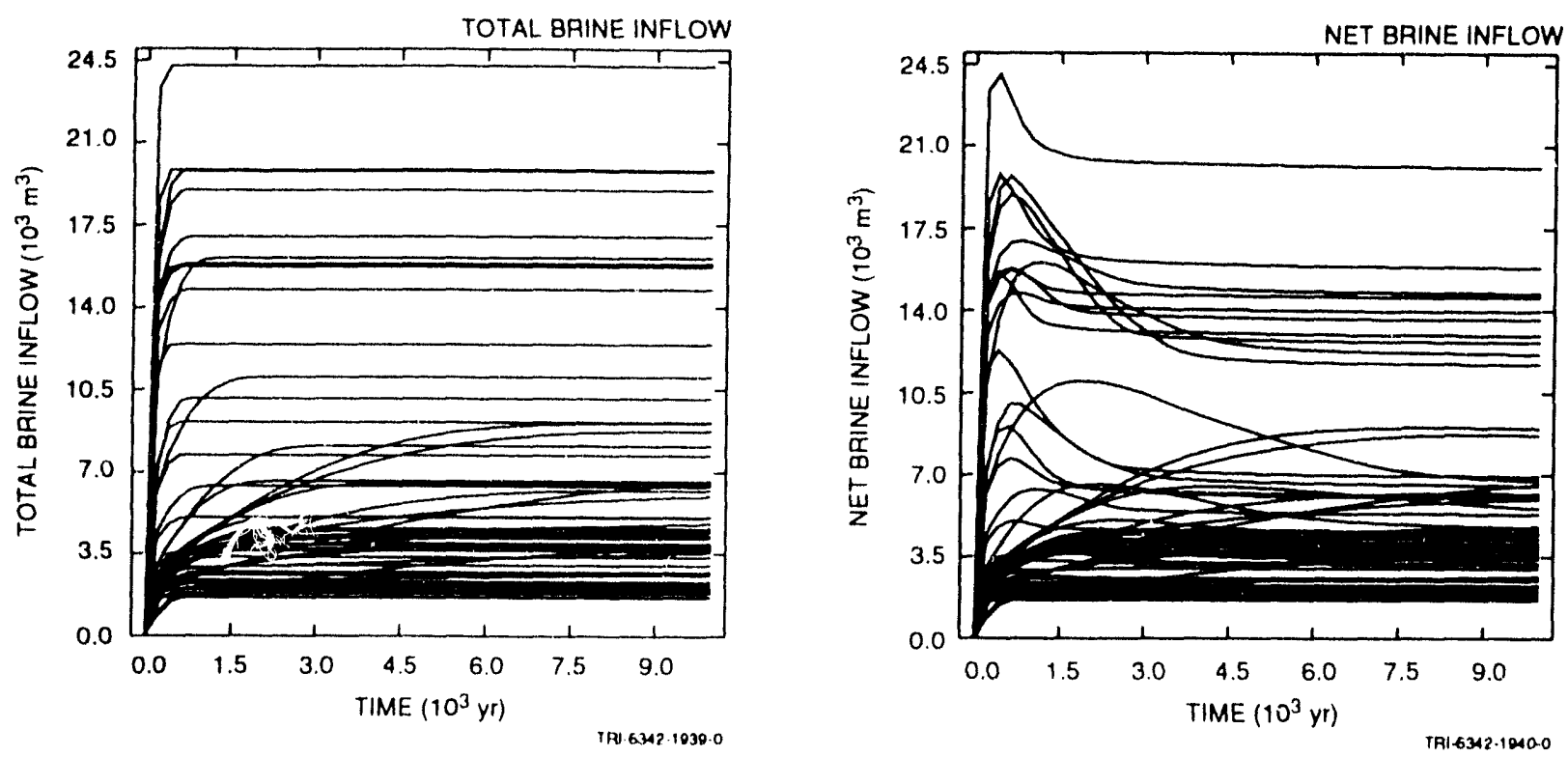

Partial Rank Correlation Coefficients for Total and Net Brine Inflow to Waste Pane 1
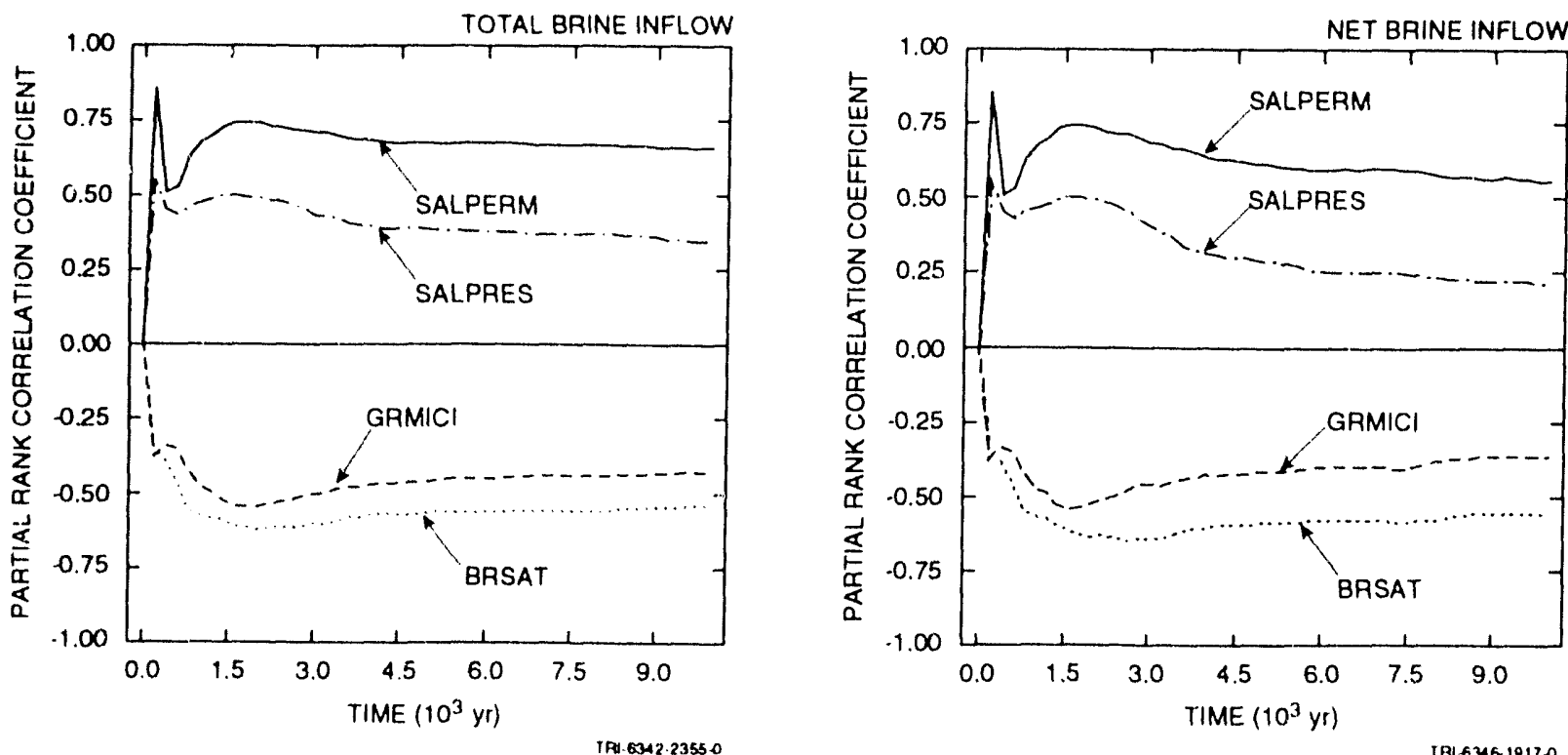

Figure 2-12. Uncertainty and sensitivity analysis results for total and net brine inflow to waste panel. 
into the analysis by setting the initial pore volume in a waste panel to the volume necessaiy to contain all waste-generated gas at lithostatic pressure (i.e., $14.8 \mathrm{MPa}$ ) in a brine-free panel. As a result, initial pore volume is a function of STOICCOR (stoichiometric factor for corrosion of steel), STOICMIC (stoichiometric coefficient for microbial degradation of cellulosics), VMETAL (fraction of total waste volume occupied by IDB metals and glass waste category) and VWOOD (fraction of total waste volume occupied by IDB combustible waste category). As shown by the upper frame in Figure 2-13, pore volume remains essentially fixed at its initial volume, although there is a small response to changing gas pressures through rock compressibility effects. Further, the partial rank correlation coefficients in the lower frame of Figure 2-13 indicate that pore volume is indeed a function of STOICCOR, STOICMIC, VMETAL and VWOOD.

\subsubsection{Lateral Gas Migration}

A primary focus of the studies contained in this report is the migration of gas away from the waste panels. For Case 1, this means gas migration into the anhydrite marker beds in the Salado Formation. Due to gravity drainage of brine to the bottom of a waste panel, gas inigration is more likely to occur into Anhydrite Layers $A$ and $B$ above the waste panels than into Marker Bed 139 below the waste panels. Of the 60 sample elements used in this study, 13 resulted in gas migration into Anhydrite Layers $A$ and $B$ and only 7 of these 13 resulted in gas migration into Marker Bed 139. Thus, a natural question to address is what controls gas migration into the marker beds rather than how much gas enters the marker beds or how far this gas travels.

Gas enters the marker beds from the disturbed rock zone surrounding a waste panel (Figure 2-2). Further, gas will enter the marker beds only if the gas pressure in the last computational cell of the disturbed rock zone exceeds the gas barrier pressure (i.e., brine pressure plus threshold displacement pressure if gas saturation is below residual, and gas pressure if gas saturation is above residual) in the adjacent computational cell of the undisturbed marker bed. To investigate these pressures, the timedependent gas pressures in the computational cell of the disturbed rock zone adjacent to Anhydrite Layers $A$ and $B$ (i.e., Cell $(10,5)$ shown in Figure 2-2) and the time-dependent gas barrier pressures in the adjoining computational cell containing undisturbed anhydrite in Anhydrite Layers $A$ and B (i.e., Cell $(11,5)$ ) were plotted as shown in the two upper frames of Figure 2-14. No gas reaches Computational Cell $(10,5)$ for 31 sample elements, as shown by the presence of only 29 nonzero gas pressure plots in the upper left frame of Figure 2-14. Further, as comparison of the upper two frames in Figure 2.14 shows, the gas barrier pressure in Computational 
Total Pore Volume in waste Panel

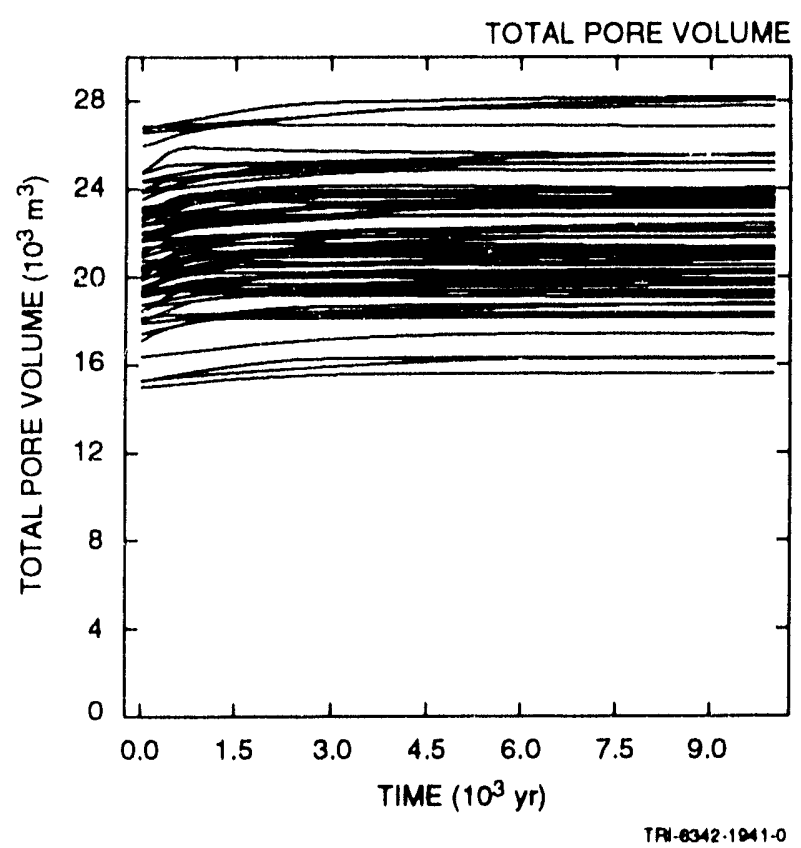

Partial Rank Correlation Coefficients for Total Pore Volume in Waste Panel

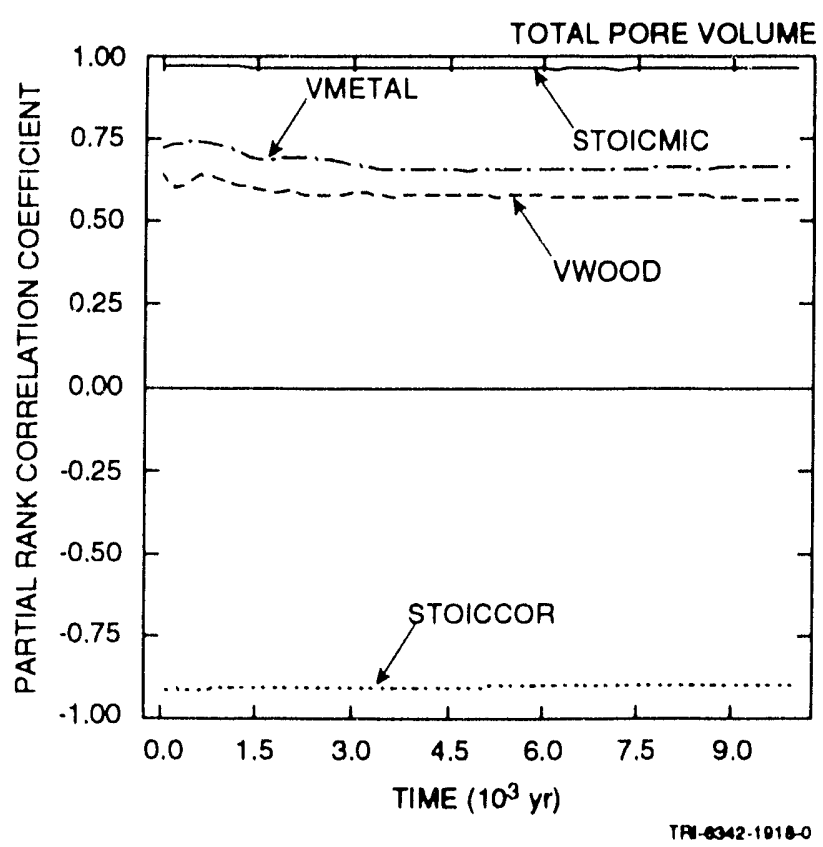

Figure 2-13. Uncertainty and sensitivity analysis results for total pore volume in waste panel. 
Gas Pressure and Gas Barrier Pressure in Adjacont Computalional Colls
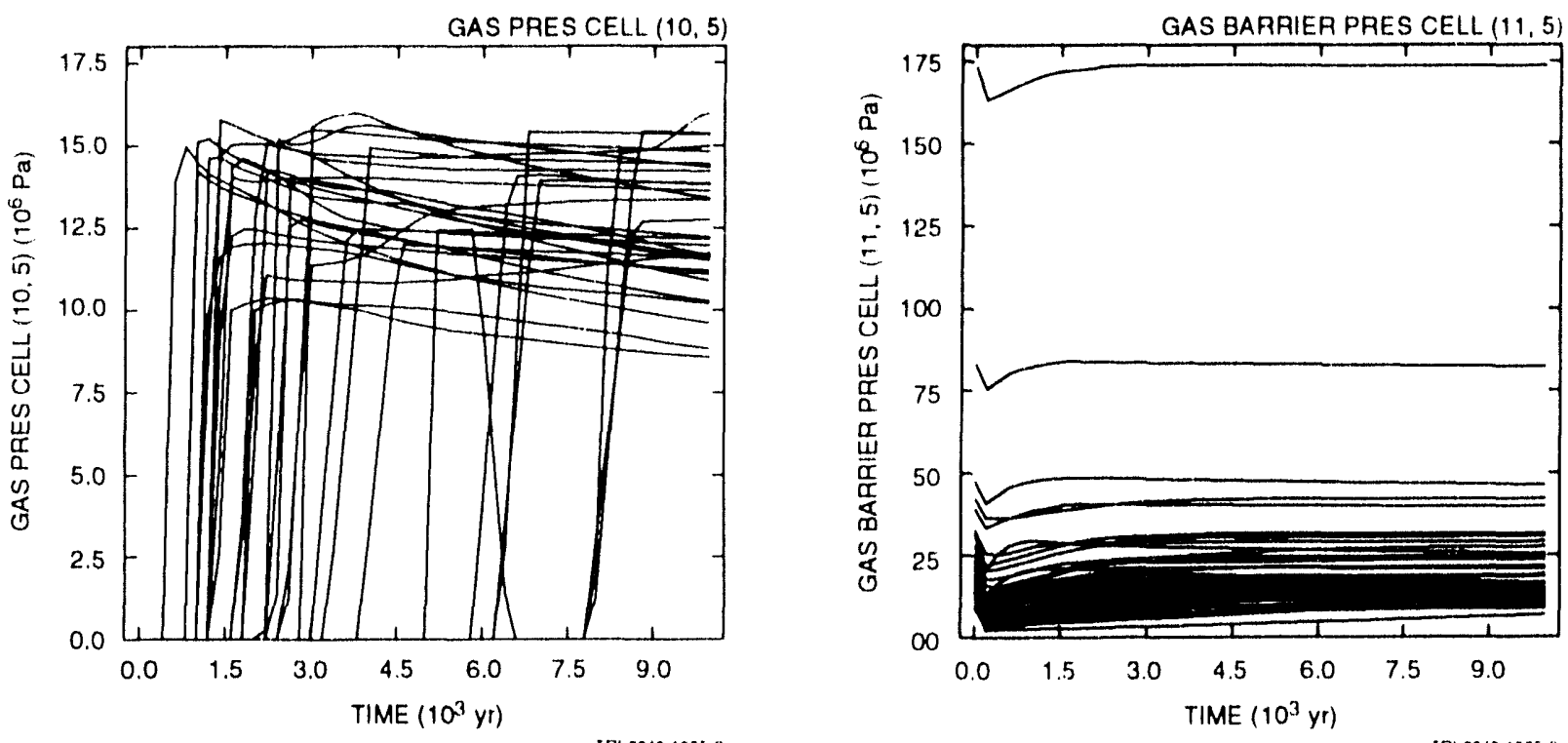

Partial Rank Correlation Coefficients for cas Pressure and Gas Barrier Pressure in Adjacent. Computational Cells
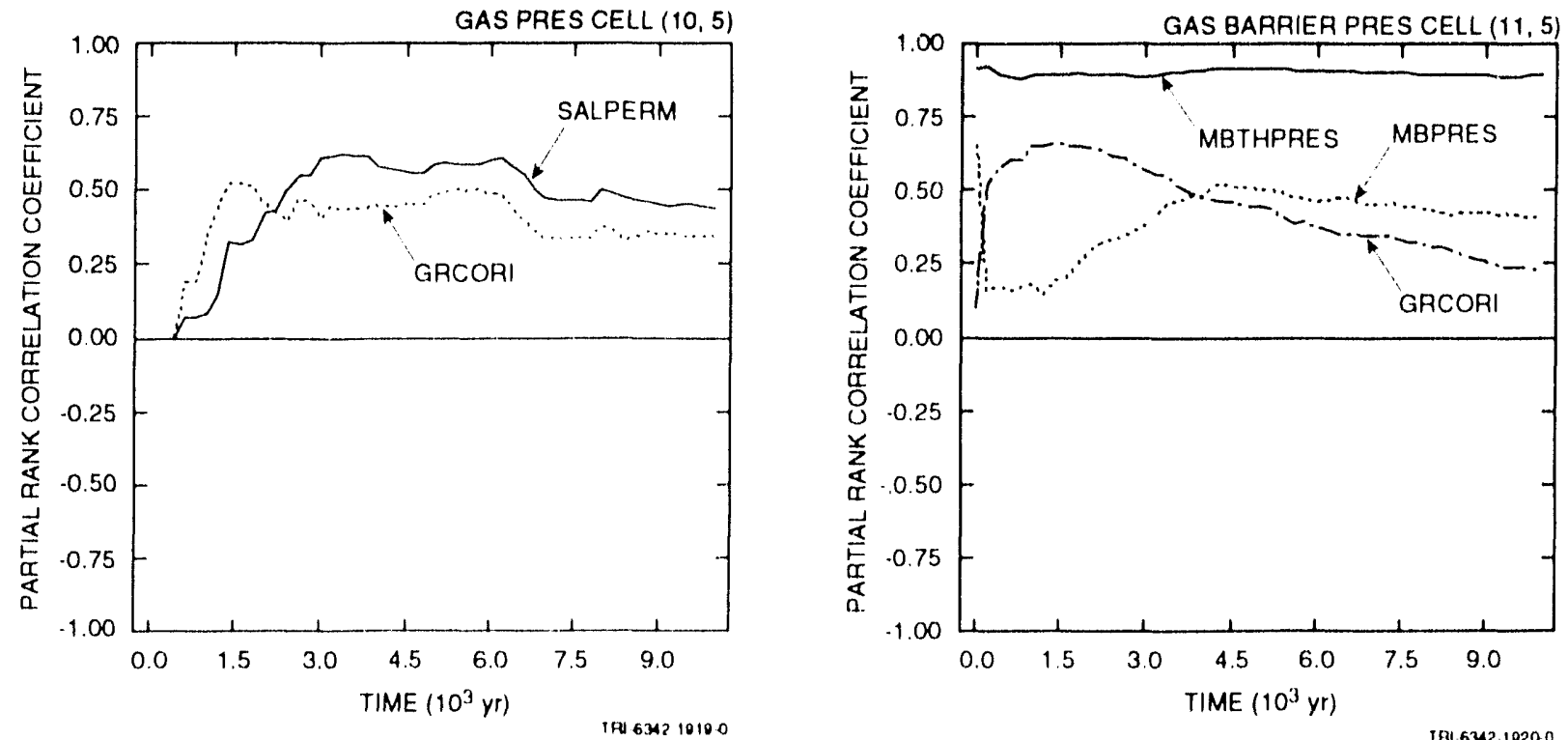

Figure 2-14. Uncertainty and sensitivity analysis results for gas pressure in computational cell of disturbed rock ano adjacent to Anhydrice layers $A$ and $B$ (i.e., Cell $(10,5)$ and gas barrier pressure in adjacont computational cell containing undisturbed anhydrite in Anhydrite Jayers $A$ and $B$ (i.e., Coll $(11,5))$. 
Cel1 $(11,5)$ often exceeds the gas pressure in Computational Ce11 $(10,5)$, with the result that no gas flow takes place into the undisturbed portion of Anhydrite Layers $A$ and $B$ (Note: the scale on the ordinate of upper right frame in Figure 2-14 is greater than the corresponding scale on the upper left frame by a factor of 10).

The partial rank correlation results in the lower right frame of Figure 2-14 indicate that the gas barrier pressure in Computational Cell $(11,5)$ is dominated by MBTHPRES (threshold displacement pressure in anhydrite marker beds in Salado Formation), with smaller effects for GRCORI (gas-generation rate for corrosion of steel under inundated conditions) and MBPRES (pressure in Marker Bed 139 under undisturbed conditions). Increasing each of MBTHPRES, GRCORI and MBPRES tends to increase the gas barrier pressure in Computational Cell $(11,5)$ and, hence, reduce the likelihood that gas will move from Computational Cell $(10,15)$ in the disturbed rock zone to Computational Cell $(11,5)$ in the undisturbed region of Anhydrite Layers $A$ and $B$. The weak influence indicated for GRCORI probably results from the 13 sample elements in which gas penetrates Anhydrite Layers $A$ and $B$, in which case the gas barrier pressure in Computational Cell $(11,5)$ becomes the actual gas pressure once residual gas saturation is exceeded. The partial rank correlation results in the lower left frame of Figure 2-14 indicate that gas pressure in Computational Ce11 $(10,5)$ tends to increase as SALPERM (Salado halite permeability) and GRCORI (gas generation rate due to corrosion under inundated conditions) increase. However, with only 29 nonzero gas pressure curves and these curves switching from zero to nonzero gas pressures at different times, partial correlation coefficients are not a particularly revealing analysis tool for the study of gas pressure in Computational Cell $(10,5)$.

As shown by the scatterplot in Figure 2-15, SALPERM (Salado halite permeability) has a complex pattern of effects on gas pressure in Computational Cell $(10,5)$ at $10,000 \mathrm{yr}$. All sample elements for which no gas reaches Computational Cell $(10,5)$ have a value of SALPERM that is less than $1 \times 10^{-20} \mathrm{~m}^{2}$. The result is a positive relationship between SALPERM and gas pressure that is consistent with the partial correlation analysis shown in the lower left frame of Figure 2-14. However, for values of SALPERM above $1 \times 10^{-20} \mathrm{~m}^{2}$, a negative relationship exists between SALPERM and gas pressure in Computational Cel1 $(10,5)$, with gas pressure tending to decrease as SALPERM increases. The patterns appearing in Figure 2-15 result primarily from the permeabilities used in the disturbed rock zone, with the halite and anhydrite permeabilities being set to values an order of magnitude above the permeabilities used for undisturbed halite and anhydrite (i.e., to 10 - SALPERM and 10 - MBPERM). Further, halite permeability (SALPERM) and anhydrite permeability (MBPERM) were sampled 


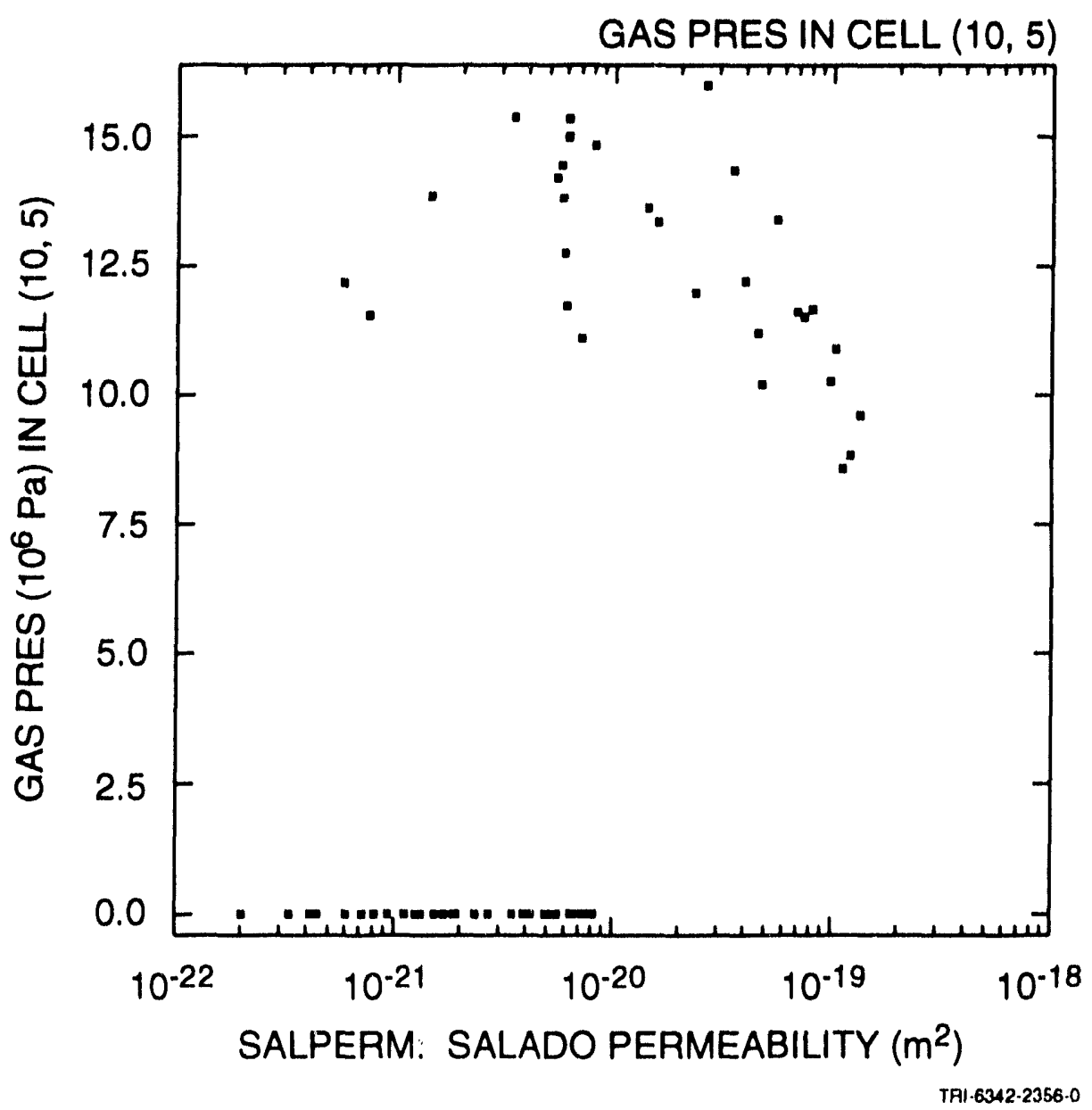

Figure 2-15. Scatterplot for gas pressure in Computational Cel1 $(10,5)$ versus SALPERM (Salado halite permeability). 
with a rank correlation of 0.8 . When SALPERM is small (1.e., $<1 \times 10-20$ $\left.\mathrm{m}^{2}\right)$, the resistance to gas and brine flow in the disturbed rock zone is increased, with the result that gas is less likely to reach Computational Cel1 $(10,5)$ than when SALPERM has larger values. As shown in figure 2-2, a layer of halite separates Computational Cell $(10,5)$ from the repository, with the result that SALPERM is more lmportant than MBPERM in determining whether or not gas reaches Computational Cell $(10,5)$. As SALPERM increases above $1 \times 10-21 \mathrm{~m}^{2}$, brine begins to flow out of Computational Ce11 $(10,5)$, with brine outflow increasing and brine pressure decreasing with increasing values for SALPERM. As a consequence of this tendency for brine pressures in Computational Cell $(10,5)$ to decrease as brine flows out for values of SALPERM above $1 \times 10^{-21} \mathrm{~m}^{2}$, the pressures for the 1 nflowing gas will also decrease, which is the pattern shown in Figure 2.15.

A more direct comparison of gas pressure and gas barrier pressure can be made by plotting the difference between gas barrier pressure in Computational Cel1 $(11,5)$ and gas pressure in Computational Cell $(10,5)$ as shown in the upper left frame of Figure 2-16. A positive difference indicates that the gas barrier pressure exceeds the gas pressure and thus that gas flow w11 not take place into undisturbed regions in anhydrites $A$ and $B$. Further, the inagnitude of this difference shows the amount of additional pressure rise that is needed to initiate gas flow into undisturbed regions in Anhydrite Layers $A$ and $B$. The partial rank correlation results in the lower left frame of Figure 2-16 indicate that MBTHPRES (threshold displacement pressure in anhydrite marker beds in Salado Formation) is the most important variable in determining the difference between gas barrier pressure and gas pressure in Computational Cells $(11,5)$ and $(10,5)$, with smaller effects indicated for GRCORI (gasgeneration rate for corrosion of steel under inundated conditions) and MBPRES (pressure in Marker Bed 139 under undisturbed conditions). The two right frames in Figure $2-16$ present similar results for the difference between the gas barrier pressure in Computational Cel1 $(11,5)$ and the gas pressure in the waste panel itself. Again, this difference is dominated by MBTHPRES, with smaller effects indicated for several additional variables.

\subsection{Discussion}

The primary purpose of the analyses presented in this chapter was to evaluate the factors influencing gas migration away from the repository. Little gas migration was observed. Of the 60 sample elements used in the analysis, only 7 resulted in gas migration into both Anhydrite Layers $A$ and $B$ and Marker Bed 139, and an additional 6 resulted in gas inigration into Anhydrite Layers A and B but not Marker Bed 139; the remaining sample elements resulted in no gas inigration into the anhydrite marker beds. The 
Differences between Gas Barrier Pressure and Gas Pressure
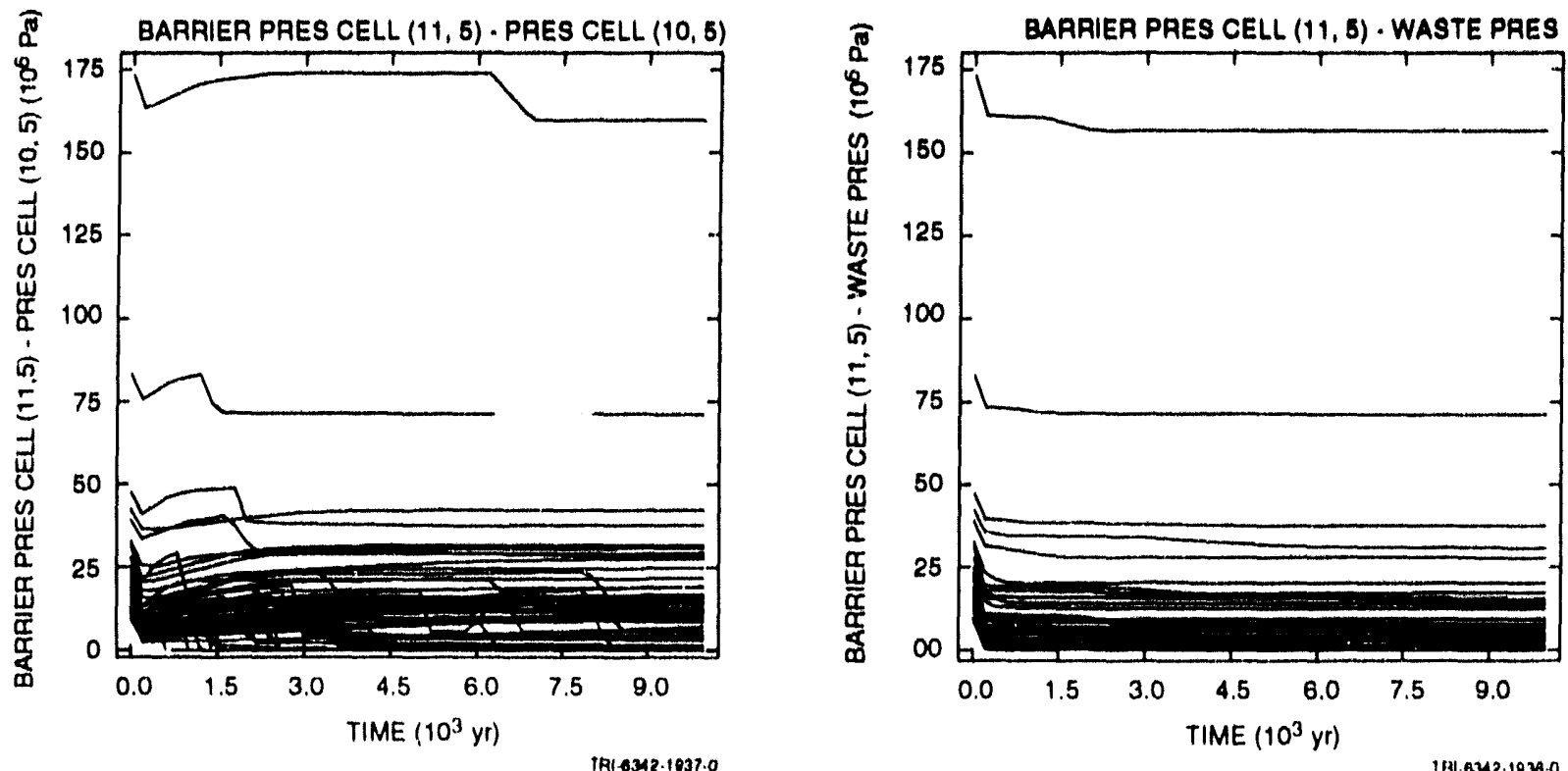

Partial Rank Correlation Coefficients for Differences between Gas Barrier Pressure and Gas Pressure
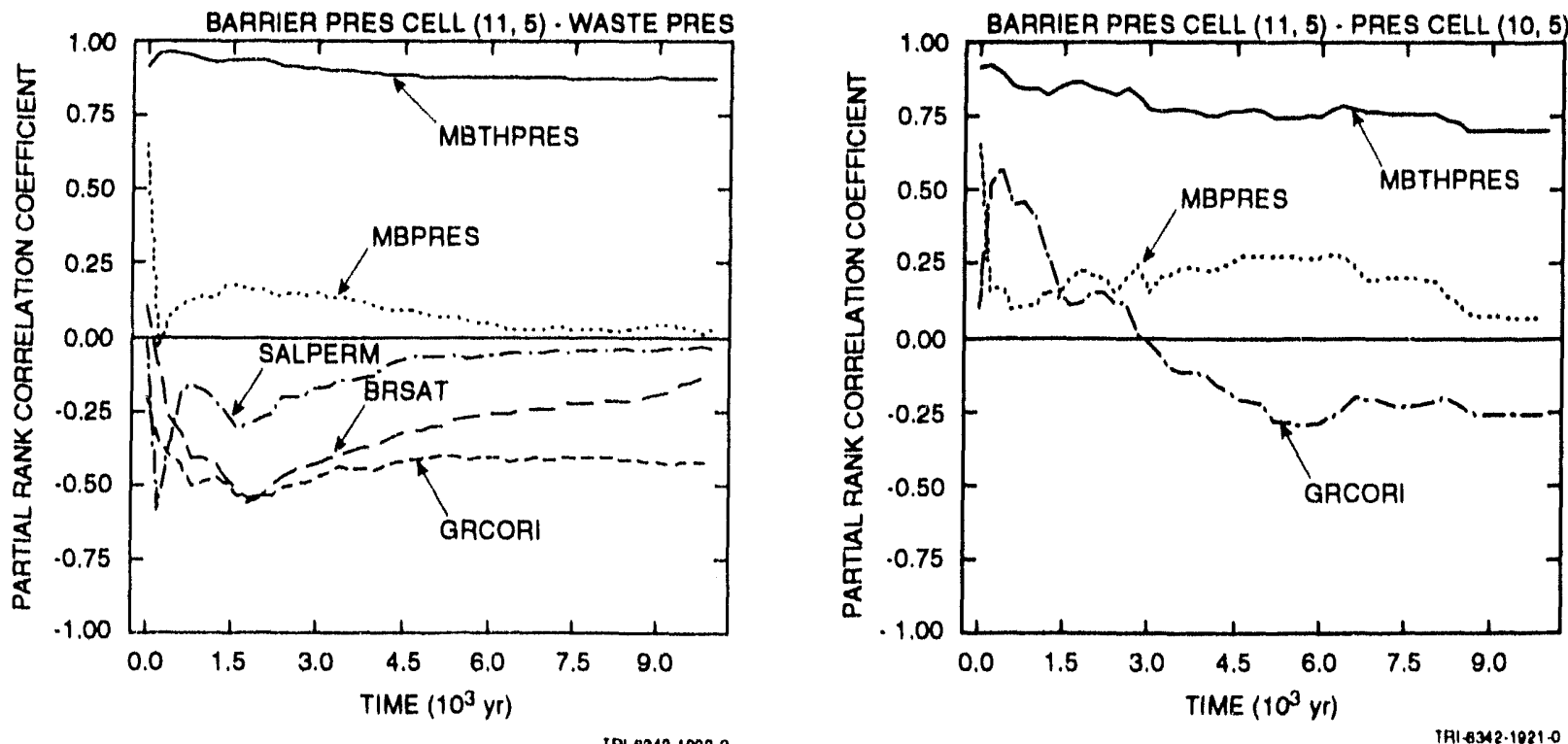

Figure 2-16. Uncertainty and sensitivity analysis results for differences between gas barrier pressure in Computational Cell $(11,5)$ and gas pressure in Computational Cell $(10,5)$ and the waste panel, respectively. 
domlnant varlable in determining whether or not gas imfgrat fon Into the anhydrite marker beds occurs is the threshold displacement pressure. For most sample elements, gas pressures in the waste panel and the surrounding disturbed rock zone never reached values that exceeded the gas barrier pressure (1.e., brine pressure plus threshold displacement pressure if gas saturation is below resldual, and gas pressure if gas saturat lon is above resldual) for undisturbed anhydrlte, with the result that waste-gonerated gas could not overcome the resistance to ontry finto the anhydrlte marker beds.

For 31 of the 60 sample elements, 110 gas reached the boundary between the disturbed rock zone and Anhydrite Layers $A$ and $B$. The sample elements for which no gas reached this boundary wore strongly assoclated with small values for hallte permeability. This pattern oceurred because small values for halle permeabllity resulted in littlo brine outflow from the disturbed rock zone, with the result that brlne pressures ln the disturbed rock zone were sufficiently high to prevent the inflow of gas.

Gas pressures In the waste panel typlcally remalned bolow the assuned lithostat lo pressure of $14.8 \mathrm{MPa}$. The role of 11 thostatie pressure as an approximate bound on waste-panel gas pressure resulted from an adjustment to waste panel pore volune that was made to incorporate the competing effects of pore-volume expanston due to waste-generated gas and pore-volume reduction due to waste compaction.

Most of the steel and cellulosic inventorles were consumed over the $10,000 \cdot y r$ period under consideration. Thus, although parancters related to rates of corrosion and interobial degradat lon affect the time at which gas is generated, they did not have a large effect on the total amount of gas generated. Under the assumptions of this analysis, the total amount of waste-generated gas is determlned by the steel and cellulosic inventorles, the stolchiometric terms, and the anount of avallable brlue. Gas production due to corrosion was approximately twice the gas production due to microbial degradation of cellulosics. However, it should be recognized that this comparison results from assumptons about stolchlometry and the steel and cellulosic inventories rather than from a mechanistic modeling of the underlying chemical and blological processes.

Brine saturation drops below resldual brine saturation in many computational cells associated with the waste panel, with the result that no brine flow can occur through these cells. This depletion of brine in the presence of gas generation is potentially tmportant with respect to radionuclide transport away from the repository. If brine cannot flow through parts of a waste panel, then the assoclated radionuclides are not avallable for transport. 
Uncertalnty and sensitfolty analysls technfques of the type cmployed In this study provide a powerful tool for model veriffeation bue to the concurrent varlation of many input varlables, the opportuntty to examlne a varlety of predicted varlables and the capabllity to ident ify the effects of inany input varlables for each predicted varlable, greater assurance wlth respect to the correct operation of a model can be obtalned than results from simply examining a few selected calculatlons. The analysls for Case 1 employed the same formulation of BRAGFLo that was used in the 1991 WIPP performance assessment. The extenslve allalyses performed for caso 1 did not reveal any errors in the Implementation of BRAGFIO, whlch helps provlde assurance that the BRAGFLO component of the 1991 WIPP performance assessment was $1 \mathrm{mplemented}$ correctly. 


\section{CASE 2: PERMEABLE SHAFT WITH PANEL SEALS}

\subsection{Summary Descriptlon*}

Unlike the single lsolated waste panel of Case 1, the entre repository is modeled 1ti Case 2. Further, Case 2 explicitly incorporates the reposltory shafts and uses a more detalled characterlation of the waste and Its surroundings by representlug the repository as a sequence of waste, panel seal, backfl11 and shaft reglons through whlch gas and be Ine flow can occur In both the veltical and horlzontal (1.e., north-south) directons.

As shown in Flgure 3-1, the computational implementation of Case 2 with BRAGFLO is based on a rectangular grld allgned north.south through the repostiory. Thls grid is a slmplification of the three-dimenslonal structure of the reposltory and Involves several assumptlons. The storage reglons (1.e., waste panels) of the ropository are grouped into the following three blocks on the bas 1 s of number of drift and pancl seals between the waste and the nearest shaft: Waste Block $A$, which corresponds to the single waste panel that is soparated from the waste and exhaust shafts by two sets of panel seals (1.o, the Northorn Panel in Figure 2-3), Waste Block $B$, whlch corresponds to the flve waste panels separated from the waste and exhaust shafts by throe sets of panel seals (1.e., Panels 1, 2, 1 and 8 and the Southern Panel In Figure 2-3), and Waste Block $C$, which corresponds to the four waste panels separated from the raste and exhaust shafts by four sets of panel seals (1,e., Panels 3,4,5 and 6 In Figure 2-3). Each waste block contains the storage volume of the corresponding waste panels and drifts. The four shafts are comblned into a single shaft at the location of the Waste Shaft, whlch is the shaft nearest the waste. disposal panels (Figure 2-3), and this single shaft is subdivided vertically into four segments. Strat graphic layers are assumed to be parallal and horlzontal. The marker beds within the Salado Formation are actually slightly undulatory, with a dip of less than $1^{\circ}$ to the southeast at the WIPP. Because the repository is befing excavated at a constant stratigraphle horlzon rather than at a constant elevation, thls dip results in a drop In floor elevation of about 7 in between the Waste shaft and the Southorn panel. The computational gridding for BRAGFLo does not fuclude this change In elevation.

The computational grid shown in Figure $3-1$ extends vertically $645 \mathrm{~m}$ from the bottom of the Salado Formation to the top of the Culobra Dolomite Member of the Rustler formation and extends horlzontally for approximately $29 \mathrm{~km}$. Stratigraphic unlts Included in the grid are the Intact halfe of

*Adapted from Section 2.3 of WIPP PA, 1992. 


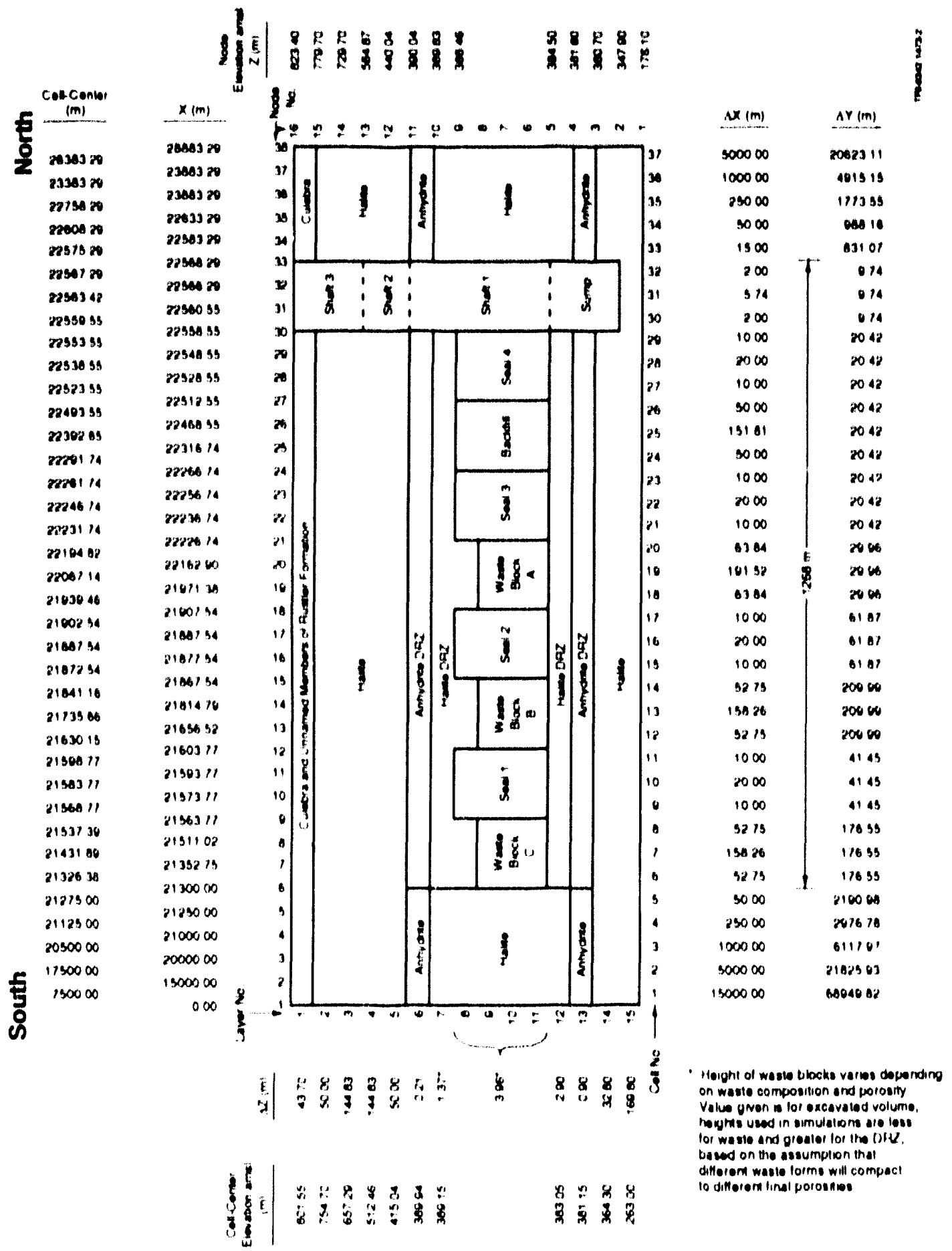

Higure 3-1. Girldelng scheme employed with BRACifle for the two-dimensional vertical cross-section model of the full repository used for Case 2 . 
the Salado Format Lon, Marker Bed 139, Anhydrite Layers A and B, which are represented as a single anhydrlte layer, and the lower unnamed member of the Rustler formation and the Culebra Dolomite, which are represented as a single layer. The computatlonal grid also lncludes a dlsturbed rock zone, which extends vertically around the reposttory and lncludes parts of Marker Bed 139 and Anhydrlte Layers $A$ and $B$. The permeabllity of the disturbed rock zone was assumed to be sufflelently low (1.e., 2.41 $\times 10^{-20} \mathrm{~m}^{2}$, which is an order of magnltude above the assumed permeabllity of $2.41 \times 10.21 \mathrm{~m}^{2}$ for halle In the salado formation) to prevent signiflcant gas flow around the panel seals.

The computational cells used with BRACFLo represont two dimenstonal projections of threo-dimenstonal features with different volumes. The widh of the computational cells (1.e., distance measured in the difection of the $y$ coordinate in Flgure 3-1, which is perpendicular 10 the page) varles significantly before profection to two dimensions, from as little as 9.74 in at the location of the shatt 10 as much as $69 \mathrm{~km}$ in the intact Salado formation. Thls dimension of the grid does not vary vertically; thus, where the grid is thln near the shaft because of the small excavated volume, all grld elements, Including the disturbed rock zone, the intact Salado formation and the Culebra Dolomite, are given the same value for the y-dimension. Figures 2.5 and 2.6 of WIPP PA, 1992 show enlarged representations of the grid in the horlzontal plane contaluing the ropository.

The third dimension (1.e., the y coordinate, whlch is perpendicular to the page in Figure 3-1) is included in the construction of the computational grid to allow for different storage volumes for brine and gas In each cell. Flow is not modeled in the third dimension and occurs only In the plane of Flgure 3.1 (1.e., In the directlons of the $x$ and $z$ coordinates). Flow from Waste Block c to the culcbra Dolomite, for example, would occur hortzontally through the other waste blocks and the panel seals, and then vertically up the shaft.

The ends of the grid, south of Waste Block $C$ and north of the shaft, require additional explanation. The intent was to simulate some threedimensional bohavior with a two-dimensional grid. With the repository or shaft acting as sources or slnks, fluld flow will be primarlly horlzontal, and mostly through the anhydrite layers. Close to the repository, flow paths will have complex orientations because of the variable geometry of the excavations. Further away from the repository, at a distance perhaps several times the maxlmum horfzontal dimension of the repository (about 1.3 kIn), flow will be nearly radial either toward or away from the sink or source. This cylindrical flow pattern can be approximated with a two. dimensional model if the width of grid blocks (i.e., the y-dimension of Figure 3-1) increases away from the source or sillk by a factor of $2 \pi r$, 
where $r$ is the distance from the source or sink at the center of the grid (Voss, 1974). In a strlct sense, this relationshlp is valld only if the entire grid is set up this way, starting from one side. Such a grid represents a vertical cylinder, and the resulting two-dimensional inodel will simulate radial flow in a three-dimensional cylinder. In the grid used here, only the north and south ends were treated in this fashion, and the results are not exact in modeling all flow outward from the reposttory/shaft region. However, as a first approximation, this procedure accounts for the radial increase in pore volume away from the central region. This radial increase in pore volume is potentlally important because brine and gas flow away from the repository will not be restricted to two dimensions (vertically and in one dimension horlaontally). Rather, at a distance of a few kilometers from the repository (approximately the disposal-unit boundary), flow wlll be radial into an increasing pore volume.

Waste Blocks $A, B$ and $C$ are separated by seai blocks that preserve both the total length and the total volume of the seals located between the panels. Thus, Seals 3 and 4 contaln the composite volume of the drift seals north of the waste (Figure 2-3). Seal 2 contains the composite volume of the 12 panel seals separating Waste Bloik A from Waste Block B, and Seal 3 contains the volume of the 8 panel seals separating waste Block B from waste Block $C$. Seals are assumed to have a height equal to that of a newly excavated room, approximately $4 \mathrm{~m}$. Actual heights of seals may vary, depending on location. Seals are assumed to occupy omly the original volume of the drifts in which they are cmplaced, and no correction is made for possible additional excavation, such as downward into Marker Bed 139 during seal construction. All panel and drift seals are assibuted to have the same properties.

The single composite shaft is divided into four sections: a sump and three arbltrarlly divided higher sections, each having different material properties. The three upper sections are used to represent different degrees of counlidation of the halite seals and backfill at differem depths, with the deeper sections havirig lower permeability. The first shaft section above the sump, labeled Shatt 1 in Figure 3-1, extends from the bottom of the waste blocks upward to the top of the Anhydrite layers $A$ and $B$. The inidde shaft section, labeled shaft 2. In Figure 3-1, extends halfway to the top of the Salado Formation, and the upper section, labeled Shaft 3, extends to the top of the Culebra Dolomite. The lower most portion of the shaft, the sump, is assumed to be backfilled, and has been included in the model because of its possible role as a brine sink. The modeled sunp extends downward $36.6 \mathrm{~m}$ from the repository tloor, resulting in a modeled volume larger than that of the actual sumps. Two of the four shafts have no sumps, and depths in the other two are 38,4 III (Waste shaft) 
and $33.5 \mathrm{~m}$ (Salt Handling Shaft) (Nowak et al., 1990). However, the pore volume of the sump is small relative to the volume in the entire shaft. The disturbed rock zone is modeled only above and below the waste, drift and panel seal, and backfill blocks.

No mass is allowed to cross the far-field outer boundary of the grid except for the northern- and southermost cells of the Culebra Dolomite. Fixed-pressure boundaries are defined for those locations to approximate the observed head in the Culebra. The initial pressure throughout the Culebra, including the lateral boundary cells, was sei at $1.053 \mathrm{MPa}$. Initial brine saturation in the Culebra was set to 1.0 (i.e., there is no initial gas in the Culebra). Any gas that does eventually appear in the Culebra must come from the waste or from gas initially in the shaft or drift blocks.

Initial far-field pressures in the Salado Formation, including halite and anhydrite layers, was varied hydrostatically relative to a specified value at the level of Marker Bed 139, with the assumption of a brine density of $1230 \mathrm{~kg} / \mathrm{m}^{3}$. Initial pressure in Marker Bed 139 is one of the imprecisely-known variables considered in the uncertainty'sensitivity analysis for Case 2. Initial pressure in the waste, seals and backfill was assumed to be atmospheric $(0.101 \mathrm{MPa})$. Initial pressure was assumed to be constant horizontally throughout any given layer in all of its constituent materials. The Salado Formation halite, the anhydrite, and the disturbed rock zone were assumed to be initially fully brine saturated.

Initial conditions in the shafts and drifts are uncertain, and two sets of calculations were carried out to evaluate the effects of assuming initial full brine saturation and initial full gas saturation. In the first set, the shaft seals, drift seals and backfill were assumed to be gas saturated, and initial pressure was atmospheric, $0.101 \mathrm{MPa}$. In the second set, these regions were assumed to be fully brine saturated, with the initial pressure in the drift seals and backfill equal to atmospheric. The initial brine pressure in the shaft was hydrostatic, varying with depth relative to the sampled value for the pressure in Marker Bed 139. In both sets of calculations, the initial shaft pressure extends to the top of the Salado Formation, with the result that a difference exists between the shaft and the Culebra pressures. For the gas-saturated shaft, this initial pressure difference was $-0.95 \mathrm{MPa}$, compared to a range from 3.9 to $4.5 \mathrm{MPa}$ for the brine-saturated shaft. This difference in gradient could cause different early-time behavior in the calculations for gas-saturated and brine-saturated shafts. Because the shaft was brine-saturated in either case within about $150 \mathrm{yr}$, results over $10,000 \mathrm{yr}$ were relatively insensitive to the initial gas saturation of the drifts and shafts. The Case 2 results presented in this report were obtained with the assumption 
of an initially gas-saturated shaft; results obtained with the assumption of an initially brine-saturated shaft are given in WIPP PA, 1992.

\subsection{Sampled Variables}

The 16 imprecisely-known variables 1 isted in Table $3-1$ were used as input to BRAGFLO for the Case 2 uncertainty and sensitivity studies. As is the case for Table 3-1, the distributions indicated in Table 3-1 for the individual variables are characterizing subjective uncertainty. The Case 2 calculations used a Latin hypercube sample of size 22 from the 16 variables in Table 3-1, which was generated in the same manner as the sample for Case 1. The resultant sample is 1 isted in Table $3.2-2 b$ of WIPP PA, 1992.

A widely-used guide for selecting the sample size to use in an uncertainty/sensitivity study based on Latin hypercube sampling is that the number of elements in the sample should equal $4 \mathrm{nV} / 3$, where $\mathrm{nV}$ is the number of variables in the sample. This rule was used for Case 2 and resulted in the choice of 22 as the sample size. However, the actual basis for this rule is the size of the sample needed for the successful numerical implementation of the Iman/Conover restricted-pairing technique (Imar and Conover, 1982) that is used to control the correlation structure within the sample. To the best of the authors' knowledge, a rule for the optimum size of a Latin hypercube sample for use in uncertainty and sensitivity analysis is not known.

The variables BFPERMF, BRSATF, GRCORHF, GRMICHF, SH2PERMF and SH3PERMF in Table 3-1 are scale factors that are used in constructing the variable values that are actually used in the analysis. Associated with each of these scale factors in Table $3-1$ is the definition of the variable that is actually used by BRAGFLO. The sensitivity analyses presented in section 3.3 use the actual BRAGFLO inputs (i.e., BFPERM, BRSAT, GRCORH, GRMICH, SH2PERM and SH3PERM) rather than the corresponding scale factors. In contrast, the sensitivity analyses for Cases 1 and 3 use the sampled variables rather than the actual BRAGFLO inputs. The transformed variables (i.e., actual BRAGFLO inputs) are used in Case 2 because of the relatively complex relationships involving BFPERMF, SH2PERMF and SH3PERMF.

In addition to the 16 sampled variables listed in Table $3-1$, the calculations for Case 2 also required values for a number of additional variables that were fixed at their best-estimate values. These variables and their values are listed in Tables 3.1-1b and 3.2-1a of WIPP PA, 1992. Further, additional discussion of the BRAGFLo input for Case 2 is available in Section 3.2 of WIPP PA, 1992. 
Table 3-1. Imprecisely Known Variables Used in BRAGFLO for Case 2 to Determine the Effects of Seal Permeabilities and Gas Generation Parameters on Gas Flow through the Repository and up the Shaft to the Culebra Dolomite.

\begin{tabular}{|c|c|}
\hline Variable & Definition \\
\hline \multirow[t]{3}{*}{ BFPERMF } & $\begin{array}{l}\text { Scale factor used in definition of permeability of backfill in waste panels } \\
\text { (dimensionless). Range: } 0 \text { to } 1 \text {. Median: } 0.5 \text {. Distribution: Normal. Actual backfill } \\
\text { permeability, BFPERM, is defined by }\end{array}$ \\
\hline & $\log$ BFPERM $=\log$ SEALPERM $+(-14-\log$ SEALPERM $)$ BFPERMF \\
\hline & $\begin{array}{l}\text { Additional information: Section 3.2.2, WIPP PA, } 1992 \text {. Variable } 13 \text { in Latin hypercube } \\
\text { sample. }\end{array}$ \\
\hline BRSATF & $\begin{array}{l}\text { Scale factor used in definition of initial brine saturation of waste (dimensionless). } \\
\text { Range: } 0 \text { to } 1 \text {. Median: } 0.5 \text {. Distribution: Uniform. Actual value for initial brine } \\
\text { saturation of waste, BRSAT, is }\end{array}$ \\
\hline & BRSAT $=0.276$ BRSATF. \\
\hline
\end{tabular}

Additional information: Section 3.4.9, WIPP PA, 1991c. Variable 1 in Latin hypercube sample.

GRCORHF Scale factor used in definition of gas generation rate for corrosion of steel under humid conditions (dimensionless). Range: 0 to $5 \times 10^{-1}$. Median: $1 \times 10^{-1}$. Distribution: Piecewise uniform. Actual gas generation rate, GRCORH, is

$$
\text { GRCORH }=\text { GRCORHF } \cdot \text { GRCORI. }
$$

Additional information: Memo from Brush, July 8, 1991, contained in Appendix A, Vol. 3; Section 3.3.8, WIPP PA, 1991c. Variable 3 in Latin hypercube sample.

GRCORI Gas-generation rate for corrosion of steel under inundated conditions $\left(\mathrm{mol} / \mathrm{m}^{2}\right.$ surface area steel $\cdot \mathrm{s})$. Range: 0 to $1.3 \times 10^{-8} \mathrm{~mol} / \mathrm{m}^{2} \mathrm{~s}$. Median: $6.3 \times 10^{-9}$ $\mathrm{mol} / \mathrm{m}^{2} \mathrm{~s}$. Distribution: Piecewise uniform. Additional information: Same as GRCORHF. Variable 4 in Latin hypercube sample.

GRMICHF Scale factor used in definition of gas-generation rate due to microbial degradation of cellulosics under humid conditions (dimensionless). Range: 0 to $2 \times 10^{-1}$. Median: 1 $\times 10^{-1}$. Distribution: Piecewise uniform. Actual gas-generation rate, GRMICH, is

$$
\text { GRMICH = GRIMICHF } \cdot \text { GRMICI. }
$$

Additional information: Same as GRCORHF. Variable 5 in Latin hypercube sample. 
Table 3-1. Imprecisely Known Varlables Used in BRAGFLO for Case 2 to Determine the Effects of Seal Permeabilities and Gas Generation Parameters on Gas Flow through the Repository and up the Shaft to the Culebra Dolomite (continued).

\begin{tabular}{|c|c|}
\hline Varlable & Definition \\
\hline GRMICl & $\begin{array}{l}\text { Gas-generation rate due to microbial degradation of cellulosics under inundated } \\
\text { conditions (mol } / \mathrm{kg} \text { cellulosics } \cdot \mathrm{s} \text { ). Range: } 0 \text { to } 1.6 \times 10^{-8} \mathrm{~mol} / \mathrm{kg} \text { s. Median: } 3.2 \times \\
10^{-9} \mathrm{~mol} / \mathrm{kg} \text { s. Distribution: Plecewise uniform. Additional information: Same as } \\
\text { GRCORHF. Varlable } 6 \text { in Latin hypercube sample. }\end{array}$ \\
\hline MBPERM & $\begin{array}{l}\text { Permeability }(\mathrm{k}) \text { in anhydrite marker beds in Salado Formation under undisturbed } \\
\text { conditions }\left(\mathrm{m}^{2}\right) \text {. Range: } 8.5 \times 10^{-21} \text { to } 1.8 \times 10^{-18} \mathrm{~m}^{2} \text {. Medlan: } 7.8 \times 10^{-20} \mathrm{~m}^{2} \text {. } \\
\text { Distribution: Piecewise uniform. Additional information: Memo from Beauheim, June } \\
\text { 14, } 1991 \text {, contained in Appendix A, WIPP PA, 1991 c; Section 2.4.5, WIPP PA, 1991c. } \\
\text { Variable } 11 \text { in Latin hypercube sample. }\end{array}$ \\
\hline MBPRES & $\begin{array}{l}\text { Pressure }(p) \text { In anhydrite marker beds in Salado Formation under undisturbed } \\
\text { conditions (Pa). Range: } 8.21 \times 10^{6} \text { to } 1.48 \times 10^{7} \mathrm{~Pa} \text {. Median: } 1.28 \times 10^{7} \mathrm{~Pa} \text {. } \\
\text { Distribution: Plecewise uniform. Additional information: Memos from Beauheim, June } \\
\text { 14, 1991, and Howarth, June 12, 1991, contained in Appendix A. WIPP PA, 1991C; } \\
\text { Section 2.4.6, WIPP PA, 1991C. Variable } 10 \text { in Latin hypercube sample. }\end{array}$ \\
\hline SEALPERM & $\begin{array}{l}\text { Permeability }(\mathrm{k}) \text { of seals between waste blocks in repository }\left(\mathrm{m}^{2}\right) \text {. Range: } 3.3 \times 10^{-21} \\
\text { to } 1 \times 10^{-14} \mathrm{~m}^{2} \text {. Medlan: } 5.7 \times 10^{-18} \mathrm{~m}^{2} \text {. Distribution: Lognormal. Additional } \\
\text { information: Section 3.2.2, WIPP PA, 1992; Section 3.2.2, WIPP PA, 1991c. Variable } \\
12 \text { in Latin hypercube sample. }\end{array}$ \\
\hline SH1PERM & $\begin{array}{l}\text { Permeability }(\mathrm{k}) \text { of lower shaft section }\left(\mathrm{m}^{2}\right) \text {. Range: } 3.3 \times 10^{21} \text { to } 1 \times 10^{-14} \mathrm{~m}^{2} \text {. } \\
\text { Median: } 5.7 \times 10^{-18} \mathrm{~m}^{2} \text {. Distribution: Lognormal. Additional information: Section } \\
\text { 3.2.2, WIPP PA, } 1992 \text {. Variable } 14 \mathrm{in} \text { Latin hypercube sample. }\end{array}$ \\
\hline SH2PERMF & $\begin{array}{l}\text { Scale factor used in definition of permeability of middle shaft section. Range: } 0 \text { to } 1 \text {. } \\
\text { Median: } 0.5 \text {. Distribution: Normal. Actual permeability of middle shaft section, } \\
\text { SH2PERM, is defined by }\end{array}$ \\
\hline & $\log$ SH2PERM $=\log$ SH1PERM + (-14 - log SH1PERM) SH2PERMF. \\
\hline & $\begin{array}{l}\text { Additional information: Section 3.2.2, WIPP PA, 1992. Variable } 15 \text { in Latin hypercube } \\
\text { sample. }\end{array}$ \\
\hline
\end{tabular}


Table 3\%1. Imprecisely Known Varlables Used in BRAGFLO for Case 2 to Determine the Effects of Seal Permeabilities and Gas Generation Parameters on Gas Flow through the Repository and up the Shaft to the Culebra Dolomite (concluded).

\begin{tabular}{|c|c|}
\hline Varlable & Definition \\
\hline \multirow[t]{3}{*}{ SH3PERMF } & $\begin{array}{l}\text { Scale factor used in definition of permeabillty of upper shaft section. Range }=0 \text { to } 1 \text {. } \\
\text { Median: } 0.5 \text {. Distribution: Normal. Actual permeability of upper shaft section, } \\
\text { SH3PERM, is defined by }\end{array}$ \\
\hline & $\log$ SH3PERM $=\log$ SH2PERM $+(-14 \cdot \log$ SH2PERM) SH3PERMF. \\
\hline & $\begin{array}{l}\text { Additional information: Section 3.2.2, WIPP PA, 1992. Variable } 16 \text { in Latin hypercube } \\
\text { sample. }\end{array}$ \\
\hline STOICCOR & $\begin{array}{l}\text { Stolchlometric factor for corrosion of steel (dimensionless). Defines proportion of two } \\
\text { different chemical reactions that take place during the corrosion process. Range: } 0 \text { t } \\
\text { 1. Median: } 5 \times 10^{-1} \text {. Distribution: Uniform. Additional information: Brush and } \\
\text { Anderson in Lappln et al., 1989, p. A-6; Sectlon 3.3.8, WIPP PA, 1991c. Variable } 2 \text { in } \\
\text { Latin hypercube sample. }\end{array}$ \\
\hline STOICMIC & $\begin{array}{l}\text { Stoichiometric coefficlent for microblal degradation of cellulosics (mol gas } / \mathrm{mol} \\
\mathrm{CH}_{2} \mathrm{O} \text { ). Range: } 0 \text { to } 1.67 \mathrm{~mol} / \mathrm{mol} \text {. Median: } 8.35 \times 10^{-1} \mathrm{~mol} / \mathrm{mol} \text {. Distribution: } \\
\text { Uniform. Additional information: Brush and Anderson in Lappln et al., 1989, p. A-10; } \\
\text { Section 3.3.9, WIPP PA, 1991c. Variable } 9 \text { in Latin hypercube sample. }\end{array}$ \\
\hline VMETAL & $\begin{array}{l}\text { Fraction of total waste volume that is occupied by IDB (Integrated Data Base) metals } \\
\text { and glass waste category (dimensionless). Range: } 2.76 \times 10^{-1} \text { to } 4.76 \times 10^{-1} \text {. } \\
\text { Median: } 3.76 \times 10^{-1} \text {. Distribution: Normal. Additional information: Section } 3.4 .1 \text {, } \\
\text { WIPP PA, } 1991 \mathrm{c} \text {. Variable } 7 \text { in Latin hypercube sample. }\end{array}$ \\
\hline VWOOD & $\begin{array}{l}\text { Fraction of total waste volume that is occupled by IDB combustible waste category } \\
\text { (dimensionless). Range: } 2.84 \times 10^{-1} \text { to } 4.84 \times 10^{-1} \text {. Median: } 3.84 \times 10^{-1} \text {. } \\
\text { Distribution: Normal. Additional Information: Section 3.4.1, WIPP PA, } 1991 \mathrm{C} \text {. } \\
\text { Variable } 8 \text { in Latin hypercube sample. }\end{array}$ \\
\hline
\end{tabular}

\subsection{Uncertainty and Sensitivity Analysis Results}

Gas flow through the repository and up the shaft to the Culebra Dolomite is the outcome of greatest interest for Case 2. Thus, as for Case 1 , a natural starting point is an exploration of gas generation. Uncertainty and sensitivity analysis results related to corrosion, microbial degradation and total gas production are presented in Sections 3.3.1, 3.3.2 and 3.3.3. Then, gas saturation and gas pressure in the individual waste blocks are investigated in Section 3.3.4. Finally, gas migration through the shaft to the Culebra Dolomite is considered in Section 3.3.5. 


\subsubsection{Gas Generation Dus to Corrosion}

A summary of the results for gas generation due to corrosion is given in Figure 3-2. The two upper franes in Figure 3-2 show cumulative gas generation as a function of time due to corrosion under humid conditions (upper left frame) and corrosion under inundated conditions (upper right frame). Each curve in the upper two frames results from a single Latin hypercube sample element (i.e., each frame has 22 curves, one for each sample element). Overall, the range of gas production under humid conditions is similar to the range of gas production under inundated conditions.

Formal sensitivity analysis techniques based on partial rank correlation can be used to investigate the variation in cumulative gas production shown in the upper two frames of Figure 3-2. The analyses in this chapter use the variables BRSAT, GRCORH, GRMICH, BFPERM, SH2PERM and SH3PERM defined in Table 3-1 rather than the scale factors BRSATF, GRCORHF, GRMICHF, BFPERMF, SH2PERMF and SH3PERMF generated in the lat in hypercube sample. As indicated by the (rank) correlation matrix

$\begin{array}{lcclll}\text { SEALPERM } & 1.00 & & & & \\ \text { BFPERM } & 0.54 & 1.00 & & & \\ \text { SH1PERM } & 0.00 & 0.04 & 1.00 & & \\ \text { SH2PERM } & -0.03 & -0.01 & 0.64 & 1.00 & \\ \text { SH3PERM } & 0.05 & 0.11 & 0.52 & 0.80 & 1.00 \\ & \text { SEALPERM } & \text { BFPERM } & \text { SH1PERM } & \text { SH2PERM } & \text { SH3PERM }\end{array}$

the transformations given in Table $3-1$ result in substantial correlations between SEALPERM and BFPERM and also between SH1PERM, SH2PERM and SH3PERM. In initial analyses based on partial rank correlation coefficients, these correlations tended to produce unstable and ambiguous results. In particular, with 16 sampled variables, a sample size of 22 and correlations between variables, there is often little information left to characterize with a partial correlation coefficient after the correction is made for the effects of the other variables (e.g., see Sections IX.1, IX.2, Beyer, 1968; David, 1938). To reduce the problems resulting from correlated input, the variables BFPERM, SH1PERM and SH3PERM were dropped from the analysis. Rank correlations also exist between GRCORH and GRCORI (i.e., 0.64) and between GRMICH and GRMICI (i.e., 0.68). However, these correlations did not seem to cause the misleading results that derived from the correlations between SEALPERM and BFPERM and also between SH1PERM, SH2PERM, and SH3PERM; thus, the transformed variables GRCORH and GRMICH were left in the partial correlation analysis. As a result, the following 13 variables were used in the calculation of the partial rank correlation coefficients presented in 
Cumulative Gas Production Due to Corrosion of Steel
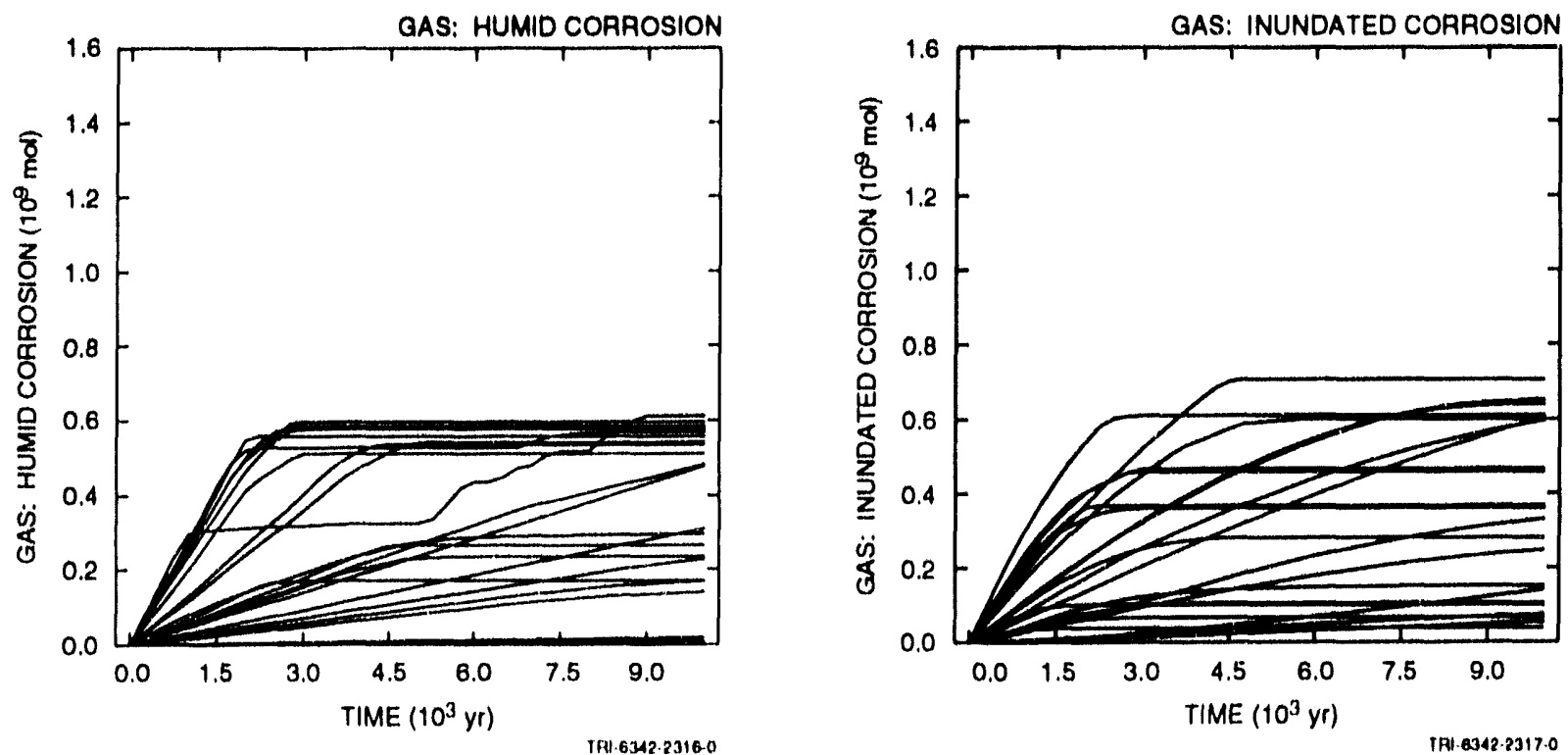

Partial Rank Currelation Coefficients for Cumulative Gas Production Due to Corrosion of Steel
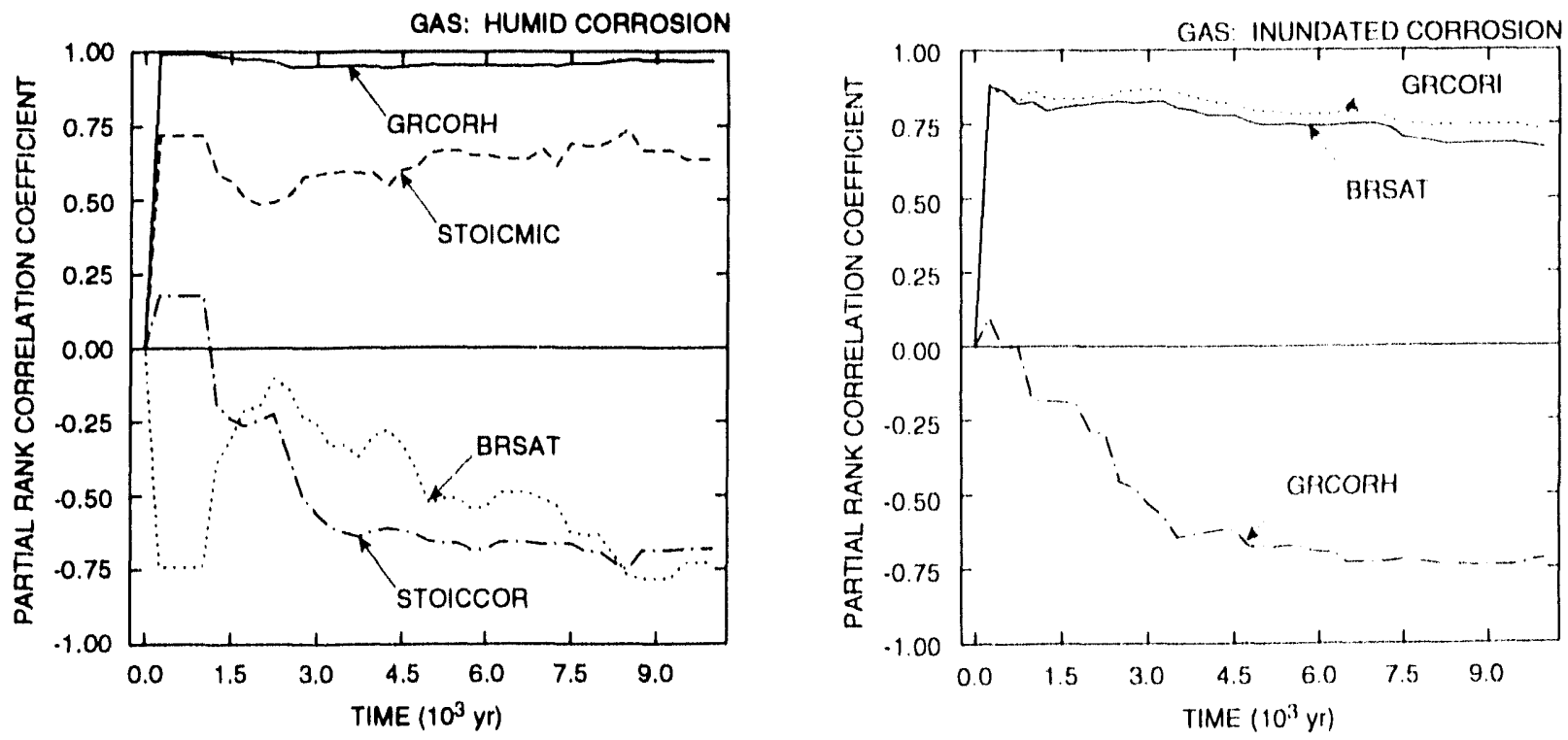

Figure 3-2. Uncertainty and sensitivity analysis results for gas generation due to corrosion of steel. 
this chapter: BRSAT, GRCORH, GRCORI, GRMICH, GRMICI, MBPLRM, MBPRES, SEALPERM, SH2PERM, STOICCOR, STOICMIC, VMETAL and VWOOD.

The lower two frames in Figure 3-2 show time-dependent plots of partial rank correlation coefficlents between cumblative gas production and Individual variables. The coefficlents in Flgure $3-2$ and other simflar figures in this chapter are calculated on the basis of vertical slices through the corresponding curves in the upper half of the figure. Due to the relatively sinall sample size in use (1.e., 22 observations for 13 Independent varlables), an absolute value cutoff of 0.7 is used for the selection of partial rank correlation coefficients for presentation in this chapter. As a reminder, a postlive rank correlation coefflclent indicates that two vartables tend to Increase and decrease together, and a negative rank correlation coefficient indicates that, as one variable increases, the other tends to decrease.

As shown by the partial correlation results in the lower left frame of Figure 3-2, cumulative gas production due to corrosion under humid conditions is dominated by GRCORH (gas-generation rate for corrosion of steel under hunfd conditions), with cumulative gas production showing a strong tendency to increase as GRCORH increases. In addition, cumulative gas production due to corrosion under hunid conditions tends to increase as STOICMIC (stoichiometric coefficient for microbial degradation of cellulosics) increases and tends to decrease as BRSAT (initial brine saturation of waste) and STOICCOR (stolchiometric factor for corrosion of steel) increase. The positive effect for STOICMIC results from increased gas generation due to inicrobial degradation of cellulosics, with a resultant increase in the amount of repository pore space that is filled with gas (i.e., humid conditions) rather than with brine (i.e., inundated conditions). The negative effect for STOICCOR results because increasing STOICCOR increases the proportion of low-gas-producing reactions in the corrosion process. The negative effect for BRSAT results because there is a fixed amount of steel in the repository for each sample element. Increasing BRSAT increases the anount of this steel that will be consumed by corrosion under inundated conditions, with the result that the anount of gas that can be producred by corrosion under humid conditions is reduced. The partial correlation coefficients for GRCORH are very close to 1 , with the result that STOICMIC, STOICCOR and BRSAT are actually making relatively small contributions to the uncertainty in gas generation due to corrosion under humid conditions.

As shown by the partial correlation results in the lower right frame of Figure 3-2, cumulative gas production due to corrosion under inundated conditions tends to increase as GRCORI (gas-generation rate for corrosion of steel under Inundated conditions) and BRSA' (initial brine saturation of 
waste) Increase and tends to decrease as GRCORH (gas-generation rate for corrosion of steel under hum d conditions) increases. The positive effects for GRCORI and BRSAT result because Increaslug GRCORI Increases the rate at which gas is produced by corrosion under inundated conditions and Increasing BRSAT Increases the anount of steel that w111 be consumed by corrosion under inundated conditions. The negative effect for GRCORH results because the fincreased consumption of steel and brine by corrosion under humld conditions reduces the amount of gas that can be produced by the corrosion of steel under inundated conditions.

Stepwise regression analysis can also be used to analyze the cumulative gas production results shown in Figure $3-2$. The two regression analyses shown in lable 3-2 are for cumulat lve gas production over 10,000 yr due to corrosion under humid and inundated conditions, respectively. Thus, these two regression analyses are for the gas production values appearing above 10,000 yr 111 the two upper frames of Figure 3-2. The regression analysis for gas production under humld condftons indfcates a positive effect (1.e., a positive regression cocfticient) for GRCORH (gasgeneration rate for corrosion of steel under humld conditions), whth this variable accounting for 81 of of the uncertainty in gas production.

The regression analysis in lable $3-2$ for gas production under inundated conditions did not ldentify any varlables that satisfy the minimum condition to enter the regresslon model (1,e., an $\alpha$-value of at least 0.02). Scatterplots of cumulative gas production over 10,000 yr due to corrosion under linundated conditions versus the Individual varlables in Table 3.2 show no obvious relationships.

Table 3-2. Stepwise Regression Analyses with Rank-Transformed Data for Cumulative Gas Production over 10,000 yr Due to Corrosion under Humid and Inundated Conditions.

Total Gas Production over 10,000 yr (Humid Corrosion)

\begin{tabular}{clll}
\hline Step $^{a}$ & Varlableb $^{b}$ & SRCC & R$^{2 d}$ \\
1 & GRCORH & 0.90 & 0.81
\end{tabular}

Total Gas Production over 10,000 yr (Inundated Corrosion)

$\begin{array}{ll}\text { Stepa } & \text { Variableb } \quad \text { SRCC } \\ & \text { No variables selected }\end{array}$

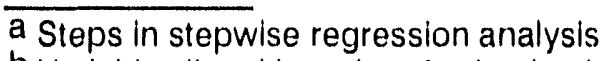

b Variables listed in order of selection in regression analysis

c Standardized regresslon coefficients in final regression model

d Cumulative $R^{2}$ value with entry of each variable into regression model 


\subsubsection{Gas Generation Due to Microbial Degradation}

A summary of the analysis results for gas generation due to microbial degradation is given in Figure 3-3. The upper two frames in Figure 3-3 show cumulative gas generation due to microblal degradation under humid and Inundated conditions, respectively. As comparlson with the corresponding plots in Figure 3-2 shows, gas generation due to microblal degradation is approximately 508 or less of gas generation due to corroslon. The range of cumulative gas generation shown in Flgure $3-3$ is slightly larger for Inundated than for humld conditions.

The lower two trames In Figure 3.3 present sensitivity analysis results based on partial rank correlation coefflclents as in flgure 3-2. For cumulative gas production under humld condltions, increasing each of STOICMIC (stolchiometric coefflclent for inlcroblal degradation of cellulosics), GRMICH (gas-generation rate due to mferoblal degradation of cellulosics under humld condltions) and VWOOD (fraction of total waste volume occupled by IDB combustible waste category) Increases gas production and Increasing BRSAT (Inftial brine saturation) decreases gas production. The posltive effects for STOICMIC, GRMICH and VwOod result because increasing STOICMIC Increases the amount of gas produced per unlt of collulose consumed, Increaslng GRMICH Increases the rate of infroblal degradation under humf conditions, and fincreasing VwOOD fincreases the amount of cellulose avallable for microbial degradation. In contrast, Increasing BRSAT decroases the amount of gas produced under hund conditions by increasing the anount of cellulosics that will be consuned under Inundated conditions.

For cumulative gas product fon under inundated conditions, fincreasing each of Stolcmic (stolchlometric coefflefent for microbial degradat fon of cellulosics), BRSAT (initial brine saturation) and (iRMlil (gas-generat on rate due to microbial degradation of cellulosics undor fnundated conditions) Increases gas production. Increasing STOICMIC fincreases the anount of gas produced per unt of cellulose consumed; Increasing BRSAT increases the anounc of cellulose that wlll be consumed under inundated conditions, and increasing GRMICI increases the rate of inf icroblal degradation under inundated conditions.

The two regression analyses in Table $3-3$ are for cumulative gas production over 10,000 yr due to microblal degradation under hunid and inundated conditions, respectively. Thus, these two regression analyses are for the gas-production values appearing above $10,000 \mathrm{yr}$ in the two upper frames of Figure 3-3. For gas production under humid conditions, the variables STOICMIC (stolchiometric coefficlent for microbial degradation of cellulosics) and GRMICH (gas generation rate due to microbial degradation 
Cumulative Gas Production Due to Microblal Degradation of Cellulosics
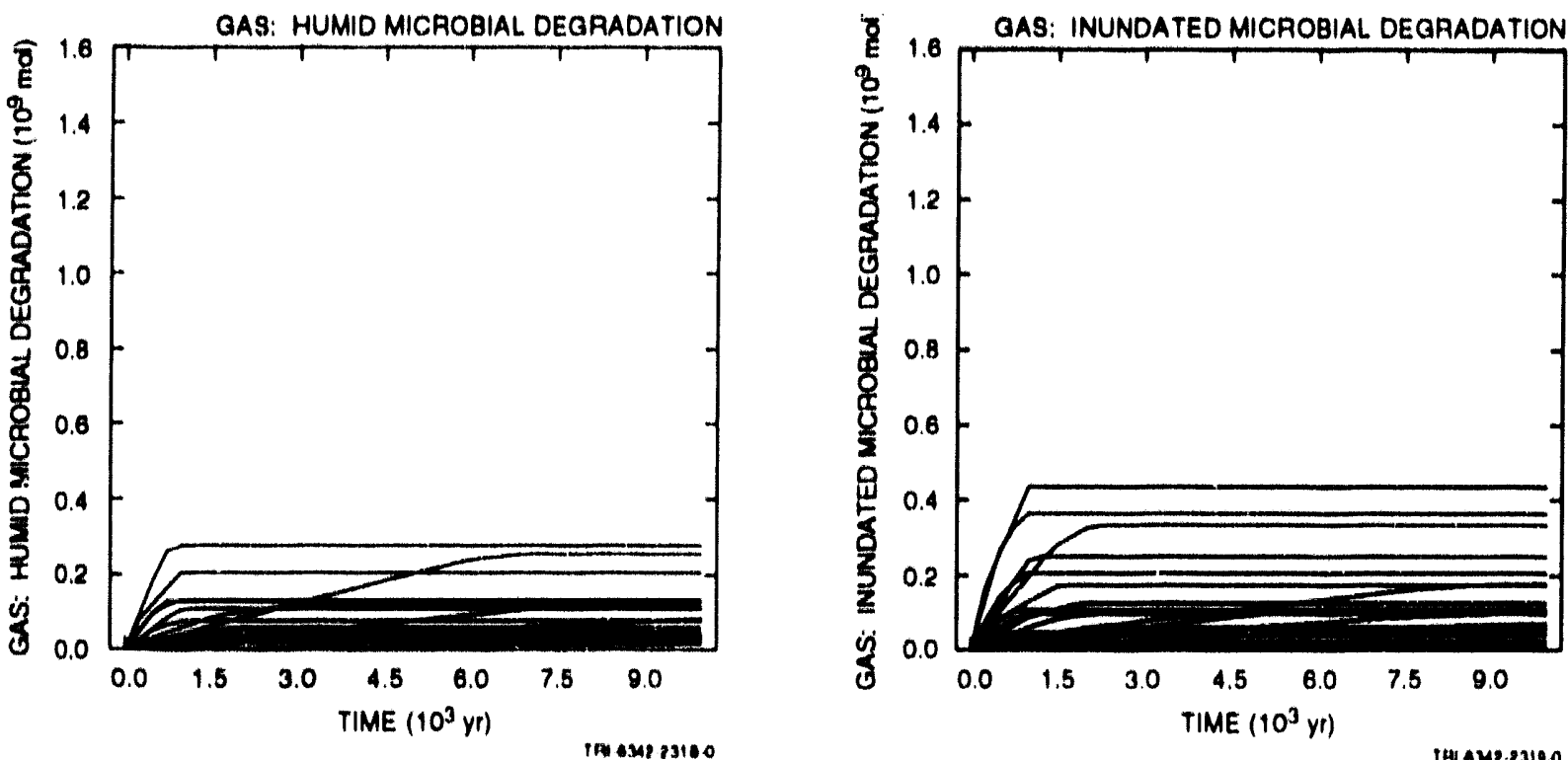

Partial Rank Correlation Coefflelents for Cumulative Gas Production Due to Microblal Degradation of Cellulosics
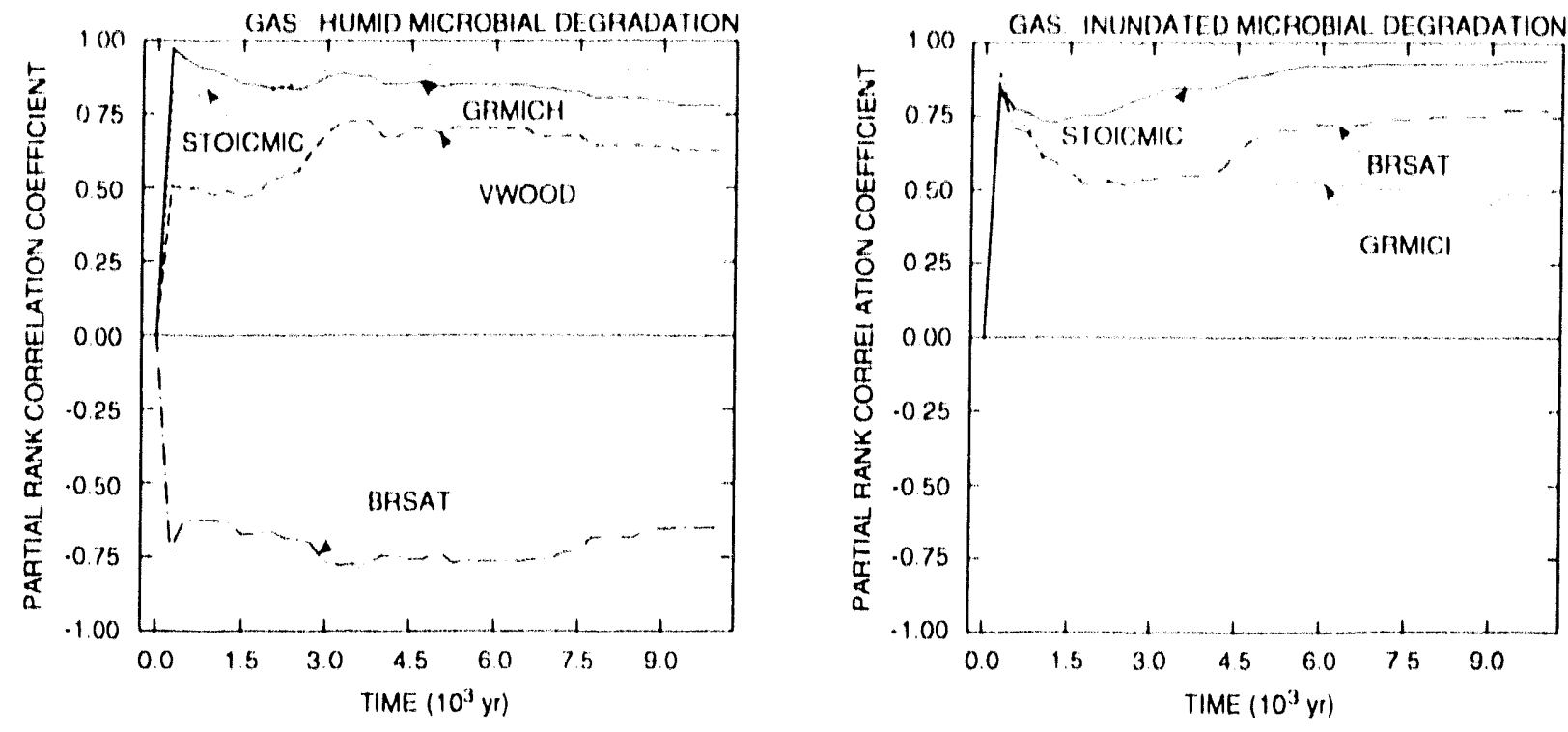

Figure 3-3. Uncertainty and sensitivity analysis results for gas generation due to microblal degradation of cellulosics under huinid and inundated conditions. 
Table 3.3. Stepwise Regression Analyses with Rank-Translormed Date for Cumulatlve Gas Production over 10,000 yr Due to Microblal Degradation under Humld and Inundated Conditions.

Total Gas Production over $10,000 \mathrm{yr}$ (Humld Degradatlon)

\begin{tabular}{clll}
\hline Step & Variable & SRCC & $R^{2 d}$ \\
1 & STOICMIC & 0.69 & 0.57 \\
2 & GRMICH & 0.34 & 0.68
\end{tabular}

Total Gas Productlon over $10,000 \mathrm{yr}$ (Intillated Degradation)

\begin{tabular}{clcc}
\hline Stepa & Variableb & SRCC & R $^{2 d}$ \\
& & & \\
1 & STOICMIC & 0.79 & 0.68 \\
2 & BRSAT & 0.33 & 0.79 \\
3 & GRCORH & -0.24 & 0.85
\end{tabular}

\footnotetext{
a Steps in stepwise regression analysis

b Variables Ilsted in order of selectlon in regression analysis

c Standardized regression coefflcients in final regression model

d Cumulative $R^{2}$ value with entry of each varlable into regression model
}

of cellulosics under humld conditlons) can account for 688 of the observed variabllity in gas productlon, whth gas production tendlug to Increase wlth Increaslag values for STOICMIC and CRMICll. For gas production under Inundated conditlons, the varlables STOLCMIC and BRSAT (Inftlal brine saturation) can account for 19 of the observed varlablllty in gas production, with gas production tendlag to lncrease as each of these vartables fucrases. When the addltional varlable ciRCORH (gas-generation rate for corroston of stoel under humb condltions) is added to the regresston model, 85 of the variablilty in gas productlon can be accounted for, whth gas production tondlug, to decrease as GRCORH fncreases because increased gas production tends to decrease the fract lon of the pore volune that is fllled with brine and henee reduce the amount of mforoblal degradation that takes place under inundated conditions.

\subsubsection{Total Gas Production}

The upper two frames in Figure $3-4$ show total gas production due to corrosion and microbial degradation and were obtained by combining the corresponding results in figures $3-2$ and $3-3$ for gas production under humid and Inundated conditions. Typically, low gas product lon under humid conditions is associated with higher gas production under inundated conditions and vlce versa. As a result, the gas-production curves in Figure 3-4 tend to 11 e farther above the absclssa than many of the individual curves in Figures 3.2 and $3-3$ overall, the gas production due to corrosion tends to be about twice the gas production due to mferobial degradation. Cias production due to microblal degradation has more curves 
Cumulative Gas Production
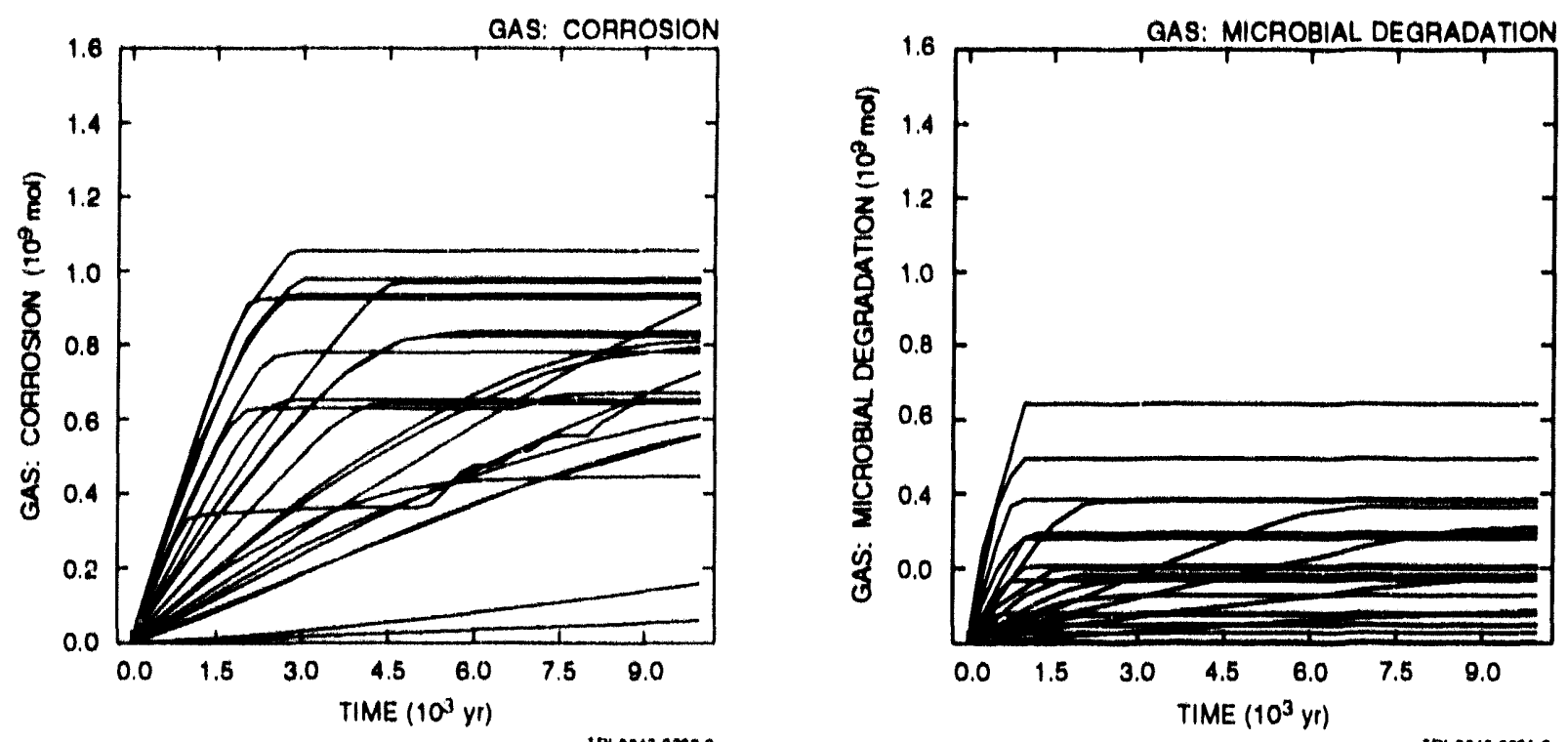

Partial Rank Correlation Coefficlents for Cunulative Gas Production
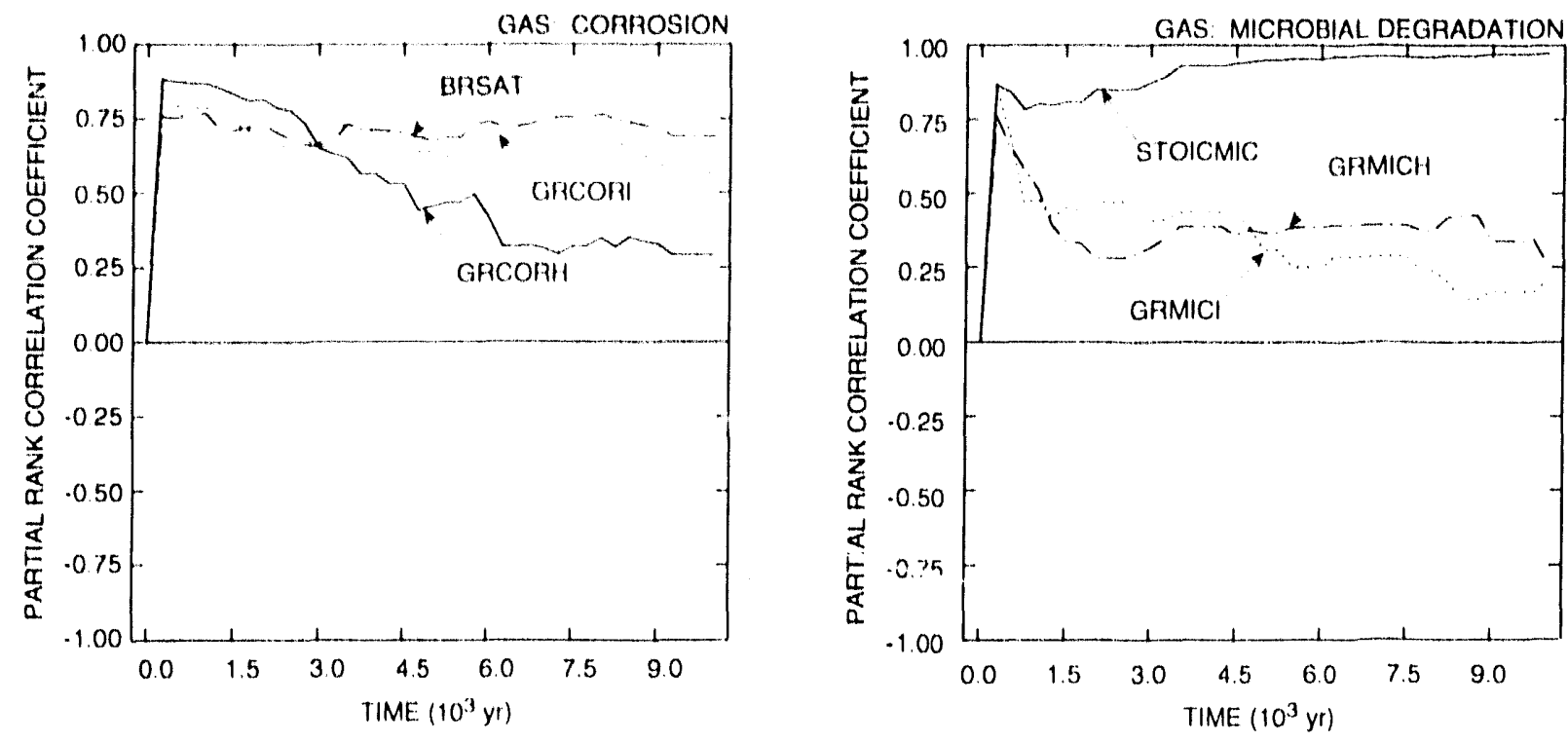

Figure 3-4. Uncertainty and sensitivity analysis results for gas generation due to corrosion of steel and microbial degradation of cellulosics. 
close to zepo than gas produet fon due to comeston due to the ass g gunent of "range of posstble values for stolcmes stofohlometrle coefflelent for microhtal degradation of cellulosics) that extends 10 acro, which results in no gats generat fon due to mierohial degradartion.

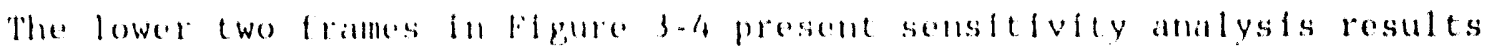

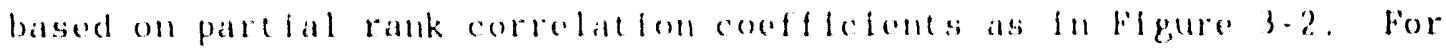
cumulat fe gas production due to corrosion, flucreasing each of CRCORI (gasgenerat fon rate for corroston of steel under lnundated condftions), cikcorH (gas-generation rate for corrosion of steel under humld conditions) and BRSAT (tuttal bithe saturation) tends to lincrease gas production. Increaslag, CRCORL, GRCORH and BRSAT tends to fncrease the rate of gas product fon and hence cumblat lve gas production, with this effect becoming less important at later thes due to exhaustion of elther steel or brine in the waste panels.

The dominant varlable for cumulat ive gas product fon due to microblal

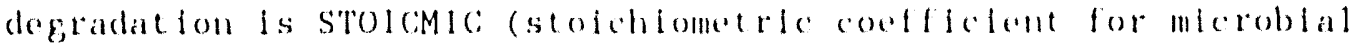

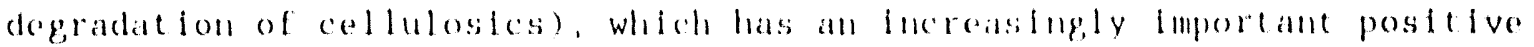

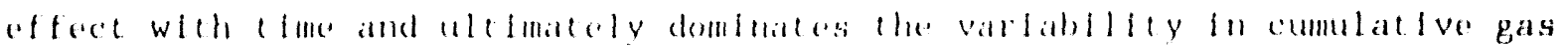

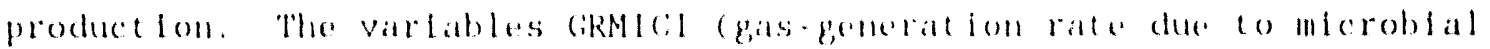

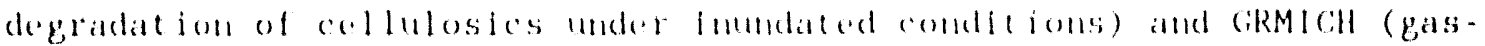

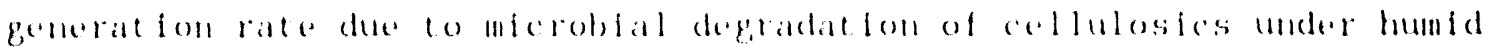
conditions) also have posit foe alfects at early thes and then docrease fo fmportance.

The two regression analyses fo Table $3-4$ are for cumblat foe gas product don over lo, (0)0 yr due to corrosion and microbial degradation, respectively. Thus, these two regressiton amalyses are for the gas production

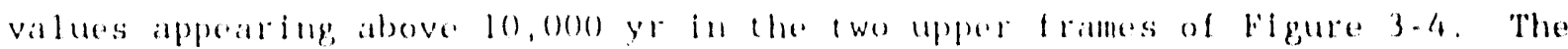

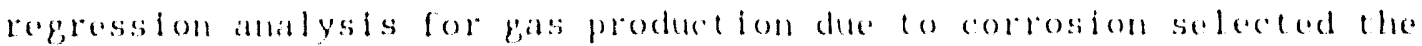

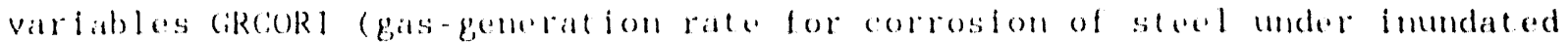
conditions) and BRSAl (Inllial hrlne satmation), with ciRcoRl and BRSAT each having a posttive offect on gas production. However, the resolution in the regression model is low, with CRCORL and BRSAT account ing, lor only bo of the variability in gas prodect ion due to corrosilon.

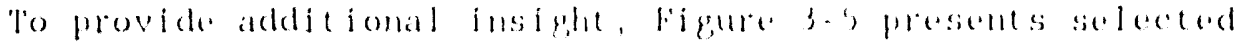
scatterplots displaylug, the relat iomships betweon fodividatal sampled

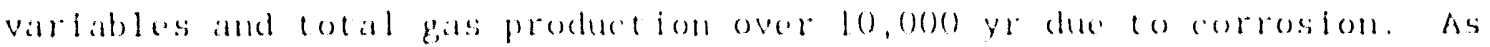
examflat ion of these plots shows, pass product ion tomds to increase als BRSAT

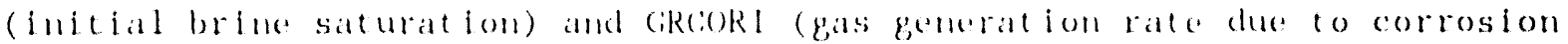


Table 3-4. Stepwise Regression Analysis with Rank-Transformed Data for Total Gas Production Due to Corrosion and Total Gas Generation Due to Microbial Degradation.

Total Gas Production over $10,000 \mathrm{yr}$ (Corrosion)

$\begin{array}{clll}\text { Stepa } & \text { Variable }^{b} & \text { SRCC } & R^{2 d} \\ & & & \\ 1 & \text { GRCORI } & 0.56 & 0.32 \\ 2 & \text { BRSAT } & 0.48 & 0.55\end{array}$

\section{Total Gas Production over $10,000 \mathrm{yr}$ (Microbial-Degradation)}

$\begin{array}{cccc}\text { Step } & \text { Variable } & \text { SRCC } & R^{2 d} \\ 1 & \text { STOICMIC } & 0.95 & 0.91\end{array}$

\footnotetext{
a Steps in stepwise regression analysis

b Variables listed in order of selection in regression analysis

c Standardized regression coefficients in final regression model

d Cumulative $R^{2}$ value with entry of each variable into regression model
}

of steel under inundated conditions) increase and tends to decrease as STOICCOR (stoichiometric factor for corrosion of steel) increases.

However, there is a large amount of variability around these trends. These patterns are consistent with the signs of the regression coefficients and low $R^{2}$ values for GRCORI and BRSAT in Table 3-4. The plots in Figure 3-5 show the best-defined patterns of the 16 scatterplots associated with total Eas production over 10,000 yr due to corrosicn (i.e., one scatterplot for each variable in Table 3-1). Thus, no one variable is exerting a dominant influence on total gas production due to corrosion. However, the actual uncertainty in total gas production due to corrosion is rather small in this analysis, with most values falling between $0.4 \times 10^{9}$ and $1.0 \times 10^{9}$ mol.

The regression analysis in Table 3-4 for gas production due to microbial degradation identified only the variable STOICMIC (stoichiometric coefficient for microbial degradation of cellulosics). However, STOICMIC was able to account for 918 of the observed variability.

The cumulative gas production due to corrosion and to microbial degradation can be combined to produce total gas production as shown in the upper frame of Figure 3-6. Most sample elements result in a total gas production over 10,000 yr between $5 \times 10^{8}$ and $1.2 \times 10^{9} \mathrm{~mol}$. Also, most sample elements show a period of rapid gas production in the first few thousand years, with considerably reduced rates of gas production at later times. As examination of the two upper frames in Figure 3-7 shows, the 

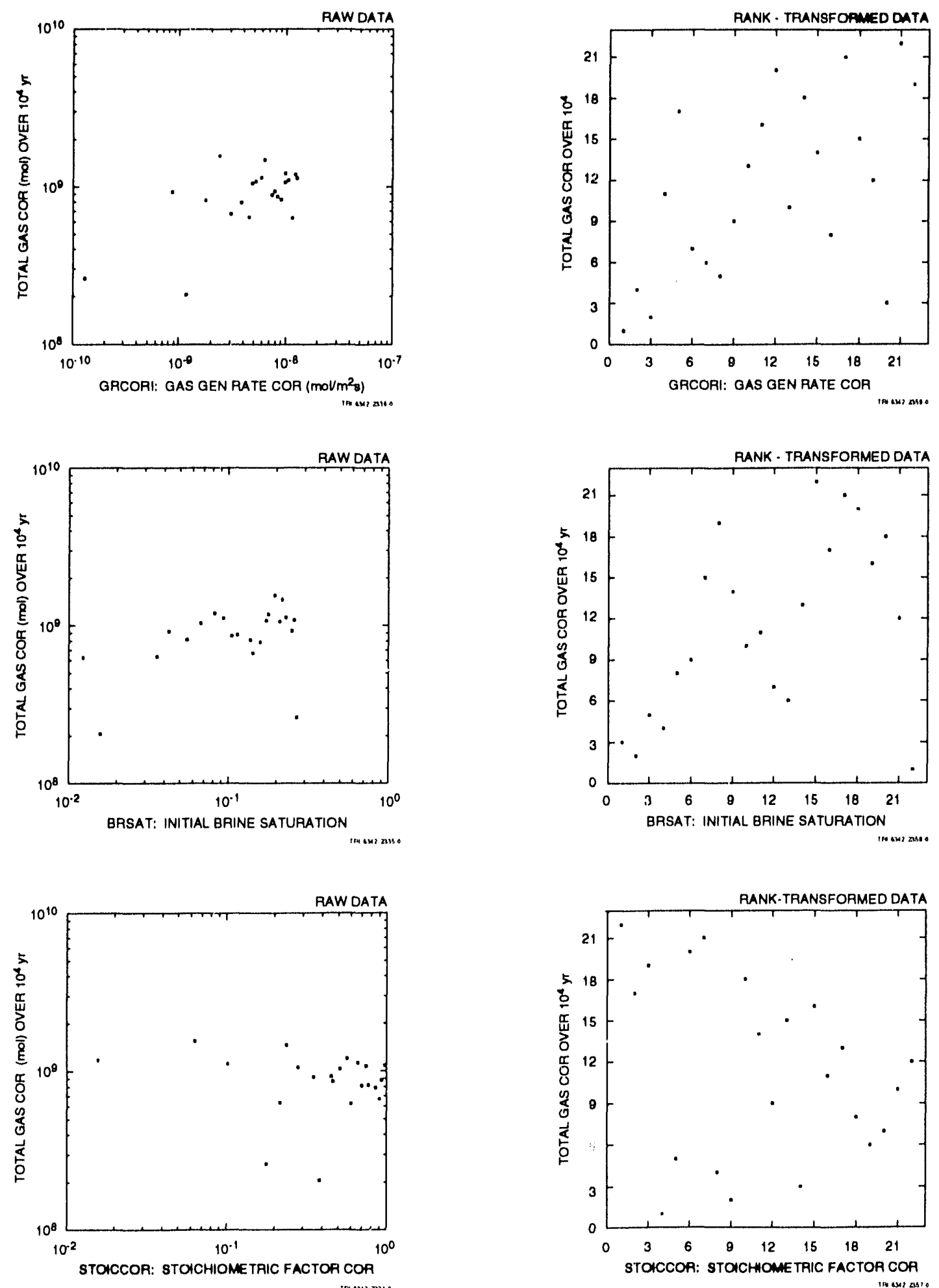

Figure 3-5. Scatterplots relating cumulative gas production over 10,000 yr due to corrosion to GRCORI (gas-generation rate due to corrosion of steel under inundated conditions), BRSAT (initial brine saturation) and STOICCOR (stoichiometric factor for corrosion of steel). 
Cumulative Gas Production

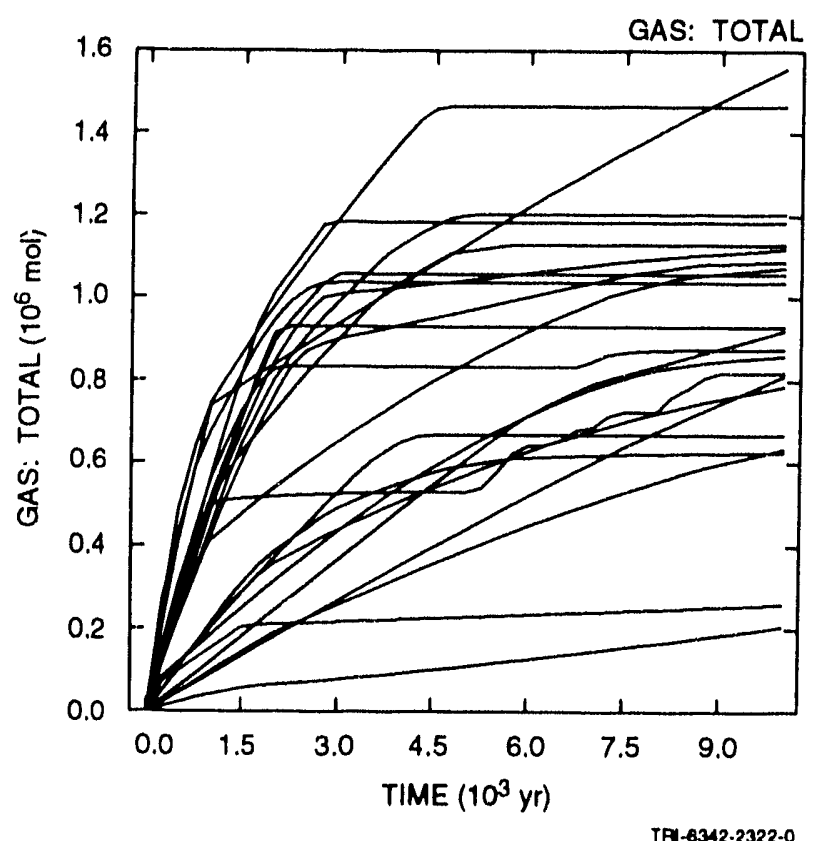

Partial Rank Correlation Coefficients for Cumulative Gas Production

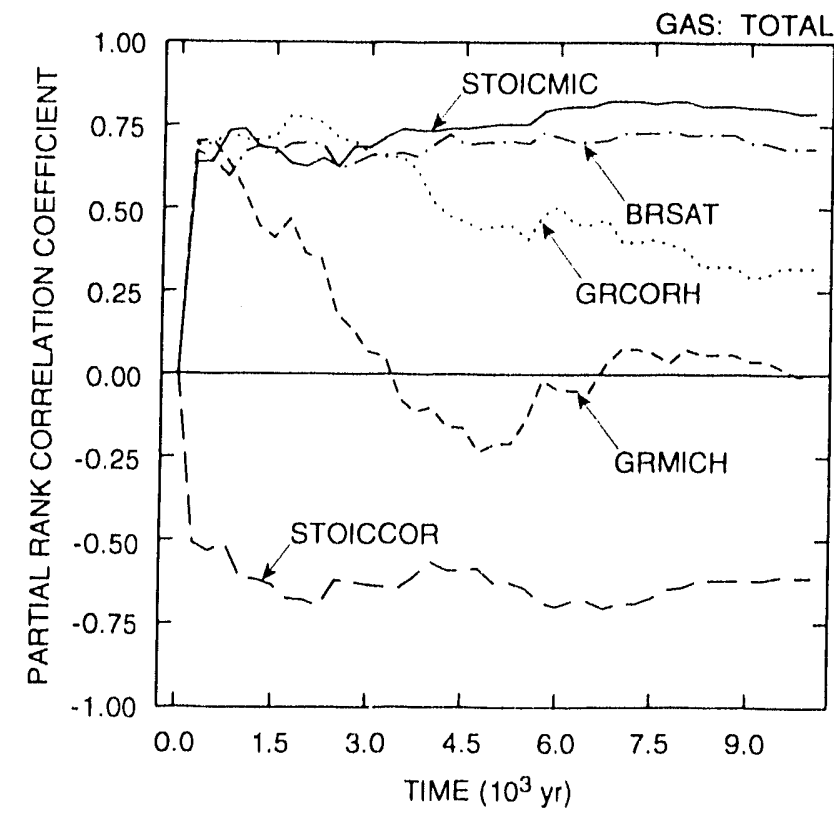

Figure 3-6. Uncertainty and sensitivity analysis results for total gas production (i.e., both corrosion of steel and microbial degradation of cellulosics). 
Steel and Cellulosic Inventories
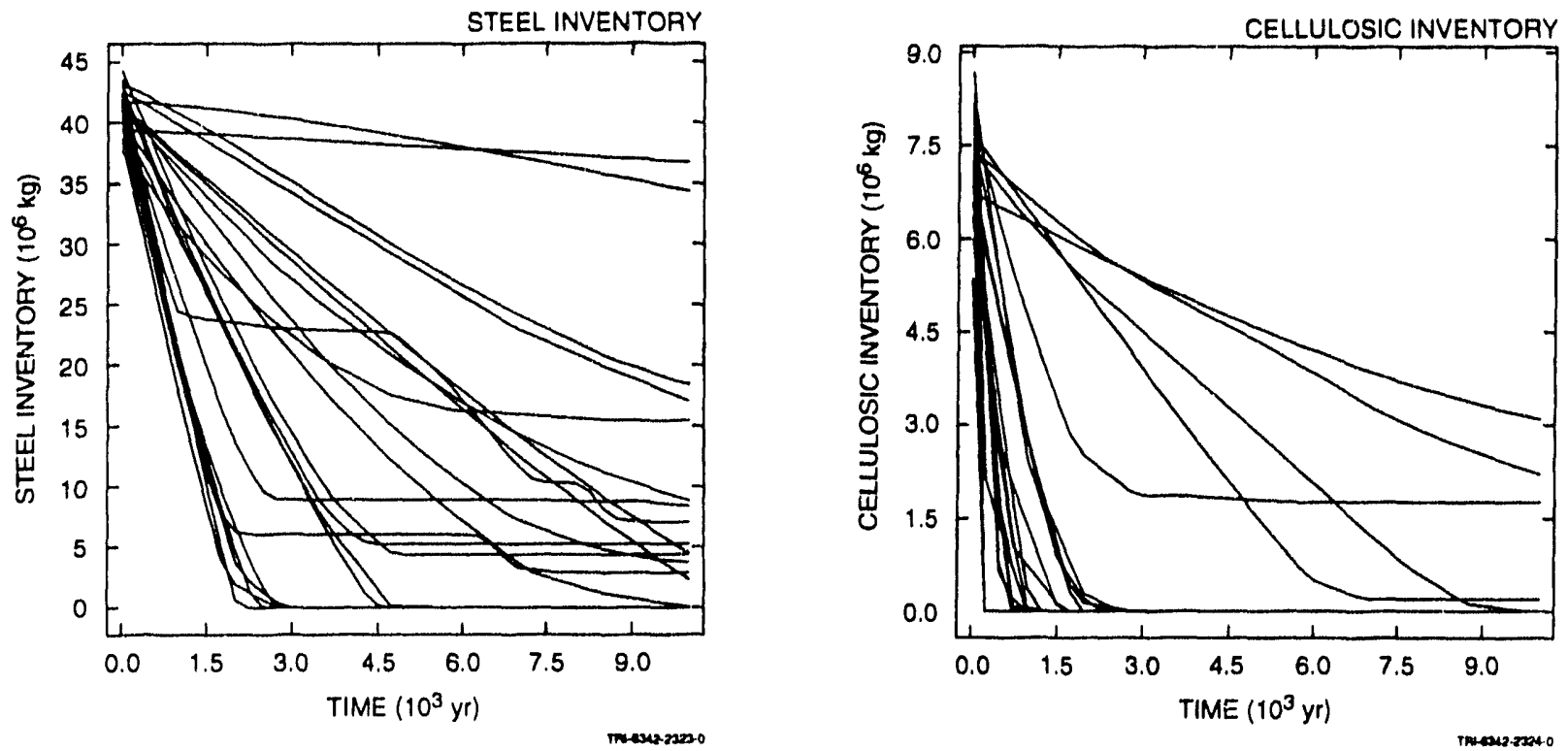

Partial Rank Correlation Coefficients for Steel and Cellulosic Inventories
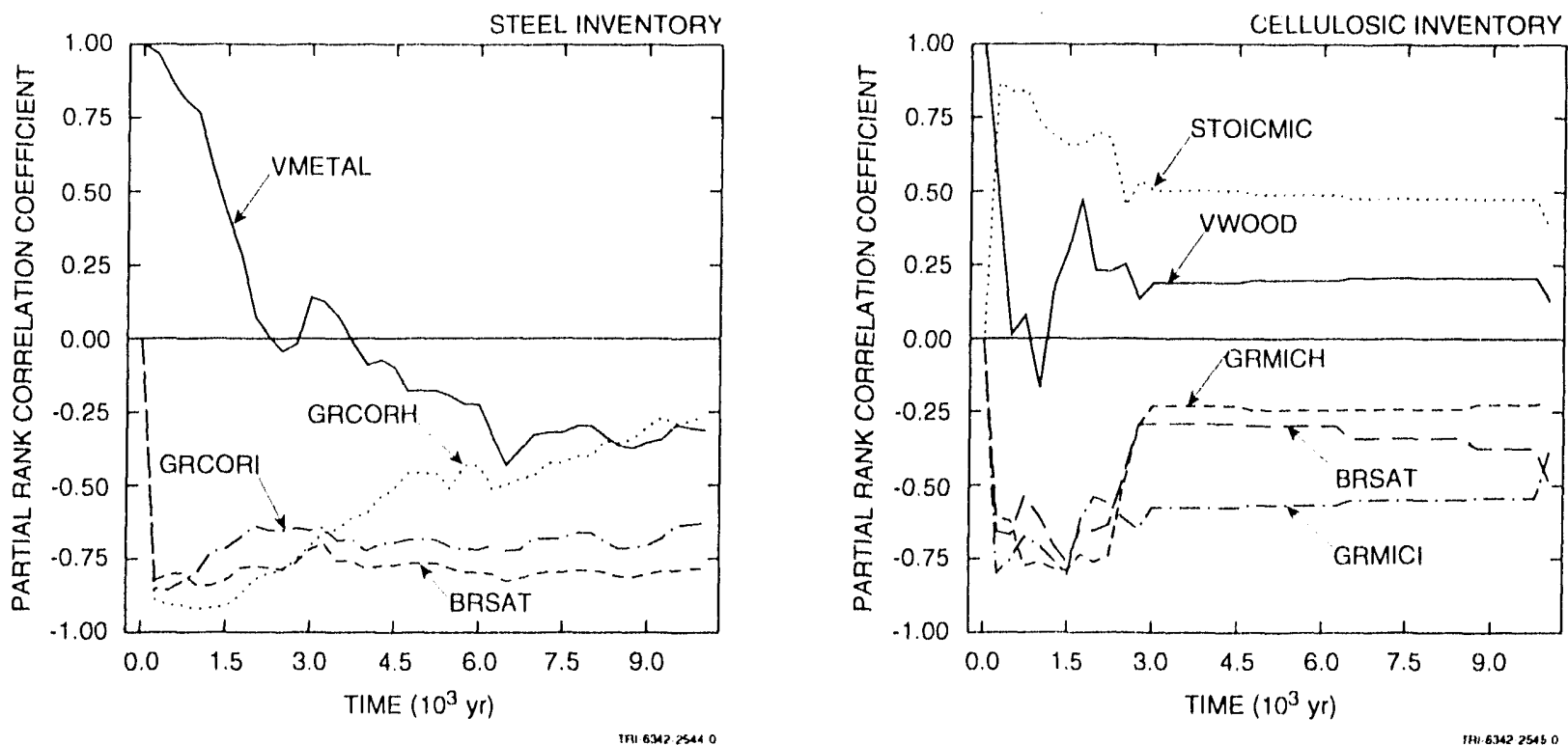

Figure 3-7. Uncertainty and sensitivity analysis results for steel and cellulosic inventories in waste panel. 
inventory of steel and cellulosics is often exhausted or significantly depleted after the first few thousand years.

The lower frame in Flgure 3-6 presents sensitivity analysis results based on partial rank correlation coefficients for total gas production. Positive effects are indicated for GRCORH (gas-generation rate for corrosion of steel under humid conditions), GRMICH (gas-generation rate for microblal degradation of cellulosics under humid conditions), STOICMIC (stoichiometric coefficient for microbial degradation of cellulosics) and BRSAT (initial brine saturation), and negative effects are indicated for STOICCOR (stoichiometric factor for corrosion of steel). For the entire $10,000-y r$ period, the most important variables are STOICMIC, BRSAT and STOICCOR.

The regression analysis in Table $3-5$ is for cumulative gas production over 10,000 yr due to both corrosion and microbial degradation. The only variable selected in the analysis is STOICMIC (stoichiometric coefficient for microbial degradation of cellulosics), which has a positive regression coefficient and can account for 33 of the variability in total gas production. The indicated effect for STOICMIC is consistent with its dominant influence on gas generation due to microbial degradation as indicated in Figure $3-3$ and Table 3-3. As for cumulative gas production over $10,000 \mathrm{yr}$ due to corrosion, the examination of scatterplots indicates that no single variable exerts a dominant influence on cumulative gas production due to corrosion and microbial degradation.

As previously indicated, the upper two frames in Figure 3-7 show the time-dependent steel and cellulosic inventories associated with the individual. sample elements. The lower two frames present sensitivity analyses based on partial rank correlation coefficients. The steel inventory is initially dominated by VMETAL (fraction of total waste volume occupied by IDB metals and glass category), with the importance of this variable decreasing with time. The variables GRCORI (gas-generation rate for corrosion of steel under inundated conditions), GRCORH (gas-generation rate for corrosion of steel under humid conditions) and BRSAT (initial brine saturation) have negative effects on the stcel inventory. The negative relationships involving GRCORI, GRCORH and BRSAT result from their effects on increasing the rate of corrosion.

The cellulosic inventory is initially dominated by VWOOD (Eraction of total waste volume that is occupied by IDB combustible waste category), with the importance of this variable decreasing rapidly with time. An additional positive effect is indicated for STOICMIC (stoichiometric coefficient for microbial degradation of cellulosics). Increasing STOICMIC tends to increase gas production and thus increase the fraction of the 
Table 3-5. Stepwise Regression Analysis with Rank-Transformed Data for Total Gas Production Over 10,000 yr Due to Both Corrosion and Mlcroblal Degradation.

\begin{tabular}{|c|c|c|c|}
\hline \multirow[b]{2}{*}{ Stepa } & \multicolumn{3}{|c|}{$\begin{array}{l}\text { Total Gas Productlon over } 10,000 \mathrm{yr} \\
\text { (Corrosion and Blodegradation) }\end{array}$} \\
\hline & Variableb & SRCC & $R^{2}$ \\
\hline 1 & STOICMIC & 0.57 & 0.3 \\
\hline
\end{tabular}

\footnotetext{
a Steps in stepwise regression analysis

b Varlables listed in order of selection in regression analysis

c Standardized regression coefficients in final regression model

d Cumulative $R^{2}$ value with entry of each varlable into regression model
}

waste panel pore volume that is filled with gas; in turn, this reduces the rate at which cellulose is consumed by microbial degradation. Negative effects are indicated for GRMICI (gas-generation rate due to microbial degradation of cellulosics under inundated conditions), GRMICH (gas generation rate due to microblal degradation of cellulosics under humid conditions) and BRSAT (initial brine saturation), with increasing values for each of these variables tending to increase the rate at which cellulose is consumed by microbial degradation. At times greater than $3000 \mathrm{yr}$, the cellulose inventory is completely depleted for most sample elements, with the result that the calculated partial correlation coefficients have little meaning due to the large number (i.e., 17 out of 22) of zeros involved.

\subsubsection{Gas Saturation and Pressure in Waste Panel}

Time-dependent values for average gas saturation in the individual waste blocks (i.e., averaged over entire waste block) are presented in the left column of Figure 3-8. Although gas saturation initially decreases for some sample elements, the overall tendency is for gas saturation to increase towards an asymptote with increasing time. The gas saturations in Waste Block A tend to be lower than those in Waste Blocks C and B. As shown in Figure 3-1, Waste Block $A$ is adjacent to the shaft and hence loses more gas by flow up the shaft than waste Blocks $C$ and $B$. As the partial rank correlation coefficients for gas saturation in the right column of Figure 3-8 show for all three waste blocks, increasing GRCORH (gasgeneration rate for corrosion of steel under humid conditions) and GRMICI (gas generation rate due to microbial degradation of cellulosics under inundated conditions) tends to increase gas saturation and increasing BRSAT (initial brine saturation) tends to decrease gas saturation, with these 

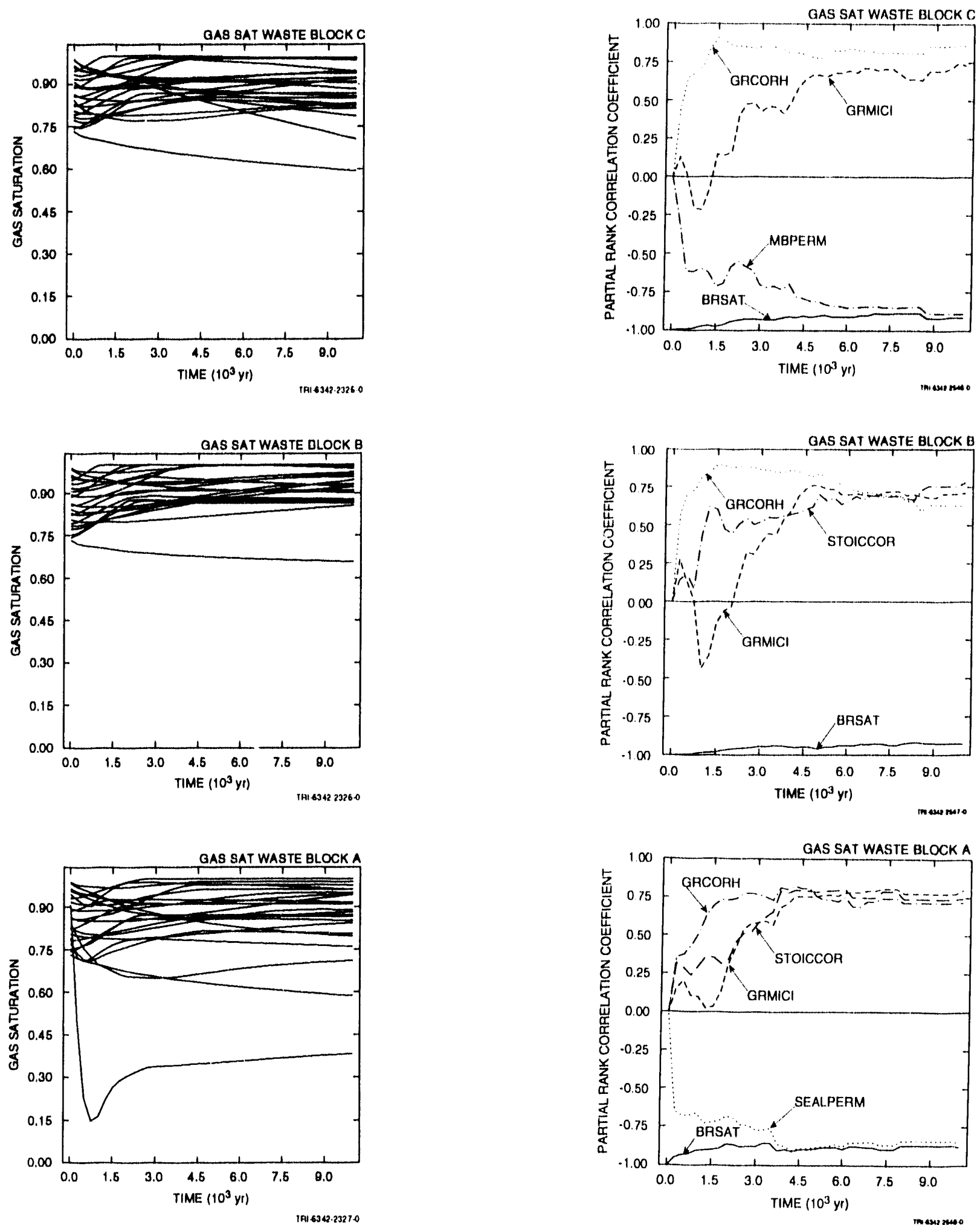

Figure 3-8. Uncertainty and sensitivity analysis results for gas saturation in individual waste blocks. 
effects resulting because increasing GRCORH and GRMICI increases the anount of gas in the panel and increasing BRSAT increases the amount of brine in the pane1.

For Waste Block $C$, a negative effect is also indicated for MBPERM (narker bed permeablity), with this effect occurring because increasing MBPERM increases the rate at which brine flows into Waste Block C from anhydrite layers in the Salado Formation. Due to the structure of the computational grid shown in Figure 3-1, most inflowing brine enters the repository through waste Block $\mathrm{C}$. In addition, the variable STOICCOR (stoichiometric factor for corrosion of steel) appears in the analysis for gas saturation in Waste Block $B$. As discussed at the end of this section, incressing STOICCOR decreases the initial pore volune in the repository. Since the infial amount of brine is set as a fraction of the pore volume, increasing STOICCOR also reduces the amount of brine initially present in the pore space of the repository. Thus, as constant gas generation rates are assumed in this analysis, the total brine inventory can be depleted more rapidly when STOICCOR is large than when STOICCOR is small (i.e., because large values for STOICCOR result in less brine being initially present). This relationship between STOICCOR and amount of brine initially present in the repository is resulting in the positive correlations between STOICOR and gas saturation in Waste Block B and also in Waste Block A. This relationship is an artifact of the manner in which initial repository pore volume was set in an attempt to incorporate the competing effects of gas generation and waste panel closure due to salt creep.

As shown in the left column of Figure 3-9, time-dependent gas pressure in the individual waste blocks tends to ncrease monotonically until a maximum is reached and then undergoes a slower monotonic decrease. The largest gas pressures are approximately $2 \mathrm{MPa}$ above the lithostatic pressure of $14.8 \mathrm{MPa}$. The gas pressures in the three waste blocks are quite similar. As comparison of the left column in Figures 3-8 and 3-9 shows, there is more variability in gas saturation between the waste blocks than in gas pressure. Thus, gas appears to be flowing between the waste blocks to a greater extent than brine.

The partial rank correlation coefficients for gas pressure in the right column of Figure $3-9$ indicate that SEALPERM (permeability of seals between waste panels) and SH2PERM (iniddle shaft section permeability) are 

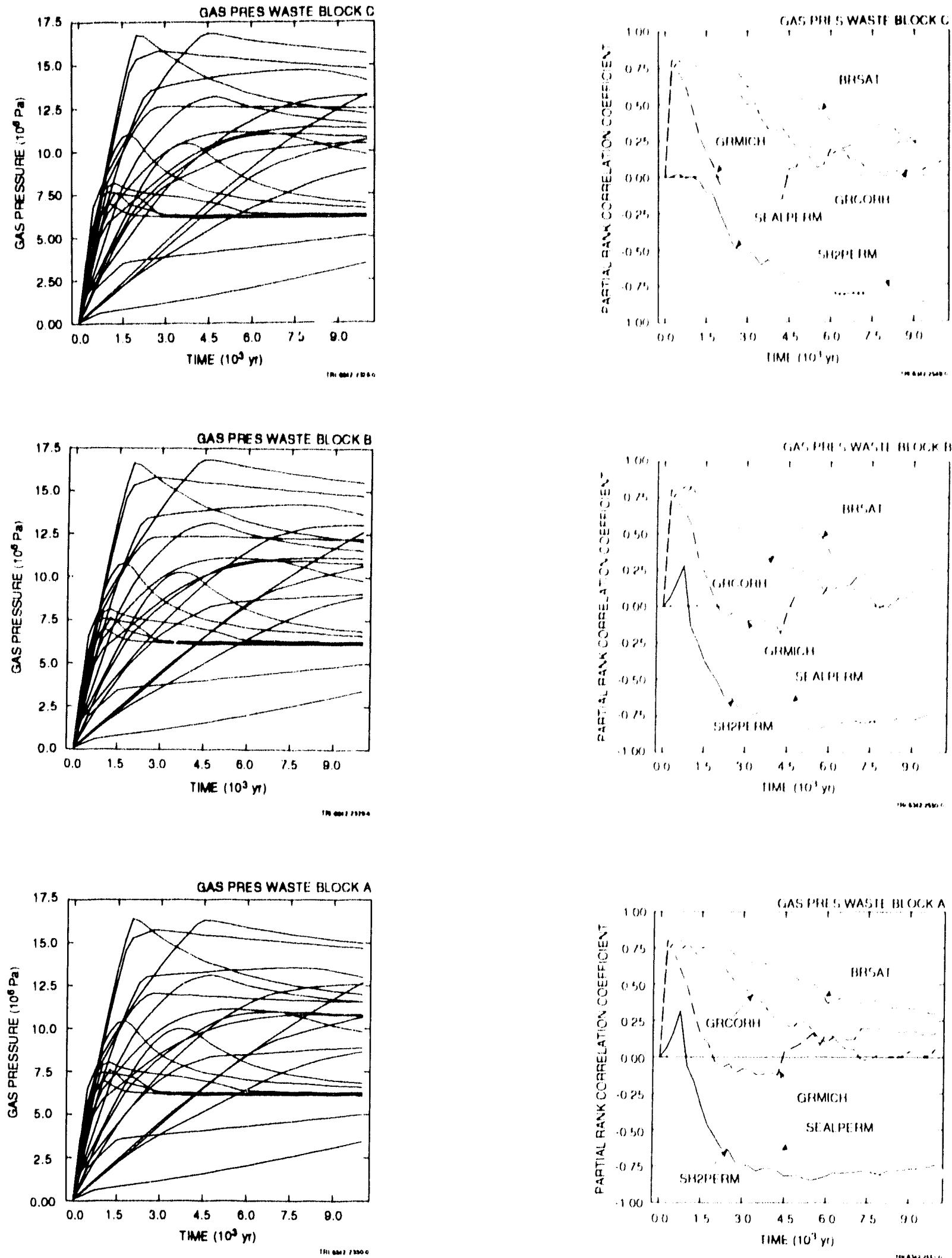

Figure 3-9. Uncertainty and sensitivity analysis results for gas pressure in individual waste blocks. 
the two most Important varlables Influencing gas pressure, with gas pressure tending to decrease as each of these varlables increases. Prior to 5000 yr, gas pressure tends to Increase as the varlables GRCORII (gasgeneration rate for corrosion of steel under humid conditions), GRMICH (gas-generation rate for inlcrobial degradation of cellulosics under humid conditions) and BRSAT (Inltial brine saturation) increase due to the influence of these varlables on increasing gas production. However, as shown in Flgure 3-4, most gas production is over by $5000 \mathrm{yr}$, with the result that gas pressure is then controlled by varlables such as SEALPERM and SH2PERM that influence gas flow out of the waste blocks.

The 1991 WIPP preliminary performance assessment dld not directly model closure of the waste panels. However, possible interaction of gas generation and panel closure was incorporated into the analysis by seting the inftal pore volume in a waste panel to the volume necessary to contain al.1 waste-generated gas at 11 thostatic pressure $(1, \mathrm{e}, 1.4 .8 \mathrm{MPa}$ ). As a result, Initial pore volume is a function of STOICCOR (stolchiometric factor for corrosion of steel), STOICMIC (stolchiometric coefficient for microbial degradation of cellulosics), VMETAL (fraction of total waste volume occupled by IDB metals and glass waste category) and VWOOD (fraction of total waste volume occupjed by IDB combustible waste category). As shown by the upper frame in Figure 3-10, pore volume remains essentially fixed at its inftial volume, although there is a small response to changing gas pressures through rock compressibility effects. Further, the partial rank correlation coefficients in the lower frame of Figure 3-10 indicate that pore volume is indeed a function of STOICCOR, STOICMIC, VMETAL and VWOOD.

\subsubsection{Gas Migration}

A primary focus of the studies contalned in this report is the migration of gas away from the waste panels. For Case 2, this means gas migration through the shaft to the Culebra Dolomite. As shown by the upper two frames in Figure $3-11$, most gas leaving the repository does indeed flow up the shaft to the Culebra Dolomite.

Sensitivity analysis results based on partial rank correlation coefficients for cumulative gas flow wht of the repository are given in the lower left frame of Figure 3-11. These results indicate that total gas flow out of the repository tends to increase with increasing gas generation and decreasing resistance to gas flow. In particular, gas outflow increases as BRSAT (Initial brine saturation), GRCORI (gas-generation rate for corrosion of steel under inundated conditions) and GRCORH (gas generation rate for corrosion of steel under humid conditions) 
Total Pore Volume In Ropository

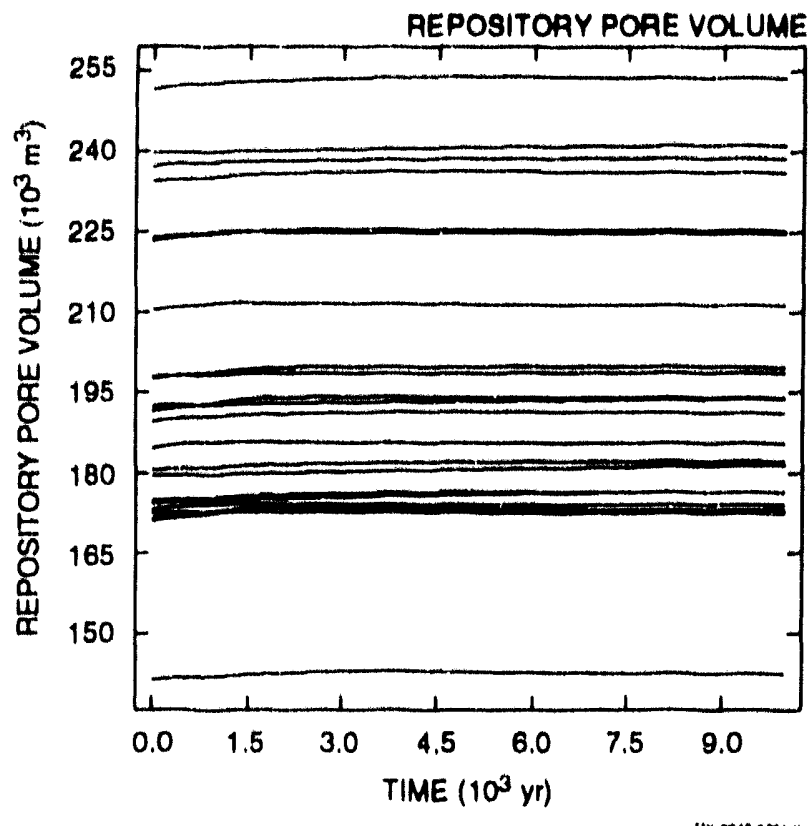

Partial Rank Correlation Coeffleients for Total Pore Volume In Repository

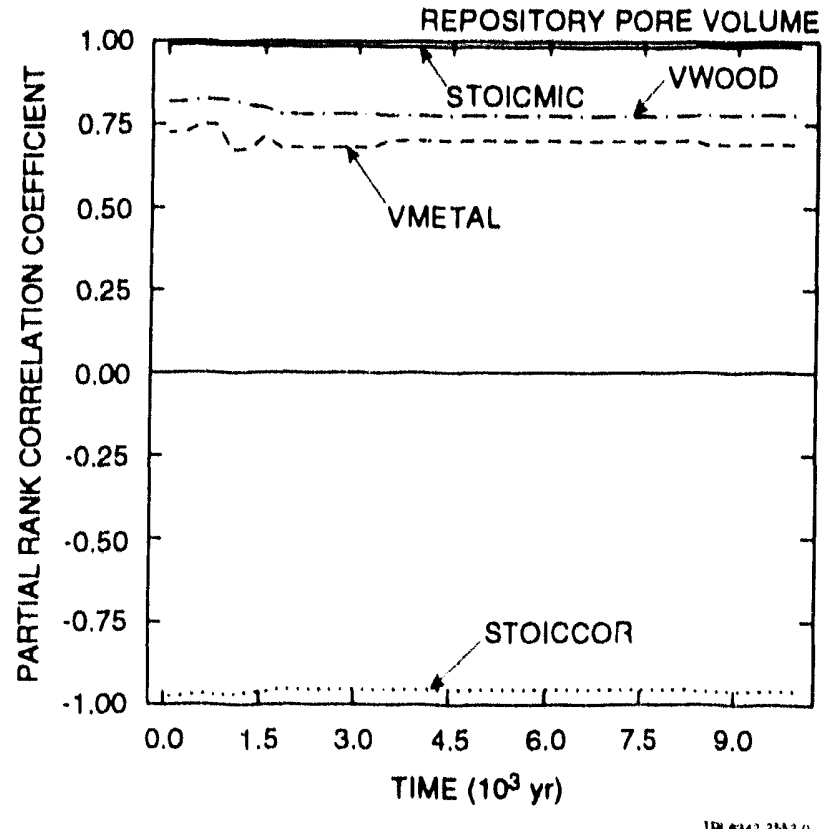

Figure 3-10. Uncertainty and sensitivity analysis results for total pore volume in repository. 
Cunulative Gas Flows out of Reposttory and through Shaft to Culebra Dolomite.
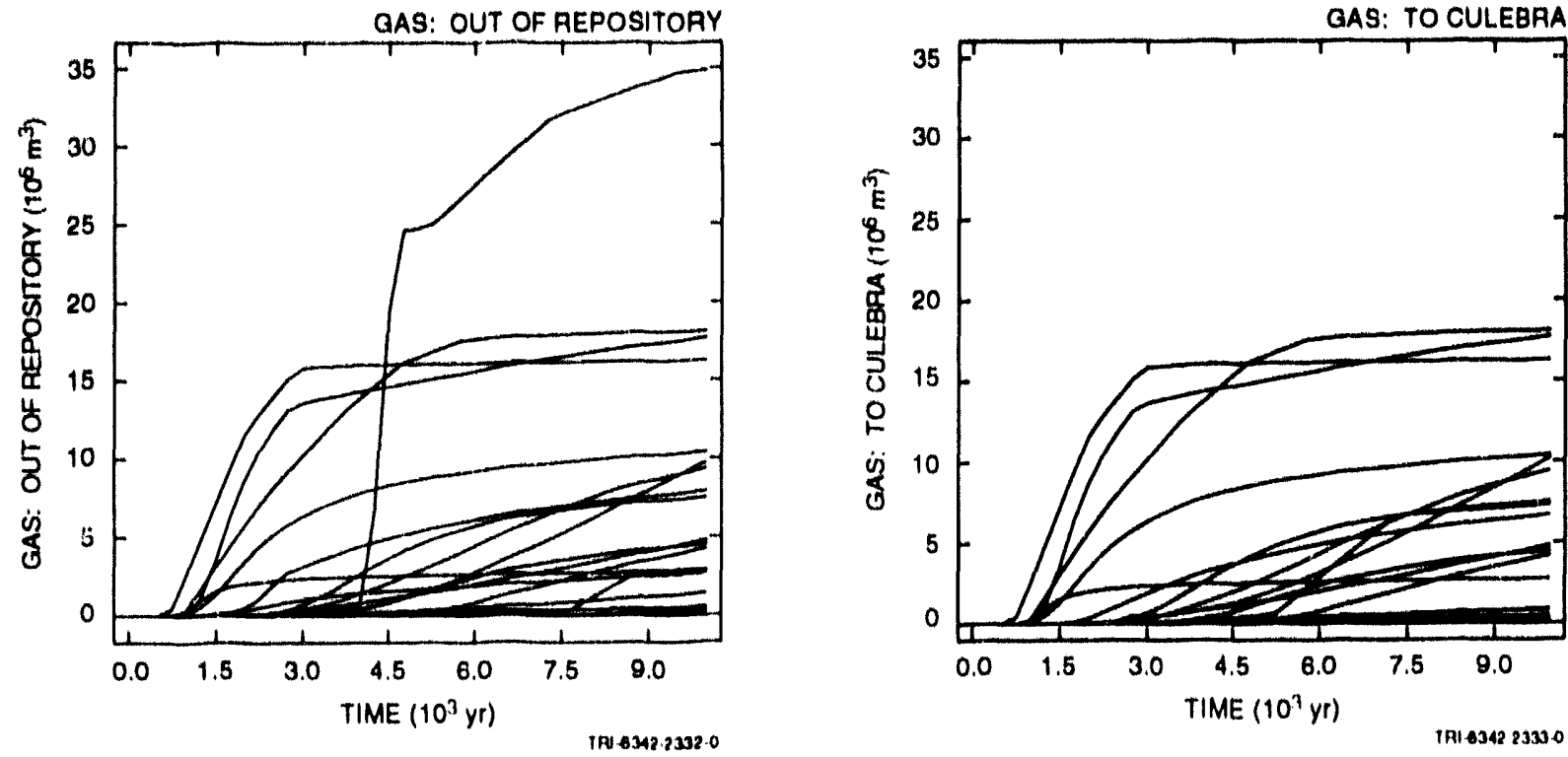

Partial Rank Correlation Coefficients for Cumulat lve Gas Flows out of Repository and through Shaft to Culebra Dolomite
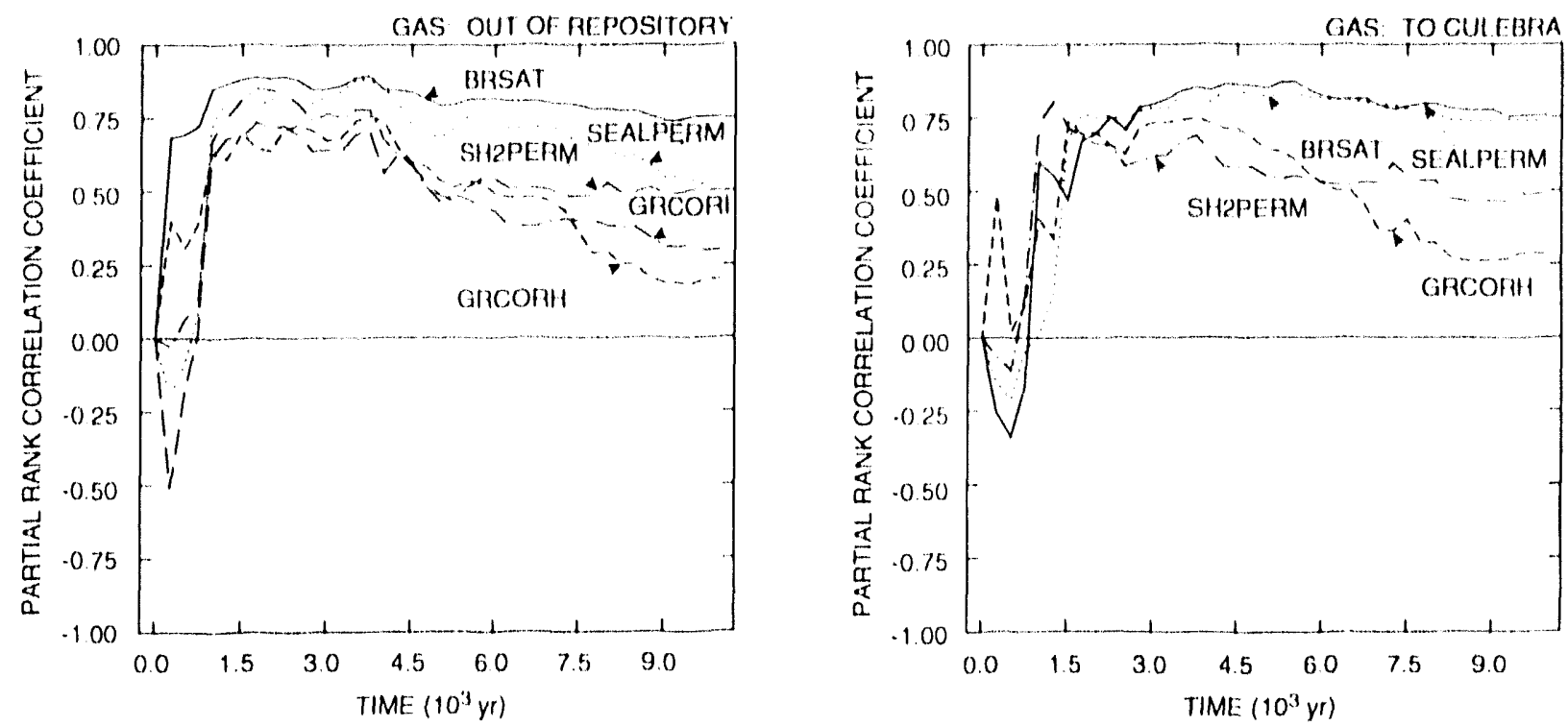

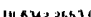

Figure 3-11. Uncertainty and sensitivity analysis results for cumulative gas flow out of repository and through shaft to Culebra Dolonite. 
Increase due to the effect of these variables on incroasing, gas generation, and gas out llow Increases as SlAAPLRM (permeablllty of seals between waste panels) and SHzPERM (permeabillty of middle shaft section) increase due to decreased resistance to gas $110 \mathrm{w}$.

The sensltivlty analysls results for cumblat lo gas flow through the shaft to the Culobra Dolomlte appear in the lower rlght of Figure 3-11. As examination of the partial rank correlation cocflfolentes fo this frame shows. the analysis is inltally unstable with wide swlugs in the values for these coeffelents. This instability results from the fact that many of the releases to the culebra bolomfte are 0 at carly times $(1.0,<<1500$ yr), wlth the result that the analysts resules are domllated by random nolse for the first 1500 yr (e.g., changing, from 19 zeros out of 22 observattons to 18 zeros out of 2 ? observal ions can caluse large, but meaningless, swings in the values for the partial correlation coeffetents). After about 3000 yr, the effects of the lndividual varlables are clearer, whth positive of fects Indleatod for varlables that Increase gas genoration (1.e., BRSA'T and (iRCORH) and decrease resistance to gas flow (1.e., SEALPERM and SHzPLRM). However, four sample elements result In no release to the culcbra, which tends to reduce the effectiveness of partial corrolation coeflicionts in fdentfying the effects of individual variables.

When zero observations and possibly other patterns of behavior are present, the exandnation of scaterplots can help reveal the relat fonships between sampled and calculated vartables. The scattorplots for cumblat lve gas flow through the shat to the culcbra bolomite over lo, ood) yr versus flve Indlufdual varlables are shown in figure 3-12. These varlables were selected as having the strongest relat jomships with cumblat lve gas flow through the shaft to the Culebra bolomite on the bassis of a vistal examination of the scatcerplots for the 16 variables deflaced in Table $3-1$. Although all the scatterplots show a posttive relat ionship between the sampled variable and cumulative gas flow, none of the relationships are very tight. Further, the four zero releases are scateced over the range of each sampled variable. Thus, no single varlable appears to dominate cumulative gas release to the culebra. As shown in lig. 3-1, the shaft seal permeabilitios SHlPERM, SH2PERM and SH3PERM are correlated, and only the middle shaft permeabllity SH?PERM was included in the partial correlation analysis. 

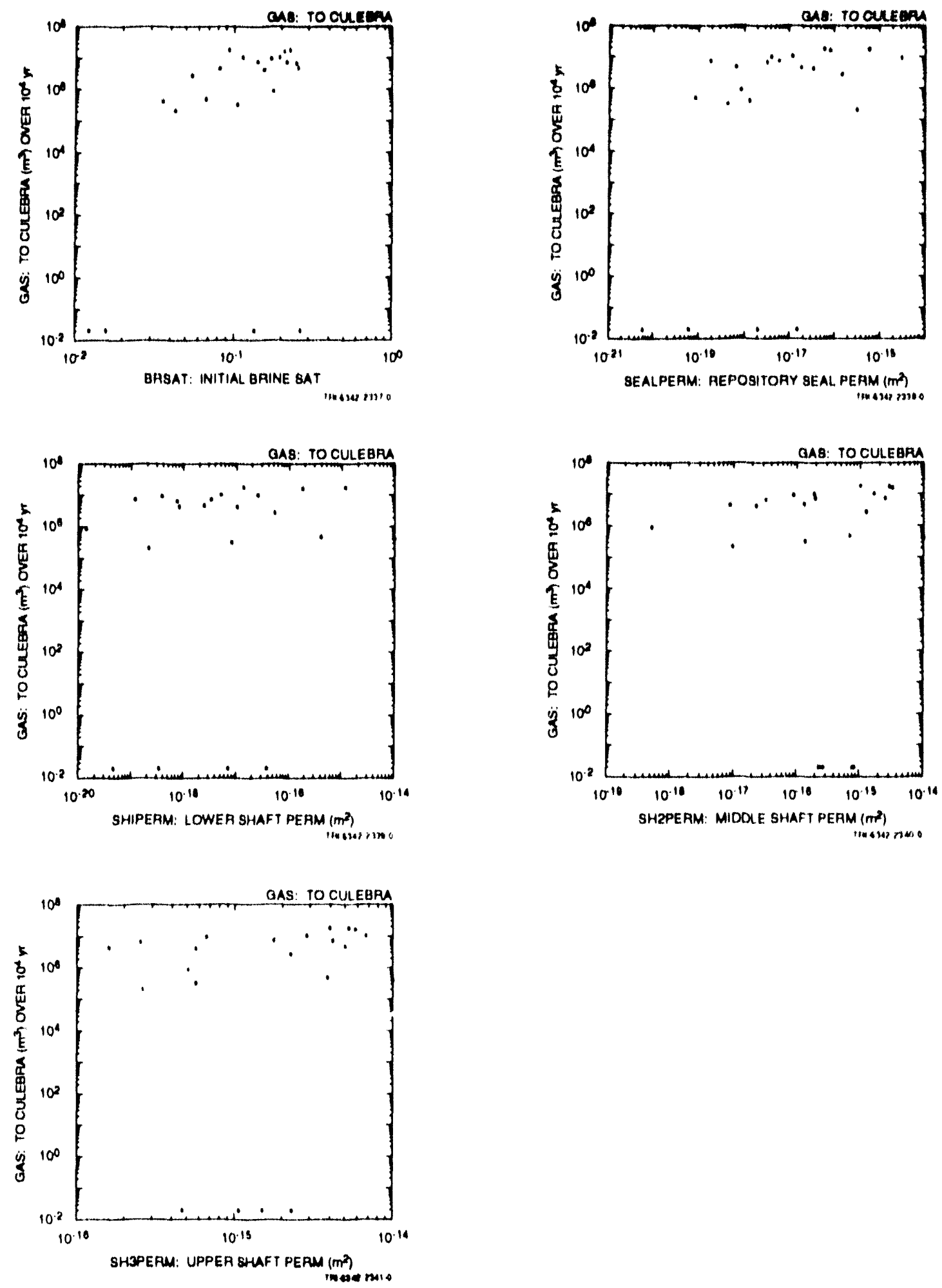

Figure 3-12. Scatterplots for cumulative gas flow over 10,000 yr through the shatt to the Culebra Dolointe for the following sampled variables: BRSAT (initial brine saturation), SEALPERM (permeabllity of seals between waste blocks in repository), SH1PERM (permeability of lower shaft section), SH2PERM (pormeability of middle shaft section) and SH3HERM (permeability of upper shaft section). 
Very little brine migration away from the waste panels occurred in this analysis case. Of the 22 sample elements used in this analysis, only 4 resulted in brine migration away from the waste panels.

As previously noted, the analysis results contained in this section were obtained under the assumption that the pore space in the shaft was initially gas-filled. The results obtained with this assumption are similar to, but not identical with, the results obtained under the as sumption that the pore space in the shaft is initially brine-filled. For example. the scatterplot of cumulative gas flow to the culebra over 10,000 yr (on a linear scale) versus SH1PERM (permeability of lower shaft section) (on a logarithmic scale) for the initially gas-filled shaft is given in Figure 3-13. The corresponding scatterplot for the initially brine-filled shaft is given in Figure 5-1 of WIPP PA, 1992. As comparison of these two scatterplots shows, the two assumptions do indeed lead to similar, but not identical, results.

\subsection{Discussion}

The inventories of steel a.ld cellulosics are substantially consumed by corrosion and microbial degradation for most sample elements. Variables affecting gas generation rates are important for gas production at early times but not for gas production over the entire 10,000 yr period under consideration. Overall, the most important variables for total gas production are the two stoichiometric terms and initial brine saturation.

The analyses often produce brine saturations that are below residual brine saturation when averaged over entire waste blocks. Thus, there are significant regions within the individual waste panels in which brine flow will not take place. Under such conditions, radionuclides cannot be transported from these regions by flowing brine.

Pressures in the waste blocks typically remained below 1 ithostatic pressure (i.e., 14.8 MPa). However, this may be primarily due to an analysis assumption made to resolve the competing effects of gas pressurization of the waste panels and compaction of the waste due to overburden pressure.

Gas flow to the Culebra resulted for 18 of the 22 sample elements used in the analysis. Thus, the sealing system modeled in this analysis does not prevent gas flow to the Culebra. The dominant variables with respect to such flow were initial brine saturation in the waste, permeability of seals between waste blocks, and permeabiliiy of seals in the shaft. In contrast, 


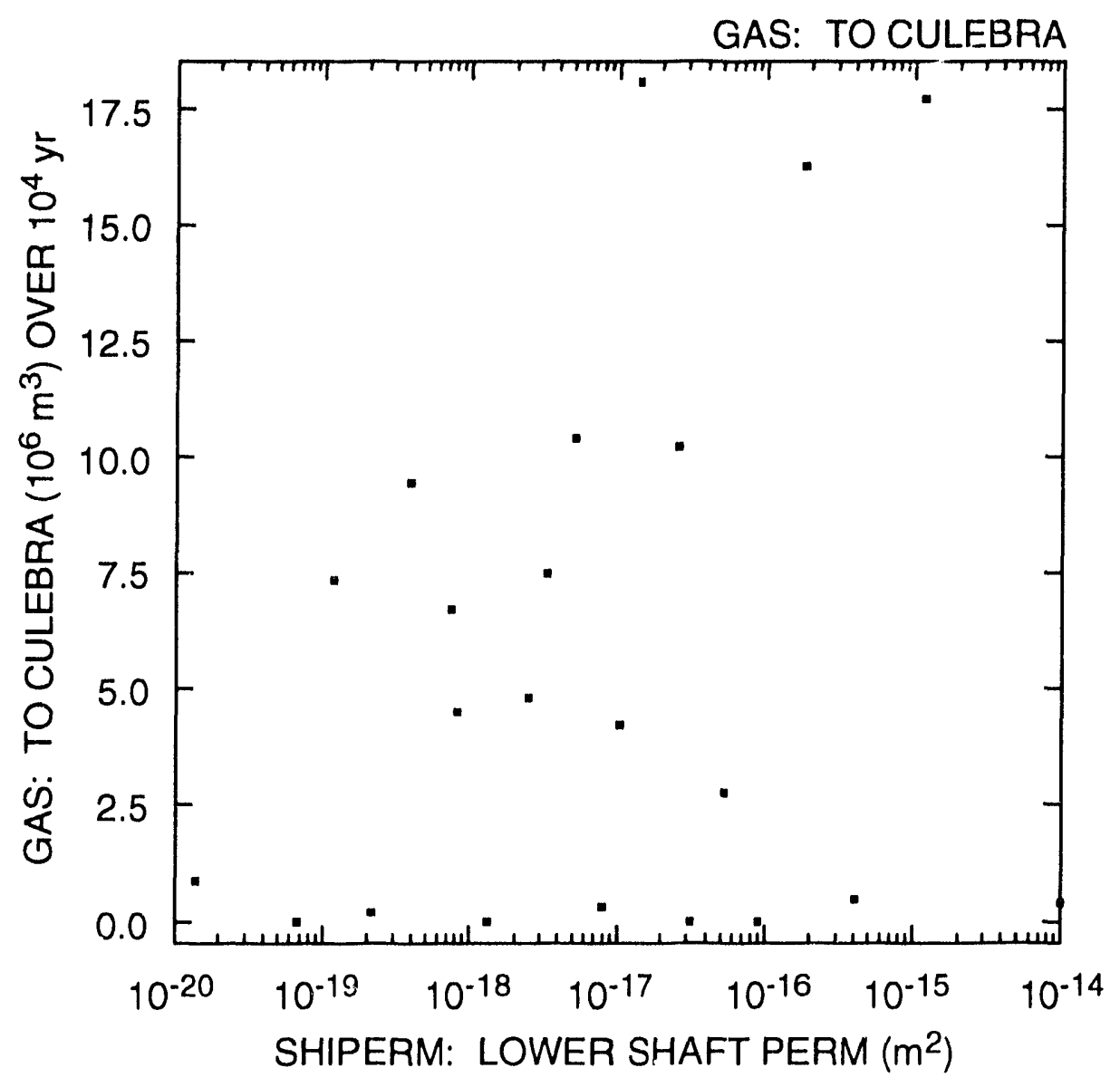

Figure 3-13. Scatterplot for cumulative gas flow over 10,000 yr through the shaft to the Culebra Dolomite versus SH1PERM (permeability of lower shaft section). The results in this figure and elsewhere in this section were generated with the assumption that the pore space in the shaft is initially gas-filled. 
brine flow away from the waste panels occurred for only 4 of the 22 sample elements. The importance of panel seal permeability results in part from the assumption that the disturbed rock zone permeability is sufficiently low to prevent significant quantities of gas from bypassing the panel seals.

The analysis for Case 2 used a Latin hypercube sample of size 22 from 16 imprecisely known variables. Comparison of analysis results with those obtained with Case 1, which used a sample of size 60 from 14 variables, suggests that use of a somewhat larger sample size would have produced better-defined results. However, it is unlikely that any of the insights obtained in the analysis would change significantly.

No errors in the implementation or operation of BRAGFLO were observed. 


\section{CASE 3: PERMEABLE SHAFT WITHOUT PANEL SEALS}

\subsection{Summary Description*}

Case 3 differs from Case 2 in the following aspects: (1) the inclusion of the experimental area north of the shaft to account for the additional volume available for gas storage, (2) the inclusion of anhydrite Marker Bed 138 above Anhydrite Layers A and B (see Figure 1-4 of WIPP PA, 1992), (3) the expansion of the disturbed rock zone to include the region around the experimental area, (4) the inciusion of a transition zone with material properties intermediate between those of the disturbed rock zone and the intact Salado Formation, (5) the definition of a single region containing the 10 waste panels and another region containing the seals and backfill, and (6) the inclusion of a single, $10-\mathrm{m}$ shaft seal above Marker Bed 138. The shaft seal design was chosen jointly by the WIPP Performance Assessment Department and the Repository Isolation Systems Department at SNL and is included in the analysis to provide insights on the potential effectiveness of very high-quality, and hence expensive, low-permeability seals emplaced over short distances. The current concept for shaft seals relies on long regions of conventionally emplaced and compacted crushed salt, comparable to the system modeled for Case 2 .

Several features of the model formulation for Case 3 are specific to investigating the effectiveness of short low permeability seals. For example, the region in the shaft above and below the $10-\mathrm{m}$ seal is assumed to be backfill that offers limited flow resistance to fluid flow. In addition, the panel seals, drift seals and backfill are combined into a single region and no credit is taken for the low-permeability barriers that panel seals might provide. The permeability of these seals is assumed to be the same as the permeability of the waste, with the result that the primary effect panel and drift seals have on repository performance is to provide additional gasstorage volume. These assumptions were made to facilitate observations on the effectiveness of the shaft seal. Thus, although Case 3 uses a more detailed representation of the Salado Formation stratigraphy and the disturbed rock zone than Case 2, it is not intended to provide a more realistic approximation of the repository than Case 2.

*Adapted from Section 2.4 of WIPP PA, 1992. 
The computational grid used for Case 3, which is shown in Figure 4-1, is similar to the grid used for Case 2. The grid extends $645 \mathrm{~m}$ vertically from the bottom of the Salado Formation to the top of the Culebra Dolomite, and approximately $39 \mathrm{~km}$ in the north-south direction. Stratigraphy is unchanged from Case 2 except for the addition of Marker Bed 138, which is $0.4 \mathrm{~m}$ of anhydrite located $6 \mathrm{~m}$ above Anhydrite Layers $\mathrm{A}$ and $\mathrm{B}$. The disturbed rock zone extends horizontally $1.0 \mathrm{~m}$ from the waste, and a transition zone with internediate material properties (Chapter 3, WIPP PA, 1992) is assumed to extend upward through Marker Bed 138 and to extend $1.0 \mathrm{~m}$ below Marker Bed 139 into the underlying halite. The shaft is divided into three segments, with a single seal separating two regions of backfill. The sump is assumed to be backfilled, and is included in the lower shaft seginent. As previously indicated, the waste disposal region is divided into two regions, one containing the waste panels and the other containing the panel seals and associated backfill. Figures 2-8 and $2-9$ of WIPP PA, 1992 provide enlarged representations of the horizontal plane through the repository horizon.

Boundary conditions are the same a for Case 2: there is no flow in the normal direction across all far-field boundaries except the lateral boundaries of the Culebra, where the initial pressure of $1.053 \mathrm{MPa}$ is held constant throughout the simulations. Initial pressure in the shaft, drifts, waste, experimental region, the disturbed rock zone, and the transition zone is atmospheric $(0.101 \mathrm{MPa})$. Initial far-field pressure in the Salado Formation is set as in Case 2 by hydrostatic variation from the sampled value for pressure in Marker Bed 139.

Initial brine saturation is assumed to be 1.00 for all undisturbed rock. Initial brine saturation in the shaft is assumed to be residual and is a sampled variable ranging from 0.0 to 0.4 . (Section 2.3.1, WIPP PA, 1991c). Initial brine saturation within the waste is also a sampled variable. The initial brine saturations of the disturbed rock zone and transition zone are adjusted relative to the sampled values for disturbed rock zone and intact halite porosities so that total brine content in these zones is not changed from undisturbed halite. The initial saturation for the seals and backfill is set to the same sampled value used for the shaft.

\subsection{Sampled Variables}

The 20 imprecisely known variables 1 isted in Table $4-1$ are used as input to BRAGFLO for the Case 3 uncertainty and sensitivity studies. As for Cases 1 and 2, the distributions indicated in Table $4-1$ characterize subjective uncertainty. The Case 3 calculations use a Latin hypercube sample of size 60 from the 20 variables in Table 4-1. The resultant sample is listed in Table 3.3-2b of WIPP PA, 1992. 


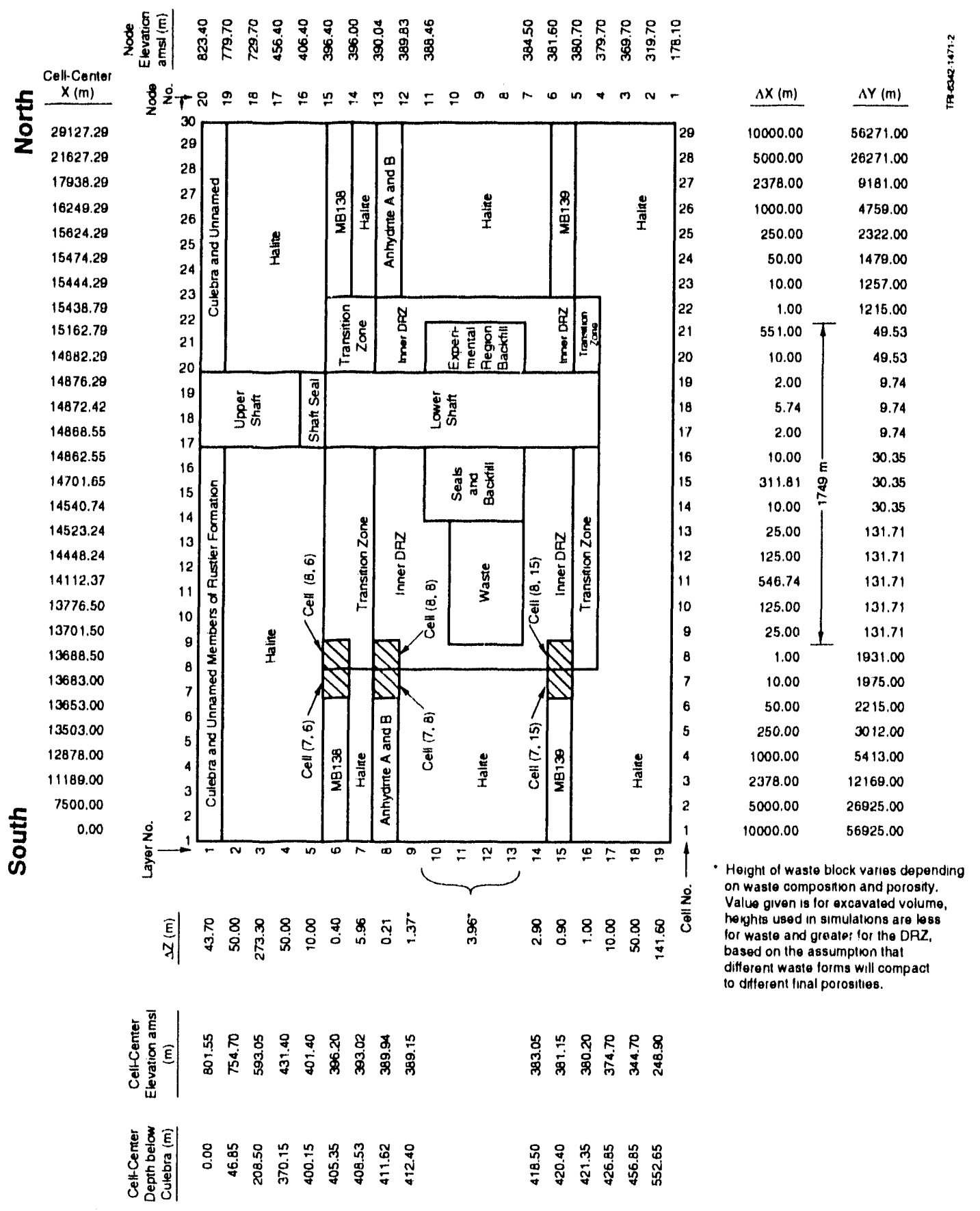

Figure 4-1. Gridding scheme employed with BRAGFLo for the two-dimensional vertical cross-section model used for Case 3 . Individual computational cells are identified with an ordered pair $(i, j)$ of integers, where $i$ designates the horizontal coordinate and $j$ designates the vertical coordinate. 
Table 4-1. Imprecisely Known Variables Used in BRAGFLO in the Estimation of Gas Flow through a 10-m Shaft Seal

Varlable

Definition

BCBRSAT Brooks and Corey residual brine saturation $\left(S_{\ell} r\right)$ (dimensionless). Range: 0.0 to 0.4 . Median: 0.2. Distribution: Plecewise uniform. Additional information: Sect. 3.3.2, WIPP PA, 1992. Variable 12 in Latin hypercube sample.

BCEXP Brooks and Corey exponent $(\eta)$ (dimensionless). Range: 0.2 to 10 . Median: 0.7 . Distribution: Plecewise uniform. Additlonal information: Same as BCBRSAT. Varlable 14 in Latin hypercube sample.

BCGSSAT Brooks and Corey residual gas saturation ( $S_{q r}$ ) (dimenslonless). Range: 0.0 to 0.4 . Medlan: 0.2. Distribution: Plecewise uniform. Additional Information: Same as BCBRSAT. Variable 13 in Latin hypercube sample.

BRSAT Initial fluld (brine) saturation of waste (dimensionless). Range: 0 to $2.76 \times 10^{-1}$. Median: $1.38 \times 10^{-1}$. Distribution: Uniform. Additional information: Section 3.4.9, WIPP PA, 1991c. Varlable 1 in Latin hypercube sample is unlformly distributed on interval $[0,1]$ and used to select value for BRSAT by preprocessor to BRAGFLO.

DRZPERM Disturbed rock zone permeability $(\mathrm{k})\left(\mathrm{m}^{2}\right)$. Range: $1 \times 10^{-18}$ to $1 \times 10^{-13} \mathrm{~m}^{2}$. Median: $3 \times 10^{-16} \mathrm{~m}^{2}$. Distribution: Plecewise loguniform. Additional information: Sect. 3.3.2, WIPP PA, 1992. Variable 17 in Latin hypercube sample.

GRCORH Scale factor used in definition of gas-generation rate for corrosion of steel under humld conditions (dimensionless). Actual gas-generation rate is GRCORH • GRCORI. Range: 0 to $5 \times 10^{-1}$. Median: $1 \times 10^{-1}$. Jistribution: Plecewlse uniform. Additional information: Memo from Brush, July 8, 1991, contained in Appendix A, WIPP PA 1991c; Section 3.3.8, WIPP $P_{i}$. 1991 c. Varlable 3 in Latin hypercube sample.

GRCORI Gas-generation rate for corrosion of steel under inundated conditions $\left(\mathrm{mol} / \mathrm{m}^{2}\right.$ surface area steel $\cdot \mathrm{s})$. Range: 0 to $1.3 \times 10^{-8} \mathrm{~mol} / \mathrm{m}^{2} \mathrm{~s}$. Median: $6.3 \times 10^{-9}$ $\mathrm{mol} / \mathrm{m}^{2} \mathrm{~s}$. Distribution: Plecewise uniform. Additional information: Same as GRCORH. Varlable 4 in Latin hypercube sample.

GRMICH Scale factor used in definition of gas-generation rate due to microbial degradation of cellulosics under humid conditions (dimensionless). Actual gas-generation rate is GRMICH.GRMICI. Range: 0 to $2 \times 10^{-1}$. Medlan: $1 \times 10^{-1}$. Distribution: Plecewise unlform. Additional information: Same as GRCORH. Variable 5 in Latin hypercube sample. 
Table 4-1. Imprecisely Known Variables Used in BRAGFLO in the Estimation of Gas Flow through a 10-m Shaft Seal (Continued)

Variable

GRMICl

MBPERM

MBPRES

SALPERM

SALPOR

SEALPERM

STOICCOR

STOICMIC

\section{Definition}

Gas-generation rate due to microblal degradation of cellulosics under inundated conditions (mol $/ \mathrm{kg}$ cellulosics $\cdot \mathrm{s})$. Range: 0 to $1.6 \times 10^{-8} \mathrm{~mol} / \mathrm{kg} \mathrm{s}$. Median: $3.2 \times 10^{-9} \mathrm{~mol} / \mathrm{kg} \mathrm{s}$. Distribution: Piecewise uniform. Additional information: Same as GRCORH. Variable 6 in Latin hypercube sample.

Permeability (k) in anhydrite marker beds in Salado Formation under undisturbed conditions $\left(\mathrm{m}^{2}\right)$. Range: $8.5 \times 10^{-21}$ to $1.8 \times 10^{-18} \mathrm{~m}^{2}$. Median: $8 \times 10^{-20} \mathrm{~m}^{2}$. Distribution: Plecewise uniform. Additional Information: Sect. 3.3.2, WIPP PA, 1992. Varlable 19 in Latin hypercube sample.

Pressure $(p)$ in anhydrite Marker Bed 139 under undisturbed conditions (Pa). Pressures at other elevations in Salado Formation were varied hydrostatically from sampled value for MBPRES. Pressures Range: $8.2 \times 10^{6}$ to $1.5 \times 10^{7} \mathrm{~Pa}$. Median: $1.3 \times 10^{-7} \mathrm{~Pa}$. Distribution: Plecewise uniform. Additional information: Section 2.4.6. WIPP PA, 1991c. Varlable 18 in Latin hypercube sample.

Permeability $(k)$ In halite component of Salado Formation $\left(\mathrm{m}^{2}\right)$. Range: $1 \times 10^{-25}$ to $1 \times 10^{-21} \mathrm{~m}^{2}$. Median: $2 \times 10^{-24} \mathrm{~m}^{2}$. Distribution: Plecewise loguniform. Additional information: Sect. 3.3.2, WIPP PA, 1992. Varlable 10 in Latin hypercube sample.

Porosity $(\phi)$ in Salado Formation halite and anhydrite under undisturbed conditions (dimensionless). Range: $1 \times 10^{-3}$ to $3 \times 10^{-2}$. Median: $1.55 \times 10^{-2}$. Distribution: Uniform. Additional information: Section 2.3.7, WIPP PA, 1991c. Variable 11 in Latin hypercube sample.

Shaft Seal Permeability $(\mathrm{k})\left(\mathrm{m}^{2}\right)$. Range: $1 \times 10^{-21}$ to $1 \times 10^{-18} \mathrm{~m}^{2}$. Median: $3.16 \times$ $10^{-20} \mathrm{~m}^{2}$. Distribution: Lognormal. Additional information: Sect. 3.3.2, WIPP PA, 1992. Variable 20 in Latin hypercube sample.

Stoichiometric factor for corrosion of steel (dimensionless). Defines proportion of two different chemical reactions that take place during the corrosion process. Range: 0 to 1 . Median: $5 \times 10^{-1}$. Distribution: Uniform. Additional information: Brush and Anderson in Lappin et al., 1989, p. A-6; Section 3.3.8, WIPP PA, 1991c. Variable 2 in Latin hypercube sample.

Stoichiometric coefficient for microbial degradation of cellulosics (mol gas $/ \mathrm{mol}$ $\mathrm{CH}_{2} \mathrm{O}$ ). Range: 0 to $1.67 \mathrm{~mol} / \mathrm{mol}$. Median: $8.35 \times 10^{-1} \mathrm{~mol} / \mathrm{mol}$. Distribution: Unlform. Additional information: Brush and Anderson in Lappin et al., 1989, p. A-10; Section 3.3.9, WIPP PA, 1991c. Variable 9 in Latin hypercube sample. 
Chapter 4. Case 3: Permeable Shaft Without Panel Seals

Table 4-1. Imprecisely Known Variables Used in BRAGFLO in the Estimation of Gas Flow through a 10-m Shaft Seal (Concluded)

Variable

TZPERM

TZPOR

VMETAL

WWOOD
Definition

Transition zone permeability $(\mathrm{k})\left(\mathrm{m}^{2}\right)$. Range: $1 \times 10^{-21}$ to $1 \times 10^{-19} \mathrm{~m}^{2}$. Median: 7 $\times 10^{-21} \mathrm{~m}^{2}$. Distribution: Plecewise Loguniform. Additional Information: Sect. 3.3.2, WIPP PA, 1992. Variable 16 in Latin hypercube sample.

Scale factor used in definition of transition zone and disturbed rock zone porosity $\left(\phi_{Z}\right)$, with the transition zone and disturbed rock zone porosity defined by $\phi_{Z}=$ SALPOR + (0.06 - SALPOR) -TZPOR. Range: 0 to 1. Median: 0.5 . Distribution: Uniform. Additional information: Sect. 3.3.2, WIPP PA, 1992. Variable 15 in Latin hypercube sample.

Fraction of total waste volume that is occupled by IDB (Integrated Data Base) metals and glass waste category (dimensionless). Range: $2.76 \times 10^{-1}$ to $4.76 \times 10^{-1}$. Median: $3.76 \times 10^{-1}$. Distribution: Normal. Additional Information: Section 3.4.1, WIPP PA, 1991c. Variable 7 in Latin hypercube sample.

Fraction of total waste volume that is occupled by IDB combustible waste category (dimensionless). Range: $2.84 \times 10^{-1}$ to $4.84 \times 10^{-1}$. Median: $3.84 \times 10^{-1}$. Distribution: Normal. Additional Information: Section 3.4.1, WIPP PA, $1991 \mathrm{C}$. Variable 8 in Latin hypercube sample.

Use of the $4 / 3$ rule indicated in Section 3.2 to select the sample size for Case 3 results in a sample of size 27. However, the sample of size 22 used for Case 2 did not seem to be as revealing as the sample of size 60 used for Case 1. Therefore, the decision was made to use a larger sample size (i.e., 60), which results in both denser stratification across the range of each variable and a greater variety of variable combinations but at the price of greater computational cost.

In addition to the 20 sanpled variables listed in Table 4-1, the calculations for Case 3 also required values for a number of additional. variables that were fixed at their best-estimate values. These variables and their values are listed in Tables 3.1-1b and 3.3-1a of WIPP PA, 1992. Further, additional discussion of the BRAGFLO input for Case 3 is available in Section 3.3 of WIPP PA, 1992. 


\subsection{Uncertainty and Sensitivity Analysis Results}

Gas flow through the repository and up the shaft to the Culebra Dolomite is the outcome of greatest interest for Case 3. Thus, as for Cases 1 and 2 , a natural starting point is an exploration of the factors affecting gas generation. Uncertainty and sensitivity analysis results for corrosion, microbial degradation and total gas production are presented in sections $4.3 .1,4.3 .2$ and 4.3.3. Then, results for gas saturation and gas pressure in the repository are presented in Section 4.3.4, followed by results for gas migration into the anhydrite marker beds in Section 4.3.5. Finaliy, gas and brine migration through the shaft to the Culebra Dolomite is considered in section 4.3.6.

\subsubsection{Gas Generation Due to Corrosion}

A summary of the results for gas generation due to corrosion is given in Figure 4-2. The two upper frames in Figure 4-2 show cumulative gas generation as a function of time due to corrosion under hunid conditions (upper left frame) and corrosion under inundated conditions (upper right frame). Each curve in the upper two frames results from a single Latin hypercube sample element (i.e., each frame has 60 curves, one for each sample element). Overal1, the range of gas production under humid conditions is similar to the range of gas production under inundated conditions.

Formal sensitivity analysis techniques based on partial rank correlation can be used to investigate the variation in cumulative gas production shown in the upper two frames of Figure 4-2. Specifically, the lower two frames in Figure $4-2$ show time-dependent plots of partial rank correlation coefficients between cumulative gas production and individual variables from Table 4-1. These coefficients were calculated on the basis of vertical slices through the cumulative gas production curves. As a reminder, a positive rank correlation coefficient indicates that two variables tend to increase and decrease together, and a negative rank correlation coefficient indicates that, as one variable increases, the other tends to decrease.

As shown by the partial correlation results in the lower left frame of Figure 4-2, cumulative gas production due to corrosion under humid conditions tends to increase as GRCORH (scale factor used in definition of gas-generation rate for corrosion of steel under humid conditions) and GRCORI (gas-generation rate for corrosion of steel under inundated conditions) increase. The positive effects for GRCORH and GRCORI result because the actual gas generation-rate due to corrosion under humid conditions is defined by GRCORH.GRCORI. As shown by the partial correlation 
Cumulative Gas Production Due to Microblal Degradation of Cellulosics
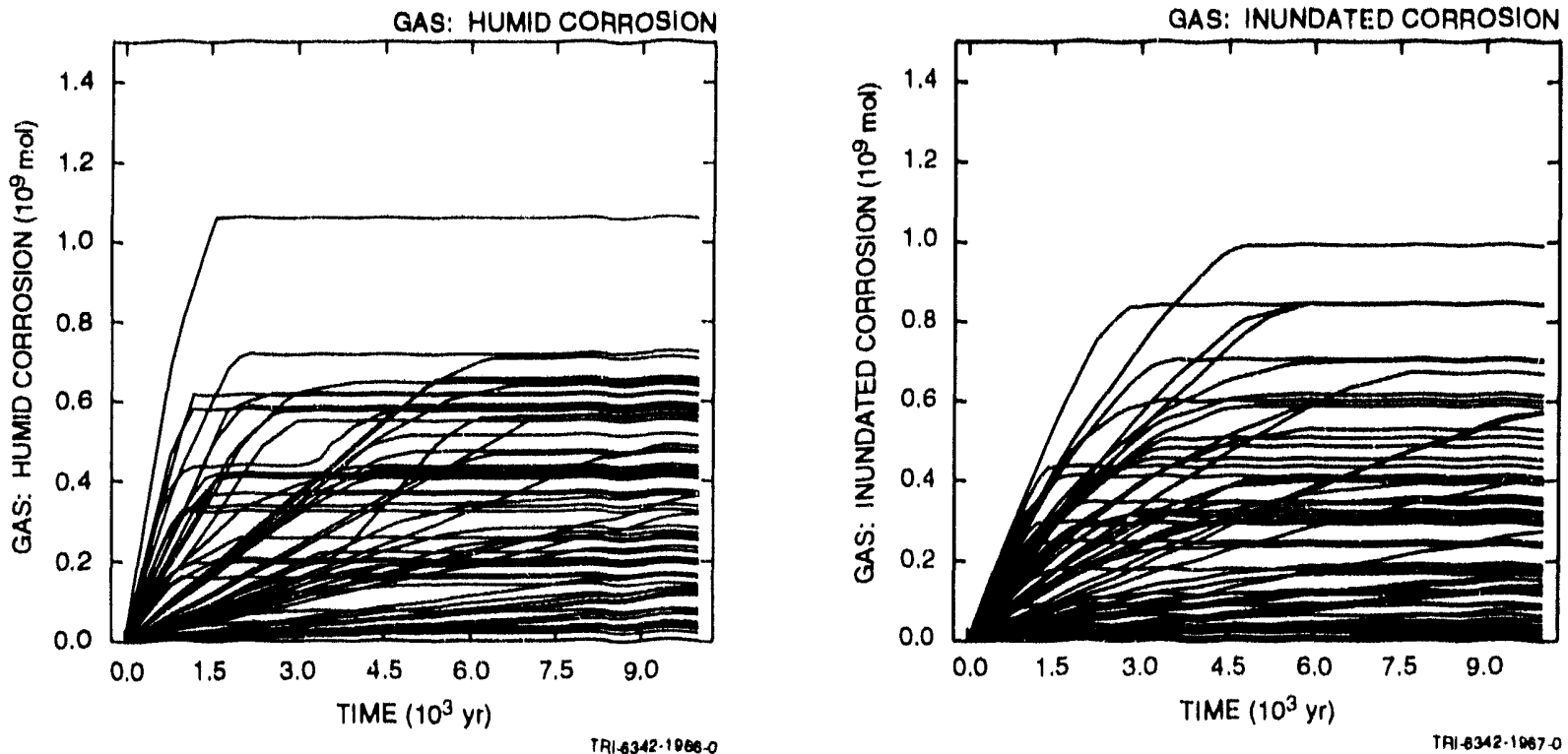

Partial Rank Correlation Coefficients for Cumulative Gas Production Due to Microbial Degradation of Cellulosics
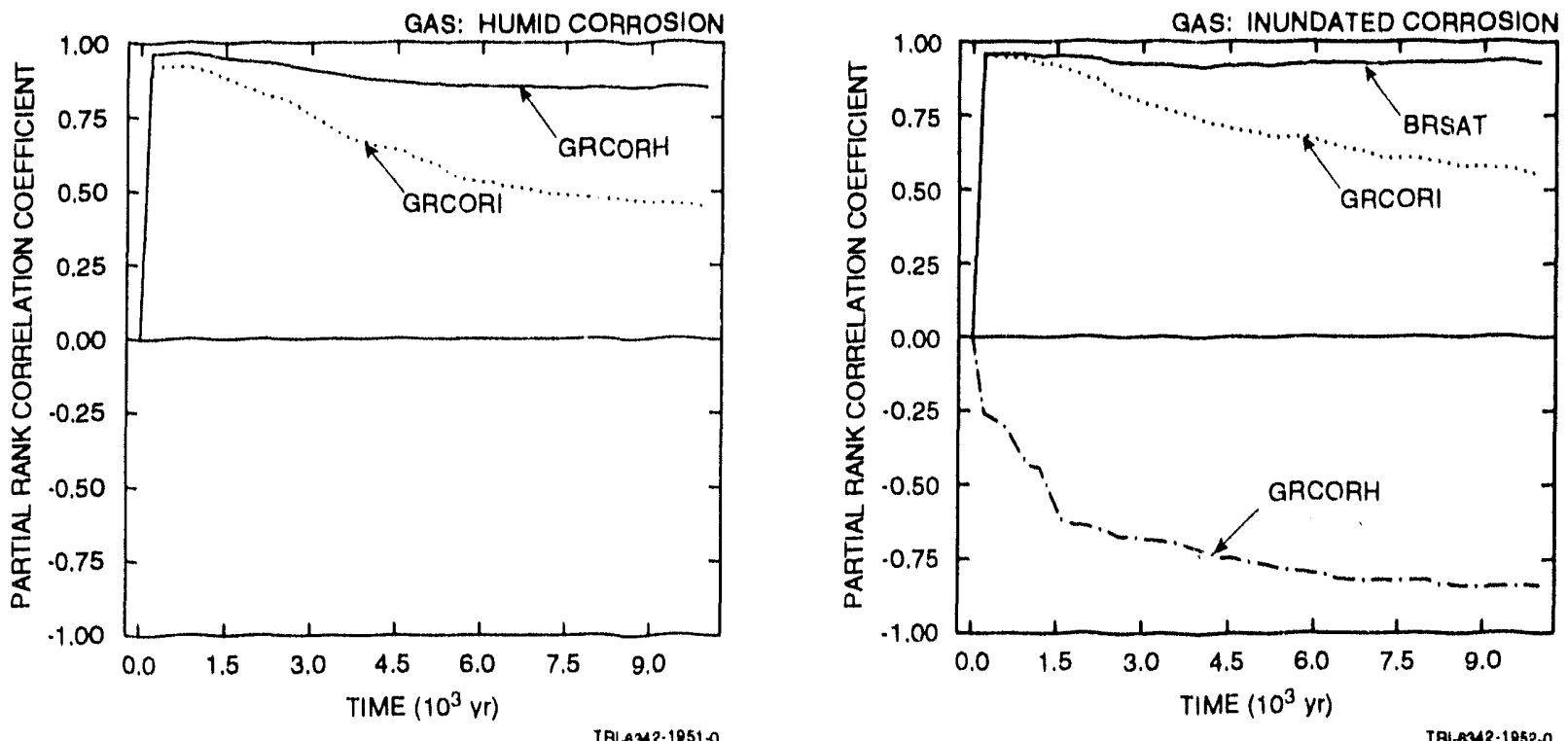

Figure 4-2. Uncertainty and sensitivity analysis results for gas generation due to microbial degradation of cellulosics. 
results in the lower right frame of Figure 4-2, cumulative gas production due to corrosion under inundated conditions tends to increase as BRSAT (initial brine saturation of waste) and GRCORI (gas-generation rate for corrosion of steel under inundated conditions) increase and tends to decrease as GRCORH (scale factor used In definition of gas generation rate for corrosion of steel under humid conditions) increases. The positive effects for BRSAT and GRCORI result because increasling BRSAl increases the amount of steel that will be consumed by corrosion under inundated conditions and increasing GRCORl increases the rate which gas is produced by corroston under inundated conditions. The negative effect for GRCORH results because the increased consumption of steel and brine by corrosion under humid conditions reduces the amount of gas that can be produced by the corrosion of steel under inundated condtelons.

Stepwise regression analysis can also be used to analyze the cumulative gas production results shown in figure 4-2. The two regression analyses shown 1.n Table 4-2 are for cumulative gas production over 10,000 yr due to corrosion under hunid and inundated conditions, respectively. Thus, these two regression analyses are for the gas production values appearing above $10,000 \mathrm{yr}$ in the two upper frames of Figure $4-2$. The regression analysis for gas production under humid conditions indicates positive effects (1.e., positive regression coefficients) for GRCORH (scale factor used in defintion of gas-generation rate for corrosion of steel under humid conditions) and GRCORL (gas-generation rate for corrosion of steel under inundated conditions. As indicated earlfer, the positive effects for GRCORH and GRCORI result because the gas-generation rate for the corrosion of steel under humid conditions is GRCORH-GRCORl. The scale factor GRCORH is the most important variable and accounts for 618 (i.e., $R^{2}=0.61$ ) of the variability in gas generation due to corrosion under hunld conditions. Further, GRCORl accounts for an additional $6 \%$ of the variability (i.e., $678-618=68)$.

The regression analysis in lable 4-2 for gas production under inundated conditions indicates positive effects for BRSAT (initlal brine saturation of waste) and GRCORI (gas-generation rate for corrosion of steel under inundated conditions) and negative effects for GRCORH (scale factor used in definition of gas-generation rate for corrosion of steel under humid conditions) and STOICCOR (stochionetric factor for corrosion of steel). These effects result because increasing BRSAT increases the amount of steel exposed to corrosion under inundated conditions, increasing GRCORI increases the gas-generation rate under inundated conditions, increasing GRCORH decreases the amount of steel available for corrosion under inundated conditions, and increasing STOICCOR decreases the amount of gas produced per unit of steel consumed in the corrosion process. Initial brine saturation (BRSAT) is the most important variable and accounts for 58 of the 
variability in gas generation due to corrosion under inundated conditions. Further, GRCORH, GRCORI and STOICCOR collectively account for an additional 28 of the variability.

\subsubsection{Gas Generation Due to Microblal Degradation}

A summary of the analysis results for gas generation due to microbial degradation is given in Figure 4-3. The upper two frames in figure 4-3 show cumulative gas generation due to interoblal degradation under humld and inundated conditions, respectively. As comparison with the corresponding plots in Figure $4-2$ shows, gas generation due to inf crobial degradation is approximately 508 or less than gas generation due to corrosion. The ranges of cumulative gas generation shown in figure $4-3$ for inundated and humid conditions are simflar.

Table 4-2. Stepwise Regression Analyses with Rank-Transformed Date for Cumulatlve Gas Production over 10,000 yr Due to Corrosion under Humid and Inundated Conditions

\begin{tabular}{|c|c|c|c|c|c|c|c|}
\hline \multicolumn{4}{|c|}{$\begin{array}{c}\text { Total Gas Production over } 10,000 \mathrm{yr} \\
\text { (Humid Corrosion) }\end{array}$} & \multicolumn{4}{|c|}{$\begin{array}{l}\text { Total Gas Production over } 10,000 \mathrm{yr} \\
\text { (Inundated Corrosion) }\end{array}$} \\
\hline Stepa & Variableb & SRCC & $\mathrm{R}^{2 \mathrm{~d}}$ & Stepa & Variableb & SRCC & $R^{2 d}$ \\
\hline $\begin{array}{l}1 \\
2\end{array}$ & $\begin{array}{l}\text { GRCORH } \\
\text { GRCORI }\end{array}$ & $\begin{array}{l}0.78 \\
0.25\end{array}$ & $\begin{array}{l}0.61 \\
0.67\end{array}$ & $\begin{array}{l}1 \\
2 \\
3 \\
4\end{array}$ & $\begin{array}{l}\text { BRSAT } \\
\text { GRCORH } \\
\text { GRCORI } \\
\text { STOICCOR }\end{array}$ & $\begin{array}{r}0.75 \\
-0.47 \\
0.20 \\
-0.14\end{array}$ & $\begin{array}{l}0.58 \\
0.80 \\
0.84 \\
0.86\end{array}$ \\
\hline \multicolumn{8}{|c|}{$\begin{array}{l}\text { a Steps in stepwise regression analysis } \\
\text { b Variables listed in order of selection in regression analysis } \\
\text { c Standardized regression coefficients in final regression model } \\
\text { d Cumulative } R^{2} \text { value with entry of each variable into regression model }\end{array}$} \\
\hline
\end{tabular}

The lower two frames in Figure $4-3$ present sensitivity analysis results based on partial rank correlation coefficients. For cumulative gas production under humid conditions, increasing each of GRMICH (scale factor used in definition of gas-generation rate due to infrobial degradation of cellulosics under humid conditions), STOICMIC (stolchiometric coefficient for inicrobial degradation of cellulosics) and GRMICI (gas-generation rate due to microbial degradation of cellulosics under inundated conditions) increases gas production. Increasing STOICMIC increases the amount of gas 
Cammlative Gas Product fon Due lo corroston of Sted
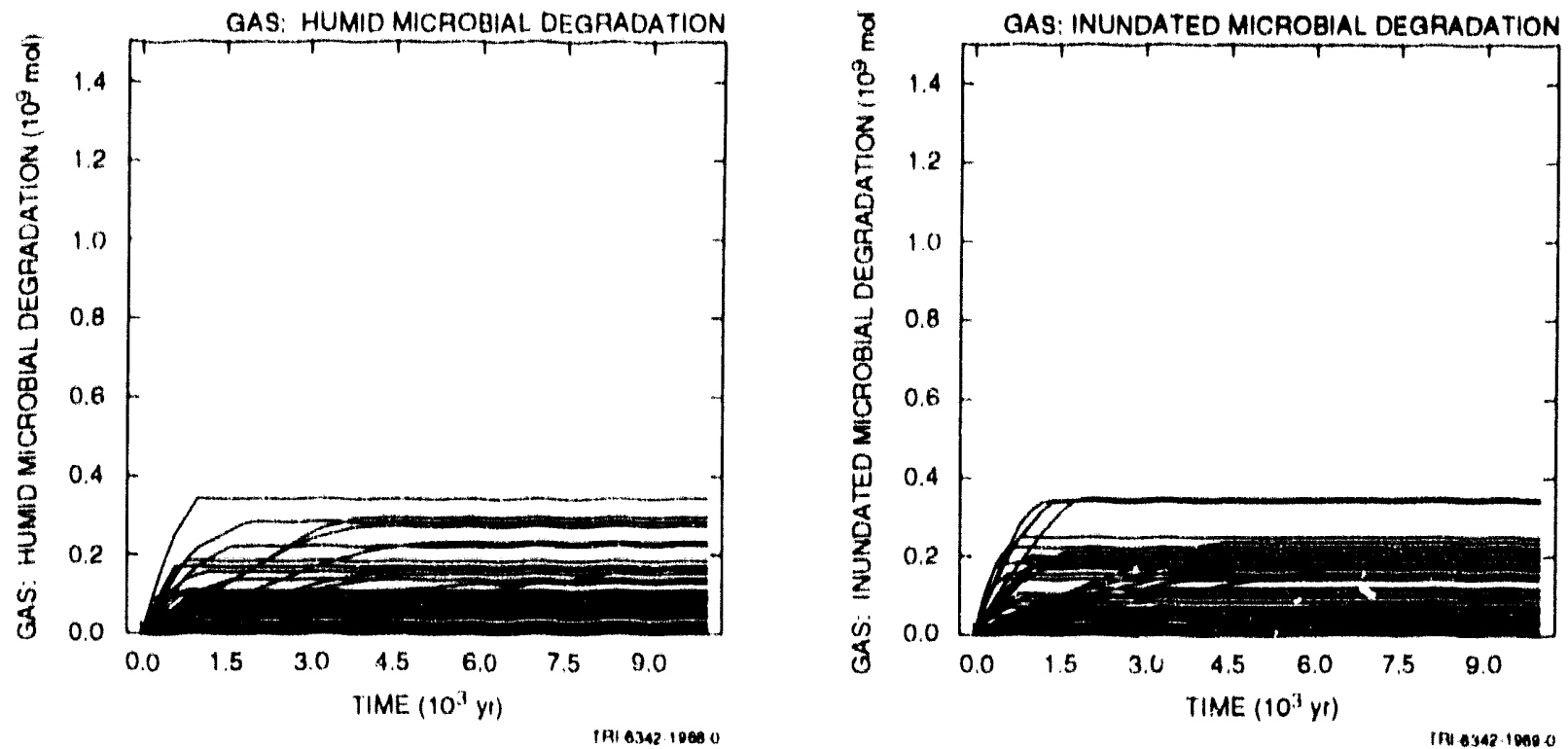

Partial Rank Correlation Coofficlents for Cumblat ivo Gas Production Due to corrosion of stool
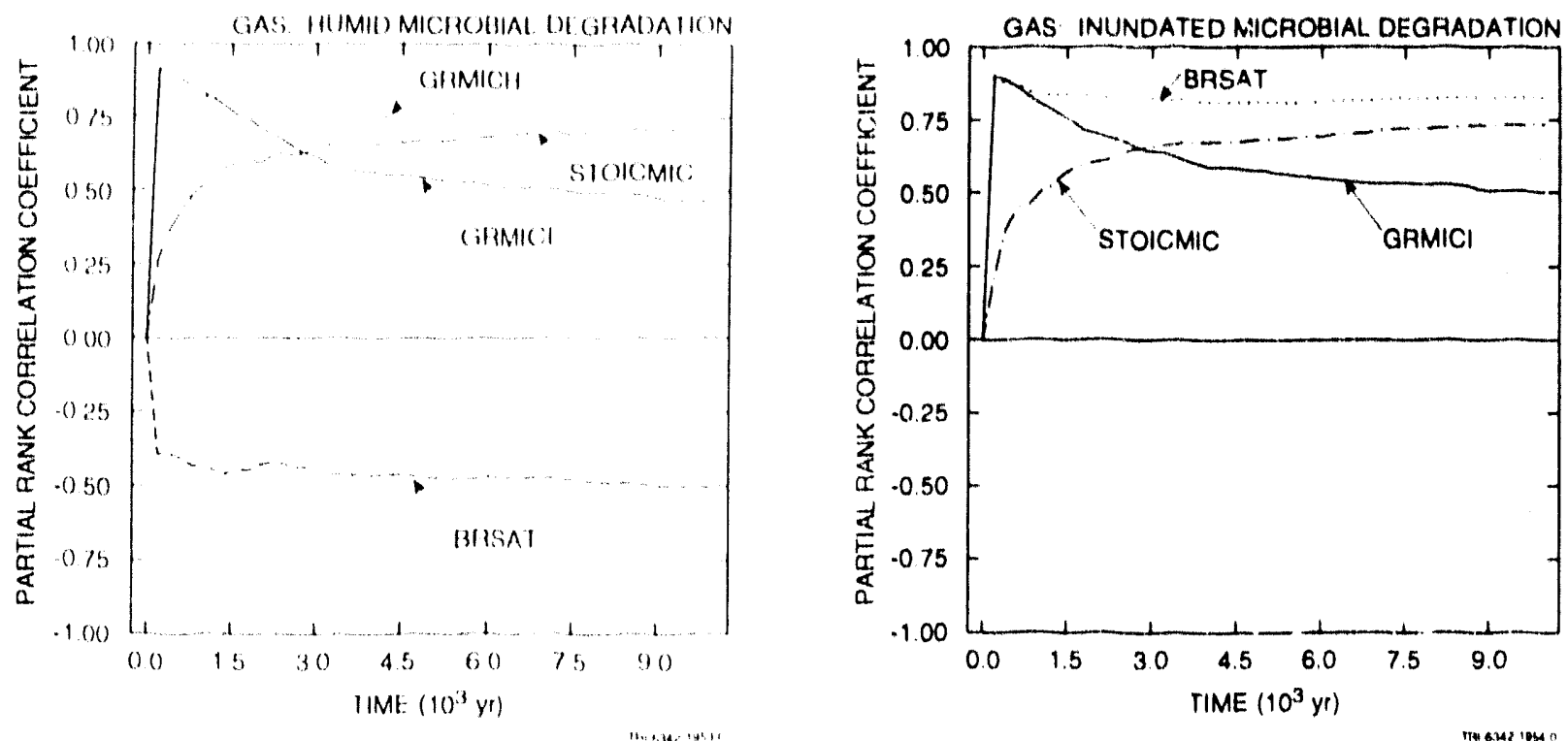

Figure 4-3. Uncertalnty and sensitivity analysis results for gas generation due to corrosion of steel. 


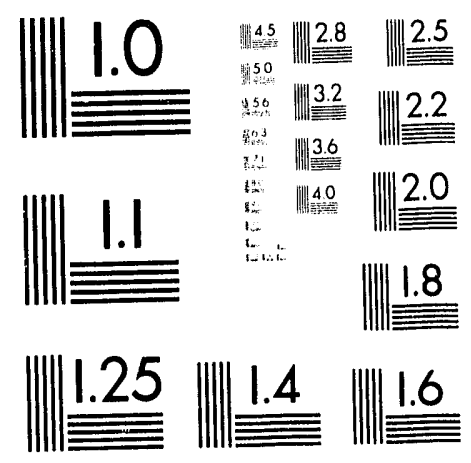



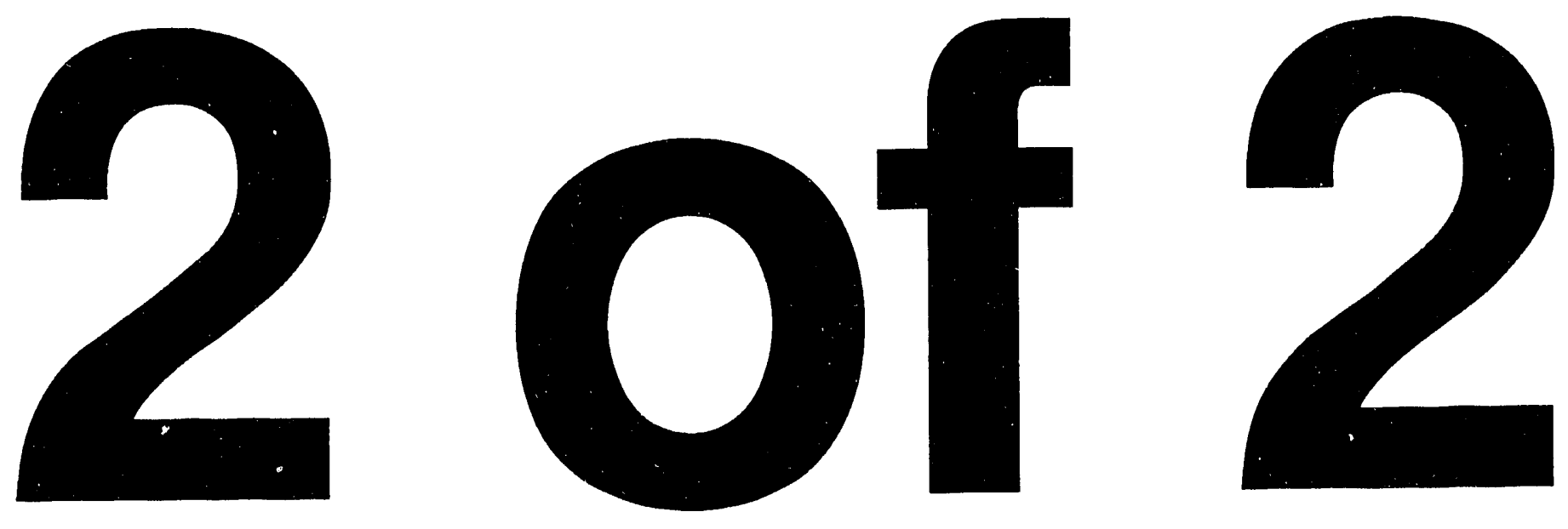
produced per unit of cellulose consumed while increasing GRMICH and GRMICI increases the rate GRMICH GRMICI of microbial degradation. The importance of GRMICI decreases over time, probably due to its influence on gas generation under both humid and inundated conditions and to the fact that it influences the rate at which gas is produced but not the total amount of gas that can be produced. In addition, increasing BRSAT (initial brine saturation) tends to decrease gas production under humid conditions by increasing the amount of cellulose that is exposed to microbial degradation under inundated conditions. For cumulative gas production under inundated conditions, increasing each of BRSAT, STOICMIC and GRMICI increases gas production.

The regression analyses for cumulative gas production over 10,000 yr due to microbial degradation under humid and inundated conditions, respectively, are presented in Table 4-3. The se analyses are for the gas production values appearing above $10,000 \mathrm{yr}$ in the two upper frames of Figure 4-3. For gas production under humid conditions, the variables GRMICH (scale factor used in definition of gas-generation rate due to microbial degradation of cellulosics under humid conditions), STOICMIC (stoichiometric coefficient for microbial degradation of cellulosics), BRSAT (initial brine saturation), VWOOD (fraction of total waste volume that is occupied by IDB combustible waste category) and GRMICI (gas-generation rate due to microbial. degradation of cellulosics under inundated conditions) can account for 728 of the observed variability in gas production, with gas production tending to increase with increasing values for GRMICH, STOICMIC, VWOOD and GRMICI and tending to decrease with increasing values for BRSAT. For gas production under inundated conditions, the variables BRSAT and STOICMIC can account for 578 of the observed variability in gas production, with gas production tending to increase as each of these variables increases. When the two additional variables GRMICI and GRMICH are added to the regression mode1, 678 of the variability in gas production can be accounted for, with gas production tending to increase as GRMICI increases and tending to decrease as GRMICH increases.

\subsubsection{Total Gas Production}

The upper two frames in Figure 4-4 show total gas production due to corrosion and microbial degradation and were obtained by combining the corresponding results in Figures 4-2 and 4-3 for gas production under hunid and inundated conditions. Typically, low gas production under humid conditions is associated with higher gas production under inundated conditions and vice versa. As a result, the gas production curves in Figure 4-4 tend to lie farther above the abscissa than many of the 
Table 4-3. Stepuvise Regression Analyses with Rank-Transformed Data for Cumulative Gas Production over 10,000 yr Due to Microbial Degradation under Humid and Inundated Conditions.

\begin{tabular}{|c|c|c|c|c|c|c|c|}
\hline \multicolumn{4}{|c|}{$\begin{array}{l}\text { Total Gas Production over } 10,000 \mathrm{yr} \\
\text { (Humid Degradation) }\end{array}$} & \multicolumn{4}{|c|}{$\begin{array}{l}\text { Total Gas Production over } 10,000 \text { yr } \\
\text { (Inundated Degradation) }\end{array}$} \\
\hline Stepa & Variable $^{b}$ & SRCC & $R^{2 d}$ & Stepa & Variableb & SRCC & $\mathrm{R}^{2 \mathrm{~d}}$ \\
\hline 1 & GRMICH & 0.57 & 0.32 & 1 & BRSAT & 0.62 & 0.37 \\
\hline 2 & STOICMIC & 0.46 & 0.52 & 2 & STOICMIC & 0.45 & 0.57 \\
\hline 3 & BRSAT & -0.26 & 0.59 & 3 & GRMICI & 0.26 & 0.63 \\
\hline 4 & VWOOD & 0.25 & 0.65 & 4 & GRMICH & -0.20 & 0.67 \\
\hline 5 & GRMICI & 0.25 & 0.72 & & & & \\
\hline
\end{tabular}

a Steps in stepwise regression analysis

b Variables listed in order of selection in regression analysis

c Standardized regression coefficients in final regression model

d Cumulative $R^{2}$ value with entry of each variable into regression model

individual curves in Figures $4-2$ and 4-3. Overall, the gas production due to corrosion tends to be approxinately two to three times the gas production due to microbial degradation. Gas production associated with microbial degradation of cellulosics has more curves close to zero than gas production due to corrosion due to the assignment of a range of possible values for STOICMIC (stoichiometric coefficient for microbial degradation of cellulosics) that extends to zero, which results in no gas generation due to microbial degradation.

The lower two frames in Figure $4-4$ present sensitivity analysis results based on partial rank correlation coefficients. For cumulative gas production due to corrosion, increasing BRSAT (initial brine saturation), GRCORI (gas-generation rate for corrosion of steel under inundated conditions) and GRCORH (scale factor used in definition of gas-generation rate for corrosion of steel under humid conditions) tends to increase gas production. Increasing BRSAT, GRCORI and GRCORH tends to increase the rate of gas production and hence cumulative gas production. In contrast, a negative effect is indicated for STOICCOR (stoichometric factor for corrosion of steel), which results because increasing STCICCOR decreases the amount of gas produced per unit of steel consumed in the corrosion process. For cumulative gas production due to inicrobial degradation, GRMICI (gas-generation rate due to microbial degradation of cellulosics under inundated conditions) and BRSAT (initial brine saturation) have 

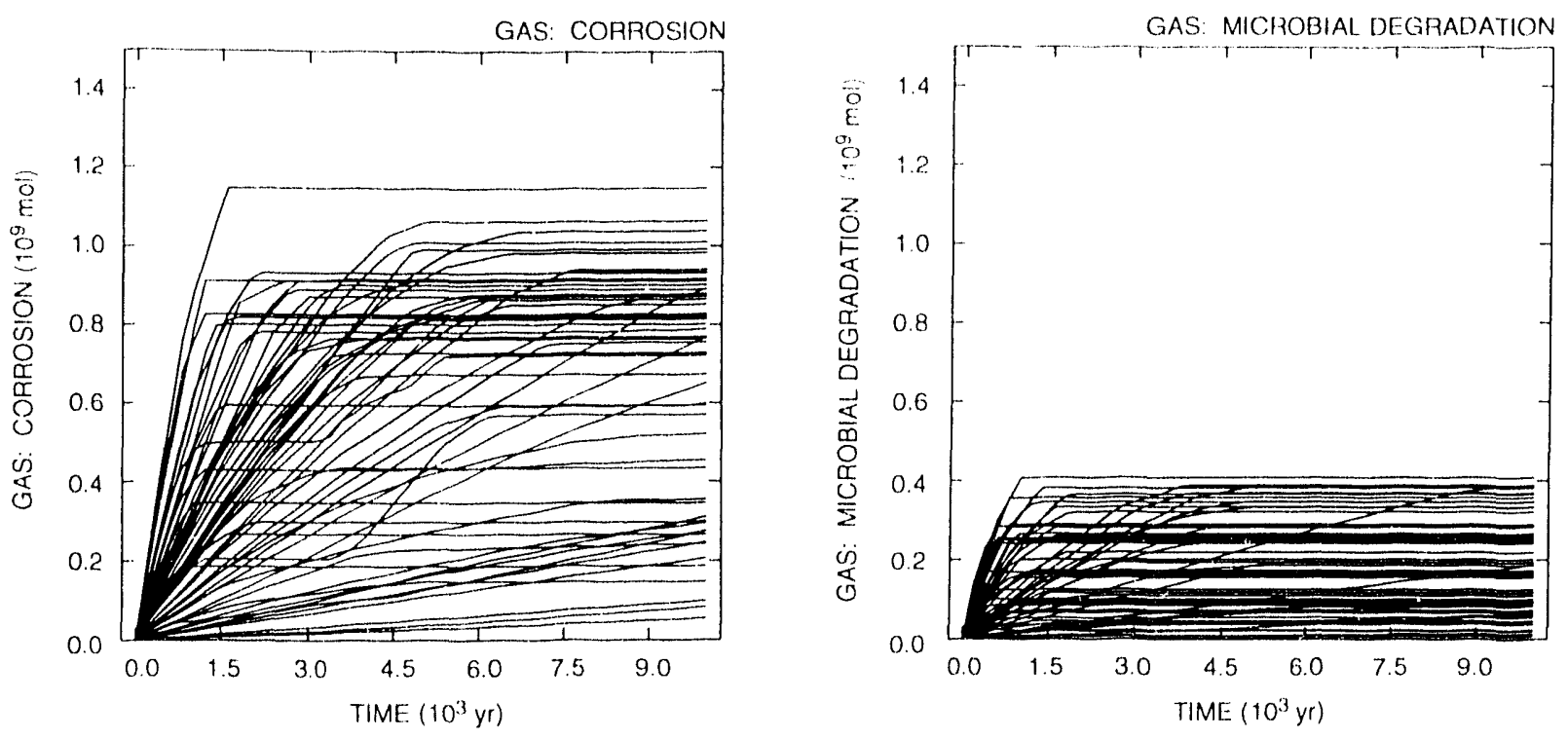

Partial Rank Correlation Coefficients for Cumulative Gas Production
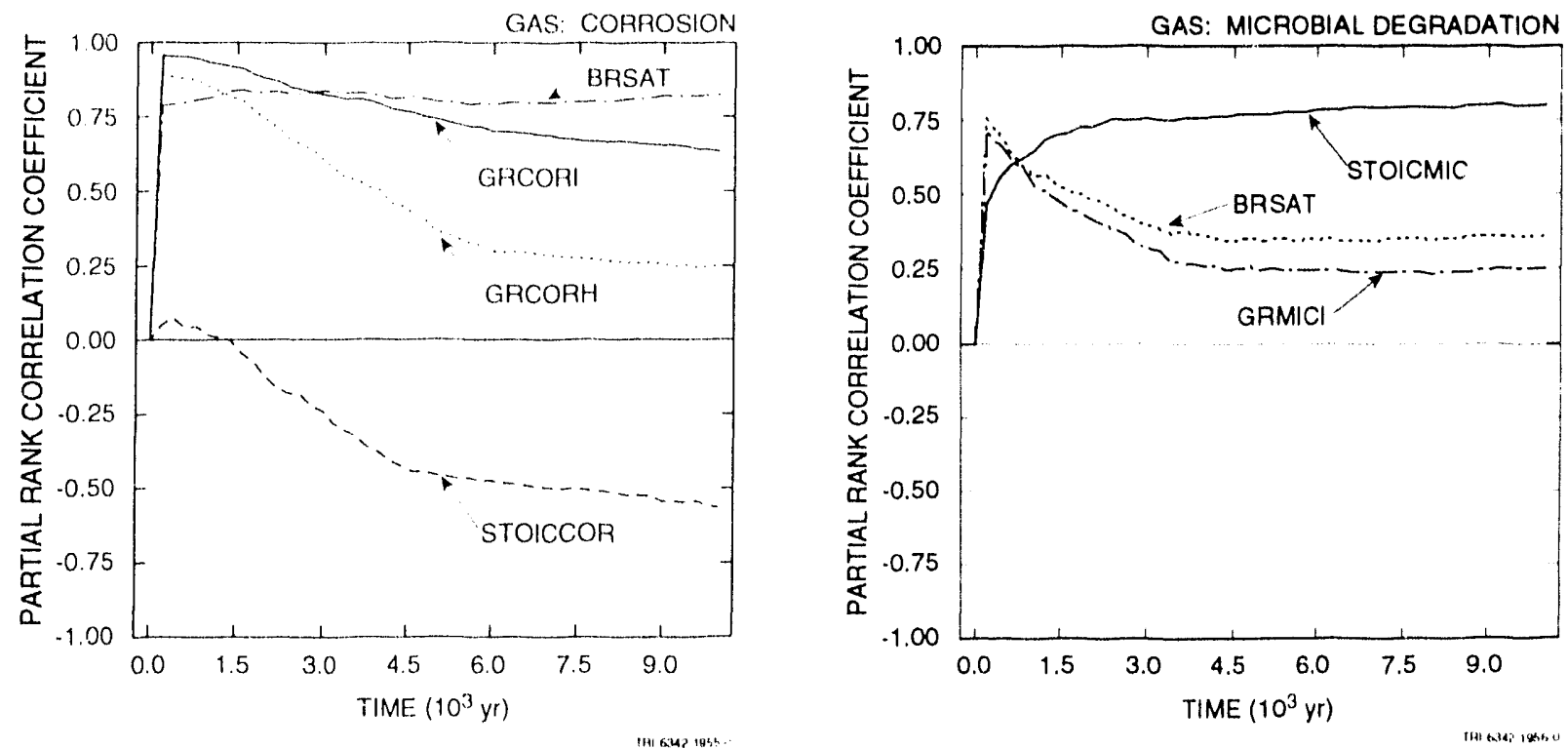

Figure 4-4. Uncertainty and sensitivity analysis results for gas generation due to corrosion of steel and inicrobial degradation of cellulosics. 
positive effects at early times and then decrease in importance. In contrast, STOICMIC (stoichiometric coefficient for microbial degradation of cellulosics) has an increasingly important positive effect with time and ultimately dominates the variability in cumulative gas production.

The two regression analyses in Table $4-4$ are for cumulative gas production over 10,000 yr due to corrosion and microbial degradation, respectively. Thus, these analyses are for the gas production values appearing above 10,000 yr in the two upper frames of Figure 4-4. The regression analysis for gas production due to corrosion selected the variables BRSAT (initial brine saturation), GRCORI (gas-generation rate for corrosion of steel under inundated conditions) STOICCOR (stoichiometric factor for corrosion of steel) and VMETAL (fraction of total waste volume that is occupied by IDB metals and glass waste category), with BRSAT, (RRCORI and VMETAL having a positive effect on gas production and STOICCOR having a negative effect on gas production. Collectively, these four variables can account fre $70 \%$ of the variability in gas production due to corrosion.

Table 4-4. Stepwise Regression Analysis with Rank-Transformed Data for Total Gas Production Due to Corrosion over 10,000 yr and Total Gas Generation Due to Microbial Degradation over $10,000 \mathrm{yr}$.

\begin{tabular}{|c|c|c|c|c|c|c|c|}
\hline \multicolumn{4}{|c|}{$\begin{array}{l}\text { Total Gas Production over } 10,000 \mathrm{yr} \\
\text { (Corrosion) }\end{array}$} & \multicolumn{4}{|c|}{$\begin{array}{l}\text { Total Gas Production over } 10,000 \mathrm{yr} \\
\text { (Microbial Degradation) }\end{array}$} \\
\hline Stepa & Variable $^{b}$ & SRCC & $R^{2 d}$ & Stepa & Variable $^{b}$ & SRCC & $\mathrm{R}^{2 \mathrm{~d}}$ \\
\hline $\begin{array}{l}1 \\
2 \\
3 \\
4\end{array}$ & $\begin{array}{l}\text { BRSAT } \\
\text { GRCORI } \\
\text { STOICCOR } \\
\text { VMETAL }\end{array}$ & $\begin{array}{r}0.64 \\
0.35 \\
-0.31 \\
0.21\end{array}$ & $\begin{array}{l}0.43 \\
0.56 \\
0.66 \\
0.70\end{array}$ & $\begin{array}{l}1 \\
2 \\
3 \\
4\end{array}$ & $\begin{array}{l}\text { STOICMIC } \\
\text { GRMICI } \\
\text { VWOOD } \\
\text { BRSAT }\end{array}$ & $\begin{array}{l}0.68 \\
0.36 \\
0.24 \\
0.20\end{array}$ & $\begin{array}{l}0.44 \\
0.56 \\
0.62 \\
0.66\end{array}$ \\
\hline $\begin{array}{l}\text { a Steps } \\
\text { b Variab } \\
\text { c Stand } \\
\text { d Cumu }\end{array}$ & $\begin{array}{l}\text { tepwise regre } \\
\text { listed in orde } \\
\text { zed regressio } \\
\text { e } R^{2} \text { value } W\end{array}$ & $\begin{array}{l}\text { on anal } \\
\text { selectic } \\
\text { soefficier } \\
\text { entry of }\end{array}$ & $\begin{array}{l}\text { is } \\
\text { in regr } \\
\text { s in fine } \\
\text { ach var }\end{array}$ & $\begin{array}{l}\text { nalysis } \\
\text { sion mo } \\
\text { o regres }\end{array}$ & hodel & & \\
\hline
\end{tabular}

The regression analysis in Table 4-4 for gas production due to microbial degradation can account for 668 of the observed variability in gas production. In particular, STOICMIC (stoichiometric coefficient for microbial degradation of cellulosics) was found to account for 448 of the observed variability and small additional effects were indicated for GRMICI (gas-generation rate due to inicrobial degradation of cellulosics under 
inundated conditions), VWOOD (fraction of total waste volume occupied by IDB combustible waste category) and BRSAT (initial brine saturation).

The gas production due to corrosion and to microbial degradation can be combined to produce the total gas production results shown in the upper frame of Figure 4-5. Most sample elements show a period of rapid gas production in the first few thousand years, with considerably reduced rates of gas production at later times. As examination of the two upper frames in Figure 4-6 shows, the inventory of steel and cellulosics is often exhausted or significantly depleted after the first few thousand years.

The lower frame in Figure $4-5$ presents sensitivity analysis results based on partial rank correlation coefficients. At early times, total fas production is dominated by GRCORI (gas-generation rate for corrosion of steel under inundated conditions), GRCORH (scale factor used in definition of gas-generation rate for corrosion of steel under humid conditions), GRMICI (gas-generation rate for inicrobial degradation of cellulosics under inundated conditions), GRMICH (scale factor used in definition of gasgeneration rate for microbial degradation of cellulosics under humid conditions) and BRSAT (initial brine saturation), with total gas generation tending to increase as each of these variables increases. As time increases, GRCORI, GRCORH, GRMICI and GRMICH become less important and have little effect on total gas generation over 10,000 yr. In contrast, STOICMIC (stoichiometric coefficient for microbial degradation of cellulosics) has little effect on total gas production at early times but increases in importance with increasing time due to the fact that total microbial gas production is determined primarily by STOICMIC.

A regression analysis for cumulative gas production over 10,000 yr due to both corrosion and microbial degradation is presented in Table 4-5. The first variable selected in the analysis is BRSAT (initial brine saturation); which has a positive regression coefficient and can account for 428 of the variability in total gas production. The indicated effect for BRSAT is consistent with its dominant influence on gas generation due to corrosion as indicated in Figure $4-4$ and Table $4-4$. The next variables selected in the regression analysis are STOLCMIC (stoichiometric coefficient for microbial degradation of cellulosics) and stolcCOR (stoichiometric factor for corrosion of steel). The positive regression coefficient for STOLCMIC and the negative regression coefficient for STOICCOR are consistent with the effects of these variables on gas generation due to microbial degradation and corrosion, respectivelv. Collectively, BRSAT, STOLCMIC and STOLCCOR can account tot 608 of the variability in total gas production over $10,000 \mathrm{yr}$. 
Cumulative Gas Production

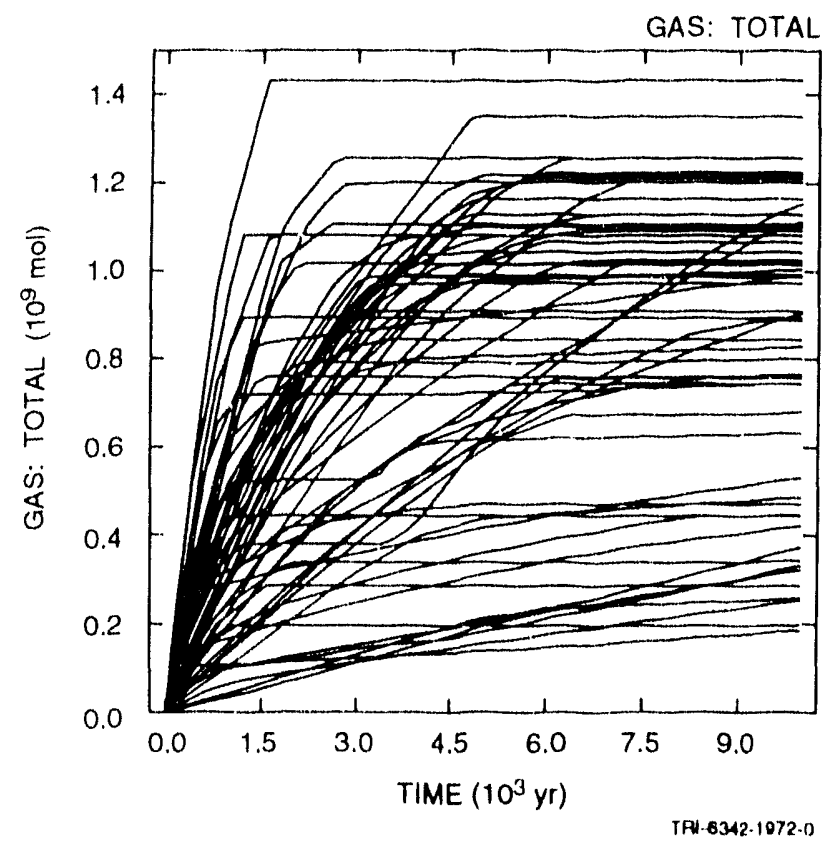

Partial Rank Correlation Coefficients for Cumulative Gas Production

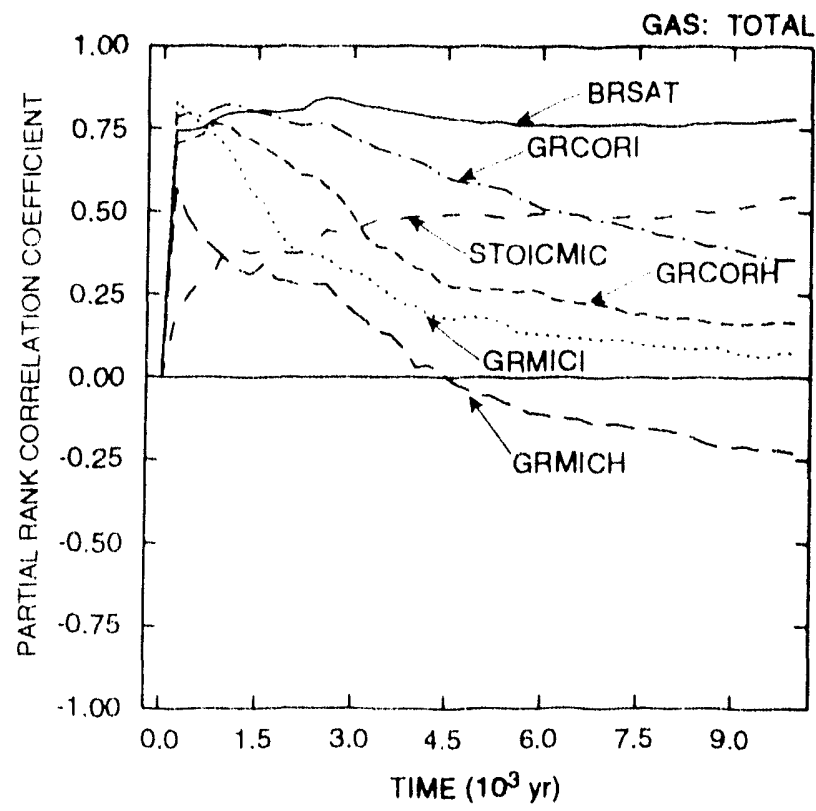

Figure 4-5. Uncertainty and semsitivity analysis results for total gas production due to both corrosion of steel and Inicrobial degradat ion of cellulosics. 
Steel and Cellulosic Inventories
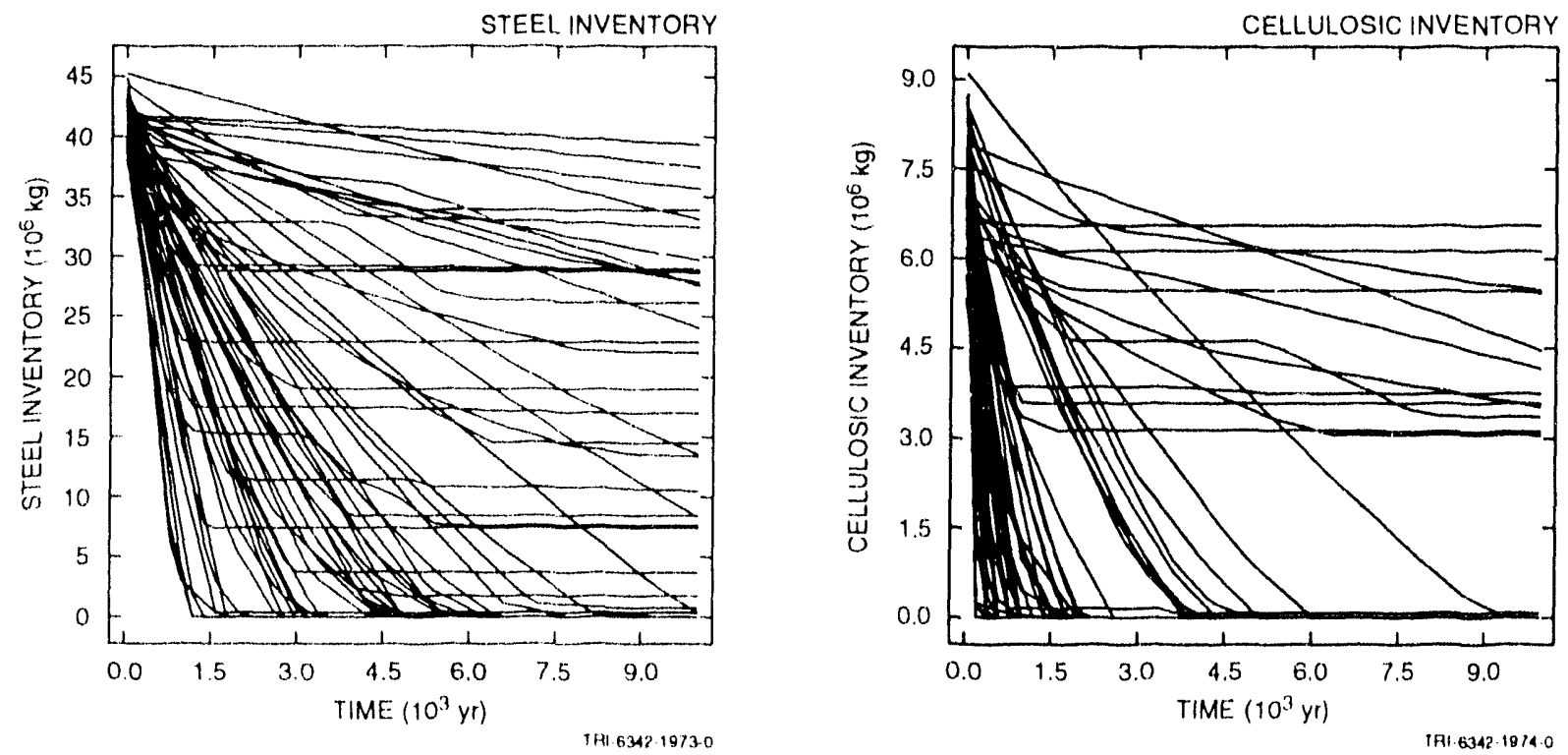

Partial Rank Correlation coefficients for steel and Cellulosic Iventories
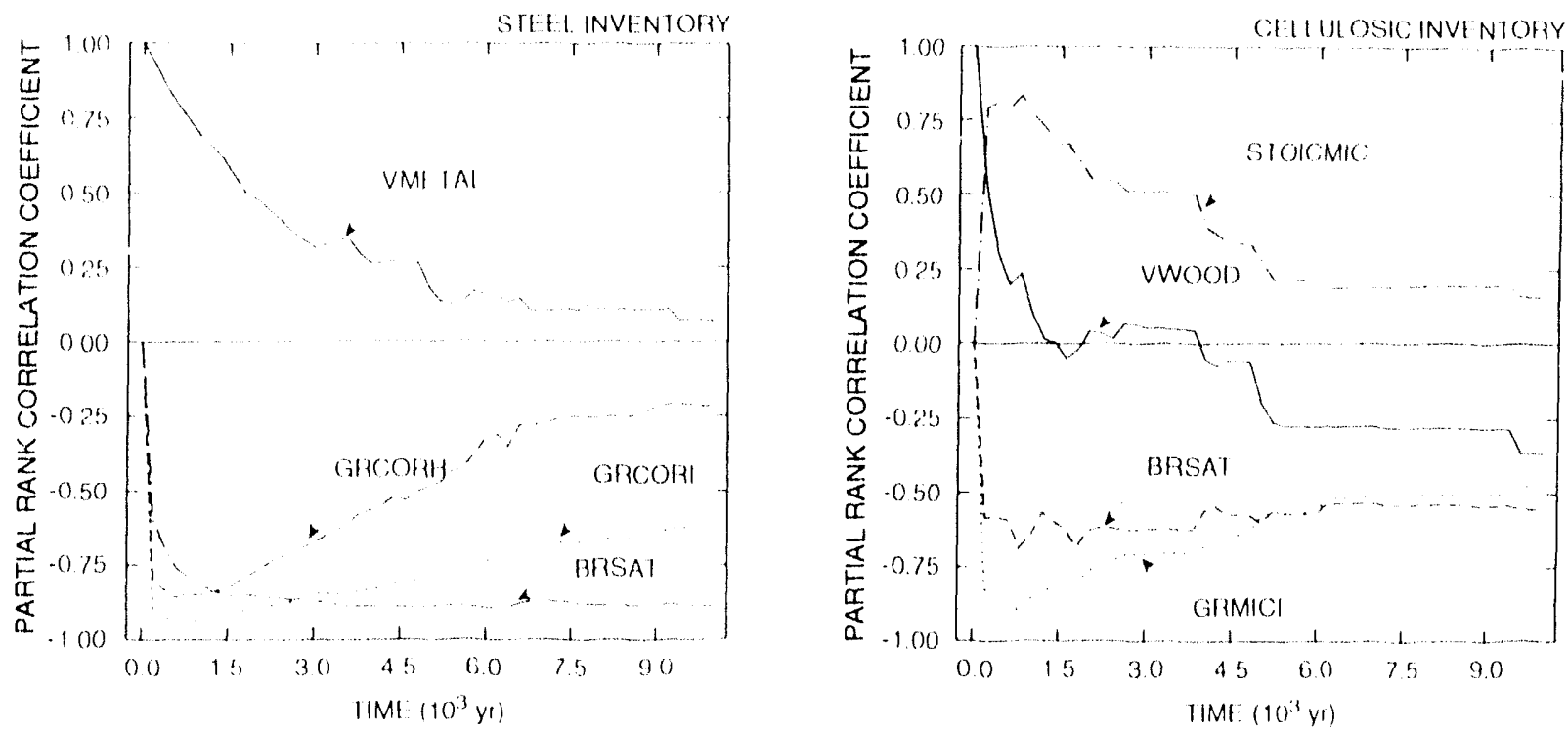

Figure 4-6. Uncertainty and sensitivity analysis results for steel and cellulosic inventorios in repository. 
Table 4-5. Stepwise Regression Analysis with Rank-Transformed Data for Total Gas Production Over 10,000 yr Due to Both Corrosion and Microbial Degradation.

Total Gas Production over $10,000 \mathrm{yr}$ (Corrosion and Microbial)

\begin{tabular}{|c|c|c|c|}
\hline Stepa & Variable $^{b}$ & $S R C^{C}$ & $R^{2 d}$ \\
\hline 1 & BRSAT & 0.64 & 0.42 \\
\hline 2 & STOICMIC & 0.33 & 0.52 \\
\hline 3 & STOICCOR & -0.28 & 0.60 \\
\hline
\end{tabular}

a Steps in stepwise regression analysis

$b$ Variables listed in order of selection in regression analysis

c Standardized regression coefficients in final regression model

d Cumulative $R^{2}$ value with entry of each variable into regression model

As previously indicated, the upper two frames in Figure 4-6 show the time-dependent steel and cellulosic inventories associated with the individual sample elements. The lower two frames present sensitivity analyses based on partial rank correlation coefficients. The steel inventory is initially dominated by VMETAL (faction of total waste volume occupied by IDB metals and glass category), with the importance of this variable decreasing with time. The variables GRCORI (gas-generation rate for corrosion of steel under inundated conditions), GRCORH (scale factor used in definition of gas-generation rate for corrosion of steel under humid conditions) and BRSAT (initial brine saturation) have negative effects on the steel inventory. As with VMETAL, the importance of GRCORI and GRCORH tends to decrease with time; in contrast, the importance of BRSAT remains relatively fixed. The negative relationships involving GRCORI, GRCORH and BRSAT result from their effects in increasing the rate of corrosion. Further, the corrosion process stops when all the brine in a computational cell is consumed. Thus, increasing BRSAT increases the amount of steel that can be consumed by corrosion before the corrosion process is stopped due to brine depletion in the absence of brine inflow from the salado Formation. The cellulosic inventory is initially dominated by VWOOD (fraction of total waste volume that is occupied by IDB combustible waste category), with the importance of this variable decreasing rapidly with time. The variable GRMICI (gas-generation rate due to microbial degradation of cellulosics under inundated conditions) shows a negative effect on cellulosic inventory due to its effect in increasing the rate at which cellulosics are consumed. Similarly, BRSAT shows a negative effect because cellulose is consumed more rapidly under inundated than under humid conditions. The positive effect indicated for STOICMIC 
(stoichiometric coefficient for microbial degradation of cellulosics) probably results because increased values for STOICMIC lead to increased rates of gas generation, which in turn lead to humid conditions and thus lower rates of inicrobial degradation of cellulosics.

\subsubsection{Gas Saturation and Pressure in Waste}

Time-dependent values for average gas saturation in the waste (i.e., averaged over entire repository) and gas pressure in the waste are presented in the two upper frames of Figure 4-7. For most sample elements, gas saturation increases monotonically with time, although there may be a small drop in gas saturation in the first few hundred years. As the partial rank correlation coefficients for gas saturation in the lower left frame of Figure 4-7 show, increasing each of GRCORI (gas-generation rate for corrosion of steel under inundated conditions), GRCORH (scale factor used in definition of gas-generation rate for corrosion of steel under humid conditions), TZPOR (scale factor used in definition of transition zone and disturbed rock zone porosity) and STOICCOR (stoichiometric factor for corrosion of steel) tends to increase gas saturation, and increasing each of BRSAT (initial brine saturation) and SALPOR (porosity in Salado Formation halite and anhydrite under undisturbed conditions) tends to decrease gas saturation. The effects for GRCORI, GRCORH, BRSAT and SALPOR result because increasing each of GRCORI and GRCORH increases the amount of gas in the panel and increasing each of BRSAT and SALPOR increases the amount of brine in the panel. The dominant effect of SALPOR on net brine flow into the waste panel is indicated by the partial correlation coefficients shown in the lower right frame of Figure 4-8. A positive effect is indicated for TZPOR, which probably results from increased brine flow from the repository to the underlying disturbed rock zone and transition zone. The cause of the positive effect indicated for STOICCOR is not immediately apparent, as increasing STOICCOR tends to decrease gas production. However, as discussed in conjunction with Figures $2-13$ and 3-10, increasing STOICCOR also tends to decrease the pore volume in the repository. In turn, decreasing pore volume tends to decrease the amount of brine initially in the repository, which is set as a fraction of the initial pore volume. Corrosion is assumed to proceed at a constant rate in each computational cell until the brine contained in the cell is consumed. As a result, large values of STOICCOR will lead to a larger percentage of the available brine being consumed; in turn, this frees up more space that can be occupied by gas and thus increases the gas saturation.

As shown in the upper right frame of Figure 4-7, time-dependent gas pressure in the repository tends to increase initially and then to decrease, with the rate of decrease being slower than the rate of increase. 
Gas Saturat ion and lias Pressure in Repository
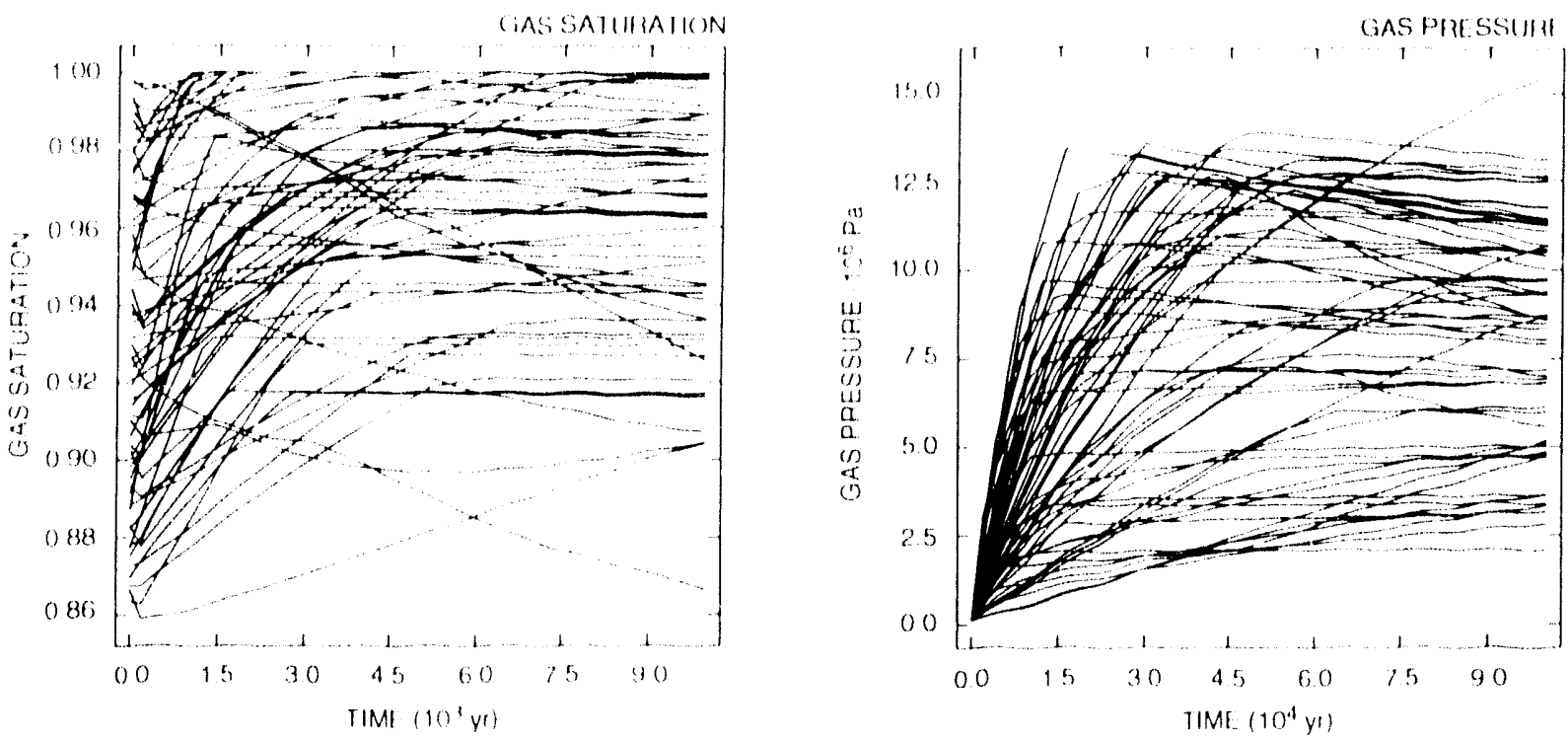

Partial Rank Corrolation Coefficients for Gas Saturation and Gas prossure in Repository
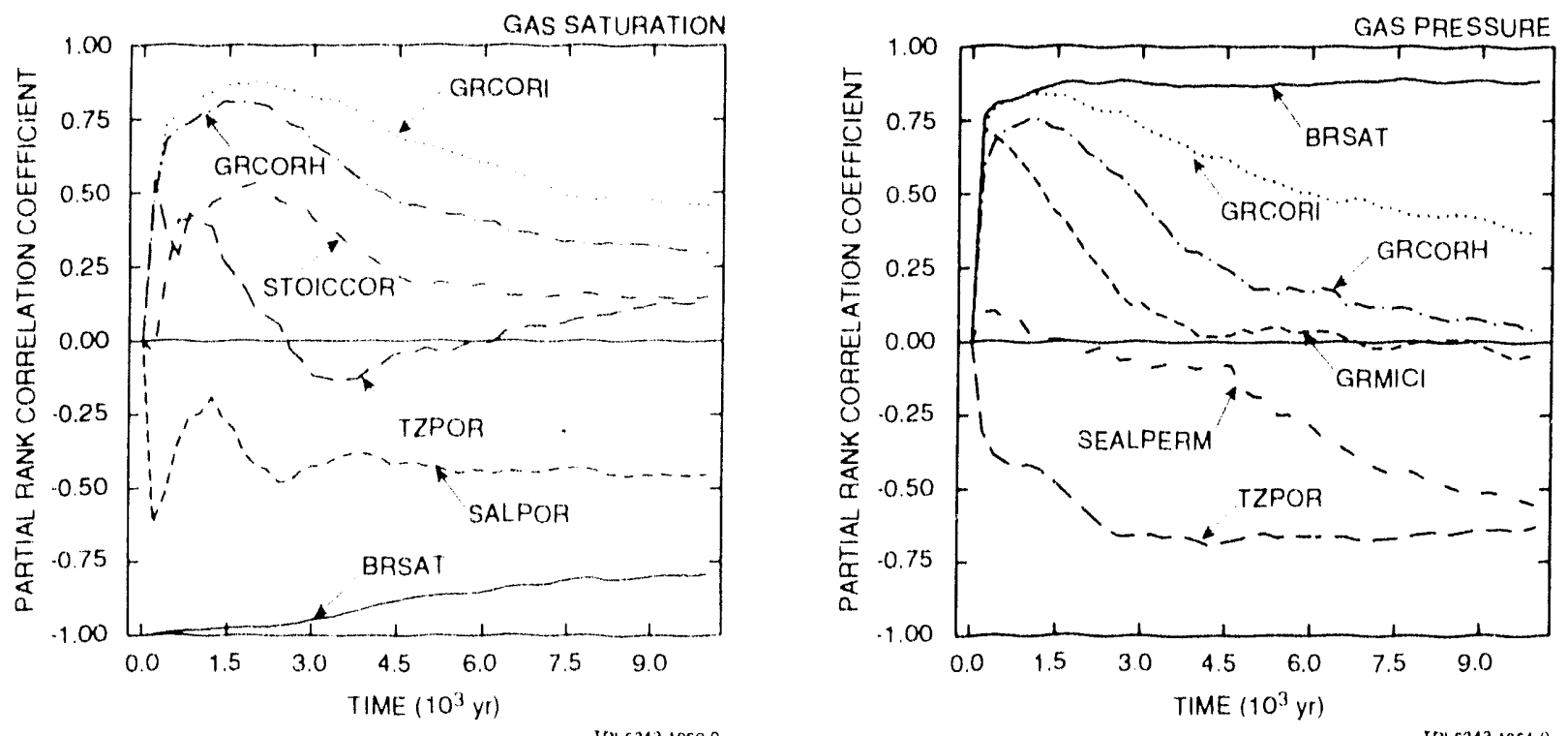

Figure 4-7. Uncertainty and sensitivity analysis rosults for average gas saturat ion and gas pressure in repository. 
Total and Net Brine Inflow to Repository
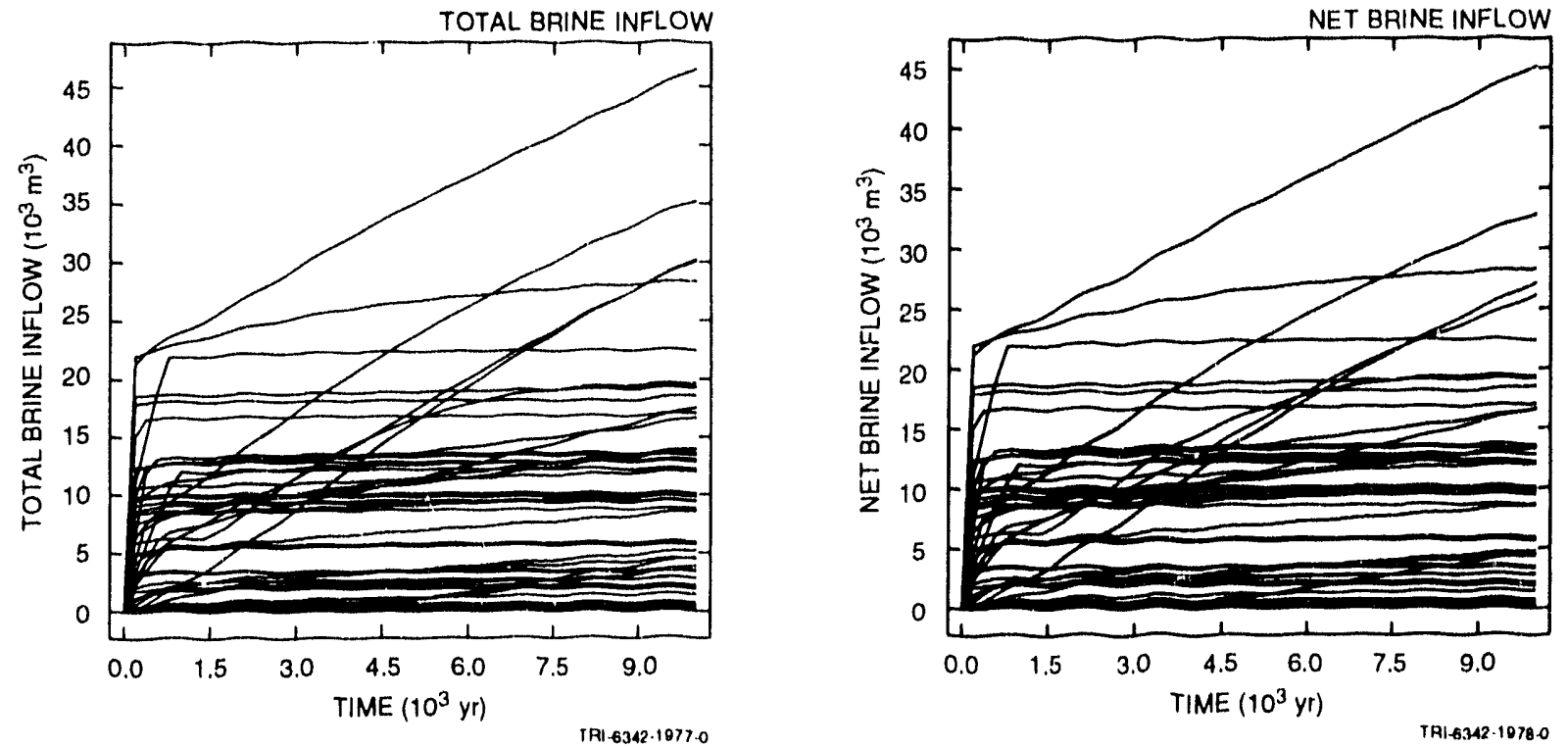

Partial Rank Correlation Coefficients for Total and Net Brine Inflow to Repository
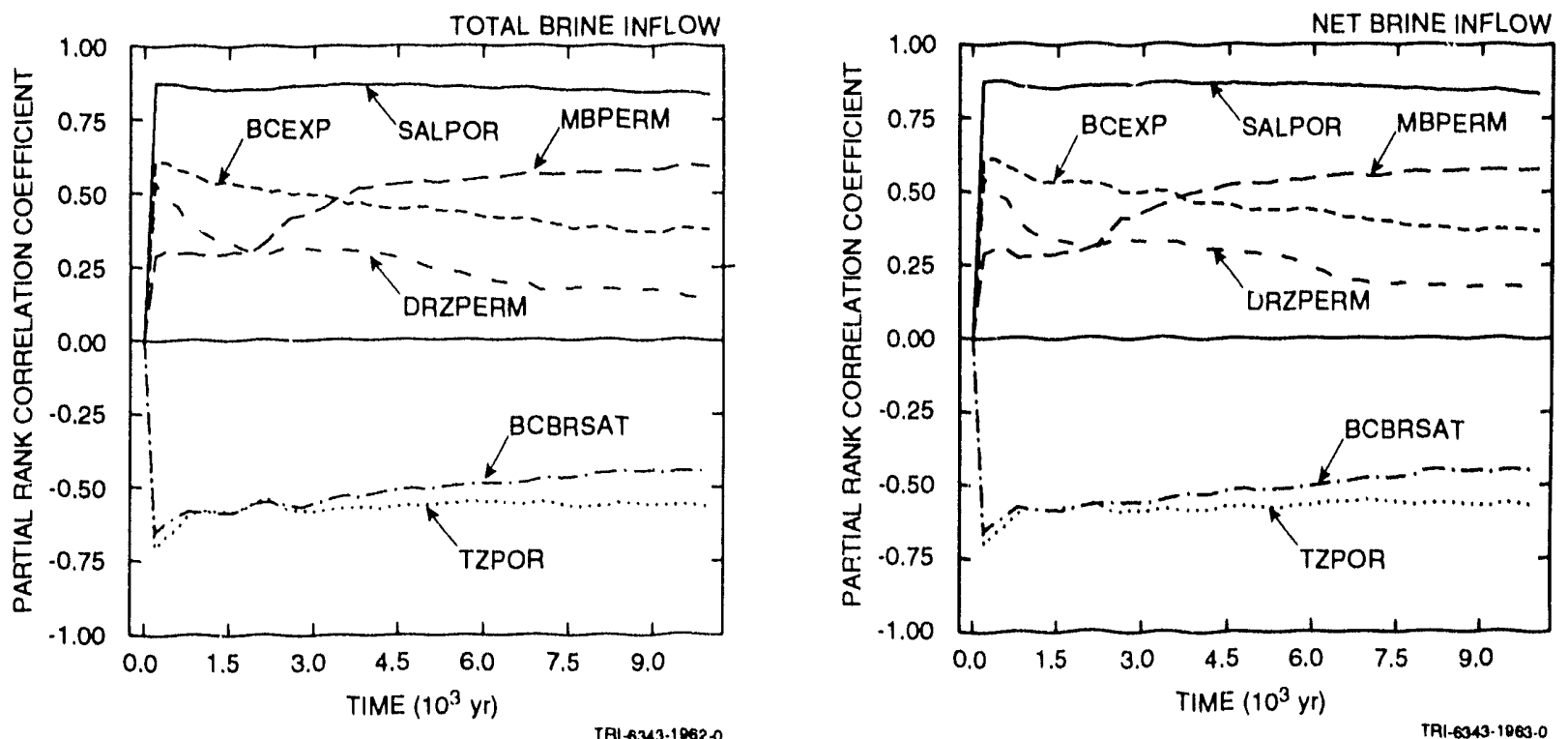

Figure 4-8. Uncertainty and sensitivity analysis results for total and net brine inflow to repository. 
Only one sample element produces gas pressures that are close to the lithostatic pressure of $14.8 \mathrm{MPa}$. The partial rank correlation coefficients for gas pressure in the lower right frame of Figure 4-7 indicate that gas pressure is dominated by BRSAT (initial brine saturation) and TZPOR (scale factor used in definition of transition zone and disturbed rock zone porosity). Increasing BRSAT increases gas pressure by increasing gas production, and increasing TZPOR decreases gas pressure by increasing the pore volume available for gas storage. In addition, GRCORH (scale factor used in definition of gas-generation rate for corrosion of steel under humid conditions), GRCORI (gas-generation rate for corrosion of steel under inundated conditions) and GRMICI (gas-generation rate due to microbial degradation of cellulosics under inundated conditions) have positive effects on gas pressure at early times. At later times SEALPERM (shaft seal permeability) has a negative effect on gas pressure due to the reduced resistance to gas flow up the shaft that results as SEALPERM increases.

Regression analyses for gas saturation and gas pressure at 10,000 yr are presented in Table 4-6. These analyses are for the gas saturation and gas pressure values appearing above 10,000 yr in Figure 4-7. For gas saturation at $10,000 \mathrm{yr}$, the dominant variable is BRSAT (initial brine saturation), which can account for 448 of the observed uncertainty. Increasing BRSAT tends to reduce gas saturation by increasing the pore volume that is occupied by brine. After BRSAT, the regression analysis selects GRCORI (gas-generation rate for corrosion of steel under inundated conditions), SALPOR (porosity in Salado Formation halite and anhydrite under undisturbed conditions) and MBPERM (permeability in anhydrite marker beds in Salado Formation under undisturbed conditions), with each of these variables accounting for 68 to $7 \%$ of the uncertainty in gas saturation. Increasing GRCORI tends to increase gas saturation by increasing gas production. In contrast, increasing each of SALPOR and MBPERM tends to decrease gas saturation. As shown in Table 4-7, the negative effects on gas saturation indicated for SALPOR and MBPERM result from the positive effects on brine inflow to the repository (i.e., increasing each of SALPOR and MBPERM tends to increase the amount of brine flowing into the repository, which in turn reduces the amount of pore space that can be occupied by gas). Collectively, BRSAT, GRCORI, SALPOR and MBPERM can account for 648 of the uncertainty in gas saturation at $10,000 \mathrm{yr}$.

For gas pressure at 10,000 yr, BRSAT (initial brine saturation) is again the dominant variable and can account for 598 of the uncertainty. Increasing BRSAT tends to increase gas pressure by both increasing gas generation and reducing the pore volume available for gas storage. The next variable selected in the regression analysis is TZPOR (scale factor used in definition of transition zone and disturbed rock zone porosity), 
Table 4-6. Stepwise Regression Analyses with Rank-Transformed Data for Gas Saturation and Gas Pressure in Repository at 10,000 yr.

\begin{tabular}{|c|c|c|c|c|c|c|c|}
\hline \multicolumn{4}{|c|}{ Gas Saturation at $10,000 \mathrm{yr}$} & \multicolumn{4}{|c|}{ Gas Pressure at $10,000 \mathrm{yr}$} \\
\hline Stepa & Variableb & SRCC & $R^{2 d}$ & Step ${ }^{a}$ & Variable $b$ & SRCC & $R^{2 d}$ \\
\hline 1 & BRSAT & -0.67 & 0.44 & 1 & BRSAT & 0.74 & 0.59 \\
\hline 2 & GRCORI & 0.28 & 0.51 & 2 & TZPOR & -0.31 & 0.68 \\
\hline 3 & SALPOR & -0.27 & 0.58 & 3 & SEALPERM & -0.27 & 0.74 \\
\hline 4 & MBPERM & -0.23 & 0.64 & 4 & STOICCOR & -0.17 & 0.77 \\
\hline & & & & 5 & GRCORI & 0.15 & 0.79 \\
\hline
\end{tabular}

a Steps in stepwise regression analysis

$b$ Variables listed in order of selection in regression analysis

C Standardized regression coefficients in final regression model

d Cumulative $R^{2}$ value with entry of each variable into regression model

Table 4-7. Stepwise Regression Analyses with Rank-Transformed Data for Total and Net Brine Inflow to the Repository over 10,000 yr.

\begin{tabular}{|c|c|c|c|c|c|c|c|}
\hline \multicolumn{4}{|c|}{ Total Brine Inflow over $10,000 \mathrm{yr}$} & \multicolumn{4}{|c|}{ Net Brine Inflow over $10,000 \mathrm{yr}$} \\
\hline Stepa & Variableb & SRCC & $\mathrm{R}^{2 d}$ & Stepa & Variableb & SRCC & $R^{2 d}$ \\
\hline 1 & SALPOR & 0.65 & 0.39 & 1 & SALPOR & 0.66 & 0.40 \\
\hline 2 & MBPERM & 0.32 & 0.51 & 2 & MBPEPM & 0.31 & 0.51 \\
\hline 3 & TZPOR & -0.31 & 0.60 & 3 & TZPOR & -0.31 & 0.61 \\
\hline 4 & BRSAT & -0.23 & 0.66 & 4 & BRSAT & -0.23 & 0.66 \\
\hline 5 & BCBRSAT & -0.19 & 0.69 & 5 & BCBRSAT & -0.19 & 0.69 \\
\hline 6 & SALPERM & 0.19 & 0.72 & 6 & SALPERM & 0.18 & 0.72 \\
\hline 7 & BCEXP & 0.19 & 0.76 & 7 & BCEXP & 0.18 & 0.76 \\
\hline
\end{tabular}

a Steps in stepwise regression analysis

b Variables listed in order of selection in regression analysis

c Standardized regression coefficients in final regression model

d Cumulative $R^{2}$ value with entry of each variable into regression model

with gas pressure tending to decrease as TZPOR increases. This negative effect results because increasing TZPOR results in more pore volume for gas storage and hence in reduced gas pressures. The variable TZPOR accounts for 98 of the uncertainty of gas pressure. An additional $6 z$ of the uncertainty is accounted for by SEALPERM (shaft seal permeability), with gas pressure tending to decrease as SEALPERM increases. This negative 
effect results because increasing SEALPERM results in more gas flow out of the waste panel and hence in lower gas pressures. Sinall effects are also indicated for STOICCOR (stoichiometric factor for corrosion of steel) and GRCORI (gas-generation rate for corrosion of steel under inundated conditions), with gas pressure tending to decrease as STOICCOR increases and to increase as GRCORI increases. These effects result because increasing STOICCOR decreases gas generation due to corrosion and increasing GRCORI increases gas generation due to corrosion. Collectively, BRSAT, TZPOR, SEALPERM, STOICCOR and GRCORI can account for 798 of the uncertainty in gas pressure at 10,000 yr.

Total and net brine inflow are summarized in Figure 4-8. As comparison of the two sets of inflow results in Figure $4-8$ shows, there is essentially no difference between total and net brine inflow. This is considerably different from the results shown in Figure 2-12 for Case 1 , where there is a substantial difference between total and net inflow. As shown in Figure 4-8, brine inflow is controlled by SALPOR (porosity in Salado Formation halite and anhydrite under undisturbed conditions), MBPERM (permeability in anhydrite marker beds in Salado Formation under undisturbed conditions), BCEXP (Brooks and Corey exponent), DRZPERM (disturbed rock zone permeability), BCBRSAT (Brooks and Corey residual brine saturation) and TZPOR (scale factor used in definition of transition zone and disturbed rock zone porosity), with brine inflow tending to increase as SALPOR, MBPERM, BCEXP and DRZPERM increase and tending to decrease as BCBRSAT and TZPOR increase. Similar results are obtained in the regression analyses presented in Table 4-7 for total and net brine inflow to the repository over $10,000 \mathrm{yr}$ (i.e., for the brine inflow values appearing above $10,000 \mathrm{yr}$ in Figure 4-8). The positive effects for SALPOR and MBPERM result because increasing SALPOR increases the reservoir of brine in the Salado Formation potentially available for flow to the repository and increasing MBPERM reduces the resistance to brine flow in the anhydrite marker beds. The positive effect for DRZPERM results from reducing resistance to brine flow through the disturbed rock zone to the repository. The positive effect indicated for $B C E X P$ and the negative effects indicated for BCBRSAT and TZPOR result from the role that these variables play in the definition of effective permeabilities for the transition and disturbed rock zones.

The 1991 WIPP performance assessment did not directly model closure of the waste panels. However, possible interaction of gas generation and panel closure was incorporated into the analysis by setting the initial pore volume in a waste panel to the volume necessary to contain all wastegenerated gas at lithostatic pressure. As a result, initial pore volume is a function of STOICCOR (stoichiometric factor for corrosion of steel), STOICMIC (stoichionetric coefficient for microbial degradation of 
cellulosics), VMETAL (fraction of total waste volume occupied by IDB metals and glass waste category) and VWOOD (fraction of total waste volume occupied by IDB combustible waste category). The behavior of pore volume for Case 3 is essentially the same as shown in Figures $2-13$ and $3-10$ for Cases 1 and 2 .

\subsubsection{Gas Movement in Anhydrite Marker Beds}

As shown in Figure 4-1, there are three anhydrite marker beds in Case 3 into which gas can flow from the disturbed rock zone surrounding the repository: Marker Bed 139, Anhydrite Layers A and B, and Marker Bed 138 . Gas flow occurs when the gas pressure in the disturbed rock zone exceeds the gas barrier pressure in the adjacent intact anhydrite layer. In BRAGFLO, the determination of whether or not gas flow occurs on the south end of the panel is made on the basis of the following pairs of adjacent computational cells: Cells $(7,6)$ and $(8,6)$ for Marker Bed 138, Cells $(7,8)$ and $(8,8)$ for Anhydrite Layers $A$ and $B$, and $\operatorname{Cells}(7,15)$ and $(8,15)$ for Marker Bed 139; a similar determination is made for the north end of the pane 1 .

The gas barrier pressures in Cells $(7,6),(7,8)$ and $(7,15)$, the gas pressures in Cells $(8,6),(8,8)$ and $(8,15)$, and the differences between gas barrier pressure in the anhydrite and gas pressure in the disturbed rock zone for adjacent cells are shown in Figure 4-9. The gas barrier pressures initially drop as brine flows out of the anhydrite layers into the disturbed rock zone; then, as brine flows through the anhydrite layers to replenish the brine initially lost to the disturbed rock zone, the gas barrier pressures cease to decrease and begin to increase. The gas pressures in the disturbed rock zone increase initially and then often show a slow decrease. As shown by the differences between gas barrier pressures and gas pressures in the third column of plots in Figure 4-9, gas pressure rarely exceeds gas barrier pressure, with the result that there is little gas flow from the disturbed rock zone to the anhydrite layers. In particular, 6 sample elements result in gas flow from the disturbed rock zone to Marker Bed 138; 5 sample elements result in gas flow to Anhydrite Layers $A$ and $B$, and 3 sample elements result in gas flow to Marker Bed 139.

As shown in Figure 4-10, sensitivity analysis results based on partial rank correlation coefficients can be used to determine the individual variables that are controlling the uncertainty in gas barrier pressures and gas pressures shown in Figure 4-9. Gas barrier pressure is initially controlled by MBPRES (pressure in anhydrite Marker Bed 139 under undisturbed conditions) and MBPERM (permeability in anhydrite marker beds in Salado Formation under undisturbed conditions), with the importance of 

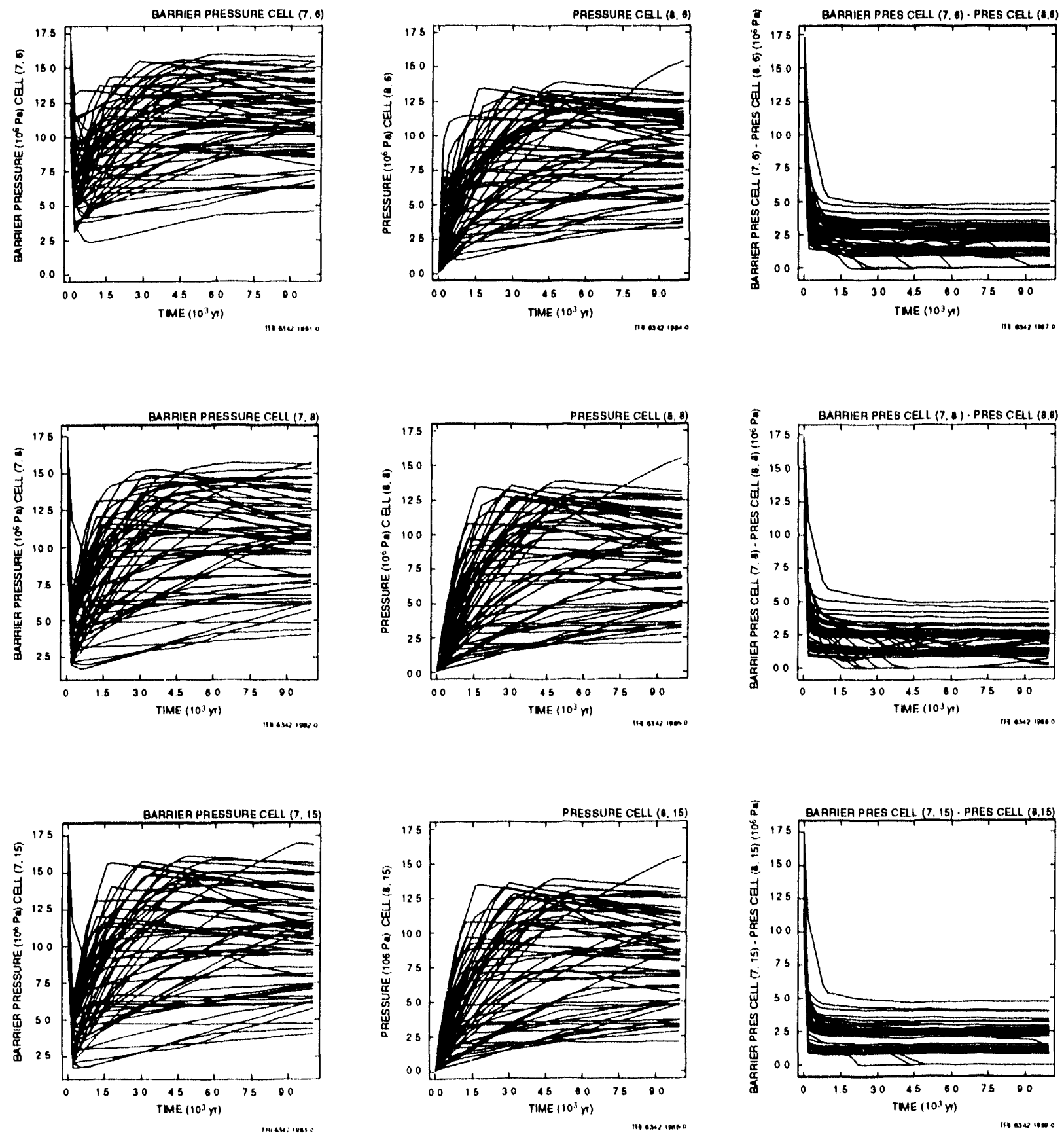

Figure 4-9. Gas barrier pressures in Computational Ce11s $(7,6),(7,8)$ and $(7,15)$, gas pressures in Computational Cel1s $(8,6),(8,8)$ and $(8,15)$, and differences between gas barrier pressure and gas pressure for adjacent computational cells. Location of individual computational cells is shown in figure 4-1. Ce1 ss are identified by an ordered pair indicating cell and layer number in the computational grid. 

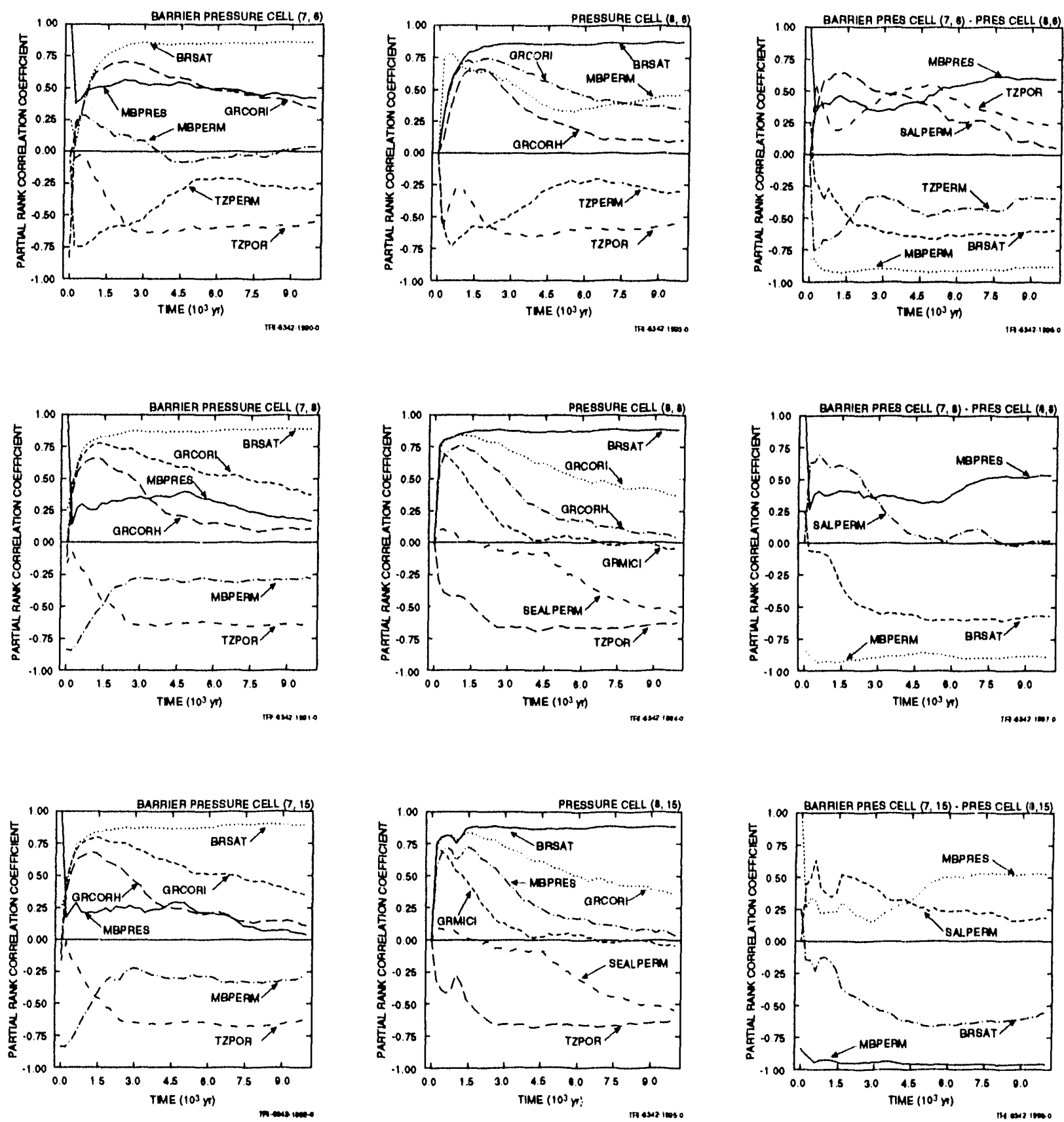

Figure 4-10. Partial rank correlation coefficients for gas barrier pressures in Computational Cells $(7,6),(7,8)$ and $(7,15)$, gas pressures in Computational Cells $(8,6),(8,8)$ and $(8,15)$, and differences between gas barrier pressure and gas pressure for adjacent computational cells. Location of individual computational cells is shown in Figure 4-1. Cells are identified by an ordered pair indicating cell and layer number in the computational mesh. 
MBPRES and MBPERM decreasing with time. Increasing MBPRES tends to increase the gas barrier pressure while increasing MBPERM tends to decrease the gas barrier pressure. At later times, the uncertainty in gas barrier pressure is dominated by BRSAT (initial brine saturation) and TZPOR (scale factor used in definition of transition zone and disturbed rock zone porosity), with gas barrier pressure tending to increase as BRSAT increases and decrease as TZPOR increases.

The gas pressures in the disturbed rock zone are controlled by BRSAT (initial brine saturation) and TZPOR (scale factor used in definition of transition zone and disturbed rock zone porosity), with gas pressure tending to increase as BRSAT increases and decrease as TZPOR increases. The positive effect for BRSAT results because jncreasing BRSAT tends to increase gas generation and hence increase gas pressure. The negative effect for TZPOR results because increasing TZPOR tends to increase the pore volume available for gas storage and hence decrease gas pressure.

The differences between gas barrier pressure and gas pressure are initially dominated by MBPRES (pressure in anhydrite Marker Bed 139 under undisturbed conditions) and MBPERM (permeability in anhydrite marker beds in Salado Formation under undisturbed conditions), with the differences tending to increase as MBPRES increases and decrease as MBPERM increases. The early effects of MBPRES and MBPERM results from their corresponding effects on gas barrier pressure, which completely controls the differences between gas barrier pressure and gas pressure at early times due to the small values for gas pressure. With increasing time, MBPRES drops rapidly in importance. However, MBPERM remains the dominant variable at all times in determining the difference between gas barrier pressure and gas pressure, and hence in determining whether or not gas flow takes place from the disturbed rock zone to the anhydrite marker beds. Increasing BRSAT (initial brine saturation) tends to decrease the difference between gas barrier pressure and gas pressure. Interestingly, increasing BRSAT also tends to increase both gas barrier pressure and gas pressure; thus, BRSAT is having a larger absolute effect on gas pressure than on gas barrier pressure.

\subsubsection{Gas and Brine Flow through Shaft Seal}

A summary of the results for gas and brine flow through the shaft seal is given in Figure 4-11. Of the 60 sample elements, 45 result in nonzero gas flows to the Culebra, with these flows ranging up to approximately 107 $\mathrm{m}^{3}$ over $10,000 \mathrm{yr}$. As the sensitivity analysis in the lower left frame of Figure 4-11 shows, gas flow through the seal is dominated by BRSAT (initial brine saturation), GRCORI (gas-generation rate for corrosion of steel under inundated conditions), SEALPERM (shaft seal permeability), GRCORH (scale 
Cumulative Gas and Brine Flow through Shaft to Culebra
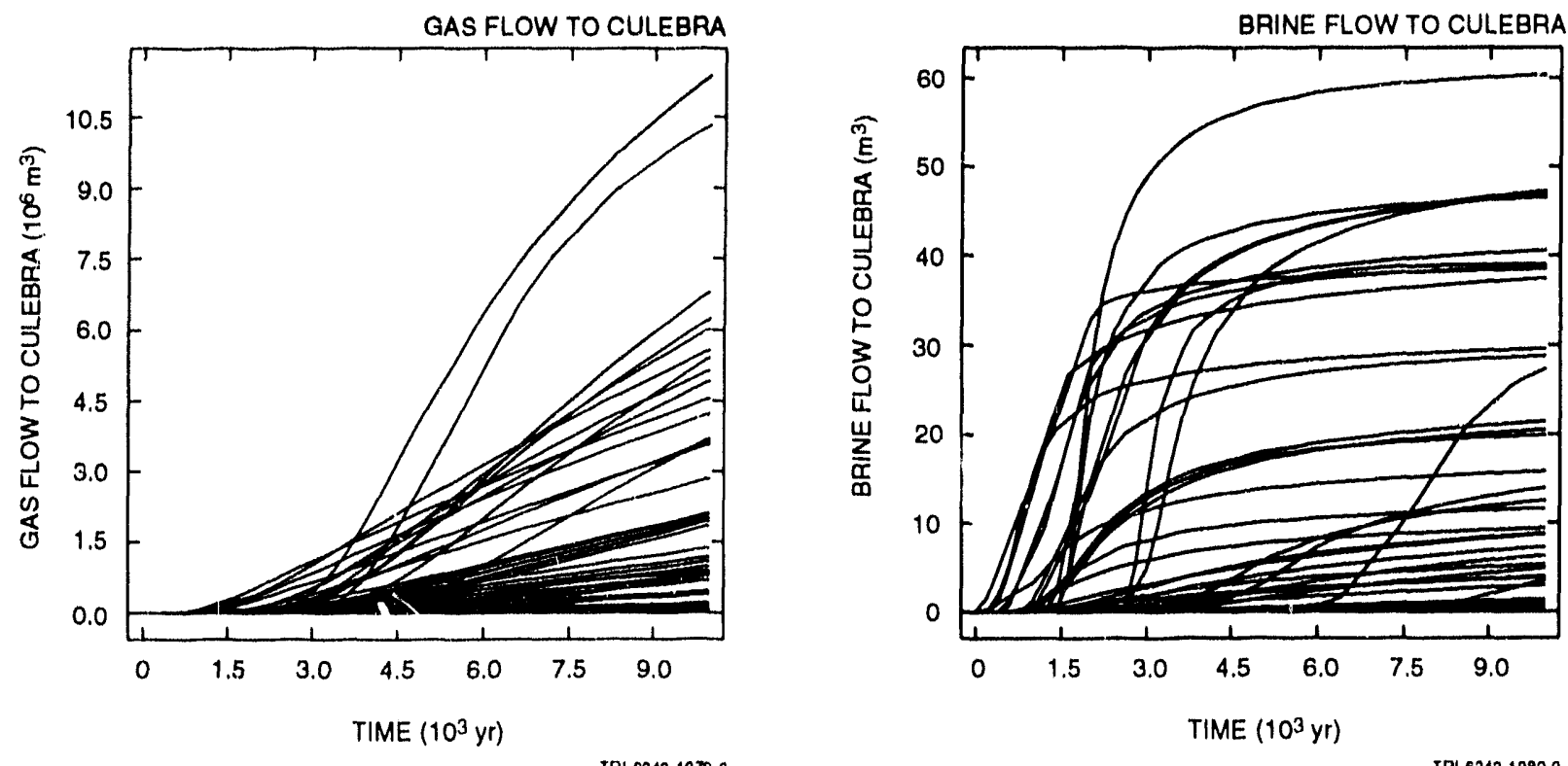

Partial Rank Correlation Coefficients for Cumulative Gas and Brine Flow through Shaft to Culebra
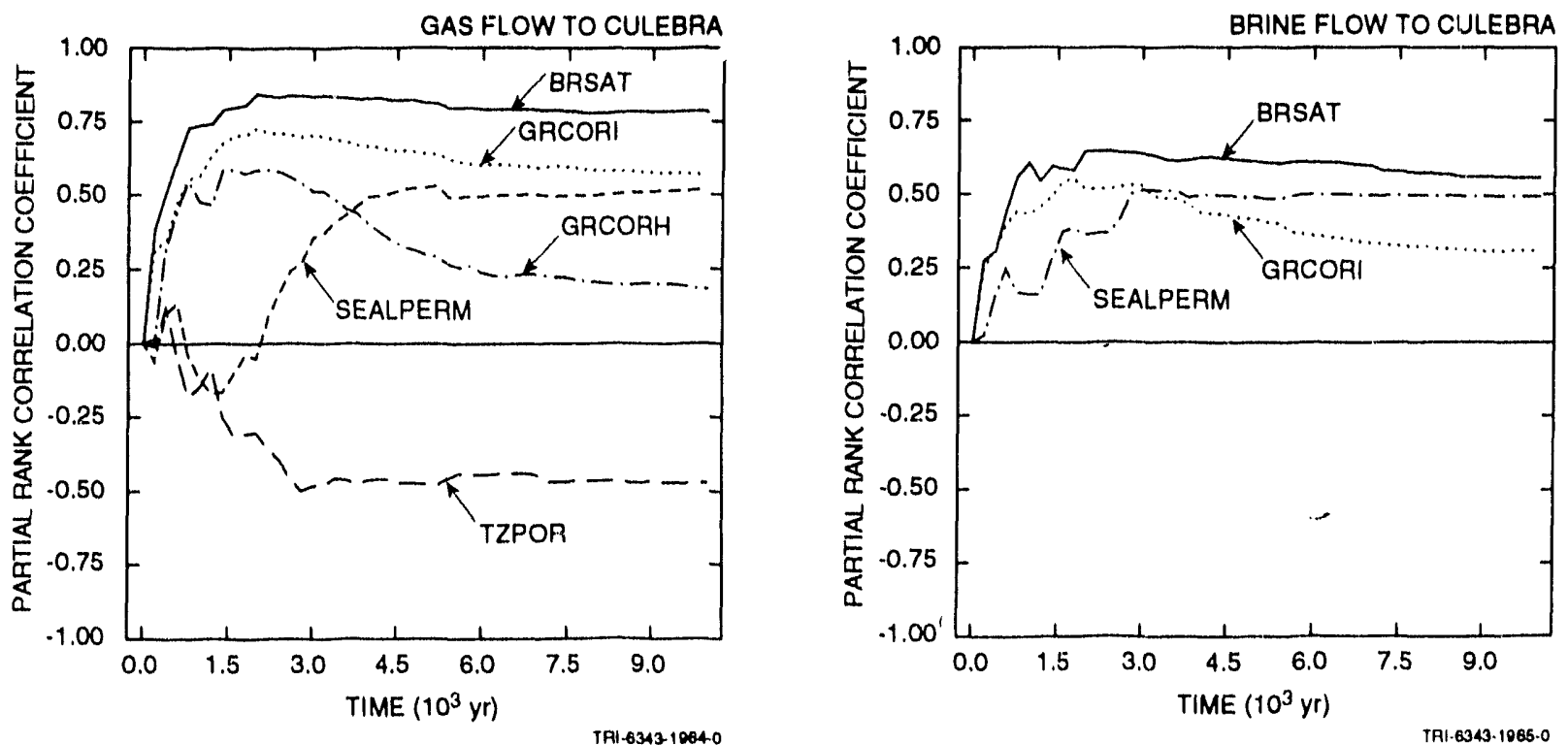

Figure 4-11. Uncertainty and sensitivity analysis results for cumulative gas and brine flow through shaft to culebra. 
factor used in definition of gas-generation rate for corrosion of steel under inundated conditions), and TZPOR (scale factor used in definition of transition zone and disturbed rock zone porosity). Increasing each of BRSAT, GRCORI and GRCORH increases gas generation, and thus increases both gas pressure in the waste panel and resultant gas flow through the shaft seal. The positive effect indicated for SEALPERM results from reduced resistance to gas flow up the shaft. The negative effect indicated for TZPOR results because increasing TZPOR increases the pore volume available for gas storage, with the result that both gas pressure and gas flow up the shaft is reduced.

A stepwise regression analysis for cumulative gas flow through the shaft over $10,000 \mathrm{yr}$ is presented in Table 4-8. The cumulative gas flows used as values for the dependent variable in this regression analysis appear above $10,000 \mathrm{yr}$ in the upper left frame of Figure 4-11. The varlables BRSAT (inftial brine saturation), GRCORI (gas-generation rate for corrosion of steel under inundated conditions) and SEALPERM (shaft seal permeability) appear in the regression analysis with positive regression coefficients; thus, increasing each of these variables tends to increase gas release. The positive effects for BRSAT and GRCORI result because increasing each of these variables tends to increase the total anount of gas generated in the panel, and the positive effect for SEALPERM results because increasing SEALPERM reduces to the resistance to gas flow through the shaft. The variable TZPOR (scale factor used in definition of transition zone and disturbed rock zone porosity) appears in the regression analysis with a negative regression coefficient; thus increasing TZPOR tends to reduce gas flow through the shaft. The negative effect for TZPOR results because increasing TZPOR tends to increase the pore space available for gas storage, thereby reducing gas pressure in the waste panel and thus gas flow up the shaft. Collectively, BRSAT, GRCORI, SEALPERM and TZPOR can account for 678 of the uncertainty in cumulative gas flow through the shaft over 10,000 yr.

Examination of the scatterplots in Figure 4-12 provides additional perspective on the effects of individual variables identified in the regression analysis in Table $4-8$ for cumulative gas flow through the shaft. In particular, scatterplots are provided for BRSAT (initial brine saturation), SEALPERM (shaft seal permeability) and TZPOR (scale factor used in definition of transition zone and disturbed rock zone porosity), with plots using logarithmically-transformed variables appearing in the left column of Figure $4-12$ and plots using rank-transformed variables appearing in the right column of Figure 4-12. An interesting pattern involving BRSAT and SEALPERM appears in Figure 4-12, with the 15 zero gas flows ali associated with the smaller values of BRSAT but a well-defined relationship existing between SEALPERM and the nonzero gas flows. In 
Table 4-8. Stepwise Regression Analyses with Rank-Transformed Data for Cumulative Gas and Brine Flow through Shaft Seal over 10,000 yr.

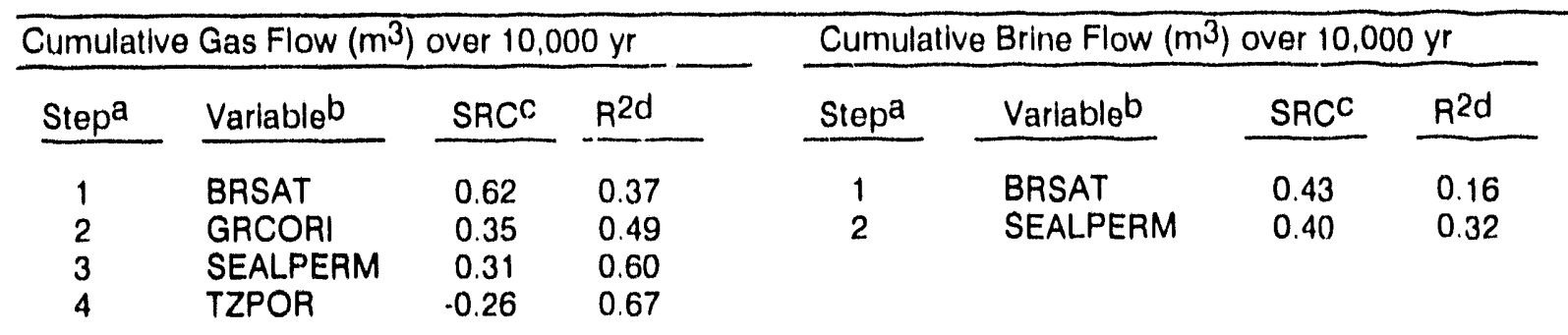

a Steps in stepwise regression analysis

b Varlables listed in order of selection in regression analysis

c Standardized regression coefficients in final regression model

d Cumulative $R^{2}$ value with entry of each varlable into regression model

particular, a stronger linear relationship (in rank or log space) exists between SEALPERM and the nonzero gas flows than exists between BRSAT and the nonzero gas flows. However, because the zero gas flows are associated with the smaller values of BRSAT but are spread randomly over the range of SEALPERM, the regression analys is in Table $4-8$ identifles BRSAT as having a stronger relationship with gas flow than SEALPER. As the rank scatcorplot for TZPOR shows, gas flow through the shaft tends to decrease as TYPOR increases, although there is constderable variability around this trend.

Cumulative brine flow to the Culebra is shown in the upper right frame of Figure 4-11. Orly 16 of the 60 sample elements result in brine flow through the shaft to the culebra. Further, the flows that do occur tend to be small (i.e., $\leq 60 \mathrm{~m}^{3}$ over $10,000 \mathrm{yr}$ ). A sensitivity analysis based on partial rank correlation coefifelents for cumblative bifine flow to the Culebra is presented in the lower right frame of Figure 4-11. Positive effects are indicated for BRSAT ilnitial brine saturation), (iRCORI (gasgeneration rate for corrosion of steel under inundated conditions) and SEALPERM (shaft seal permeability). The positive offects for BRSAT and SEALPERM result because increasing BRSAT reduces the anount of additionat brine required to fill the repository and increasing SEALPERM reduces resistance to brine flow up the shaft. The reason for the selection of GRCORI is not apparent and could be spurious. As a reminder, only 16 of the 60 sample elements resulted in nonzero brtue flows to the culebra. This large muber of acro values makes it diffecule for partial complat fon coefficients to fdentify the dominant variahles and also increases the likelihood that spurious vartables will be solected. The stepwise 

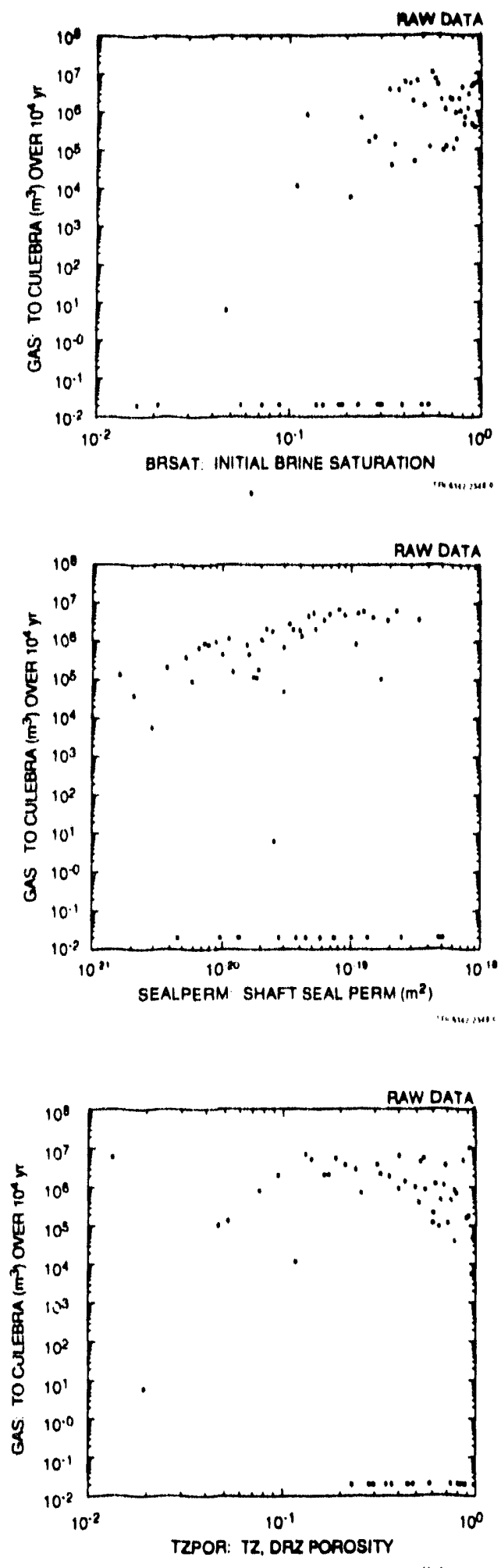

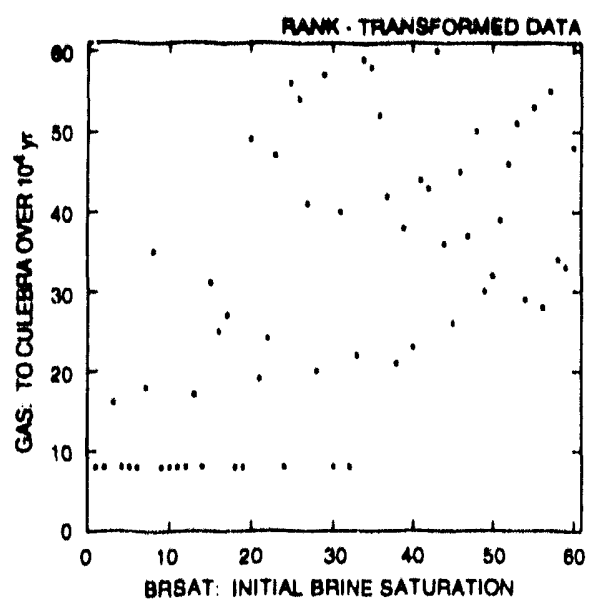

inatom?
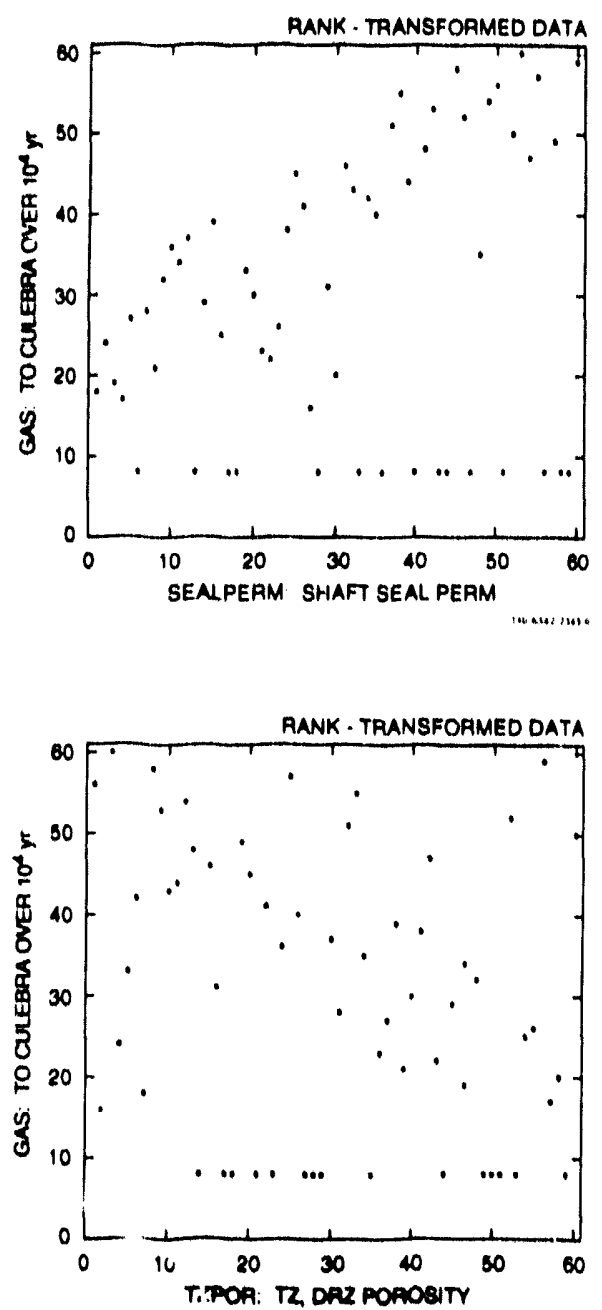

imatisuce

Flgure 4-12. Scatterplots for cumulative gas flow through shaft seal over 10,000 yr with raw and rank-transformed data for the variables BRSA'T (initial brine saturation), SEALPERM (shaft seal permeability) and TZPOR (scale factor used in defintion of transilion zone and disturbed rock zone porosity). 
regression analysis in Table $4-8$ for cumulative brine flow to the culebra over $10^{4}$ yr indicates positive effects for BRSAT and SEALPER, but with an $R^{2}$ value of only 0.32 .

The scatterplots in Figure 4-13 provide more insight on the varlables controlling brine flow to the Culebra than the partial correlation analysls in Figure $4-11$ or the stepwise regression analysis in Table 4-8. As shown in these scatterplots, there is a well-deflned rolationshlp between brine flow and SEAlPFRM (shaft scal permeabflity), with brine flow tending to Ancrease as SEALPERM incroases. However, as was the case for gas flow, this relationship is complicated by the apparent random appearance of zero brine flows scattered over the range of SlinlplikM. As shown by the scatterplots for BRSAT (fultal brine saturation), these zero flows tend to be associated with the smaller values of BRSAT. Also, the scatterplots for TZPOR (scale factor used in defintiton of transit lon zone and disturbed rock zone porosity) suggest that there may also be a condency for zoro brine flows to be associated with larger values for T\%lok. The association of zero brflle flows with small values of BRSAT results becallse of both more

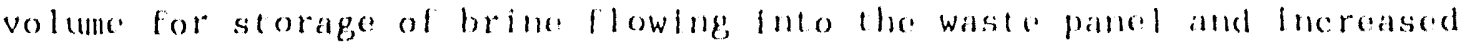
constumption of this brthe in corroston of strol and microbial degradation of cellulosics. If the assoctation of zero brine flows with the larger values of TZPOR is real, it probably results because increasing TZPOR increases the pore volume in the disturbed rock zone avallable for the storage of brine.

\subsection{Discussion}

The anount of brine reaching the repostery is not adequate to assure the constumption of the steel and celluloside fuventortes by orroston and mferobial degradation. The sensltivity allalyses indleate that the domfluate varlable with respect to total steol and cellulosic consumplon is inflial brine saturat fon of the waste, with total constumption showing a tendeney to fncroase as intial brine salturation increasess. In collsistency with the corroston and microblal degradat fon processess boluge brine limitad, varlables affecting the rates of these processsess are fmportant for cumblat ive gas production all arly times but are lesss fmportant for lotal gas production over 10,000 yr. The edluloste fuventory is more likely to be completely consumed than the steel lnventory.

For most sample olements, the gats saturation averaged over the ont ire repository excoeds 0.9 within a fow hundred years of repository closure. lhus, brtae saturation is below restdual saturat fon in most of the

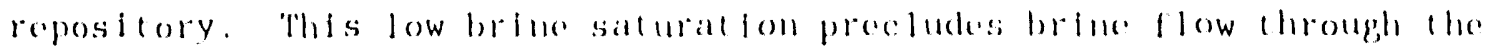

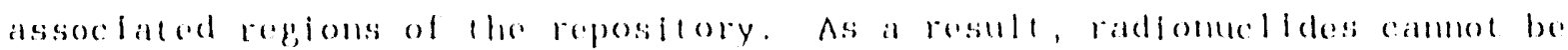




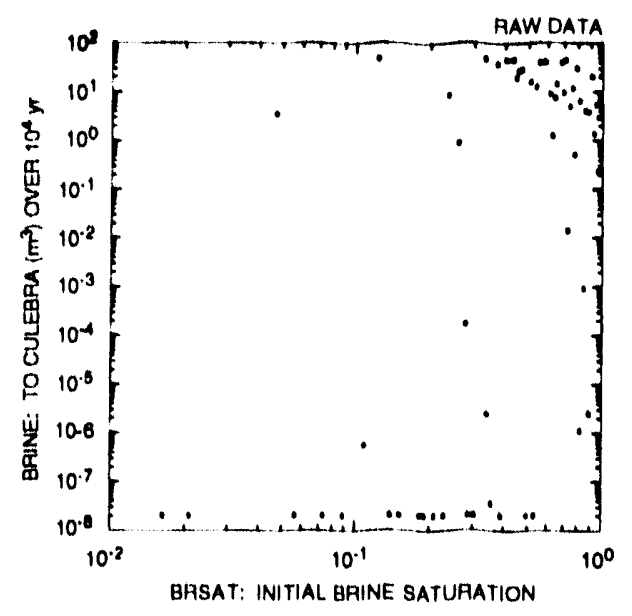

im surn:
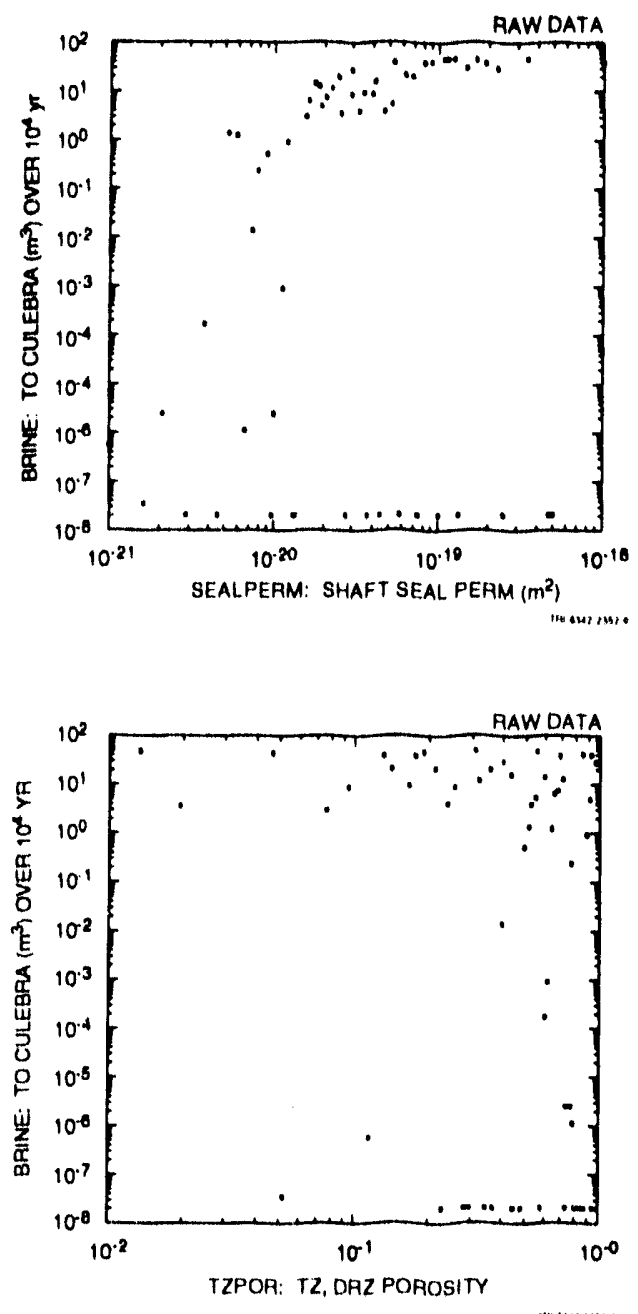
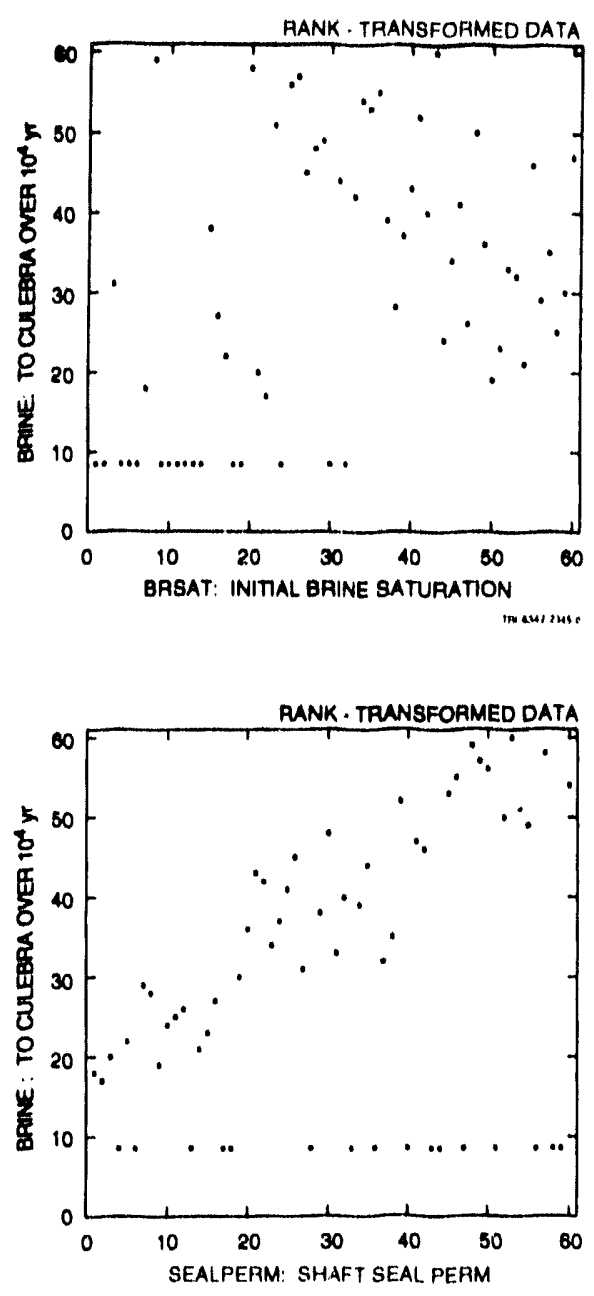

incosine.

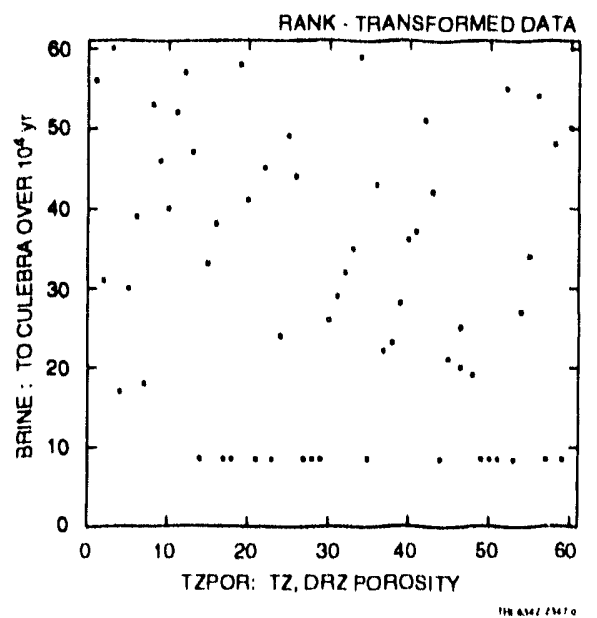

Figure 4-13. Scatterplots for cumulative brine flow through shaft seal over $10,000 \mathrm{yr}$ with raw and rank-transformed data for the variables BRSA'T (initial brine saturation), SEALPERM (shaft seal permeability) and TZPOR (scale factor used in definition of transition zone and disturbed rock zone porosity). 
transported out of most of the repository by flowing brine under the conditions that existed in this analysis.

The short, low permeability seals considered in this analysis did not offer sufficient resistance to preclude gas and brine flow up the shaft to the Culebra. Of the 60 sample elements used in this analysis, 45 resulted in nonzero gas flows to the Culebra and 16 resulted in nonzero brine flows to the Culebra. The nonzero flows showed a strong tendency to be associated with the larger values for initial brine saturation in the waste. However, given that a nonzero flow to the Culebra occurred, its size tended to increase as shaft seal permeability increased.

To provide a correction for the competing effects of waste panel expansion due to gas pressure and waste panel compaction due to overburden pressure, the initial pore volune of the repository was set to the volume necessary to contain all potential waste-generated gas at 1 ithostatic pressure (i.e., $14.8 \mathrm{MPa}$ ). As a result, gas pressure in the repository typically remained below lithostatic pressure. Thus, gas movement up the shaft is occurring in the presence of an effective bound of 14.8 MPa on gas pressure in the repository.

There was little gas movement away from the rerository in the anhydrite marker beds. For most sample elements, gas pressure did not rise to levels necessary to exceed the gas barrier pressures associated with undisturbed anhydrite. 


\section{DISCUSSION}

Five primary topics were investigated in this analysis: (1) gas production due to corrosion, (2) gas production due to microbial degradation, (3) gas migration into annydrite marker beds in the Salado Formation, (4) gas migration through a system of shaft seals to the Culebra Dolomite, and (5) gas migration through a single shaft seal to the Culebra Dolomite. A summary of the most important variables for each of these topics is given in Table $5-1$.

Table 5-1. Important Variables Identified in Uncertainty and Sensitivity Analyses for Gas and Brine Migration

Total Gas Production Due to Corrosion

- Initial brine saturation of waste

- Stoichlometric factor for corrosion of steel

- Gas generation rate for corrosion of steel under inundated conditions

- Fraction of total waste volume occupied by IDB metals and glass waste category

Total Gas Production Due to Microbial Degradation

- Stoichiometric coefficient for microbial degradation of cellulosics

- Gas generation rate due to microbial degradation of cellulosics under inundated conditions

- Fraction of total waste volume occupied by IDB combustible waste category

Gas Migration into Anhydrite Marker Beds

- Gas barrier pressure, which is defined as a function of anhydrite permeability

Gas Migration through Shaft to Culebra Dolomite for a System of Shaft Seals with Panel Seals and Disturbed Rock Zone Permeability Sufficiently Low to Prevent Significant Amounts of Gas from Bypassing Panel Seals (i.e., Case 2)

- Initial brine saturation of waste

- Permeability of seals between waste panels

- Permeability of shaft seals

Gas Migration through Shaft to Culebra Dolomite for a Single Shaft Seal without Panel Seals (i.e., Case 3)

- Initial brine saturation

- Gas generation rate for corrosion of steel under inundated conditions

- Permeability of shaft seals

- Porosity of distributed rock zone 
Initial brine saturation in the waste was the most important variable with respect to total gas production due to corrosion. For many observations in the analysis, the consumption of steel by corrosion was limited by the amount of brine in the repository. As a result, initial brine saturation often controlled the amount of steel that was consumed by corrosion and hence the amount of gas produced by corrosion. The stoichiometric factor for corrosion defined the proportion of two different corrosion reactions, with each reaction producing a different amount of gas per mole of steel consumed by corrosion. Factors affecting the rate of gas generation due to corrosion were important early (i.e., before $3000 \mathrm{yr}$ ) but had less effect on total gas generation over 10,000 yr. For most observations, gas generation due to corrosion stopped before 10,000 yr due to either brine depletion or steel depletion, with the result that the rate of corrosion was not the dominant factor in determining the amount of gas produced over $10,000 \mathrm{yr}$. The initial inventory of steel has a positive effect on the amount of gas produced by corrosion, although this effect is less than the effects for initial brine saturation, the stoichiometric factor for corrosion and the gas generation rate due to the relatively small range of uncertainty assigned to the initial steel inventory. When the corrosion processes run to completion, the total amount of gas generated is determined by the stoichiometric factor for corrosion and the initial steel inventory.

The stoichiometric coefficient was the most important variable with respect to total gas production due to microbial degradation of cellulosics. As for gas production due to corrosion, factors affecting the rate of microbial degradation were important at early times but had less effect on the total gas production over $10,000 \mathrm{yr}$. A small positive effect was also indicated for the initial inventory of cellulosics, with this effect tending to be obscured by the large uncertainty assigned to the stoichiometric coefficient. When the microbial degradation processes run to completion, the total amount of gas generated is determined by the stoichiometric coefficient and the initial inventory of cellulosics. Overall, the cellulosics showed a greater tendency to be completely consumed over 10,000 yr than was shown by steel. The amount of gas produced by corrosion tended to be several times the amount of gas produced by microbial degradation. This difference between total gas production results in large part from the stoichiometric coefficient for microbial degradation, which was assigned an uncertainty range that extends to zero.

Gas migration into the anhydrite marker beds was dominated by the gas barrier pressure that had to be overcome for gas to move from the disturbed 
rock zone to the undisturbed anhydrite. For most sample elements, gas pressures in the disturbed rock zone never reached levels that were sufficient to overcome the gas barrier pressure associated with the first computational cell in the undisturbed anhydrite. For all three cases considered in this study, the gas barrier pressure was defined as a function of the permeability of undisturbed anhydrite.

Three analysis cases were considered in this study: (1) Fully consolidated shaft, (2) System of shaft seals with panel seals, and (3) Single shaft seal without panel seals. Case 1 does not result in any meaningful gas or brine movement from the repository to the Culebra Dolomite and was included in this analysis to facilitate observing the factors affecting gas and brine migration into the anhydrite marker beds of the Salado Formation in the presence of an effective shaft seal system. Case 2 provides a more realistic representation of the repository in that the analysis includes the waste panels, the seals between the waste panels, and a system of three shaft seals. Case 3 was included in the analysis to investigate the effect that a single, short, low permeability shaft seal might have on gas and brine migration to the Culebra Dolomite. To provide a bounding perspective on the effect of the permeability of this single shaft seal on gas and brine migration to the Culebra Dolomite, no seals were assumed to exist between the panels in the repository.

For Case 2, gas migration through the shaft was dominated by initial brine saturation of the waste, permeability of seals between waste panels, and permeability of shaft seals. No single variable played a dominant role, although the strongest effect was due to initial brine saturation. Of the 22 sample elements used in this analysis, 18 resulted in gas migration to the Culebra Dolomite. In contrast, only 4 sample elements resulted in the movement of brine away from the waste panels.

For Case 3, gas migration through the shaft was dominated by initial brine saturation of the waste and shaft seal permeability. Initial brine saturation tends to act as a switch, with no gas release to the Culebra Dolomite often resulting when initial brine saturation is small (i.e., $<0.15)$. However, given that a gas release to the Culebra Dolomite occurs, the size of this release shows a strong tendency to increase as the shaft seal permeability increases. A similar pattern involving initial brine saturation and shaft seal permeability also occurs for the movement of brine through the shaft to the Culebra Dolomite. Of the 60 sample elements used in this analysis, 45 resulted in nonzero gas flows to the Culebra and 16 resulted in nonzero brine flows to the Culebra. Thus, the short, low permeability shaft seal considered in this analysis did not offer sufficient resistance to preclude gas and brine flow from the repository to the Culebra. 


\section{REFERENCES}

Allen, D.M. 1971. The Prediction Sum of Squares as a Criterion for Selecting Predictor Variables. Report No. 23. Lexington, KY: Department of Statistics, University of Kentucky. (Copy on file at the Waste Management and Transportation Library, Sandia National Laboratories, Albuquerque, NM.)

Bertram-Howery, S.G., and R.L. Hunter, eds. 1989. Prellminary Plan for Disposal-System Characterization and Long-Term Performance Evaluation of the Waste Isolation Pilot Plant. SAND89-0178. Albuquerque, NM: Sandia National Laboratories.

Bertram-Howery, S.G., M.G. Marfetta, R.P. Rechard, P.N. Swift, D.R. Anderson, B.L. Baker, J.E. Bean, Jr., W. Beyeler, K.F. Brinster, R.V. Guzowski, J.C. He1ton, R.D. McCurley, D.K. Rudeen, J.D. Schrelber, and P. Vaughn. 1990. Preliminary Comparison with 40 CFR Part 191, Subpart B for the Waste Isolation Pilot Plant, December 1990. SAND90-2347. Albuquerque, NM: Sandia National Laboratories.

Beyer, W.H., ed. 1968. CRC Handbook of Tables for Probability and Statistics. 2nd ed. Cleveland, $\mathrm{OH}$ : Chemical Rubber Co.

David, F.N. 1938. Tables of the Ordinates and Probability Integral of the Distribution of the Correlation Coefficient in Small Samples. London, England: Biometrika Office, University College; Cambridge, England: The University Press.

Davies, P.B. 1991. Evaluation of the Role of Threshold Pressure in Controlling Flow of Waste-Generated Gas into Bedded Salt at the Waste Isolation Pilot Plant. SAND90-3246. Albuquerque, NM: Sandia National Laboratories.

Draper, N.R., and H. Smith. 1981. Applied Regression Analysis. 2nd ed. New York, NY: Wiley.

Helton, J. C. 1983. "Health Effects Associated with Unit Radionuclide Releases to the Environment," Technical Assistance for Regulatory Development: Review and Evaluation of the Draft EPA Standard 40 CFR 191 for Disposal of High-Level Waste. NUREG/CR-3235, SAND87-1557. Albuquerque, NM: Sandia National Laboratories. Vol. 5.

Helton, J.C. [1992.] "Uncertainty and Sensitivity Analysis Techniques for Use in Performance Assessment for Radioactive Waste Disposal," Reliability Engineering and System Safety. (Copy on file at the Waste Management and Transportation Library, Sandia National Laboratories, Albuquerque, NM.)

Helton, J.C., J.W. Garner, R.D. McCurley, and D.K. Rudeen. 1991. Sensitivity Analysis Techniques and Results for Performance Assessment at the Waste Isolation Pilot Plant. SAND90-7103. Albuquerque, NM: Sandia National Laboratories. 
Helton, J.C., J.W. Garner, R.P. Rechard, D.K. Rudeen and P.N. Swift. 1992. Preliminary Comparison with 40 CFR Part 191, subpart $B$ for the Waste Isolation Pilot Plant, December 1991, Volume 4: Uncertainty and Sensitivity Analysis Results. SAND91-0893/4. Albuquerque, NM: Sandia National Laboratories.

Iman, R.L., and W.J. Conover. 1979. "The Use of the Rank Transform in Regression," Technometrics. Vo1. 21, no. 4, 499-509.

Iman, R.L., and W.J. Conover, 1982, "A Distribution-Free Approach to Inducing Rank Correlation Among Input Varlables," Communications in Statistics: Simulation and Computation. Vol 11, no. 3, 311-334.

Iman, R.L., and J.M. Davenport. 1982. "Rank Correlation Plots for Use with Correlated Input Variables, "Communications in Statistics: Simulation and Computation. Vol. 11, no. 3, 335-360.

Iman, R.L., and M.J. Shortencarier. 1984. A FORTRAN 77 Program and User's Guide for the Generation of Lat in Hypercube and Random Samples for Use with Computer Mode1s. NUREG/CR-3624, SAND83-2365. Albuquerque, NM: Sandia National Laboratories.

Iman, R.L., J.M. Davenport, E.L. Frost, and M.J. Shortencarier. 1980. Stepwise Regression with PRESS and Rank Regression (Program User's Guide). SAND79-1472. Albuquerque, NM: Sandia National Laboratories.

Iman, R.L., M.J. Shortencarier, and J.D. Johnson. 1985. A FORTRAN 77 Program and User's Guide for the Calculation of Partial Correlation and Standardized Regression Coefficients. NUREG/CR-4122, SAND85-0044. Albuquerque, NM: Sandia National Laboratories.

Lappin, A.R., R.L. Hunter, D.P. Garber, P.B. Davies, R.L. Beauheim, D.J. Borns, L.H. Brush, B.M. Butcher, T. Cauffinan, M.S.Y. Chu, L.S. Come\%, R.V. Guzowski, H.J. Iuzzolino, V. Kelley, S.J. Lambert, M.G. Marictta, J.W. Mercer, E.J. Nowak, J. Pickens, R.P. Rechard, M. Reeves, K.L. Robinson, and M.D. Siege1. 1989. Systems Analysis, Long-Term Radionuclide Transport, and Dose Assessments, Waste Isolation Pilot Plant (WIPP), Southeastern New Mexico; March 1989. SAND89-0462. Albuquerque, NM: Sandia National Laboratories.

Marietta, M.G., S.G. Bertran-Howery, D.R. Anderson, K.F. Brinster, R.V. Guzowski, H. Iuzzolino, and R.P. Rechard. 1989. Performance Assessment Methodology Demonstration: Methodology Development for Evaluating Compliance with EPA $40 \mathrm{CFK}$ 191, Subpart B, for the Waste Isolation Pilot Plant. SAND89-2027. Albuquerque, NM: Sandia National laboratories.

Mckay, M.D., R.J. Beckman, and W.J. Conover. 1979. "A Comparison of Three Methods for Selecting Values of Input Variables in the Analys is of output. from a Computer Code," Techmometrics. Vol. 21, no. 2, 239-245. 
Nowak, E.J., J.R. Tillerson, and T.M. Torres. 1990. Initial Reference Seal System Design: Waste Isolation Pilot Plant. SAND90-0355. Albuquerque, NM: Sandia National Laboratories.

Powers, D.W., S.J. Lambert, S-E. Shaffer, L.R. Hill, and W.D. Weart, eds. 1978. Geological Characterization Report, Waste Isolation Pilot Plant: (WIPP) Site, Southeastern New Mexico. SAND78-1596. Albuquerque, NM: Sandia National Laboratories. Vols. 1-II.

Rechard, R.P., W. Beyeler, R.D. McCurley, D.K. Rudeen, J.E. Bean, and J.D. Schreiber. 1990. Parameter Sensitivity Studies of Selected Components of the Waste Isolation Pllot Plant. Repository/Shaft Systems. SAND89-2030. Albuquerque, NM: Sandia National laboratorles.

U.S. DOE (Department of Energy). 1980. Final Environmental Impact Statement: Waste lsolation Pilot Plant. DOE/ELS-0026. Washington, DC: U.S. Department of Energy. Vols. 1-2.

U.S. DOE (Department of Energy). 1990. Final Supplement Environmental Impact Statement, Waste lsolation Pilot Plant. DOE/EIS-0026-FS. Washington, DC: U.S. Department of Energy, Office of Environmental Restoration and Waste Management. Vols. 1-13.

U.S. DOE (Department of Energy). 1991. Strategy for the Waste Isolation Pilot Plant Test Phase, Revised Draft \#3. DOE/EM/48063-2. Washington, DC: U.S. Department of Energy, Office of Waste Operations. (Copy on file at the Waste Management and Transportation Library, Sandia National Laboratories, Albuquerque, NM.)

U.S. EPA (Environmental Protection Agency). 1985. "Environmental Standards for the Management and Disposal of Spent Nuclear Fuel, High-Level and Transuranic Radioactive Wastes; Final Rule, 40 CFR Part 191," Federal Register. Vol. 50, no. 182, 38066-38089.

U.S. EPA (Environmental protection Agency). 1986. "Land Disposal Restrictions," Code of Federal Regulations 40, Part 268. Washington, DC: Office of the Federal Register, National Archives and Records Administration.

Voss, C.1. 1974. SUTRA (Saturated-Unsaturated Transport): A Finite-Element Simulation Model for Saturat ed-Unsaturated, Fluid-Density-Dependent GroundWater Flow with Energy Transport or Chemically-React ive Single-Species Solute Transport. Water-Resourcea Investigat lons Report 8/14369. Reston, VA: U.S. Geological Survey National Center.

WIPP PA (Performance Assessment) Division. 1991a. Preliminary Comparison with 40 CFR Part 191, Subpart B for the Waste lsolation Pilot Plant, December 1991, Volume 1: Methodology and Results. SAND91-0893/1. Albuquerque, NM: Sandia National Laboratorles. 
WIPP PA (Performance Assessment) Division. 1991b. Preliminary Comparison with 40 CFR Part 191, Subpart B for the Waste Isolation Pilot Plant, December 1991, Volume 2: Probability and Consequence Modeling.

SAND91-0893/2. Albuquerque, NM: Sandia National Laboratories.

WIPP PA (Performance Assessment) Division. 1991c. Preliminary Comparison with 40 CFR Part 191, Subpart B for the Waste Isolation Pilot Plant, December 1991, Volume 3: Reference Data. SAND91-0893/3. Albuquerque, NM: Sandia National Laboratories.

WIPP PA (Performance Assessment) Department, 1992. Long-Term Gas and Brine Migration at the Waste Isolation Pllot Plant: Preliminary Sensitivity Analyses for Post-Closure 40 CFR 268 (RCRA), May 1992. SAND92-1933. Albuquerque, NM: Sandia National Laboratories. 


\section{DISTRIBUTION}

(Send Distrlbution list changes to M.M. Gruebel, Dept. 6342, Sandla

National Laboratories, PO Box 5800, Albuquerque, NM 87185-5800)

\section{Federal Agencies}

US Department of Energy (6)

Office of Civilian Radioactive Waste

Management

Attn: Deputy Director, RW-2

Associate Director, RW-10/50

Office of Program and

Resources Management

Office of Contract Business Management

Director, Analysis and

Verification Division, RW-22

Associate Director, RW-30

office of systems and

Compliance

Associate Director, RW-40

office of storage and

Transportation

Director, RW $-4 / 5$

Office of Strategic Planning and International Programs Uffice of External Relations

Forrestal Bullding

Washington, DC 20585

US Department of Energy

Albuquerque Operations office

Attn: National Atomic Museum Library PO Box 5400

Albuquerque, NM 87185

US Department of Energy (2)

office of Environmental Restoration

and Waste Management

Attn: EM-1

C. Frank, EM-50

Washington, DC 20585

US Departinent of Energy (3)

Office of Environmental Restoration and Waste Management

Attn: M. Fre1, EM-34, Trevion II

Director, Waste Management Projects

Washington, DC 20585-0002

US Department of Energy

Office of Environmental Restoration and Waste Management

Attn: J. Lytle, EM-30, Trevion II

Washington, DC 20585-0002
US Department of Energy

office of Environmental Restoration and Waste Management

Attn: S. Schneider, EM-342, Trevion II

Washington, DC 20585-0002

US Department of Energy (3)

WIPP Task Force

Attn: G.H. Daly

S. Fucigna

B. Bower

12800 Middlebrook Rd, Sufte 400

Germantown, MD 20874

US Department of Energy (4)

office of Environment, Safety and

Health

Attn: R,P. Berube, EH-20

C. Borgstrum, EH-25

R. Pelletier, EH-231

K. Taim1, EH-232

Washington, DC 20585

US Department of Energy (6)

WIPP Project Integration office

Attn: S. Alcorn

W.J. Arthur III

J. Coffey

L.W. Gage

P.J. Higgins

D. A. Olona

PO Box 5400

Albuquerque, NM 87115-5400

US Department of Energy (2)

WIPP Project Integration Satellite

office

Attn: R. Batra

R. Becker:

PO Box 3090, Mall stop 525

Car1sbad, NM 88221-3090

US Department of Energy (10)

WIPP Project Site office (Carlsbad)

Attn: A. Hunt (4)

V. Daub (4)

J. Lippis

$k$. Hunter

PO Box 3090

Carlsbad, NM 88221-3090 
US Department of Energy

Research \& Waste Management DIvision

Attn: Director

PO BoX E

Oak Ridge, TN 37831

US Department of Energy

Idaho Operations offlce

Fuel Processing and Waste

Management Division

785 DOE Place

Idaho Fa1ls, ID 83402

US Department of Energy

Savannah River Operations office

Defense Waste Processing

Facility Profect office

Attn: W.D. Pearson

PO Box A

Alken, SC 29802

US Department of Energy (2)

Richland Operations office

Nuclear Fuel Cycle \& Production

Division

Attn: R.E. Gerton

$825 \mathrm{Jadwin}$ Ave.

PO Box 500

Richland, WA 99352

US Department of Energy

Offlce of Geologic Disposal

Yucca Mountain Project Office

Attn: Associate Director, RW-20

PO Box 98608

Las Vegas, NV 89193-8608

US Department of Energy ( 3 )

Nevada Operations office

Attn: J.R. Bol and

D. Livingston

P.K. Fitzsimuons

2753 S. Highland Drive

Las Vegas, NV 89183-8518

US Department of Energy (2)

Technical Information Center

PO BOX 62

Oak RIdge, TN 37831

US Department of Energy

Los Alamos Area office

52835 th Street

Los Alamos, NM 87544
US Department of Energy (2)

Chicago Operations offlce

Attn: J.C. Haugen

9800 South Cass Avenue

Argonne, IL 60439

US Department of Energy (3)

Rocky Flats Area Offlce

Attn: W.C. Rask

G. llufeman

T. Lukow

PO Box 928

Golden, CO 80402-0928

US Department of Energy

Dayton Area Office

Attn: R. Grandfleld

PO Box 66

Mlamisburg, OH 45343-0066

US Department of Energy

Attn: E. Young

Room E-178

GAO/RCED/GTN

Washington, DC 20545

US Bureau of Land Management

Carlsbad office

101 E. Mermod

Carlsbad, NM 88220

US Bureau of Land Management

New Mexico State Office

PO Box 1449

Santa Fe, NM 87507

US Environmental Protection Agency (2)

Radiation Protection Prograns

Attn: $M$. Oge

ANR -460

Washington, DC 20460

US Environmental Protection

Agency, Region 6

Attn: C. Byrum, 6T-ET

1445 Ross Ave.

Dallas, TX 75202

US Geological Survey (2)

Water Resources Division

Attn: C. Peters

4501 Indian School NE

Suite 200

Albuquerque, NM 87110 
US Nuclear Regulatory Commission Divis Lon of Waste Management

Attn: H. Marson

Ma11 Stop $4 \cdot \mathrm{H} \cdot 3$

Washington, DC 20555

US Nuclear Regulatory Commission (/4) Advisory Commlttee on Nuclear Wasto

Attn: D. Moel10.

M.J. Steindler

P.W. Poine roy

W.J. HInze

7920 Norfolk Ave.

Bethesda, MD 20814

Defense Nuclear Facllitles Safoty

Board

Attil: D. Winters

625 Indlana Ave. NW

sulte 700

Washlugton, DC 20004

Nuclear Wasto Technleal Rovlew Board

Attu: Library (2)

1100 WILson Blva.

Sulte 910

Arlington, VA 22209.2297

Energy and Solonce DIvision

Offlce of Management and Budgot

Attu: K. Yuracko

72517 th stroot NW

Washlingtom, DC: 20503

\section{State Agencies}

New Mexlco Buroau of Mlnes

and MIneral Resources

Socorro, NM 87801

New Moxico Energy, Mlnerals and

Natural Resources Department

Attn: l.lbrarian

2040 South pacheco

Santa Fe, NM 87505

New Mexico Energy, Minerals and

Natural Resources Department

New Mexlco Radloactive Task Forec (2)

(Covernor's WIPP Task Force)

Attn: A. Lockwood, Chairman

C. Wentz, Pollcy Analyst

2040 South Pacheco

Santa Fo, NM 87505
Bob Forrest

Mayor, City of Carlsbad

PO Box 1569

Carlsbad, NM 88221

Carlsbad Department of Development Exacuclua Diroctor

Attn: C, Bermard

PO BOX 1090

Carlsbad, NM 88221

New Mexico Envi romment Department

Secretary of the linviroment (3)

Attin: J. Esplnosa

PO Box 968

$1190 \mathrm{St}$. Francls Drive

Satila Fe, NM 87503.0968

New Moxlco Rinvl romment Department

Attil: P. Mochal and

WIPp Project site office

P() $\operatorname{Hox} 3090$

Carlsbad, NM 88221-3090

Now Moxlco State Fnginoor's offleo

Attı: M. Chuduoft

PO Box 25102

Santa Fe, NM 8/b()/-510?

Environmontal livaluat Attil: R. Noill

100) Wyoming, Blvd. NE, Sulte F-?

Albuquergue, NM $8 / 109$

\section{Advisory Committee on Nuclear Facillity Safoty}

John $F$. Ahearne

Execut I ve DIrector, SIgina $X I$

99 Alexander Dilve

Research Trlangle Park, NC 27709

James F. Martin

109 Observatory Road

Ann Arbor, MI 1,8109

\section{WIPP Panel of National Research Council's Board on Radioactive Waste Management}

Charles Falrhurst, Chalrman

Department of Cifvil and

Mineral linglueerling

Univorsity of Minnesota

sOO Plllsbury Dr. SE

Mlmacapolls, MN bb4sb-0220 
John 0 . Blomeke

3833 Sandy Shore Drive

Lenolr Clty, TN 37771.9803

John D. Bredehoeft

Western Region Hydrologist

Water Resources DIvision

US Geologlcal Survey (M/S 439)

345 Middlefield Road

Menlo Park, CA 94025

Rodney C. Ewing

Department of Geology

Unlverslty of New Mexico

Albuquerque, NM 87131

B. John Garrick

PLG, Inc.

4590 MacArthur Blvd.

Sulte 400

Newport Beach, CA 92660.2027

Leonard F. Konlkow

US Geological Survey

431 National Center

Reston, VA 22092

Jeremiah O'Driscoll

505 Valley HIll Drfve

Atlanta, GA 30350

Chrls G. Whipple

ICF Kalser Engineers

1800 Harrison St.

Oakland, CA 94612-3430

National Research Councll (3)

Board on Radloactive

Waste Management

RM HA456

Attn: P.B. Myers (2)

G.J. Grube

2101 Constitution Ave.

Washington, DC 20418

\section{Pertormance Assessment Peer Revlew Panel}

G. Ross Heath

College of Ocean and Fishery

Sclences, HN- 15

583 Henderson Hall

University of Washingtun

Seattle, WA 98195
Thomas H. Plgford

Departinent of Nucloar Eng I neering

4159 Etcheverry Hall

University of Callfornia

Berkeley, CA 94720

Thomas A. Cotton

JK Research Associates, Inc.

4429 Butterworth Place NW

Washington, DC 20016

Robert J, Budnitz

Presldent, Future Resources

Assoclates, Inc.

2000 Center Street, Sulte 418

Berkeley, CA $94 \% 04$

C. John Mann

Department of Geology

245 Natural History Bldg.

1301 West Green Street

Unlverslty of 111 inols

Urbana, IL. 61801

Frank W. Schwartz

Departinent of Geology and Mineralogy

The Ohlo State University

Scott Hall

1090 Carmack Rd.

Columbus, OH 43210

\section{National Laboratories}

Argonie Natlonal Laboratory (2)

Attn: A. Sinlth

D. 'Tomasko

9700 South Cass, Bldg, 201

Argonne, IL 60439

Battelle Pacifle Northwest

Laboratory (2)

Attn: S. Bates

R.E. Westerman

MSIN P8.44

Battelle Boulavard

Richland, WA 99352

Idaho National EnglneerIng

Laboratory (2)

Attn: H. Loo

R. Kllnger

Mall Stop 5108

Idaho Falls, ID 83403-4000 
Los Alamos National Laboratory (5)

Attn: B. Erda1, CNC-11

M. Fnnls, HS-12

Mall Stop 3900

S. Koslowlez, EM-7

Ma11 Stop J595

L. Soholt, EM-13

Mall Stop M992

J. Wenzel, HS 12

Mall Stop K482

PO Box 1663

Los Alamos, NM 87545

Oak R1dge National Laboratory

Transuranic Waste Manager

Attn: D.W. Turner

B1Ag. 3047

PO Box 2008

Oak RIdge, TN 37831.6060

Pacific Northwest Laboratory

Attn: B. Kennady

PO Box 999

Richland, WA 99352

West Inghouse-Savannah River

Technology Center (4)

Attn: N. Bibler

J.R. Harbour

M.J. Plodinec

G.G. WI cks

Alken, SC 29802

\section{Corporatlons/Members of the Publlc}

Battelle Memorlal Institute

Attn: R. Root

J. Kircher

505 Marquette NW

Sulte 1

Albuquerque, NM 87102

Benchmark Environinental Corp.

Attn: C. Frederickson

4501 Indian School NE.

Sulte 105

Albuquerque, NM 87110

Beta Corporation Int.

Attn: E. Bonano

6613 Esther NE

Albuquerque, NM 87109
City of Albuquerque

Publlc Works Department

Utility Planning Division

Attn: W.K. Summers

PO Box 1293

Albuquerque, NM 87103

Douel and Assoclates, Inc.

Attn: R.W. Prindle

1208 Jefferson NE

Albuquerque, NM 87109

Disposal Safety, Inc.

Attn: B. Ross

1660 L Street. NW, Sulte 314

Washington, DC 20036

Ecodynamics (2)

Attn: P. Roache

R. Blalne

PO Box 9229

Albuquerque, NM 87119.9229

EG \& G Idaho (3)

1955 Fremont street

Attn: C. Atwood

C. Hertzler

T.I. Clements

Idaho Falls, ID 83415

Geomatrix

Attn: K. Coppersinth

100 Pine St., Sulte 1000

San Francisco, CA 94111

Golder Assoclates, Inc.

Attn: R. Kossik

$4104148 \mathrm{th}$ Avenue NE

Redimond, WA 98052

INTERA, Inc .

Attn: A.M. LaVenue

1650 Unlversity Blvd. NE, Sulte 300

Albuquerque, NM 87102

INTERA, InC.

Attn: J.F. Pickens

6850 Austin Center Blvd., Sulte 300

Austin, TX 78731

INTERA, Inc.

Attn: W. Stensrud

PO Box 2123

Carlsbad, NM 88221 . 
INTERA, InC.

Attn: W. Nelson

101. Convention Center Drive

Sulte 540

Las Vegas, NV 89109

IT Corporation (2)

Attn: R.F. Mekinney

J. Myers

Regional office

sulte 700

5301 Central Avenue NE

Albuquerque, NM 871.08

John Hart and Assoclates, P.A.

Attn: J.S. Hart

2815 Candelaria Road NW

Albuquerque, NM 87107

John Hart and Assoclates, P.A.

Attn: K. Licklitor

1009 North Washington

Tacoma, WA 98406

MAC Technlcal Services Co.

Attn: D.K. Duncan

8418 Zunl Road SE

Sulte 200

Albuquerque, NM 87108

Newiman and Holtalnger

Attn: C. Mallon

1615 L Street NW

Sulte 1000

Washington, DC 20036

RE/SPEC, Ine. (2)

Attn: W. Coons

4775 Indian school NE

Sulte 300

Albuquerque, NM 87110

RE/SPEC, lne.

Attn: J.L. Ratigan

PO Box 725

Rapid City, SD 57709

Reynolds Electric and linglneoring

Company, Inc.

Attn: E.W. Kendall

Bullding 790

Warehouse Row

PO Box 98521

Las Vegas, NV 89193-8521
Sclence Appl lcations International Corporation (SATC)

Attn: H.R. Pratt

10260 Campus Polnt Drive

San Dlego, CA 92121

Sclence Applications International

Corporation (2)

Attn: D.C.Royer

C.G. Pflum

101. Convention Center Dr.

Las Vegas, NV 89109

Sclence Applications International

Corporation (3)

Attn: M. Davis

R. Guzowski

J. Tol11son

2109 Alr Park Road SE

Albuquerque, NM 871.06

Sclence Applications International

Corporation (2)

Aten: J, Young

D. Lester

18706 North Creek Parkway, Sulte 110

Bothe11, WA 98011

Southwest Research Institute

Center for Nuclear Waste Regulatory

Analysis (2)

Attn: P.K. Nalr

6220 Culebra Road

San Antonio, TX 78228-0510

Systerns, Sclence, and Software (2)

Attn: E. Peterson

Box 1620

P. Lagus

La Jolla, CA 92038

TASC

Attn: S.G. Oston

55 Walkers Brook Drive

Readling, MA 01867

Tech Reps, Ine. (7)

Attn: J, Chapman

C. Crawford

D. Marchand

T. Peterson

J. Stikar

D. Scott

M. Minahan

5000 Marble NE, Suite 222

Albuquerque, NM 87110 
Tolan, Beeson \& Assoctates

Attn: T.L. Tolan

2320 W. 15th Avenue

Kennewick, WA 99337

TRW Enviromental Safety Systems (2)

Attn: I. Sacks, Sulte 800

L. Wildiman, Sulte 1300

2650 Park Tower Drive

Vienta, VA 22180.7306

Sanford Cohen and Assoclates

Attn: J. Channell

7101 Carriage Rd NE

Albuquerque, NM 87109

Westinghouse Electrle Corporation (5)

Attn: L.Ibrary

C. Cox

L. Fitch

B.A. Howard

R, F. Kehroman

PO Box 2078

Carlsbad, NM 88221

Westinghouse Hanford Company

Attn: D. B. Wood, MSIN HO-32

PC Box 1970

Richland, WA 99352

Western Water consultants

Attn: P.A. Rechard

PO Box 4128

Laramie, WY 82071

Western Water consultants

Attn: D. Fritz

1949 Sugarland Drive \#134

sheridan, WY 82801-5720

P. Drez

8816 Cherry $11111 \mathrm{~s}$ Road NE

Albuquerque, NM 87111

David Lechel

9600 Allende Rd. NE

Albuquerque, NM 871.09

C.A. Marchese

PO Box 21790

Albuquerque, NM 87154

Arend Meijer:

3821 Anderson SE

Albuquerque, NM 87108

\author{
D.W. Powers \\ Star Route Box 87 \\ Anthony, IX 79821 \\ Shirley Thideda \\ PO Box 2109, RR1 \\ Bernal1110, NM 87004 \\ Jack Urich \\ c/O (IARI) \\ $1 / 4$ Harvard SE \\ Albuquerque, NM 87106
}

\section{Universilties}

Unlverslty of Callfornla

Mechanleal, Aerospace, and

Nuclear Englneerlng, Department (2)

Attn: W. Kastenberg,

D. Browne

j532. Boeller Hall

Los Angelos, CA 90024

University of Callfornia

Enginoerling and Applied Sclence Attn: D. Okrent

48-121A kinginoering IV

los Angeles, CA 90(2).4.1597

Unlversity of California

Mine Engineering Department

Rock Mechanies Engineering

Aton: N. Cook

Berkeley, in $94 / 20$

Unlversity of Hawail at Hilo

Busfoness Admlnistration

Attin: S. Hora

11110, $11196 / 20-14091$

Untversity of New Mexico

Geology Department

Attn: Library

Albuquerque, NM $8 / 131$

University of New Mexico

Research Adininistration

Attn: H. Schreyer

102 Scholes Hall.

Albuquerque, NM 87131

University of Wyoming

Department of Civil Englneering

Attn: V.R. Hasfurther

Laranie, WY 82071 
University of Wyoming

Department of Geology

Attn: J.I. Drever

Laramie, WY 82071

University of Wyoming

Department of Mathematics

Attn: R.E. Ewing

Laramie, WY 82071

\section{Libraries}

Thomas Brannigan Library

Attn: D. Dresp

$106 \mathrm{~W}$. Hadley St.

Las Cruces, NM 88001

New Me:.j.co State Library

Attn: N. McCallan

325 Don Gaspar

Santa Fe, NM 87503

New Mexico Tech

Martin Speere Memorial Library

Campus Street

Socorro, NM 87810

New Mexico Junior College

Pannell Library

Attn: R. Hill

Lovington Highway

Hobbs, NM 88240

Carlsbad Municipal Library

WIPP Pub1ic Reading Room

Attn: L. Hubbard

$101 \mathrm{~S}$. Halagueno St.

Carlsbad, NM 88220

University of New Mexico

Zimmerman Library

Government Publications Department

Albuquerque, NM 87131

\section{NEA/Performance Assessment Advisory Group (PAAG)}

P. Duerden

ANSTO

Lucas Heights Research Laboratories Private Mail Bag No. 1

Menai, NSW 2234

AUSTRALIA
Gordon S. Linsley

Division of Nuclear Fuel Cycle and

Waste Management

International Atomic Energy Agency

PO Box 100

A-1400 Vienna, AUSTRIA

Nicolo Cadelli

Commission of the European

Communities

200, Rue de la Loi

B-1049 Brussels, BELGIUM

$R$. Heremans

Organisme Nationale des Déchets

Radioactifs et des Matiéres Fissiles (ONDRAF)

Place Madou 1, Boitec 24/25

B-1030 Brussels, BELGIUM

J. Marivoet

Centre d'Etudes de 1'Energie

Nucléaire (CEN/SCK)

Boeretang 200

B-2400 Mol, BELGIUM

P. Conlon

Waste Management Division

Atomic Energy Control Board (AECB)

PO Box 1046

ottawa, Ontario KIP 559, CANADA

A.G. Wikjord

Manager, Environmental and Safety

Assessment Branch

Atomic Energy of Canada Limited

Whiteshell Research Establishment

Pinewa, Manitoba ROE 1 LO

CANADA

Teollisuuden Voima Oy (TVO) (2)

Attn: Timo Äikäs

Jukka-Pekka Salo

Annankatu $42 \mathrm{C}$

SF-00100 Helsinki Suomi

FINLAND

Timo Vieno

Technical Research Centre of Finlar (VTT)

Nuclear Energy Laboratory

PO Box 208

SF-02151 Espoo, FINLAND 
Division de la Sécurité et de la Protection de 1'Environment (DSPE) Commissariat á l'Energie Atomique Agence Nationale pour la Gestion des Déchets Radioactifs (ANDRA)

Attn: Gérald Ouzounian M. Claude Ringeard

Route du Panorama Robert Schuman B. P. No. 38 F-92266 Fontenay-aux-Roses Cedex FRANCE

Claudio Pescatore Division of Radiation Protection and Waste Management OECD Nuclear Energy Agency 38, Boulevard Suchet F-75016 Paris, FRANCE

M. Dominique Greneche Commissariat á 1'Energie Atomique IPSN/DAS/SASICC/SAED

B.P. No. 6

F-92265 Fontenay-aux-Roses Cedex FRANCE

Robert Fabriol

Bureau de Recherches Géologiques et Miniéres (BRGM)

B.P. 6009

45060 Orléans Cedex 2, FRANCE

\section{P. Bogorinski}

Gesellschaft für Reaktorsicherheit (GRS) MBH

Schwertnergasse 1

D-5000 Köln 1, GERMANY

R. Storck

GSF - Institut für Tieflagerung

Theodor-Heuss-Strabe 4

D-3300 Braunschweig, GERMANY

Ferrucio Gera

ISMES S.P.A

Via del Crociferi 44

I-00187 Rome, ITALY

Hiroyuki Umeki

Isolation System Research Program

Radioactive Waste Management Project

Power Reactor and Nuclear Fuel

Development Corporation (PNC)

1-9-13, Akasaka, Minato-ku

Tokyo 107, JAPAN
P. Carboneras Martinez

ENRESA

Calle Emilio Vargas, 7

R-28043 Madrid

SPAIN

Tönis Papp

Swedish Nuclear Fuel and Waste

Management Co.

Box 5864

S 10248 Stockholm

SWEDEN

Conny Hägg

Swedish Radiation Protection

Institute (SSI)

Box 60204

S-104 01 Stockholm

SWEDEN

J. Hadermann

Paul Scherrer Institute

Waste Management Programme

$\mathrm{CH}-5232$ Villigen PSI

SWITZERLAND

$\mathrm{J}$. Vigfusson

HSK-Swiss Nuclear Safety Inspectorate

Federal Office of Energy

$\mathrm{CH}-5232$ Villigen-HSK

SWITZERLAND

D.E. Billington

Departmental Manager-Assessment

Studies

Radwaste Disposal R\&D Division

AEA Decommissioning \& Radwaste

Harwell Laboratory, B60

Didcot Oxfordshire OXI1 ORA

UNITED KINGDOM

P. Grimwood

Waste Management Unit

BNFL

Sellafield

Seascale, Cumbria CA20 1PG

UNITED KINGDOM

Alan J, Hooper

UK Nirex Ltd

Curie Avenue

Harwell, Didcot

Oxfordshire, OXI1 ORH

UNITED KINGDOM 
Jerry M. Boak

Yucca Mountain Project Office

US Department of Energy

PO Box 98608

Las Vegas, NV 89193

Seth M. Coplan (Chairman)

US Nuclear Regulatory Commission

Division of High-Level Waste

Management

Mail Stop 4-H-3

Washington, DC 20555

A.E. Van Luik

INTERA/M\&O

The Valley Bank Center

101 Convention Center Dr.

Las Vegas, NV 89109

\section{NEA/Probabilistic System Assessment Group (PSAG)}

Shaheed Hossain

Division of Nuclear Fuel Cycle and Waste Management

International Atomic Energy Agency Wagramerstrasse 5

PO Box 100

A-1400 Vienna, AUSTRIA

Alexander Nies (PSAC Chairman)

Gesellschaft für Strahlen- und

Institut für Tieflagerung

Abteilung für Endlagersicherheit

Theodor-Heuss-Strasse 4

D-3300 Braunschweig, GERMANY

Eduard Hofer

Gesellschaft für Reaktorsicherheit (GRS) MBH

Forschungsgelände

D-8046 Garching, GERMANY

Andrea Saltelli

Commission of the European

Communities

Joint Resarch Centre of Ispra

I-21020 Ispra (Varese)

ITALY

Alejandro Alonso

Cátedra de Tecnologia Nuclear

E.T.S. de Ingenieros Industriales

José Gutiérrez Abascal, 2

E-28006 Madrid, SPAIN
ENRESA (2)

Attn: M. A. Cuñado

F. J. Elorza

Calle Emilio Vargas, 7

E-28043 Madrid, SPAIN

Pedro Prado

CIEMAT

Instituto de Tecnologia Nuclear

Avenida Complutense, 22

E-28040 Madrid, SPAIN

Nils A, Kjellbert

Swedish Nuclear Fuel and Waste

Management Company (SKB)

Box 5864

S-102 48 Stockholm, SWEDEN

Björn Cronhjort

Royal Institute of Technology

Automatic Control

S-100 44 Stockholm, SWEDEN

Richard A. Klos

Paul-Scherrer Institute (PSI)

CH-5232 Villingen PSI, SWITZERLAND

Nationale Genossenschaft für die

Lagerung Radioaktiver Abfälle (2)

Attn: C. McCombie

F. Van Dorp

Hardstrasse 73

$\mathrm{CH}-5430$ Wettingen, SWITZERLAND

N. A. Chapman

Intera Information Technologies

Park View House

14B Burton Street

Melton Mowbray

Leicestershire LE13 IAE

UNITED KINGDOM

Daniel A. Galson

Galson Sciences Ltd.

35, Market Place

Oakham

Leicestershire LE15 6DT

UNITED KINGDOM

David P. Hodgkinson

Intera Information Technolugies

45 Station Road, Chiltern House

Henley-on-Thames

Oxfordshire RG9 1AT

UNITED KINGDOM 
Brian G.J. Thompson

Department of the Environment: Her Majesty's Inspectorate of Pollution Room A5.33, Romney House

43 Marsham Street

London SW1P $2 \mathrm{PY}$

UNITED KINGDOM

Intera Information Technologies

Attn: M.J.Apted

3609 South Wadsworth Blvd.

Denver, CO 80235

US Nuclear Regulatory Commission (2)

Attn: R. Codell

N. Eisenberg

Mail Stop 4-H-3

Washington, DC 20555

Battelle Pacific Northwest

Laboratories

Attn: P.W. Eslinger

MS K2 - 32

PO Box 999

Richland, WA 99352

Center for Niclear Waste Regulatory Analys is (CNWRA)

Southwest Research Institute

Attn: B. Sagar

Po Drawer 28510

6220 Culebra Road

San Antonio, TX 78284

\section{Geostatistics Expert Working Group (GXG)}

Rafael L. Bras

R.L. Bras Consulting Engineers

44 Percy Road

Lexington, MA 02173

Jesus Carrera

Universidad Politécnica de Cataluna

E.T.S.I. Caminos

Jordi, Girona 31

E-08034 Barcelona

SPAIN

Gedeon Dagan

Department of Fluid Mechanics and

Heat Transfer

Tel Aviv University

PO Box 39040

Ramat Aviv, Tel Aviv 69978

ISRAEL
Ghislain de Marsily (GXG Chairman)

University Pierre et Marie Curie

Laboratorie de Geologie Applique

4, Place Jussieu

T.26 - 5 e etage

75252 Paris Cedex 05, FRANCE

Alain Galli

Centre de Geostatistique

Ecole des Mines de Paris

35 Rue St. Honore

77035 Fontainebleau, FRANCE

Christian Ravenne

Geology and Geochemistry Division

Institut Francais du Pétrole

1 \& 4, Av. de Bols-Préau B.P. 311

92506 Rueil Malmaison Cedex

FRANCE

Peter Grindrod

INTERA Information Technologies Ltd.

Chiltern House

45 Station Road

Henley-on-Thames

Oxfordshire, RG9 1AT, UNITED KINGDOM

Alan Gutjahr

Department of Mathematics

New Mexico Institute of Mining and

Technology

Socorro, NM 87801 .

C. Peter Jackson

Harwell Laboratory

Theoretical Studies Department

Radwaste Disposal Division

Bldg. 424.4

Oxfordshire Didcot Oxon OX11 ORA

UNITED KINDGOM

Rae Mackay

Department of Civil Engineering

University of Newcastle Upon Tyne

Newcastle Upon Tyne NE1 7RU

UNITED KINGDOM

Steve Gorelick

Department of Applied Earth Sciences

Stanford University

Stanford, CA 94305-2225

Peter Kitanidis

60 Peter Coutts Circle

Stanford, CA 94305 


\author{
Dennis McLaugh1 in \\ Parsons Laboratory \\ Room 48-209 \\ Department of Clvil Engineering \\ Massachusetts Institute of Technology \\ Cambridge, MA 02139 \\ Shlomo P. Neuman \\ College of Englneering and Mines \\ Department of Hydrology and Water \\ Resources \\ University of Arizona \\ Tucson, AZ 85721 \\ Yoram Rubin \\ Department of Civil Engineering \\ University of California \\ Berkeley, CA 94720
}

\section{Foreign Addresses}

Studiecentrum Voor Kernenergie

Centre D'Energie Nucleaire

Attn: A. Bonne

SCK/CEN

Boeretang 200

B- $2400 \mathrm{Mol}$

BELGIUM

Atomic Energy of Canada, Ltd. (3)

Whiteshell Research Establishment.

Attn: M.E. Stevens

B.W. Goodwin

D. Wushke

Pinewa, Manitoba ROE 1LO, CANADA

Juhani Vira

Teollisuuden Voima Oy (TVO)

Annankatu $42 \mathrm{C}$

SF-00100 Helsinki Suomi

FINLAND

Jean-Plerre Olivier

OECD Nuclear Energy Agency (2)

38, Boulevard Suchet

F-75016 Paris

FRANCE

D. Alexandre, Deputy Director

ANDRA

31 Rue de la Federation

75015 Paris

FRANCE

\author{
Claude Sombret \\ Centre D'Etudes Nucleaires \\ De La Vallee Rhone \\ CEN/VALRHO \\ S.D.H.A. B.P. 171 \\ 30205 Bagnols-Sur-Ceze, FRANCE \\ Bundesministerlum fur Forschung und \\ Technologie \\ Postfach 200706 \\ 5300 Bonn 2, GERMANY \\ Bundesansta1t fur Geowissenschaften \\ und Rohst offe \\ Attn: M. Langer \\ Postfach 510153 \\ 3000 Hanover 51, GERMANY \\ Gesellschaft fur Reaktorsicherheit \\ (GRS) (2) \\ Attn: B. Baltes \\ W. Muller \\ Schwertnergasse 1 \\ D-5000 Cologne, GERMANY \\ Institut fur Tieflagerung (2) \\ Attn: K. Kuhn \\ Theodor-Heuss-Strasse 4 \\ D-3300 Braunschweig, GERMANY \\ Physikalisch-Technische \\ Bundesanstalt \\ Attn: P. Brenneke \\ Postfach 3345 \\ D-3300 Braunschweig, GERMANY \\ Shingo Tashiro \\ Japan Atomic Energy Research \\ Institute \\ Tokai-Mura, Ibaraki-Ken \\ $319-11$, JAPAN \\ Netherlands Energy Research \\ Foundation (ECN) \\ Attn: L.H, Vons \\ 3 Westerduinweg \\ PO Box 1 \\ 1755 ZG Petten, THE NETHERLANDS \\ Johan Andersson \\ Swedish Nuclear Power Inspectorate \\ Statens Kärnkraftinspektion (SKI) \\ Box 27106 \\ S-102 52 Stockholm, SWEDEN
}


Fred Karlsson

Svensk Karnbransleforsorjning

$A B$ SKB

Box 5864

S-1.02 48 Stockholm, SWEDEN

Nationale Genossenschaft für die

Lagerung Radioaktiver Abfalle (2)

Attn: S, Volmvoris

P. Zuidema

Hardstrasse 73

$\mathrm{CH}-5430$ Wettingen, SWITZERLAND

AEA Technology

Attn: J.H. Rees

D5W/29 Culham Laboratory

Abington

Oxfordshire OX14 3DB, UNITED KINGDOM

AEA Technology

Attn: W.R. Rodwel1

044/A31 Winfrith Technical Centre

Dorchester

Dorset DT2 8DH, UNITED KINGDOM

AEA Technology

Attn: J.E. Tinson

B4244 Harwel1 Laboratory

Didcot, Oxfordshire OX11 ORA

UNITED KINGDOM

D.R. Knowles

British Nuclear Fuels, plc

Risley, Warrington

Cheshire WA3 6AS, 1002607

UNITED KINGDOM

\section{Internal}

$\begin{array}{ll}1 & \text { A. Narath } \\ 20 & \text { O.E. Jones } \\ 1502 & \text { J.C. Cumnings } \\ 1511 & \text { D.K. Gartling } \\ 6000 & \text { D.L. Hartley } \\ 6115 & \text { P.B. Davies } \\ 6115 & \text { R.L. Beauhein } \\ 6119 & \text { E.D. Gorham } \\ 6119 & \text { Staff (14) } \\ 6121 & \text { J.R. Tillerson } \\ 6121 & \text { Staff (7) } \\ 6233 & \text { J.C. Eichelberger } \\ 6300 & \text { D.E. E11is } \\ 6302 & \text { L.E. Shephard } \\ 6303 & \text { S.Y. Pickering }\end{array}$

a U.S GOVEANMENT PRINTING OFFICE 1993-774-122/80238
6303

8523-2 Central Technical Files

\author{
DOE/OST I (10) \\ W.D. Weart \\ S.A. Goldstein \\ A.R. Lappin \\ A.L. Stevens \\ F.W. Bingham \\ S. Costin \\ D.R. Anderson \\ J.C. Helton (20) \\ Staff (30) \\ $V$. Harper-Slaboszewicz \\ Staff (3) \\ R.C. Lincoln \\ taff (9) \\ Schafer \\ R.E. Thompson \\ D.P. Garber \\ S.E. Sharpton \\ N.R. Ortiz \\ R.M. Cranwe 11 \\ R.L. Iman \\ C. Leigh \\ M.S.Y. Chu
}



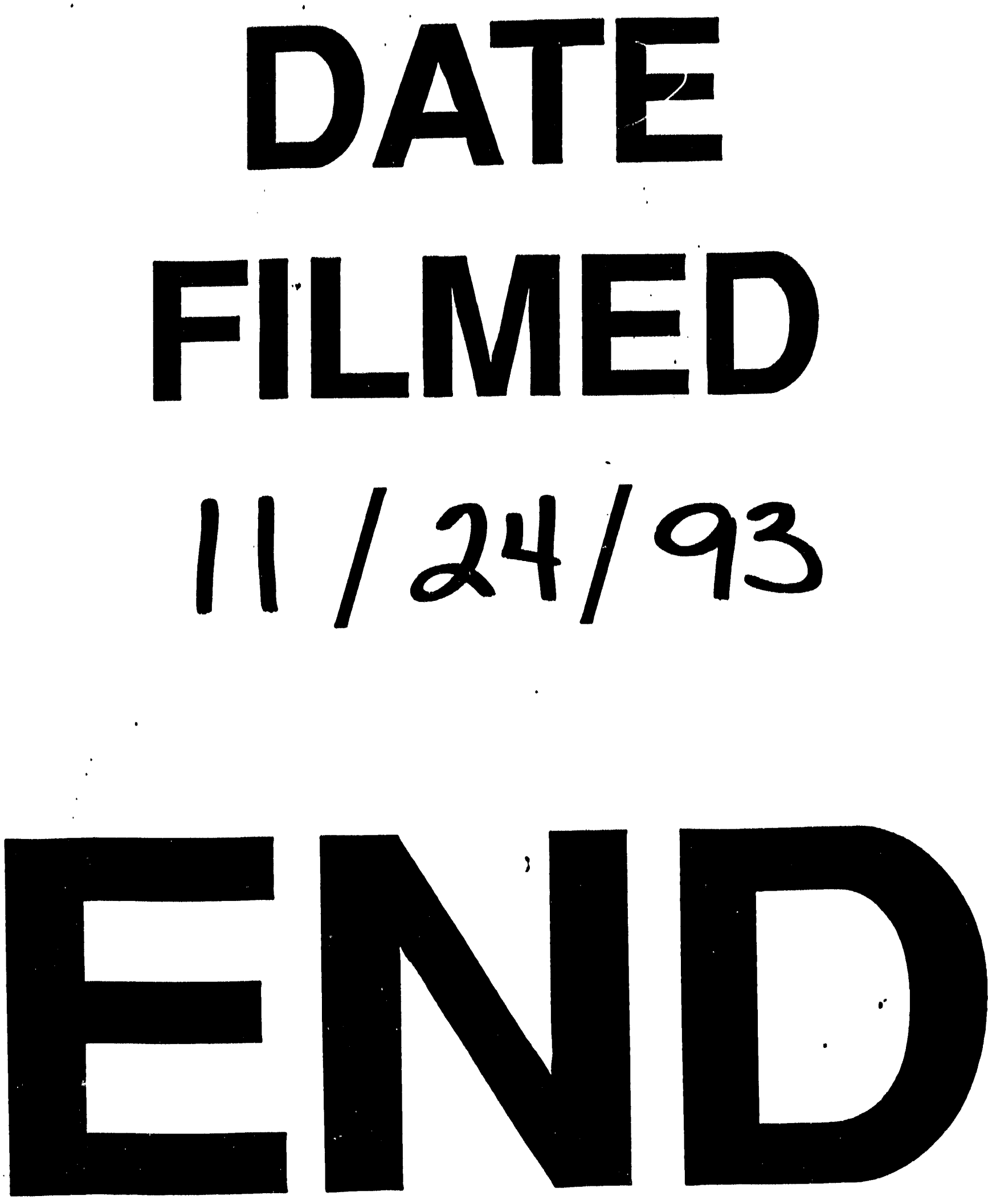
